\title{
On the role of sugar compartmentation and stachyose synthesis in symplastic phloem loading
}

\author{
Dissertation \\ zur Erlangung des Doktorgrades \\ der Mathematisch-Naturwissenschaftlichen Fakultäten \\ der Georg-August-Universität zu Göttingen
}

Vorgelegt von

Olga Vladimirovna Voitsekhovskaja

aus St.-Petersburg, Rußland

Göttingen 2001 
Referentin: PD Dr. Gertrud Lohaus

Koreferent: Prof. Dr. Hans-Walter Heldt

Tag der mündlichen Prüfung: 30.01.2002 


\section{Content}

1. Introduction ................................................................................................ 1

1.1. Types of companion cells in minor vein phloem................................... 2

1.2. Symplastic (dis)continuity between mesophyll and phloem ..................... 3

1.3. Apoplastic phloem loading mode......................................................... 4

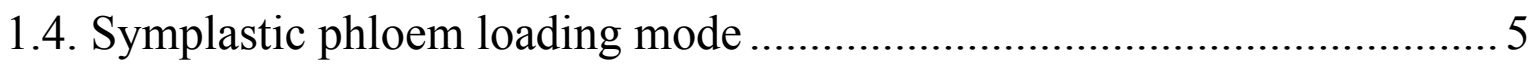

1.5. Relationship between companion cell types and the types of translocated sugars

1.6. The polymerization trap model and the role of stachyose synthesis in symplastic phloem loading.......................................................................... 10

1.7. The aim of this thesis and the choice and characterization of model plants. 12

1.7.1. The aim of this thesis 12

1.7.2. Phloem sap composition and characterization of minor vein anatomy in two related species, Alonsoa meridionalis and Asarina barclaiana........................ 12

1.7.3. Choice of the model plants ........................................................................ 15

2. Materials and Methods ................................................................. 17

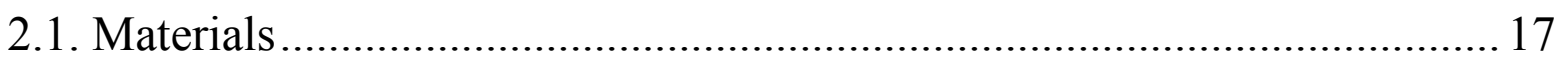

2.1.1. Biochemicals.................................................................................................. 17

2.1.2. Enzymes used in molecular biology ............................................................ 18

2.1.3. Kits ................................................................................................... 18

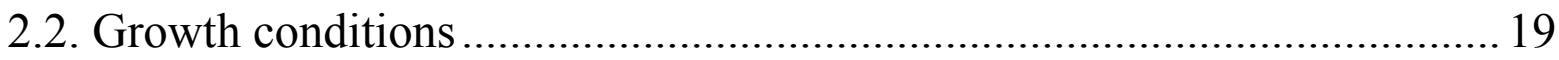

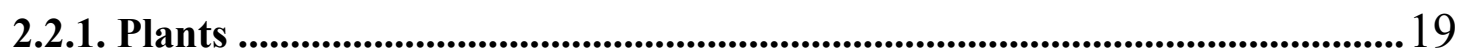

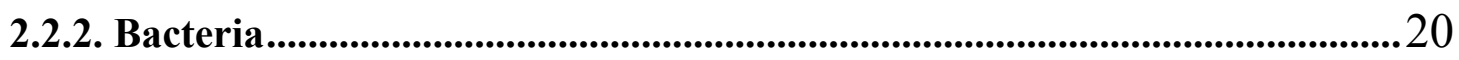

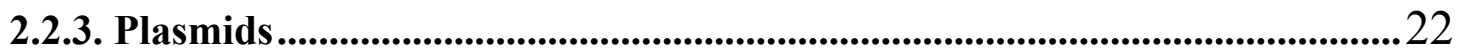

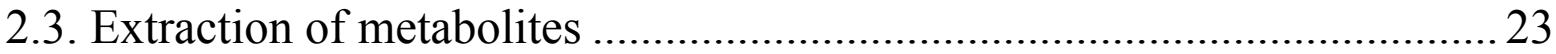

2.3.1. Chloroform:methanol extraction ...............................................................23

2.3.2. Isolation of galactinol and antirrhinoside from plant material.................... 24

2.3.2.1. Preparative isolation of galactinol ..................................................24

2.3.2.2. Preparative isolation and confirmation of the chemical structure

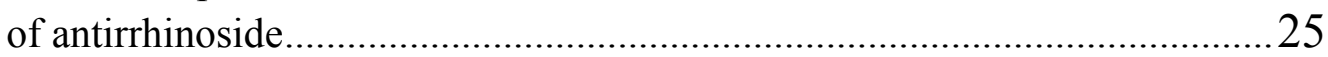

2.4. Extraction of apoplastic sap (intercellular washing fluid) ....................... 26

2.5. Determination of enzyme activities ........................................................ 26

2.5.1. Glucose-6-phosphate dehydrogenase (G6PDH)...........................................227

2.5.2. NADP-dependent Glyceraldehyde 3-phosphate dehydrogenase

(GAPDH) .....................................................................................................................2

2.5.3. Phosphoenolpyruvate carboxylase (PEPCx) ................................................28

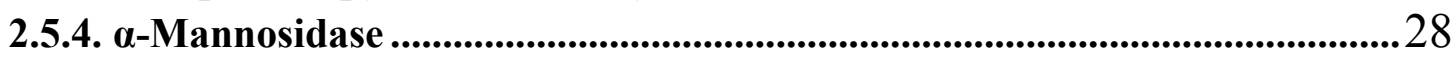

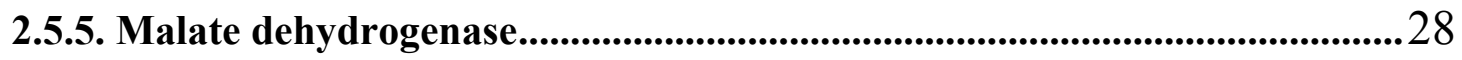


2.5.6 Stachyose synthase activity assays................................................................... 29

2.5.6.1 Establishment of the AmSTS activity assay using leaves of

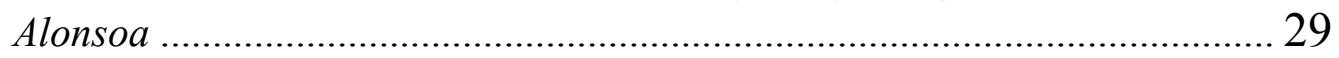

2.5.6.2 AmSTS activity assay in protein extracts of E. coli BL21 (DE3)

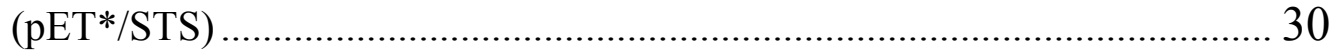

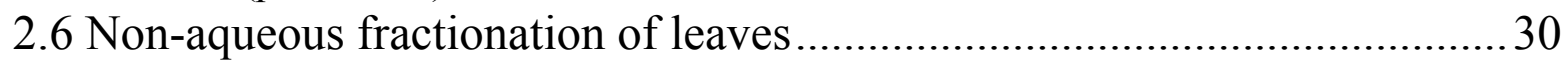

2.6.1. Preparation of leaf material........................................................................ 30

2.6.2. Non-aqueous fractionation of leaf tissue in a density gradient..................... 30

2.6.3. Determination of the activities of marker enzymes in the gradient

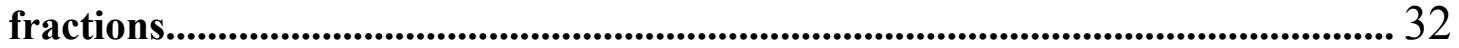

2.6.4. Determination of metabolite concentrations in the gradient fractions ...... 32

2.6.5. Calculation of the subcellular distribution of metabolites .......................... 32

2.6.6. Determination of the chlorophyll:protein ratio.......................................... 33

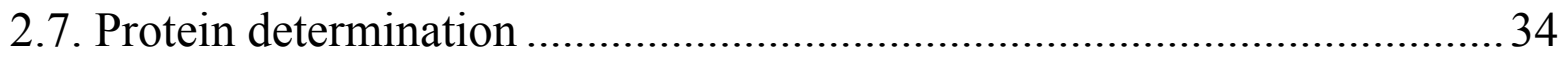

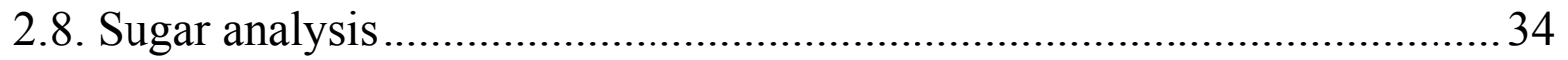

2.8.1. HPLC................................................................................................................... 34

2.8.2. Enzymatic measurements of glucose, fructose and sucrose ......................... 35

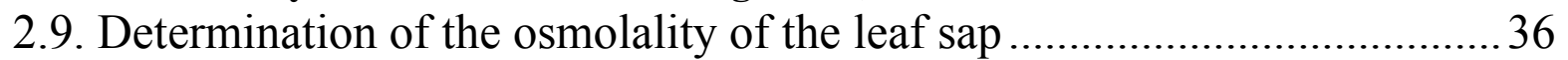

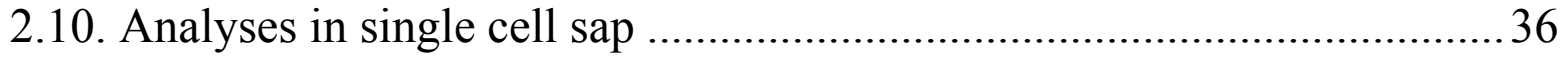

2.10.1. Single cell sampling.................................................................................... 36

2.10.2. Osmolality of single cell sap ............................................................................. 37

2.10.3. Sugar concentrations in single cell sap........................................................ 37

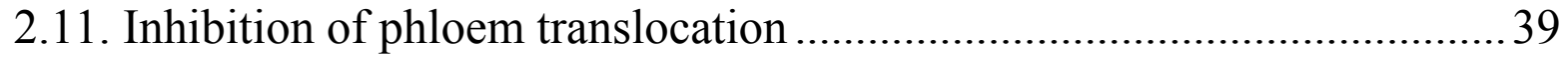

2.12. Study of sugar uptake from the apoplast in vivo......................................39

2.12.1. Feeding experiments ..................................................................................... 39

2.12.2. Gas and $\mathrm{H}_{2} \mathrm{O}$ exchange mesurements.............................................................. 40

2.12.3. Recordings of $\mathrm{pH}$ - and membrane potential changes................................... 40

2.13. Electron microscopy and determination of partial volumina of

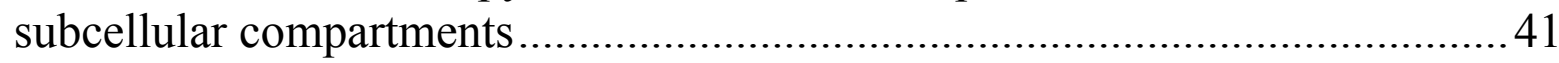

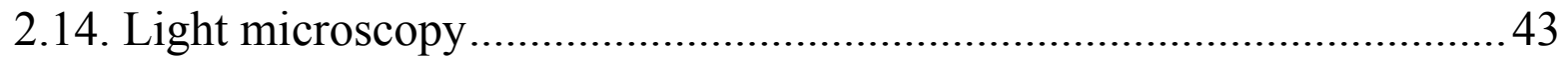

2.15. Isolation of total RNA and genomic DNA from plant tissues ................ 45

2.15.1. Isolation of RNA from Asarina and Alonsoa ............................................. 45

2.15.2. Isolation of genomic DNA from Alonsoa .................................................... 46

2.15.3. Isolation of DNA from Arabidopsis thaliana F1 transformants................. 46

2.16. Plasmid DNA isolation from bacteria ................................................... 47

2.16.1. Isolation of plasmid DNA from $E$. coli (miniprep and maxiprep)............. 47

2.16.1.1. Plasmid DNA miniprep isolation using a triton boiling protocol .... 48

2.16.1.2. Plasmid DNA miniprep isolation with the Qiagen Miniprep Kit .... 48

2.16.1.3. Plasmid DNA maxiprep isolation with E.Z.N.A. Plasmid

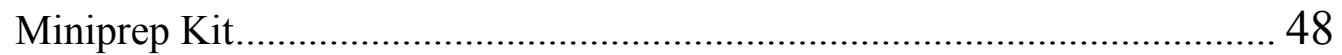

2.16.2. Isolation of plasmid DNA from Agrobacterium tumefaciens....................... 49

2.17. Determination of RNA and DNA concentration by spectrophotometry .49

2.18. Purification and precipitation of DNA and RNA....................................50

2.19. Agarose gel electrophoresis of DNA and RNA …................................50 


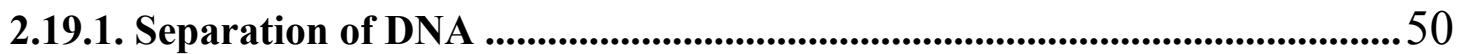

2.19.2. DNA gel blots (Southern blots).............................................................51

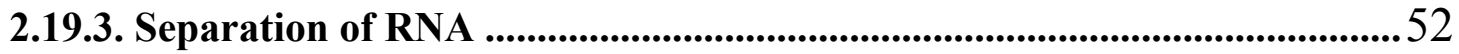

2.19.4. RNA gel blot (Northern blot)................................................................53

2.19.5. Hybridization of DNA and RNA gel blots ......................................................5 54

2.19.5.1. Labelling of probes.....................................................................5 54

2.19.5.2. Hybridization and washing of blots...................................................54

2.20. Gene cloning .......................................................................... 55

2.20.1. Elution of DNA fragments from agarose gels ...........................................56

2.20.2. Filling of 5 ' overhanging ends with Klenow polymerase .............................55

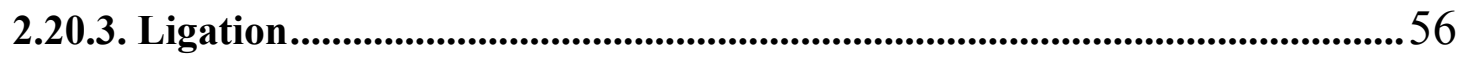

2.20.4. Preparation of competent cells of $E$. coli strains DH5 $\alpha$ and BL21

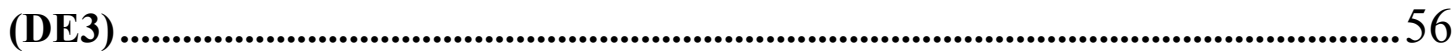

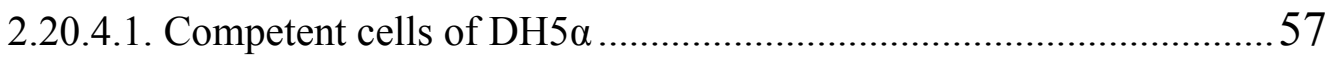

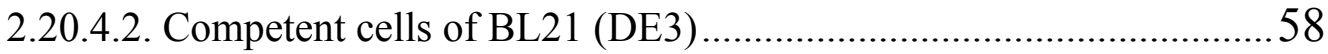

2.20.5. Transformation of $E$. coli .....................................................................58

2.20.6. Bacterial glycerol cultures ......................................................................59

2.21. Amplification of DNA by the polymerase chain reaction (PCR) ...........59

2.21.1. Design of specific and degenerate primers .........................................55

2.21.2. cDNA synthesis and Rapid Amplification of cDNA Ends (RACE) ..........6 60

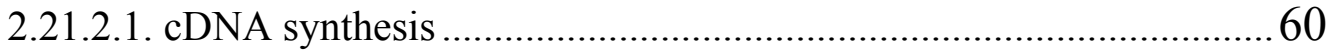

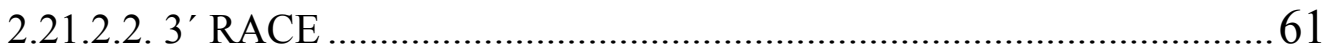

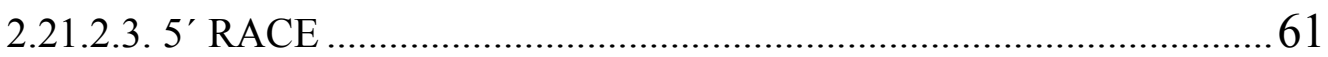

2.21.3. Amplification and cloning of the AmSTS full length cDNA ....................66

2.21.4. Amplification of a promoter fragment by Genome Walker DNA

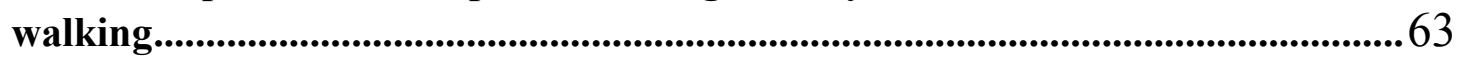

2.21.5. Colony PCR .........................................................................................................64 64

2.22. Expression of AmSTS in E. coli using pET expression system .............. 65

2.22.1. Transformation of $E$. coli BL21 (DE3) ........................................................66 65

2.22.2. Induction of the expression of the transgene using IPTG...........................65

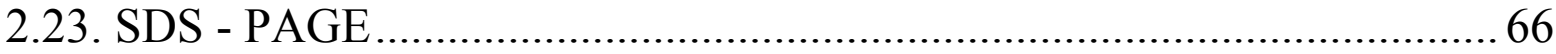

2.23.1. Protein extraction from $E$. coli cells...........................................................66 66

2.23.2. SDS-Polyacrylamide gel electrophoresis ..................................................66

2.23.3. Coomassie staining of the gels ...................................................................66 67

2.24. Promoter-GUS fusions in transgenic plants ....................................... 68

2.24.1. Preparation of competent Agrobacterium tumefaciens GV3101 cells .......68

2.24.2. Transformation of Agrobacterium tumefaciens by electroporation ...........68

2.24.3. Transformation of Arabidopsis thaliana with Agrobacterium

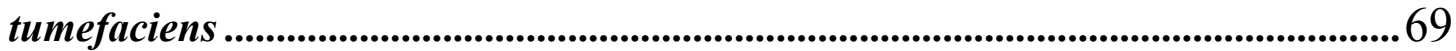

2.24.4. Qualitative GUS assay ..........................................................................69

2.24.4.1. Staining of rosette leaves from F1 plants .......................................69

2.24.4.2. Infiltration of seedlings to induce GUS expression..........................70

2.25. in situ RNA hybridization of thin paraffin sections of Alonsoa .............. 70

2.25.1. Preparation of the RNA probes................................................................... 70 
2.25.1.1. Construction and linearization of plasmids.................................... 70

2.25.1.2. In vitro transcription .................................................................. 71

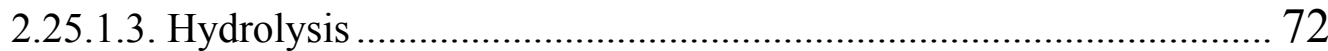

2.25.2. Prehybridization..................................................................................... 72

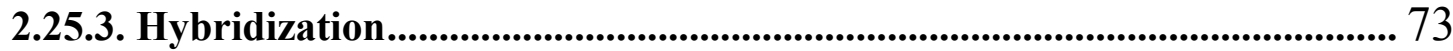

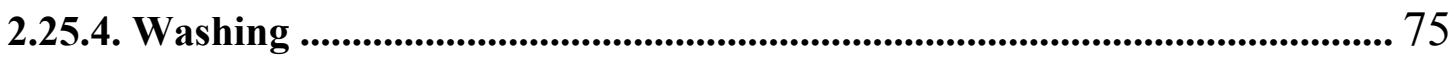

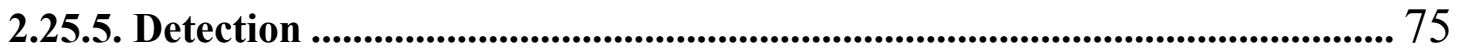

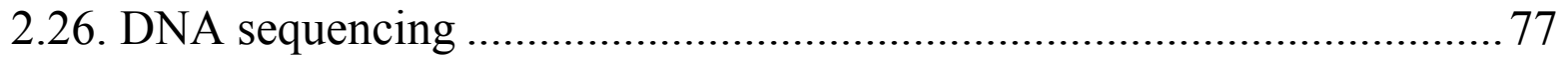

2.27. DNA and amino acid sequence analysis ......................................... 78

3. Results ....................................................................................... 79

3.1. Compartmentation of phloem-translocated carbohydrates in leaves and within mesophyll cells in Alonsoa meridionalis and Asarina barclaiana ....... 79

3.1.1. Leaves of Alonsoa and Asarina contain different types of soluble

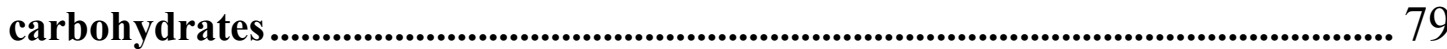

3.1.2. Subcellular compartmentation of carbohydrates ....................................... 80

3.1.2.1. Distribution of carbohydrates between the subcellular compartments of mesophyll cells............................................................. 80

3.1.2.2. Estimation of the volumes of subcellular compartments of mesophyll cells in Alonsoa and Asarina .................................................. 83

3.1.2.3. Sugar contents and concentrations in subcellular compartments of mesophyll cells in Alonsoa and Asarina .............................................. 85

3.1.3. Concentrations of sucrose, glucose and fructose in mesophyll cells measured by single cell sampling technique agree well with the non-aqueous

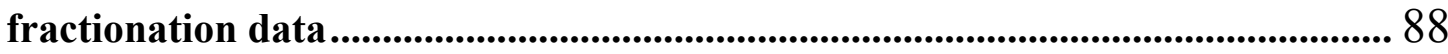

3.1.4. Epidermal concentrations of sucrose and hexoses in Alonsoa and Asarina were similar to those in mesophyll cells

3.1.5. Soluble carbohydrates in Alonsoa and Asarina essentially contributed to the osmolality of the cytosol in mesophyll cells

3.1.6. Levels of phloem-translocated carbohydrates other than raffinose and stachyose increased in the leaves with blocked translocation

3.2. Sugar concentrations in the apoplast of leaves in putative symplastic and apoplastic phloem loaders

3.2.1. Diurnal levels of the translocated carbohydrates in the apoplast .

3.2.2. Levels of the translocated carbohydrates in the apoplast increased in apoplastic but not in symplastic phloem loaders when phloem translocation was blocked

3.2.3. Uptake of sugars including non-metabolizeable isomeres fed exogenously into the apoplast was driven by proton-motive force in both symplastic and apoplastic phloem loaders.

3.3. Characterization of AmSTS, a stachyose synthase from Alonsoa meridionalis

3.3.1. Cloning of cDNA fragments of Alonsoa meridionalis raffinose synthase and stachyose synthase

3.3.2. The full length cDNA of stachyose synthase from Alonsoa (AmSTS) was cloned 
3.3.3. Stachyose synthase activity assay with protein extracts of Alonsoa meridionalis leaves and of $E$. coli cells containing an expression vector carrying the AmSTS ORF

3.3.3.1. Stachyose synthase activity assay using leaves of Alonsoa

3.3.3.2. The induction of AmSTS expression did not function in $E$. coli cells.

3.3.4. AmSTS is encoded by a small gene family containing most probably two members

3.3.5. Localization of AmSTS mRNA in leaves of Alonsoa meridionalis by in situ RNA hybridization: $A m S T S$ expression is confined to intermediary cells.... 117 3.3.6. Expression of $\boldsymbol{A m S T S}$ promoter-GUS fusion constructs in Arabidopsis..... 120

3.3.6.1. Cloning of the AmSTS promoter..................................................... 120

3.3.6.2. Promoter-GUS fusion constructs and 5'uORF .................................. 120

3.3.6.3. The AmSTS promoter directed GUS activity in minor veins in transgenic F1 lines of Arabidopsis containing either AmSTS promoterGUS fusion construct.

3.3.6.4. GUS activity was also found in the vascular tissue of sepals and siliques of $\mathrm{F} 2$ plants

3.3.6.5. The expression of the AmSTS promoter-GUS fusion was strongly enhanced by sucrose and glucose in Arabidopsis.

4.1. Subcellular compartmentation of carbohydrates and estimation of phloem:mesophyll concentration ratios: implications for the phloem loading mode of different carbohydrates in Asarina and Alonsoa

4.1.1. Subcellular distributions of carbohydrates in the symplastic phloem loader Alonsoa meridionalis do not differ from those in apoplastic phloem loaders

4.1.2. Concentration ratios between the cytoplasm of mesophyll cells and the phloem sap indicate the presence of an active loading step for sucrose and antirrhinoside, the major transported carbohydrates in Asarina.

4.1.3. Concentration ratios between the cytoplasm of mesophyll cells and the phloem sap indicate that the minor transported sugars, mannitol in Asarina and sucrose in Alonsoa, may be symplastically loaded into the phloem.

4.2. Inhibition of the export of sugars from the leaves results in the recompartmentation of translocated carbohydrates in leaves of Asarina and Alonsoa

4.3. Apoplastic compartmentation of translocated sugars in symplastic and apoplastic phloem loaders

4.3.1. Inhibition of phloem translocation leads to the accumulation of sucrose in the apoplast of leaves in apoplastic, but not in symplastic phloem loaders ..... 137 4.3.2. The exchange of sucrose, raffinose and stachyose through plasma membrane in both symplastic and apoplastic phloem loaders is not limited by the lack of specific transporters

4.3.3. The non-metabolizeable sucrose isomeres palatinose and turanose can be taken up from the apoplast into the leaf cells in a proton motive forcedependent manner 
4.3.4. Sugar exchange between apoplast and phloem is limited in symplastic but not in apoplastic phloem loaders

4.4. Molecular characterization of AmSTS, a stachyose synthase from the symplastic phloem loader Alonsoa meridionalis.

4.4.1. AmSTS is expressed in intermediary cells of Alonsoa meridionalis ............ 143

4.4.2. The AmSTS promoter directs $G U S$ expression into the phloem in Arabidopsis

4.4.3. Preliminary results indicate that the AmSTS promoter is inducible by sugars but also by osmotically active solutes

4.5. Reformulation of the model of symplastic phloem loading....................... 148

5. Summary ........................................................................... 153

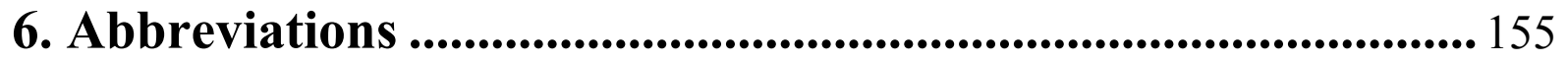

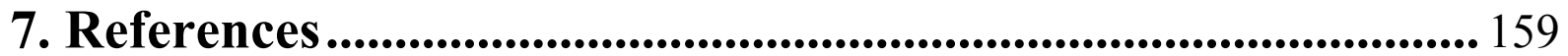




\section{INTRODUCTION}

In leaves of higher plants, photosynthesis results in the production of carbohydrates from carbon dioxide and water. For the most part they are converted into carbon and nitrogen compounds destined to be exported from the leaves to other plant organs. The development of the whole plant, its flowering and seed production completely depend on this transport from source leaves to sink organs such as meristems, young leaves, flowers, fruits, roots and storage organs. At most stages of the plant life, mature leaves are the only carbon source organs. In dicotyledonous plants, the source function is established in leaves during the sinksource transition which occurs within some hours or days (Turgeon and Webb, 1973, 1975). During this process, the terminal phloem becomes functional and starts collecting assimilates and loading them into the conducting route of the phloem. The process by which the major translocated substances are selectively and actively delivered to the sieve tubes in the source region prior to translocation has been termed phloem loading (Geiger, 1975). The longdistance assimilate transport is driven by the osmotic potential between source and sink organs which draws the water flux into the phloem (Münch, 1930).

The elementary functional unit of the phloem tissue is sieve element-companion cell (SE-CC) complex. These two cells derive from the division of one initial cell. During this division, plasmodesmal connections between the daughter cells are formed and retained later on. After the division, the daughter cells differentiate into SE and $\mathrm{CC}$, respectively. Mature sieve elements are devoid of nuclei and of the apparatus for protein synthesis, and possess an extremely developed stacked smooth endoplasmic reticulum, abundant mitochondria and plastids of different types but no chloroplasts. Companion cells retain the nucleus and the apparatus for protein synthesis. Their further characteristics depend on their specific differentiation. The most specialized part of the leaf phloem is present in "minor veins" (Esau, 
1967). Minor veins are the very endings of the vein network which are in close contact with mesophyll cells (approximately 20 - 40 mesophyll cells per minor vein; Gamalei, 1990) and, like most veins, typically include both xylem and phloem elements. Minor veins represent as much as $95 \%$ of the whole length of the leaf conducting tissue (Gamalei, 1990). The phloem part of the minor veins consists of SE-CC complexes which are mostly specialized for collecting and loading assimilates into the phloem. This specialization has led to the appearance of several types of companion cells which can be found in minor veins only. Because structure is a key to function, the understanding of their structure is important when the mechanisms of phloem loading will be discussed.

\subsection{Types of companion cells in minor vein phloem}

The ultrastructure of companion cells in minor veins has been studied in more than one thousand species of dicotyledonous plants (Esau, 1967; Gunning and Pate, 1969; Pate and Gunning, 1969; Fisher, 1986; Gamalei, 1990; Batashev and Gamalei, 1996; Batashev, 1997). The following types of companion cells were described: intermediary cells (IC), transfer cells (TC) and ordinary cells (OC; Table 1.1).

Table 1.1. Characterization of the three ultrastructural types of companion cells found in minor veins of leaves of dicotyledonous plants. IC, intermediary cells; TC, transfer cells; OC, ordinary cells.

\begin{tabular}{|c|c|c|c|}
\hline & $I C$ & $T C$ & $O C$ \\
\hline cytoplasm & dense & dense & dense \\
\hline mitochondria & abundant & abundant & abundant \\
\hline $\begin{array}{c}\text { characteristics of } \\
\text { endomembrane system }\end{array}$ & $\begin{array}{l}\text { highly developed } \\
\text { smooth ER with many } \\
\text { small "cisterns" }\end{array}$ & a single large vacuole & a single large vacuole \\
\hline plastids & $\begin{array}{c}\text { leucoplasts, no starch } \\
\text { accumulation }\end{array}$ & $\begin{array}{l}\text { chloroplasts, able to } \\
\text { accumulate starch }\end{array}$ & $\begin{array}{c}\text { leucoplasts or } \\
\text { chloroplasts }\end{array}$ \\
\hline $\begin{array}{l}\text { interface with } \\
\text { mesophyll }\end{array}$ & $\begin{array}{l}\text { highly developed } \\
\text { branched } \\
\text { plasmodesmata in } \\
\text { plasmodesmal fields }\end{array}$ & $\begin{array}{l}\text { highly developed cell } \\
\text { wall ingrowths with no } \\
\text { or very few } \\
\text { plasmodesmata }\end{array}$ & single plasmodesmata \\
\hline $\begin{array}{l}\text { taxon specificity } \\
\text { (examples) }\end{array}$ & $\begin{array}{c}\text { Buddlejaceae } \\
\text { Cucurbitaceae } \\
\text { Lamiaceae } \\
\text { Oleaceae } \\
\text { Scrophulariaceae }\end{array}$ & $\begin{array}{c}\text { Asteraceae } \\
\text { Boraginaceae } \\
\text { Campanulaceae } \\
\text { Fabaceae } \\
\text { Scrophulariaceae }\end{array}$ & $\begin{array}{c}\text { Betulaceae } \\
\text { Brassicaceae } \\
\text { Chenopodiaceae } \\
\text { Solanaceae } \\
\text { Scrophulariaceae } \\
\end{array}$ \\
\hline ecological specificity & $\begin{array}{l}\text { plants families } \\
\text { representing mostly } \\
\text { vines and trees from } \\
\text { warm areas }\end{array}$ & $\begin{array}{l}\text { herbaceous plants able } \\
\text { to inhabitate cold and } \\
\text { temperate regions }\end{array}$ & $\begin{array}{l}\text { plants spread over } \\
\text { many climate zones } \\
\text { and life forms; the only } \\
\text { type found in plants } \\
\text { from very extreme } \\
\text { biotopes (arid zones, } \\
\text { solontschaks)* }\end{array}$ \\
\hline
\end{tabular}

*Gamalei and Sjutkina, 1999 
Two unique features of IC are the presence of a highly developed smooth ER and the abundance of branched plasmodesmata organized in plasmodesmal fields which connect IC to the mesophyll cells of the bundle sheath. These plasmodesmata are secondary, i.e. they are not the remainder of cell division but appear later, during the establishment of the source function of the leaf.

The distinct feature of TC is the presence of numerous cell wall ingrowths consisting of hemicellulose, which are formed just when intensive transport starts. These cells typically possess extremely few or no plasmodesmal connections with mesophyll cells.

OC are less specialized than the two other cell types described above. They are present not only in minor veins but also in veins of higher orders. Plants whose minor veins contain IC or TC also have OC in their larger veins. OC also can occur in minor veins together with IC or TC. However, in a large group of plants they are the only companion cell type found in the phloem of minor veins. They possess neither plasmodesmal fields nor cell wall ingrowths, although single plasmodesmal connections with mesophyll cells are always present.

On the basis of these three types of companion cells, ultrastructural variations are possible and altogether 14 subtypes have been described thus far (Batashev, 1997). The type of companion cells has turned out to be specific for a plant species and for a plant family, with rare exceptions. For instance, in Scrophulariaceae, all three types of companion cells are found.

\subsection{Symplastic (dis)continuity between mesophyll and phloem}

An important basic feature for the classification of companion cells is the abundance of plasmodesmata at the companion cell/mesophyll interface. As shown in Figure 1.1 (data are taken from Gamalei, 1995), this feature is gradually changing between two extremes which correspond to IC and TC, respectively.

This has important consequences for the assimilate transfer from the mesophyll into the phloem. In companion cells where plasmodesmata are absent (TC), sugars have to enter the apoplast before they can be taken up into the phloem. This apoplastic pathway also exists in plants with IC but here, the highly developed plasmodesmata provide an additional route, entirely symplastic, for sugar transfer from mesophyll cells into the companion cells and further into the sieve elements. This led to the proposal that in dicotyledonous plants, two mechanisms of assimilate loading into the phloem exist: an apoplastic one and a symplastic one. However, as shown in Figure 1.1, the boundary between "pure" apoplastic and "pure" symplastic phloem loaders cannot be set precisely. The only exception are species with TC 


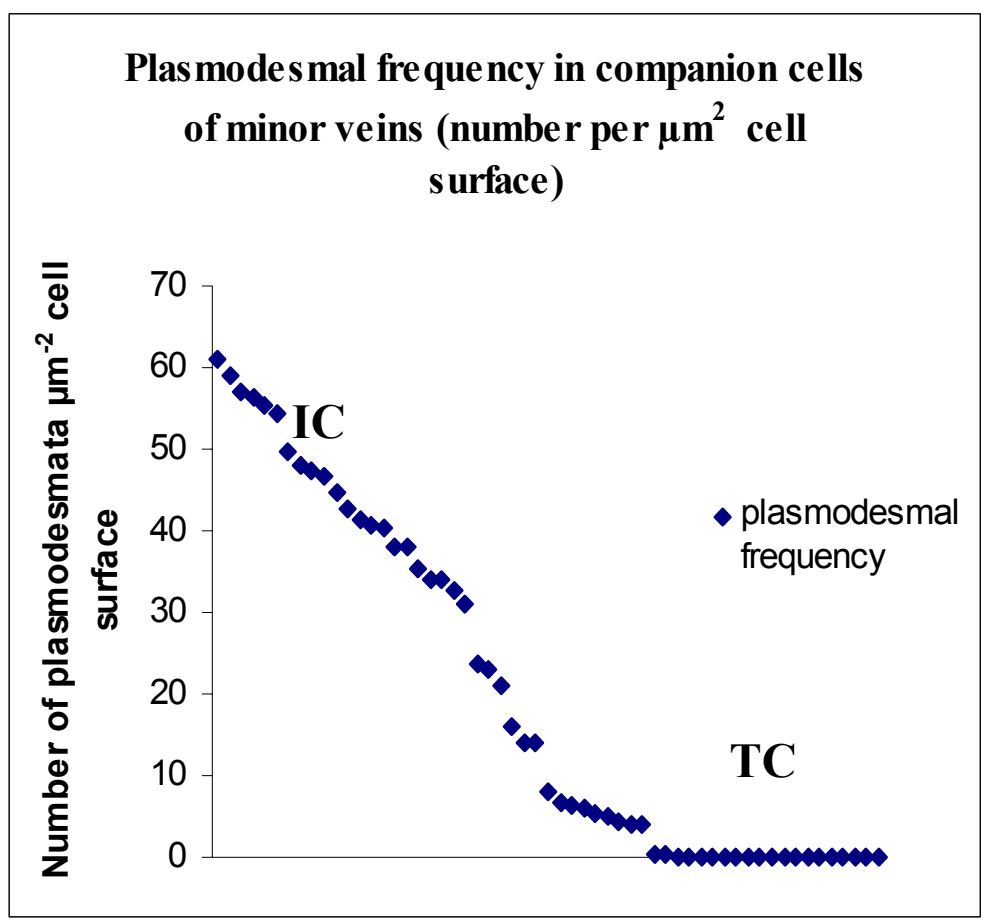

Figure 1.1. Plasmodesmal frequencies between mesophyll bundle sheath cells and companion cells as determined in 60 species selected from 34 families of dicotyledonous plants (data taken from Gamalei, 1995).

and, therefore, a lack of symplastic connections between mesophyll and phloem, which represent pure apoplastic phloem loaders.

\subsection{Apoplastic phloem loading mode}

A short summary of the model of apoplastic phloem loading is given in Figure 1.2.

Apoplast

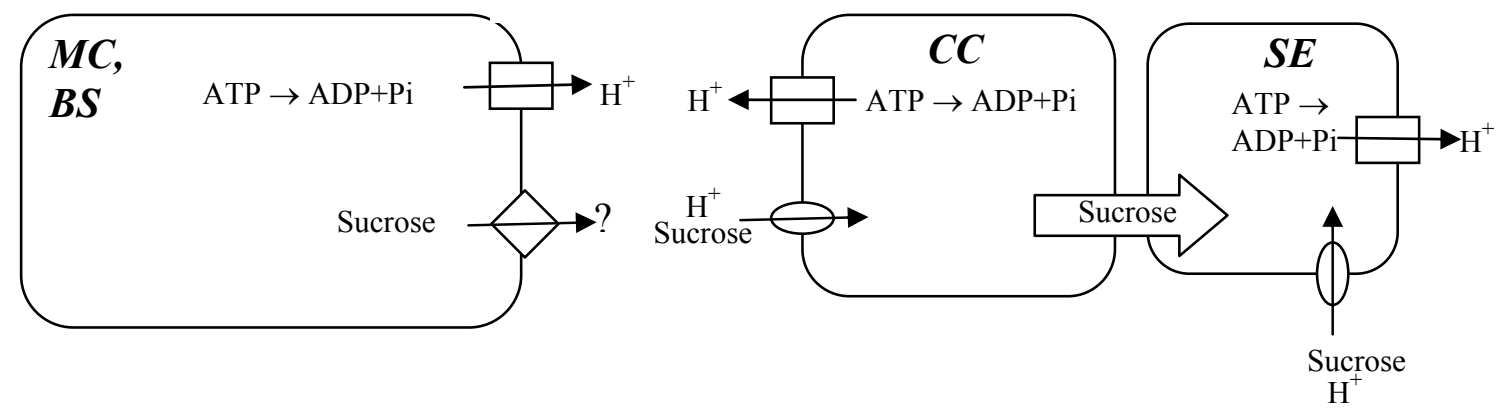

Figure 1.2. Apoplastic phloem loading. $\mathrm{H}^{+} /$sucrose-symporters are shown as elipses and plasma membrane $\mathrm{H}^{+}$-ATPases as squares. Sucrose exporters from mesophyll cells and bundle sheath cells, which may or may not be identical with $\mathrm{H}^{+} /$sucrose-symporters, are shown as diamonds. Sucrose transfer between CC-SE via plasmodesmata is indicated by a white arrow. MC, Mesophyll cell; BS, bundle sheath cell; CC, companion cell; SE, sieve element.

In apoplastic phloem loading, assimilates have to pass through at least two membranes: the plasmalemma of mesophyll cells and the plasma membrane of companion cells or sieve elements. The transmembrane transfer occurs via sugar transporter proteins 
which are specific for certain sugars. This requires that the variety of plant carbohydrates are converted to just one or a few transport forms. In most plant species, the dominant transport sugar is sucrose. Sucrose transporters have been found in many plants and seem to be ubiquitous (Lemoine, 2000). They translocate sucrose together with a proton using the proton motive force (PMF; PMF $=0,059 \Delta \mathrm{pH}+\Delta \Psi)$ as an energy source for the transfer against a sucrose concentration gradient (Giaquinta, 1980). Evidence for the crucial role of sucrose transporters for apoplastic phloem loading was obtained in a study of transgenic potato plants expressing a sucrose transporter antisense construct (Riesmeier et al., 1994). This study has confirmed the theory of apoplastic phloem loading in general. However, a lot of information about the regulation of apoplastic phloem loading is still missing. For instance, knowledge on the mechanism of sugar export from mesophyll cells into the apoplast and its regulation is scarce (Lemoine et al., 1996; Schulz et al., 1998).

\subsection{Symplastic phloem loading mode}

Although in plants with IC in minor veins both apoplastic and symplastic routes are considered to participate in phloem loading (e.g. Kursanov, 1984), the latter is assumed to dominate. This is implied because of the extremely developed plasmodesmata at the mesophyll/phloem interface of these plants. Evidence that the loading of assimilates into the phloem in plants with IC occurs differently from those with OC or TC has been obtained in studies on partitioning of ${ }^{14} \mathrm{C}$-labelled assimilates (Turgeon and Gowan, 1992; Flora and Madore, 1993, 1996), dynamics of sugar uptake and release from the apoplast (Madore and Webb, 1981; Schmitz et al., 1987; Turgeon and Wimmers, 1988) and ultrastructural changes (Gamalei et al., 1994; Gamalei and Pakhomova, 2000). However, the exact mechanism has not yet been revealed. According to the organization of plasmodesmata, there are two possible channels for the symplastic transfer of assimilates, the cytosolic sleeve and the endoplasmic reticulum (Figure 1.3, insert). Two models are depicted in Figure 1.3.

The traffic of viruses through plasmodesmata occurs via the cytosolic sleeve (see e.g. Ghoshroy et al., 1997). This has led to the conclusion that sugar transport should also occur through the cytosolic continuum between two types of cells, although no direct evidence is available. Contrarily, a role of the ER desmotubule in assimilate transfer and in water transport has been suggested by several studies (Gamalei, 1994; Gamalei et al., 1994, 2000; Zhang and Tyerman, 1997; Blackman and Overall, 2001) including some with fluorescent dyes (Cantrill et al., 1999, 2001). However, direct evidence for sugar transport via the ER is also missing. 
In most studied plants, sugar concentrations in the phloem are higher than in other tissues. They are in the molar range (Ohshima et al., 1999; Lohaus and Fischer, 2001 and references therein). The exact phloem concentrations are known only for a few species with IC (Moing et al., 1997; Knop et al., 2001) but the data available suggest that phloem concentrations are equally high in these plants as in apoplastic phloem loaders. Thus, also in

A

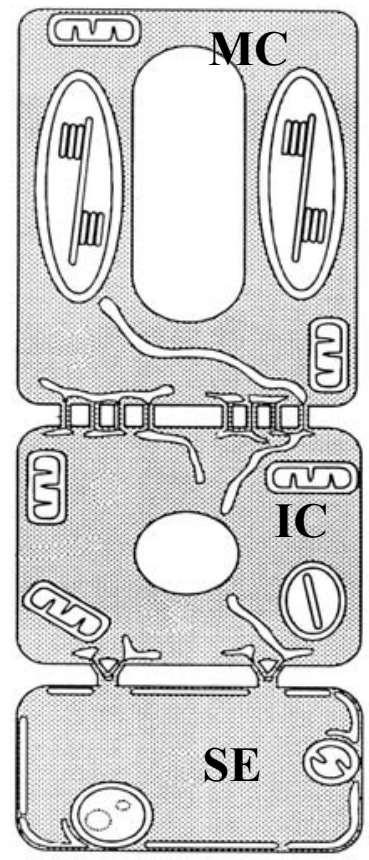

B

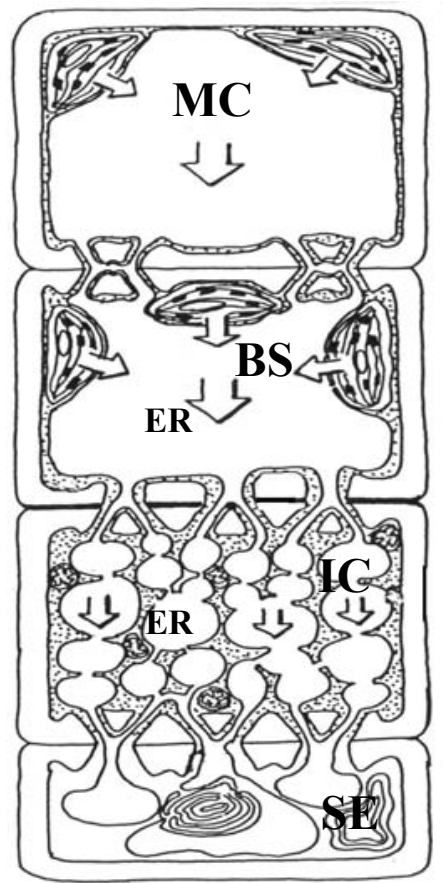

Figure 1.3. Two contemporary models of symplastic phloem loading. A, Schulz (1997); B, Gamalei (1994). A, assimilates move along the cytosol of the mesophyll cell through the cytosolic sleeve of plasmodesmata into the IC and further into the SE where they are moving in the cytosol; B, assimilates move from the vacuoles of mesophyll cells through the endoplasmatic reticulum (ER) spreading from cell to cell into the IC and further into the SE whose lumen corresponds to ER lumen. MC, mesophyll cell; BS, bundle sheath cell; IC, intermediary cell; $\mathbf{S E}$, sieve element. The insert shows a scheme of a plasmodesma. $\mathbf{C W}$, cell wall; Cyt, cytoplasm; PM, plasmalemma. The cytosolic sleeve is the region between ER and PM.

symplastic phloem loaders sugar movement from sites of lower concentration (mesophyll cells) to sites with higher concentration (phloem) has to take place.

Several questions have to be answered before a complete model of symplastic phloem loading can be established. (1) Which mechanism enables the plant to keep up the sugar concentration gradient between mesophyll and phloem? (2) Which compartment, cytosolic sleeve or ER lumen, is involved in sugar transfer? (3) How is the distribution of assimilate flux between symplastic and apoplastic routes regulated in plants with IC? (4) Is there a connection between the structure of companion cells and the types of sugars transported? (5) Why have plasmodesmata between mesophyll and companion cells been retained in several 
groups of plants during evolution? What has prevented a complete switch to apoplastic phloem loading in many plant species? (6) Are there other fuctions of plasmodesmata on the mesophyll/companion cell boundary than phloem loading?

\subsection{Relationship between companion cell types and the types of translocated sugars}

The phloem sap composition is specific for plant families (Zimmermann and Ziegler, 1975). Comparison of these data with the minor vein anatomy has revealed a relationship between types of companion cells and types of transported sugars (Gamalei, 1984; Turgeon et al., 1993; Flora and Madore, 1993, 1996). Plants with abundant symplastic connections between mesophyll and phloem translocate a large spectrum of organic compounds including sucrose, raffinose family oligosaccharides (RFOs, Figure 1.4), sugar alcohols and glucosamines. Plants with scarce or absent symplastic connections translocate almost exclusively sucrose.

Plants fall into three classes with regard to percentage of RFOs in the phloem sap (Gamalei, 1984). In the first group, RFOs are absolutely predominating, in the second group, RFOs are completely absent and in the third group, RFOs are minor components $(<25 \%)$ of the phloem sap carbohydrates. The first group represents plants with IC, the second group consists of plants with OC and TC, whereas the third group includes plants with OC as well as plants with abundant plasmodesmata not organized in plasmodesmal fields. The latter type is the type 1-2a in Gamalei's classification, and the companion cells of these plants are considered as intermediates between IC and OC (Gamalei, 1995).

As revealed by studies of F. Keller and coworkers on Ajuga reptans, a Lamiaceae with IC (Bachmann et al., 1994; Bachmann and Keller, 1995; Büchi et al., 1998), RFOs in leaves occur also in vacuoles of mesophyll cells and can play a role in carbon storage and cold resistance in addition to their transport function. Importantly, two different isoforms of galactinol synthase were found in this species, one expressed in mesophyll cells and another one in IC (Sprenger and Keller, 2000). Because galactinol is a precursor for the synthesis of all RFOs, this finding implies that there are two pathways for RFO synthesis in Ajuga, one in the mesophyll and another in IC. Are there plants with only one, transport-independent RFO synthesis pathway present in leaves? The answer to this question would require a simultaneous study of RFO contents in leaves and in phloem sap in a large number of plant species from different families. Some information can be obtained from exhaustive studies on the occurrence of RFOs in leaves (Senser and Kandler, 1967) and on phloem sap composition 
(Zimmermann and Ziegler, 1975). In Table 1.2, a comparison is made that includes data on the companion cell type taken from Gamalei (1990).

Figure 1.4. Biosynthesis of raffinose and stachyose. Raffinose family oligosaccharides are $\alpha-$ galactosylated derivatives of sucrose which differ in the number of galactosyl moieties (n). Galactinol (1L-1-O-( $\alpha$-D-galactosyl)-myo-Inositol) serves as a donor of galactosyl moiety in the reactions of raffinose and stachyose synthesis. Galactinol is synthesized by galactinol synthase (UDP-galactose:myo-Inositol galactosyltransferase, EC 2.4.1.123) from UDPgalactose and myo-inositol. The fisrt member of RFOs, the raffinose $(n=1)$ is synthesized via galactosylation of sucrose by raffinose synthase (galactinol:sucrose 6- $\alpha$-Dgalactosyltransferase, EC 2.4.1.82; RS). The second member of RFOs, stachyose is formed via galactosylation of raffinose by stachyose synthase (galactinol:raffinose 6- $\alpha$-Dgalactosyltransferase, 2.4.1.67; STS). Further extensions of the chain of galactosyls lead to formation of other members of RFO (not shown).

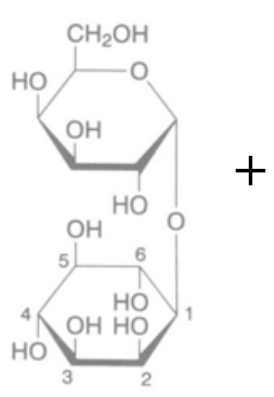

galactinol

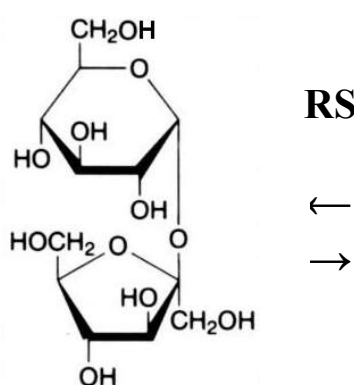

sucrose
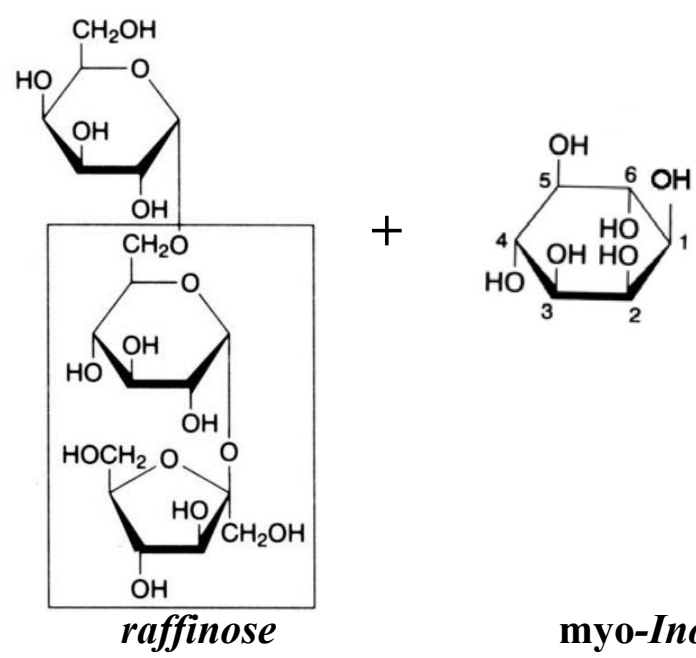

myo-Inositol
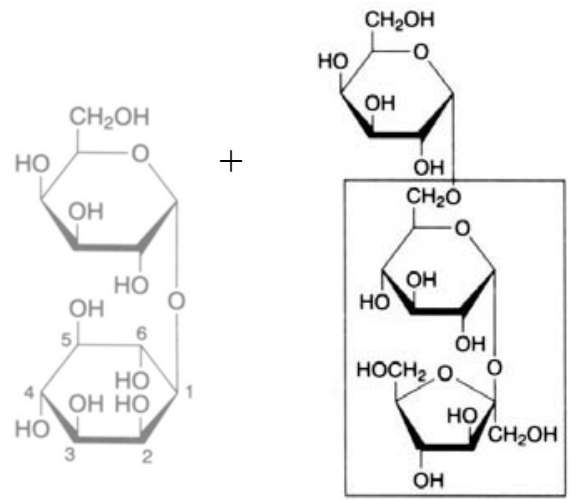

galactinol raffinose
STS

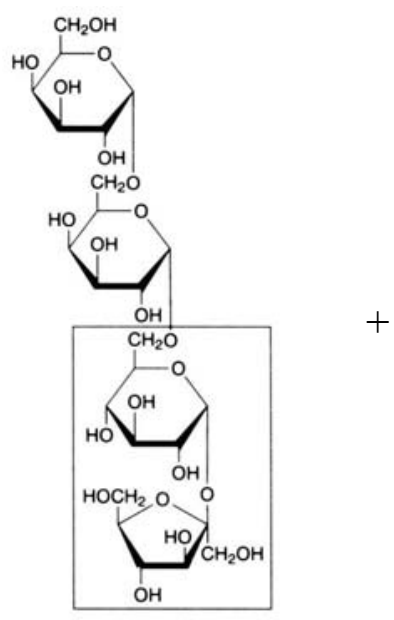

stachyose

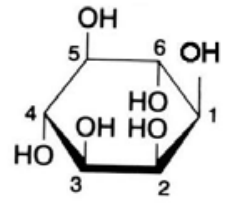

myo-Inositol 
Table 1.2. Comparison of companion cell types and presence of RFOs in leaves and in phloem sap of several plant families/species. For some families/genera where a number of species have been studied, this number is indicated in parentheses. Abbreviations: raf, raffinose; sta, stachyose; tr, found in trace amounts.

\begin{tabular}{|c|c|c|c|c|}
\hline Plant family & $\begin{array}{c}\text { Companion } \\
\text { cell type in } \\
\text { minor veins } \mathbf{s}^{2,10}\end{array}$ & $\begin{array}{c}\text { Galactinol and } \\
\text { raffinose in leaves } \\
1,3,4,9,10\end{array}$ & $\begin{array}{l}\text { Stachyose in } \\
\text { leaves } 9,10\end{array}$ & $\begin{array}{c}\text { RFOs in } \\
\text { phloem sap } \\
1,3,5-8,10-12\end{array}$ \\
\hline $\begin{array}{l}\text { Bignoniaceae: } \\
\text { Catalpa bignonioides }\end{array}$ & $\mathrm{IC}$ & + & + & + \\
\hline Buddlejaceae: Buddleja davidii & “ & + & + & + \\
\hline Celastraceae (4) & “ & + & + & + \\
\hline Cucurbitaceae (5) & “ & + & + & + \\
\hline Lamiaceae (2) & “ & + & + & + \\
\hline Oleaceae (2) & “ & + & + & + \\
\hline Onagraceae (3) & “ & + & + & + \\
\hline Verbenaceae: Verbena hybrida & “ & + & + & + \\
\hline $\begin{array}{l}\text { Apiaceae: } \\
\text { Petroselinum crispum }\end{array}$ & $\mathrm{OC}$ & no & no & no \\
\hline Araliaceae: Hedera helix & “ & + & no & tr raf \\
\hline $\begin{array}{l}\text { Brassicaceae: } \\
\text { Arabidopsis thaliana } \\
\text { (ecotype Columbia) }\end{array}$ & “ & + & no & tr raf \\
\hline Chenopodiaceae (4) & “ & no & no & no \\
\hline Rosaceae (4) & “ & + & $\mathrm{no} / \operatorname{tr}$ & no/tr raf sta \\
\hline Solanaceae (2) & $\mathrm{OC}, \mathrm{TC}$ & no & no & no \\
\hline Violaceae (2) & $\mathrm{OC}$ & + & $\operatorname{tr}$ & ? \\
\hline Asteraceae (2) & $\mathrm{TC} / ?$ & $\mathrm{no} / \mathrm{tr}$ & no & no/tr raf \\
\hline Boraginaceae(3) & $\mathrm{TC}$ & no & no & no \\
\hline Fabaceae (10) & a & no & no & no \\
\hline Scrophulariaceae: & & + & + & \\
\hline Verbascum longifolium & “ & + & + & + \\
\hline Mimulus cardinalis & “ & + & + & + \\
\hline Rhodochiton atrosargineum & $\mathrm{IC}+\mathrm{TC}$ & + & + & + \\
\hline Asarina (2) & $\mathrm{OC}+\mathrm{TC}, \mathrm{IC}+\mathrm{TC}$ & + & + & tr raf sta \\
\hline Digitalis grandiflora & $\mathrm{OC}$ & + & no & $\operatorname{tr} \mathrm{raf}$ \\
\hline Cymbalaria muralis & $\mathrm{TC}$ & + & no & tr raf \\
\hline Linaria maroccana & $\mathrm{TC}$ & galactinol & no & no \\
\hline
\end{tabular}

1-11 Data from: (1) Flora and Madore, 1996; (2) Gamalei, 1990; (3) Haritatos et al., 2000a; (4) Hoffmann-Thoma et al., 2001; (5) Knop et al., 2001; (6) Lohaus et al., 1994; (7) Hendrix, 1982; (8) Riens et al., 1991; (9) Senser and Kandler, 1967; (10) Turgeon et al., 1993; (11) Winzer et al., 1996; (12) Zimmermann and Ziegler, 1975.

As shown in Table 1.2, stachyose and a precursor of its synthesis, raffinose, are always present and transported in leaves which contain IC. Stachyose is absent, with two exceptions, from leaves with OC in minor veins. However, raffinose is often present in these leaves, and, when present, is always transported. In leaves with exclusively $\mathrm{TC}$ in minor veins, neither RFOs nor galactinol could be detected (Senser and Kandler, 1967), with the exceptions of Artemisia (Asteraceae) and Cymbalaria (Scrophulariaceae) which were found to translocate trace amounts of raffinose (Zimmermann and Ziegler, 1975; Turgeon et al., 1993). It seems 
that in leaves, the "primary" function of RFOs is in transport. Leaves which have lost the ability to synthesize RFOs for transport, do not produce them for other purposes. The ability to synthesize RFOs in leaves also seems to correlate with the development of symplastic connections between mesophyll and phloem (IC $>>>0 C>T C)$.

In all plants studied thus far, RFOs occur in germinating seeds (Peterbauer and Richter, 2001). This indicates that RFO synthesis certainly has other important functions in the plant organism apart from phloem tranlocation.

\subsection{The polymerization trap model and the role of stachyose synthesis in symplastic phloem loading}

One model to explain the mechanism of symplastic phloem loading was proposed by Turgeon (1991). According to this model, the precursors of RFO synthesis, galactinol and sucrose, diffuse from the mesophyll into IC via plasmodesmata following their concentration gradient. In the IC, they serve as substrates for the synthesis of raffinose and stachyose. The tetrasaccharide stachyose has a size of ca. $0.6 \mathrm{kDa}$. The size exclusion limit (SEL) of plasmodesmata in the IC/mesophyll interface was estimated to be about $0.7-0.8 \mathrm{kDa}$ (Wolf et al., 1989; Robards and Lucas, 1990). Therefore, stachyose should not be able to diffuse back into mesophyll via plasmodesmata. It is supposed to be "trapped" in the IC and to be able to diffuse only into the sieve elements because the SEL of plasmodesmata of CC-SE complexes is estimated as $>3 \mathrm{kDa}$ (Wolf et al., 1989; Robards and Lucas, 1990). Thus, stachyose synthesis and its phloem loading are mechanistically linked in this so-called “polymerization trap" model (Turgeon, 1991).

The polymerization trap model has been supported by experimental evidence with regard to the localization of stachyose synthesis in intermediary cells (Holthaus and Schmitz, 1991b). Although the synthesis of stachyose can occur in mesophyll cells of some plants that store RFOs in leaves, the existence of two isoforms of galactinol synthase specific for either mesophyll or IC (Sprenger and Keller, 2000) suggests that also in these plants a distinct ICspecific isoform of stachyose synthase exists. Galactinol synthesis could be shown to occur in IC (Sprenger and Keller, 2000) so that it does not need to be imported from mesophyll cells as the polymerization trap model postulates.

The occurence of stachyose synthesis in IC has been confirmed by immunolocalization of the protein in Cucurbita pepo (Holthaus and Schmitz, 1991b). The biochemical specialization of IC for stachyose synthesis temporally correlates with the structural specialization of these cells, i.e, the development of ER and of plasmodesmal fields because all these features are established in IC at the same time, namely during the sink- 
source transition of leaves (Turgeon and Webb, 1975; Gamalei, 1990). The exact mechanism underlying this relationship remains to be unravelled.

However, some observations indicate that the part of the model regarding the diffusion barrier for stachyose is too much simplified. For one, the polymerization trap model gives no explanation for the symplastic loading of molecules even smaller than sucrose and galactinol, like sugar alcohols, which also occurs in plants with IC (e.g. Flora and Madore, 1993, 1996; Häfliger et al., 1999). Also, it was shown that the SEL of plasmodesmata can be increased due to the action of certain endogenous and viral movement proteins (Waigmann et al., 1994; Kragler et al., 2000; Xoconostle-Cázares et al., 2000). According to the polymerization trap model, sucrose should enter IC via the cytosolic sleeve. The synthesis of stachyose and galactinol is also considered to occur in the cytosol because the $\mathrm{pH}$ optima of stachyose and galactinol synthases match the cytosolic conditions (Keller and Pharr, 1996). Therefore, the enlargement of the cytosolic sleeve of plasmodesmata should favour sugar diffusion from the IC to mesophyll cells due to the sugar concentration gradient. However, this was not observed when the cytosolic sleeve was enlarged by the action of cucumber mosaic virus (CMV) movement proteins (Shalitin and Wolf, 2000). In this experiment, infection of melons by CMV led to an increase of the phloem sucrose concentration but did not affect the concentration of stachyose in the phloem. The translocation rate was enhanced in infected melon, although the opposite would be expected if the increase in SEL would have led to destruction of the loading mechanism and diffusion of sucrose back into mesophyll following the increased concentration gradient (Shalitin and Wolf, 2000). Obviously, the diffusion of sugars through the cytosolic sleeve was not facilitated by the enlargement of plasmodesmal SEL in melon. At the same time, in transgenic tobacco plants, the diffusion of fluorescent dyes via plasmodesmata was enhanced due to the action of the CMV protein when the dyes were introduced into the cytosol (Vaquero et al., 1994).

A powerful tool for the further study of this relationship can be obtained by the investigation of the regulation of genes encoding enzymes involved in stachyose synthesis. Up to now, no information on the regulation of stachyose synthase expression is available. However, two recent investigations can provide a basis for such studies. The first full length cDNA clone of a stachyose synthase from seeds of Vigna angularis was obtained by Peterbauer et al. (1999) and the expression of the VaSTS cDNA in Baculovirus expression system has confirmed its biochemical function. Second, the promoter of galactinol synthase fused to the $\beta$-glucuronidase (GUS) reporter gene in Arabidopsis thaliana was shown to direct GUS expression into companion cells (Haritatos et al., 2000b). A serious challenge for this 
approach is the absence of a well-established transformation procedure for a plant species with IC in minor veins. The only species which so far has been successfully transformed is Cucumis melo (Guis et al., 2000)

\subsection{The aim of this thesis and the choice and characterization of model plants.}

\subsubsection{The aim of this thesis}

This study was focused on several aspects of symplastic phloem loading. When a comparison with the apoplastic phloem loading mode was necessary, some aspects of the apoplastic transfer of sugars were also investigated.The following points had to be studied:

1. Subcellular distribution of various translocated carbohydrates in mesophyll cells of plants with different types of companion cells in minor veins.

2. Estimation of concentration gradients between the cytoplasm of mesophyll cells and the phloem for various translocated carbohydrates in plants with different types of companion cells in minor veins.

3. The participation of the apoplast in phloem loading in plants with IC in minor veins and, therefore, a high potential for symplastic phloem loading, and comparison with apoplastic phloem loaders.

4. Isolation of a full length cDNA of a stachyose synthase from leaves of a symplastic phloem loader.

5. Analysis of the expression pattern of stachyose synthase gene(s) in situ.

6. Isolation of the promoter of a stachyose synthase gene and construction of transgenic Arabidopsis thaliana plants expressing the GUS reporter gene under control of this promoter.

\subsubsection{Phloem sap composition and characterization of minor vein anatomy in two related species, Alonsoa meridionalis and Asarina barclaiana}

The choice of the model plant species was based on the following required characteristics:

(1) To make conclusions about the concentration barriers for symplastic transport, the composition and the concentrations of carbohydrates in the phloem sap should be known precisely;

(2) The minor vein anatomy and the companion cell type should be characterized. 

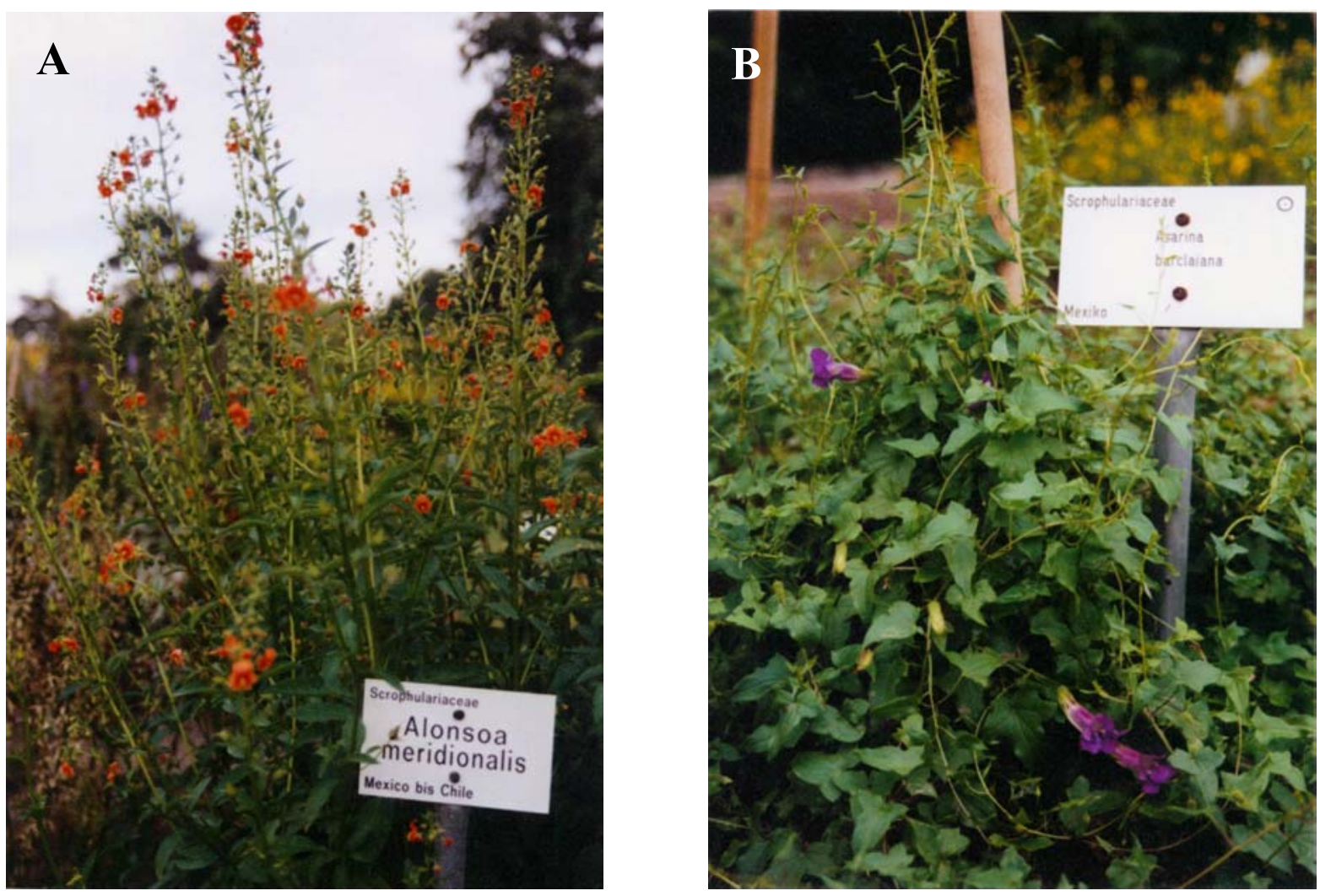

Figure 1.5. Alonsoa meridionalis (A) and Asarina barclaiana (B).

The limiting factors are data on the exact concentrations of the phloem sap carbohydrates. Such data can only be obtained by the laser aphid stylet technique, and species that can be investigated by this method are scarce. Two Scrophulariaceae, Alonsoa meridionalis and Asarina barclaiana (Figures 1.5 A and B), have been studied and data on their phloem sap composition and concentrations are available (Knop, 1998; Table 1.3).

Table 1.3. Phloem sap concentrations determined in Alonsoa meridionalis and Asarina barclaiana (Knop,1998; n=9).

\begin{tabular}{l|c|c|c|c}
\hline & \multicolumn{2}{|c|}{ Alonsoa meridionalis } & \multicolumn{2}{c}{ Asarina barclaiana } \\
\hline & $\mathrm{mM}$ & $\begin{array}{c}\% \text { of total carbon } \\
\text { transported }\end{array}$ & $\begin{array}{c}\text { \% of total carbon } \\
\text { transported }\end{array}$ \\
\hline sucrose & $174 \pm 85$ & 20.8 & $963 \pm 280$ & 47.9 \\
\hline hexoses & + & & $12 \pm 9$ & 0.6 \\
\hline galactose & $1 \pm 2$ & 0.1 & $10 \pm 20$ & 0.5 \\
\hline galactinol & $2 \pm 3$ & 0.2 & $2 \pm 2$ & 0.1 \\
\hline myo-inositol & $12 \pm 4$ & 1.4 & $29 \pm 9$ & 1.4 \\
\hline raffinose & $249 \pm 51$ & 29.7 & $54 \pm 17$ & 2.7 \\
\hline stachyose & $397 \pm 68$ & 47.3 & $136 \pm 101$ & 6.8 \\
\hline mannitol & + & & $786 \pm 136$ & 39.1 \\
\hline antirrhinoside* & not detected & & $\mathbf{2 0 0 8} \pm \mathbf{4 0 0}$ & $\mathbf{1 0 0}$ \\
\hline sum & $\mathbf{8 3 9} \pm \mathbf{1 7 7}$ & $\mathbf{1 0 0}$ & & \\
\hline
\end{tabular}

* data added from this thesis (2.3.2) 

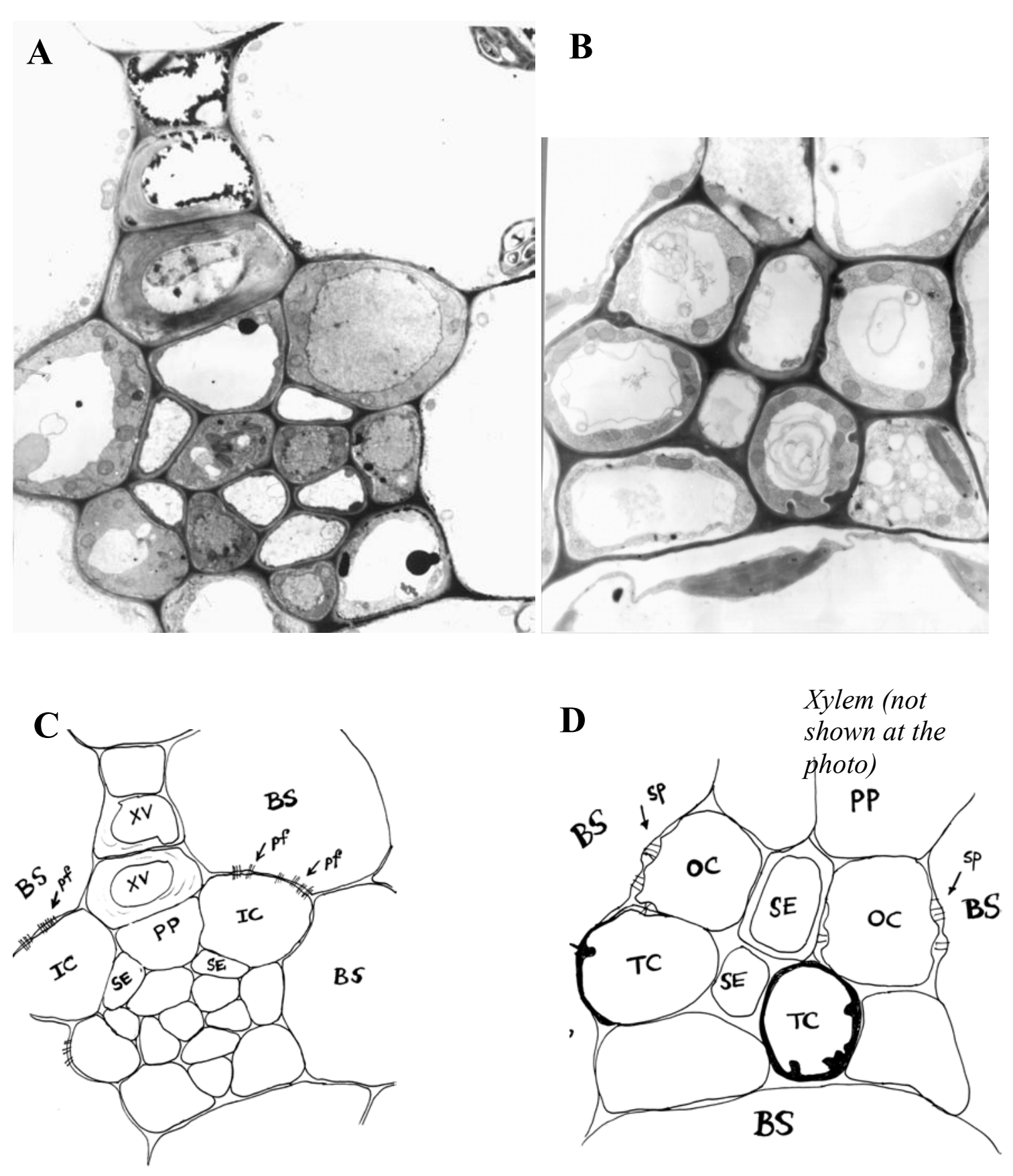

Figure 1.6. The minor vein anatomy of Alonsoa meridionalis and Asarina barclaiana as studied by electron microscopy. A, a minor vein of Alonsoa meridionalis; $\mathbf{B}$, a minor vein of Asarina barclaiana; $\mathbf{C}$, schematic picture of A with the indication of cell types; $\mathbf{D}$, schematic picture of $\mathrm{B}$ with the indication of cell types. XV, xylem vessel; PP, phloem parenchyma, IC, intermediary cell; SE, sieve element; BS, bundle sheath; TC, transfer cell; OC, ordinary cell; pf, plasmodesmal field; sp, single plasmodesma.

As shown in Table 1.3, both plants translocate stachyose and raffinose. RFOs are predominating in the phloem sap of Alonsoa but are only minor components in Asarina. Contrarily, sucrose is the main translocated sugar in Asarina but plays only a minor role in 
Alonsoa. In Asarina, an additional unidentified major component of the phloem sap was indicated in amounts comparable to those of sucrose. This component was characterized by a preparative isolation from the leaves of Asarina and its structure was determined by NMR (this thesis, 2.3.2.2, Figure 2.1). It is the iridoid glycoside antirrhinoside. After this, its concentation in the phloem sap of Asarina could be determined (Table 1.3).

The minor vein anatomy was studied in both plants by electron microscopy (this thesis, 2.13; Figure 1.6). Alonsoa meridionalis possesses minor veins with intermediary cells (Figure 1.6 A, C). In minor veins of Asarina barclaiana, two types of companion cells occur. Some minor veins had only TC (data not shown). In others, transversal leaf sections show that two CC-SE complexes of different composition occur in minor veins. In CC-SE complexes of the upper parts of these veins (next to xylem; Figure 1.6, B, D), companion cells with many single plasmodesmata were present. In CC-SE complexes of lower parts of these minor veins, TC were found (Figure 1.6, B, D). This complex type of companion cells is typical for Scrophulariaceae. The most complete characterization of minor vein anatomy of Scrophulariaceae was performed by Batashev on 59 species (1997). Scrophulariaceae plants possess, along with IC, TC and OC, many different structural subtypes where cell wall ingrowths, plasmodesmata and even small plasmodesmal fields can occur simultaneously. Sometimes, plasmodesmal fields are present on the cell wall ingrowths at the mesophyll side (Batashev, 1997). In Asarina scandens, similar cells were found and were referred to as "modified intermediary cells" (Turgeon et al., 1993). In Asarina barclaiana, symplastic connections are less developed than in A. scandens. According to Gamalei's classification, these cells would correspond to the 1-2a type (Gamalei, 1995), an intermediate between IC and OC. Since no plasmodesmal fields were observed in A. barclaiana, its companion cells are referred to as $\mathrm{OC}$ in this thesis.

\subsubsection{Choice of the model plants}

(1) Alonsoa meridionalis and Asarina barclaiana were chosen for the study on subcellular metabolite concentrations in mesophyll cells and concentration gradients between mesophyll and phloem. These plants represent convenient model systems because they translocate several types of carbohydrates.

(2) For the characterization of stachyose synthase, Alonsoa meridionalis was selected because it possesses IC in minor veins and translocates large amounts of stachyose in the phloem. 
(3) In addition to these two plants, a number of species from different plant families containing all three types of companion cells (IC, TC, OC) were selected for a comparative study on the apoplastic transport of assimilates. This was necessary to make sure that the observed differences were related to companion cell structure and not specific to a certain species. Plants were selected on the basis of the reported companion cell structure in their minor veins (Gamalei, 1990). 


\section{MATERIALS AND METHODS}

\subsection{Materials}

\subsubsection{Biochemicals}

Most chemicals were purchased from Sigma (Sigma-Aldrich, Taufkirchen, Germany), Merck (Darmstadt, Germany) and Carl Roth (Karlsruhe, Germany). Enzymes used for biochemical analyses were obtained from either Sigma or Roche Molecular Biochemicals (Mannheim, Germany) if not otherwise indicated. For chemicals and products from other companies, the sources are listed below:

dNTPs

Digoxigenine-UTP

tRNA

DNA size marker (bacteriophage $\lambda$ DNA) $\left[\alpha-{ }^{32} \mathrm{P}\right] \mathrm{dATP}$

IPTG (Isopropyl- $\beta$-D-thiogalactopyranoside) oligonucleotides

X-Gal (5-bromo-4-chloro-3-indolyl- $\beta$-Dgalactopyranoside)

X-Gluc (5-bromo-4-chloro-3-indolyl- $\beta$-Dglucuronide)
Roche Molecular Biochemicals, Mannheim,

\section{Germany}

Roche Molecular Biochemicals, Mannheim, Germany

Sigma (Sigma-Aldrich, Taufkirchen, Germany)

MBI Fermentas, Vilnius, Lithuania

Hartmann Analytik, Braunschweig, Germany

AppliChem, Darmstadt, Germany

MWG Biotech, Ebersberg, Germany

Roche Molecular Biochemicals, Mannheim, Germany

MWG Biotech, Ebersberg, Germany 
Microspin S-300 HR columns

Sephadex G25 columns

Hybond $\mathrm{N}$ and Hybond $\mathrm{N}^{+}$

3MM Whatman paper

Chr 17 Whatman paper
Amersham Pharmacia Biotech, Freiburg, Germany

Amersham Pharmacia Biotech, Freiburg,

Germany

Amersham Pharmacia Biotech, Freiburg,

Germany

Biometra Whatman, Germany

Biometra Whatman, Germany

\subsubsection{Enzymes used in molecular biology}

Restriction enzymes and buffers were obtained either from MBI Fermentas (Vilnius, Lithuania) or from Gibco BRL (Eggenstein, Germany). For other enzymes, the source is given below:

DNA polymerase I large fragment

(Klenow fragment)

Klenow fragment, exonuclease ${ }^{-}$

MLV Reverse transcriptase

Thermoscript ${ }^{\mathrm{TM}}$ RT-PCR system

T3 RNA polymerase

T7 RNA polymerase

T4 DNA ligase

Taq polymerase

RNase A
MBI Fermentas, Vilnius, Lithuania

MBI Fermentas, Vilnius, Lithuania

MBI Fermentas, Vilnius, Lithuania

Gibco BRL, Eggenstein, Germany

Gibco BRL, Eggenstein, Germany

Gibco BRL, Eggenstein, Germany

Gibco BRL, Eggenstein, Germany

Promega, Mannheim, Germany

Sigma-Aldrich, Taufkirchen, Germany

\subsubsection{Kits}

HexaLabel Kit

Invisorb Spin-Plant RNA Mini Kit

Qiaquick Gel Extraction Kit

Qiagen Mini Prep Kit

DNeasy Plant Maxi Kit

E.Z.N.A.Peq Lab Mini Prep Kit
MBI Fermentas, Vilnius, Lithuania

Invitek, Berlin, Germany

Qiagen, Hilden, Germany

Qiagen, Hilden, Germany

Qiagen, Hilden, Germany

Peq Lab Biotechnologie GmbH, Erlangen, Germany

ABI PRISM dRhodamine Terminator PE Applied Biosystems, Weiterstadt, Germany

Cycle Sequencing Ready Reaction Kit 
Genome Walker ${ }^{\mathrm{TM}}$ DNA Walking Kit

Low molecular weight calibration Kit

RNA ladder, high range

Bacteriophage $\lambda$ DNA
CLONTECH, Palo Alto, CA. USA

Amersham Pharmacia, Freiburg, Germany

MBI Fermentas, Vilnius, Lithuania

MBI Fermentas, Vilnius, Lithuania

\subsection{Growth conditions}

\subsubsection{Plants}

Alonsoa meridionalis O. Kuntze and Asarina barclaiana Pennell (Scrophulariaceae) were grown in a greenhouse on pot soil. The growth conditions were $600-700 \mu \mathrm{mol} \mathrm{m} \mathrm{m}^{-2} \mathrm{~s}^{-1}$ photon fluence rate, $14 / 10$ hour light/dark period and $22^{\circ} \mathrm{C} / 14^{\circ} \mathrm{C}$ temperature period. Some experiments were performed at the University of Würzburg where plants were kept in the greenhouse with a similar light regime and slightly different temperature conditions $\left(20^{\circ} \mathrm{C} /\right.$ $15^{\circ} \mathrm{C}$ ). For the experiments carried out at the University of Wales (Bangor, UK), plants were grown on pot soil in a controlled environment chamber (Sanyo Gallenkamp, Loughborough, Leicester UK) at $20^{\circ} \mathrm{C}$ in a $16 \mathrm{~h}$ light $/ 8 \mathrm{~h}$ dark cycle and a photon flux of $500 \mu \mathrm{mol} \mathrm{m}{ }^{-2} \mathrm{~s}^{-1}$ and $0.035 \% \mathrm{CO}_{2}$.

For the comparative study of apoplastic sugar contents in plants with different minor vein anatomy, several species were selected on the basis of their reported companion cell structure (Gamalei, 1990) in addition to the two species Alonsoa meridionalis and Asarina barclaiana:

\begin{tabular}{ll|ll}
\multicolumn{2}{c|}{ species with transfer/ordinary cells } & \multicolumn{2}{c}{ species with intermediary cells } \\
\hline Calendula officinalis L. & Asteraceae & Cucurbita pepo L. & Cucurbitaceae \\
Symphytum officinale L. & Boraginaceae & Coleus blumei Benth. & Lamiaceae \\
Lepidium sativum L. & Brassicaceae & Mentha sp. & Lamiaceae \\
Spinacea oleracea L. & Chenopodiaceae & Ligustrum vulgare L. & Oleaceae \\
Pisum sativum L. & Fabaceae & & \\
Vicia faba L. & Fabaceae & & \\
Atropa belladonna L. & Solanaceae &
\end{tabular}

These plants were grown outdoors in the Botanical Garden of the University of Würzburg.

All physiological studies, extractions of apoplastic sap and sugar analyses in whole leaves and in single cell samples were performed using mature fully expanded leaves (usually the third leaf from the top of the branch). For the isolation of RNA young leaves (up to $15 \%$ 
size of the mature fully expanded leaf), mature leaves, stems and flowers were used. DNA was isolated from young leaves and seedlings of Alonsoa meridionalis.

For plant transformation experiments, Arabidopsis thaliana ecotype Columbia was used. Arabidopsis plants were grown in a growth chamber on Mini-tray soil (Baster Einheitserdewerk $\mathrm{GmbH}$, Fröndenberg, Germany) at $22^{\circ} \mathrm{C}$ with a photon flux of $130 \mu \mathrm{mol}$ $\mathrm{m}^{-2} \mathrm{~s}^{-1}$ in a 16 hours light/ 8 hours dark cycle. For the collection of seeds, the inflorescences of plants were placed in paper bags. The seeds were cleaned from plant debris through a metallic sieve and stored at room temperature.

The transformants of Arabidopsis were grown in sterile culture as follows. The seed surfaces were sterilized in a chlorine atmosphere. For this purpose, ca. $50 \mu 1$ volume of seeds in open $1.5 \mathrm{ml}$ Eppendorf tubes and a glass containing $100 \mathrm{ml}$ of $12-14 \%$ sodium hypochlorite solution were placed in a desiccator. After adding $5 \mathrm{ml}$ fuming $\mathrm{HCl}$ to the hypochlorite solution and mixing vigorously, the desiccator was rapidly closed, vacuum was applied for about one minute, and the desiccator was left closed for 12 hours for seed sterilization. Then, the desiccator was opened under a clean bench. The plastic tubes with the surface-sterilized seeds were left open under the clean bench for several minutes.

The seeds were resuspended in $0.1 \%$ agar and placed on MS2-medium plates containing $50 \mu \mathrm{g} / \mathrm{ml}$ kanamycin. The plates were sealed with tape and incubated for 2 days at $4^{\circ} \mathrm{C}$ in the dark. Then the plates were transferred into a growth chamber $(13 / 11$ hour light/dark period, $24^{\circ} \mathrm{C}, 63 \mu \mathrm{mol} \mathrm{m} \mathrm{m}^{-2} \mathrm{~s}^{-1}$ photon flux). After about two weeks, the transformants were still keeping their green colour and had a developed root system whereas non-transformed seedlings were bleached due to the presence of kanamycin and had very poorly developed roots. The green seedlings were transferred to Mini-Tray soil and cultivated in a growth chamber.

MS2 (Murashige-Skoog) medium according to Murashige and Skoog (1962):

$4.405 \mathrm{~g} / 1 \quad$ Murashige and Skoog medium, micro- and macroelements including vitamins (Duchefa, Haarlem, The Netherlands)

$2 \%(\mathrm{w} / \mathrm{v}) \quad$ sucrose

The $\mathrm{pH}$ was adjusted to 5.8 with $\mathrm{KOH}$, and $0.8 \%$ (w/v) Select Agar (Gibco BRL) were added before autoclaving.

\subsubsection{Bacteria}

Cloning of DNA fragments was performed using the Escherichia coli strain DH5 $\alpha$. For the expression of the stachyose synthase gene from Alonsoa meridionalis (2.22), the 
E. coli strain BL21 (DE3) was used. For transformation of Arabidopsis thaliana (2.24), the Agrobacterium tumefaciens strain GV3101 (pMP90) was used.

Liquid cultures of $E$. coli cells were grown overnight at $37^{\circ} \mathrm{C}$ in a roller or shaker in either LB or TB medium supplemented with antibiotics. For growth on agar plates, 1.5\% agar was added to the liquid medium before autoclaving. Antibiotics and other additives were pipetted into the melted agar medium under a clean bench after cooling the medium down to about $70^{\circ} \mathrm{C}$.

A. tumefaciens cells were grown in liquid YEB medium or on YEB agar plates supplemented with antibiotics in a roller or shaker at $28^{\circ} \mathrm{C}$. Usually, they needed two days to reach the stationary phase.

\begin{tabular}{|c|c|c|}
\hline Bacterial Strain & Relevant Characteristics & Reference \\
\hline E.coli DH5 $\alpha$ & $\begin{array}{l}\mathrm{F}^{-}, \phi 80 \mathrm{~d} l a c Z \Delta \mathrm{M} 15, \text { end } A 1, \text { recA } 1, \text { hsdR17 }\left(\mathrm{rk}^{-},\right. \\
\left.\mathrm{mk}^{+}\right), \sup E 44, \text { thi-1, gyrA96, relA1, } \Delta(\text { lacZYA- } \\
\operatorname{argF}) \mathrm{U} 169, \lambda^{-}\end{array}$ & $\begin{array}{l}\text { Woodcock et al. } \\
(1989)\end{array}$ \\
\hline E. coli $\mathrm{BL} 21$ (DE3) & 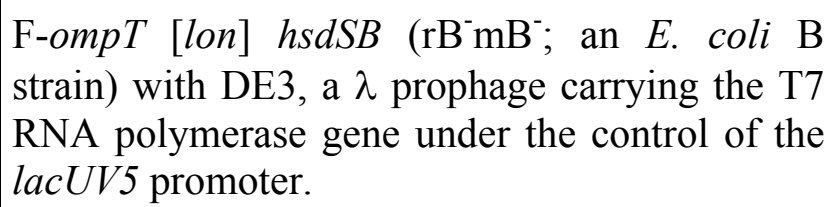 & $\begin{array}{l}\text { Studier and } \\
\text { Moffat (1985) }\end{array}$ \\
\hline $\begin{array}{l}\text { A. tumefaciens } \\
\text { GV3101 (pMP90) }\end{array}$ & $\begin{array}{l}\text { GV3101 }\left(\text { Chr C58 } \text { Rif }^{\mathrm{R}} \text { ) harbours the virulence }\right. \\
\text { helper plasmid pMP90 } \mathrm{Gm}^{\mathrm{R}} \text { (oncogenic parent: } \\
\text { pTiC58, nopaline type) }\end{array}$ & $\begin{array}{l}\text { Koncz and } \\
\text { Schell (1985) }\end{array}$ \\
\hline
\end{tabular}

\section{LB (Luria - Bertani) medium (1 l):}

$\begin{array}{ll}10 \mathrm{~g} & \text { Select Pepton } 140 \\ 5 \mathrm{~g} & \text { yeast extract } \\ 10 \mathrm{~g} & \mathrm{NaCl}\end{array}$

\section{TB medium (1 l):}

$900 \mathrm{ml} \mathrm{TB} 1$ and $100 \mathrm{ml}$ TB2 were autoclaved separately and combined under a laminar flow hood afterwards.

$\underline{\text { TB1: }}$

$\begin{array}{ll}12 \mathrm{~g} & \text { Select Pepton } 140 \\ 24 \mathrm{~g} & \text { yeast extract } \\ 4 \mathrm{ml} & \text { glycerol } \\ \text { ad } 900 \mathrm{ml} & \text { dd } \mathrm{H}_{2} \mathrm{O}\end{array}$


TB2:

$$
\begin{array}{ll}
2.3 \mathrm{~g} & \mathrm{KH}_{2} \mathrm{PO}_{4} \\
16.4 \mathrm{~g} & \mathrm{~K}_{2} \mathrm{HPO}_{4} \\
\text { ad } 100 \mathrm{ml} & \mathrm{dd} \mathrm{H}_{2} \mathrm{O}
\end{array}
$$

YEB medium (11) :

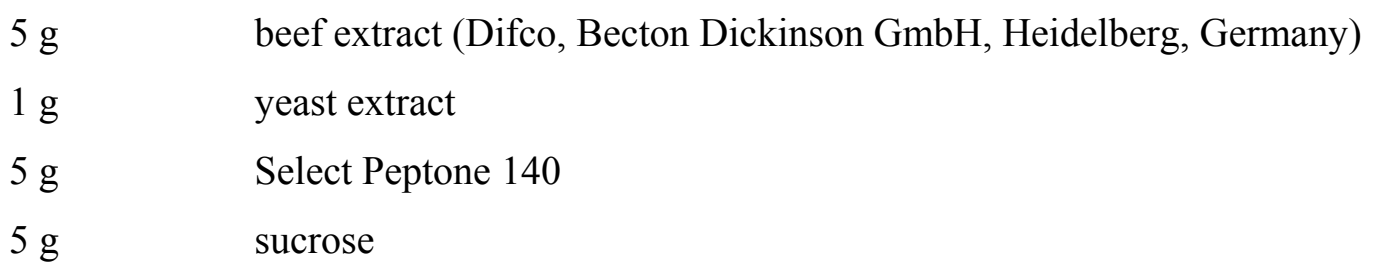

The $\mathrm{pH}$ was adjusted to $7.3-7.4$ with $\mathrm{NaOH}$ before autoclaving.

Agar (Select Agar), agarose, yeast extract and Select Peptone 140 were obtained from Gibco BRL, Eggenstein, Germany. All antibiotics were obtained from Sigma-Aldrich, Taufkirchen, Germany. For other additives, see 2.1.1. Water-soluble additives were filtersterilized using sterile syringe filters with $0.2 \mu \mathrm{m}$ pore size from Sarstedt (Nümbrecht, Germany). All additives were stored at $-20^{\circ} \mathrm{C}$.

\begin{tabular}{|c|c|c|c|c|c|}
\hline Plasmid & Used for & $\begin{array}{c}\text { Used in } \\
\text { Organism/ } \\
\text { Strain }\end{array}$ & $\begin{array}{c}\text { Relevant } \\
\text { Characteristics }\end{array}$ & $\begin{array}{l}\text { Selection } \\
\text { Marker }\end{array}$ & Source \\
\hline $\begin{array}{l}\text { pGEM®-T } \\
\text { Easy }\end{array}$ & $\begin{array}{l}\text { cloning of PCR } \\
\text { products }\end{array}$ & E. coli $\mathrm{DH} 5 \alpha$ & $\begin{array}{l}\text { AT-cloning, blue/white } \\
\text { selection of transformants }\end{array}$ & $A m p^{R}$ & $\begin{array}{l}\text { Promega } \\
\text { Madison } \\
\text { WI. USA }\end{array}$ \\
\hline $\begin{array}{l}\text { pBluescript }{ }^{\circledR}- \\
\mathrm{IIKS}^{+}\end{array}$ & $\begin{array}{l}\text { cloning of templates } \\
\text { for in vitro } \\
\text { transcription } \\
\text { (pAmSTSish, } \\
\text { pAmRSish and } \\
\text { pAmSUTish) }\end{array}$ & E. coli $\mathrm{DH} 5 \alpha$ & $\begin{array}{l}\text { blue/white selection of } \\
\text { transformants }\end{array}$ & $A m p^{R}$ & $\begin{array}{l}\text { Stratagene, } \\
\text { La Jolla, } \\
\text { CA. USA }\end{array}$ \\
\hline
\end{tabular}

\begin{tabular}{c|c|c}
\hline Additives & stock solution & concentration in medium \\
\hline Antibiotics: & & \\
\hline ampicillin & $100 \mathrm{mg} / \mathrm{ml}$ in $\mathrm{dd} \mathrm{H}_{2} \mathrm{O}$ & $100 \mu \mathrm{g} / \mathrm{ml}(1: 1000)$ \\
\hline kanamycin & $50 \mathrm{mg} / \mathrm{ml} \mathrm{in} \mathrm{dd} \mathrm{H}_{2} \mathrm{O}$ & $50 \mu \mathrm{g} / \mathrm{ml}(1: 1000)$ \\
\hline rifampicin & $33 \mathrm{mg} / \mathrm{ml} \mathrm{in} \mathrm{methanol}$ & $33 \mu \mathrm{g} / \mathrm{ml}(1: 1000)$ \\
\hline IPTG & $100 \mathrm{mM}$ in dd $\mathrm{H}_{2} \mathrm{O}$ & $200 \mu \mathrm{M}(1: 500)$ \\
\hline X-Gal & $2 \%(\mathrm{w} / \mathrm{v})$ in DMF & $0.004 \%(1: 500)$ \\
\hline
\end{tabular}

\subsubsection{Plasmids}




\begin{tabular}{|c|c|c|c|c|c|}
\hline $\mathrm{pET} 3 \mathrm{~b}$ & $\begin{array}{l}\text { construction of } \\
\mathrm{pET}^{*} / \mathrm{STS} ; \\
\text { expression in E. coli }\end{array}$ & $\begin{array}{l}\text { E. coli } \mathrm{DH} 5 \alpha \\
\text { E. coli } \mathrm{BL} 21 \\
\text { (DE3) }\end{array}$ & $\begin{array}{l}\text { gene expression using } \mathrm{T} 7 \\
\text { RNA polymerase expression } \\
\text { system }\end{array}$ & $A m p^{R}$ & $\begin{array}{l}\text { Rosenberg } \\
\text { et al. (1986) }\end{array}$ \\
\hline $\mathrm{pET}^{* / \mathrm{STS}}$ & expression in $E$. coli & $\begin{array}{l}\text { E. coli } \mathrm{DH} 5 \alpha \\
\text { E. coli } \mathrm{BL} 21 \\
\text { (DE3) }\end{array}$ & $\begin{array}{l}\text { the plasmid contains the ORF } \\
\text { of Alonsoa stachyose } \\
\text { synthase under control of the } \\
\text { T7 promoter }\end{array}$ & $A m p^{R}$ & this thesis \\
\hline pBI101.3 & $\begin{array}{l}\text { construction of } \\
\text { pBIstsA and } \\
\text { pBIstsB }\end{array}$ & E. coli $\mathrm{DH} 5 \alpha$ & $\begin{array}{l}\text { pRK origin, T-DNA region } \\
\text { carries a polylinker upstream } \\
\text { of the GUS ORF }\end{array}$ & $\mathrm{Km}^{\mathrm{R}}$ & $\begin{array}{l}\text { Jefferson } \\
\text { and Hirsch. } \\
(1986)\end{array}$ \\
\hline pBIstsA & $\begin{array}{l}\text { transformation of } \\
\text { plants using } A \text {. } \\
\text { tumefaciens }\end{array}$ & $\begin{array}{l}\text { E. coli } \mathrm{DH} 5 \alpha, \\
\text { A. tumefaciens } \\
\mathrm{GV} 3101, \\
\text { A. thaliana ecotype } \\
\text { Columbia }\end{array}$ & $\begin{array}{l}\text { plasmid carries a } 1959 \mathrm{bp} \\
\text { fragment of the Alonsoa } \\
\text { stachyose synthase promoter } \\
\text { (including the 5'-untranslated } \\
\text { region) upstream of the GUS } \\
\text { ORF }\end{array}$ & $\begin{array}{l}\mathrm{Km}^{\mathrm{R}} \\
\text { (bacteria) } \\
\mathrm{Km}^{\mathrm{R}} \text { (plants) }\end{array}$ & this thesis \\
\hline pBIstsB & $\begin{array}{l}\text { transformation of } \\
\text { plants using } A \text {. } \\
\text { tumefaciens }\end{array}$ & $\begin{array}{l}\text { E. coli } \mathrm{DH} 5 \alpha, \\
\text { A. tumefaciens } \\
\mathrm{GV} 3101, \\
\text { A. thaliana ecotype } \\
\text { Columbia }\end{array}$ & 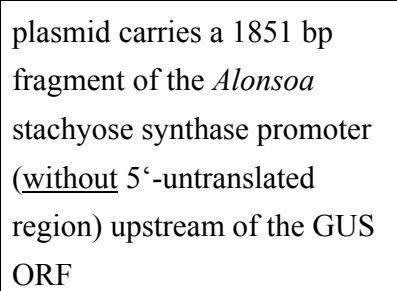 & $\begin{array}{l}\mathrm{Km}^{\mathrm{R}} \\
\text { (bacteria) } \\
\mathrm{Km}^{\mathrm{R}} \text { (plants) }\end{array}$ & this thesis \\
\hline
\end{tabular}

\subsection{Extraction of metabolites}

\subsubsection{Chloroform:methanol extraction}

Chloroform:methanol extraction was performed for measurements of sugar and amino acid contents in fresh leaves or in gradient fractions obtained by non-aqueous fractionation (2.6).

Leaves were weighed and ground to a fine powder in liquid nitrogen using a mortar and a pestle. $300 \mathrm{mg}$ of powder were added to $5 \mathrm{ml}$ of a chloroform:methanol mixture (1.5:3.5 $\mathrm{v} / \mathrm{v}$ ) in a plastic tube. When working with gradient fractions, the dried sediments were extracted in $5 \mathrm{ml}$ of a chloroform:methanol mixture. The samples were mixed vigorously for 2 min and kept on ice for $30 \mathrm{~min} .3 \mathrm{ml}$ of water were then added to the homogenates, and the separation of two phases (the upper water/methanol phase and the lower chloroform phase) was achieved by centrifugation of the samples at $5000 \mathrm{rpm}$ for $5 \mathrm{~min}$ in a Hettich EBA $3 \mathrm{~S}$ centrifuge (Hettich, Tuttlingen, Germany). The upper (aqueous) phase was saved, and the rest was extracted once more with $3 \mathrm{ml}$ of water. The aqueous phases were combined and dried completely in a rotary evaporator at $34^{\circ} \mathrm{C}$. The dried residues were dissolved in $2 \mathrm{ml}$ ultrapure $\mathrm{H}_{2} \mathrm{O}$ (Millipore), filtered through a syringe with a cellulose-nitrate membrane filter $(0.45 \mu \mathrm{m}$; Schleicher and Schuell, Germany) and stored at $-80^{\circ} \mathrm{C}$. 


\subsubsection{Isolation of galactinol and antirrhinoside from plant material}

\subsubsection{Preparative isolation of galactinol}

The method of Pharr et al. (1987) was used with some modifications. Plant material with a high content of galactinol had to be used. Leaves from several plant species known to produce galactinol were analysed by HPLC. The analysis showed that leaves of Buddleja davidii contained the highest amount of galactinol (up to $0.9 \mathrm{mg}$ per $\mathrm{g}$ fresh weight). $450 \mathrm{~g}$ of Buddleja leaves were ground to a powder in liquid nitrogen and extracted in $1.5 \mathrm{~L}$ of a chloroform:methanol mixture on ice for $30 \mathrm{~min}$ (see 2.3.1). Then, $500 \mathrm{ml} \mathrm{dd} \mathrm{H}_{2} \mathrm{O}$ were added, and phases were separated by centrifugation for $20 \mathrm{~min}$ at $11000 \mathrm{~g}$ (Sorvall DuPont, Dreieich, Germany; rotor GS3). The upper (aqueous) phase containing the water-soluble metabolites was saved. The rest was extracted once again with $400 \mathrm{ml} \mathrm{dd} \mathrm{H}_{2} \mathrm{O}$. The upper phases from both centrifugation steps were combined, and the volume was reduced to $100 \mathrm{ml}$ in a rotary evaporator at $34^{\circ} \mathrm{C}$. Then, cations were removed from the extract by adding a cation exchanger Dowex AG 50W-X8 (in $\mathrm{H}^{+}$-form) and stirring for $30 \mathrm{~min}$. The supernatant was decanted, and the procedure was repeated with 1/10 volume of Polyclar AT (Sigma) to remove polyphenols and polysaccharides. The extract was filtered through a paper filter to remove the Polyclar AT. Afterwards, the volume of the extract was reduced to $10 \mathrm{ml}$ in the rotary evaporator and the extract was applied to an anion exchange column of $50 \mathrm{~cm}$ length and $2.8 \mathrm{~cm}$ diameter filled with Dowex $1 \times 8\left(\mathrm{OH}^{-}\right.$-form $)$. Passing the extract through the column allowed the removal of anions and at the same time led to a separation of the extract into fractions with different sugar composition. The elution was performed with $0.2 \mathrm{M} \mathrm{NaOH}$ at a rate of $2.5 \mathrm{ml} / \mathrm{min}$. 120 Fractions $(5 \mathrm{ml}$ per fraction) were collected. The sugar composition of the fractions was determined by HPLC (2.8.1). Galactinol eluted after about 2 hours and was found in the fractions No. 60-80. No other sugars were detectable in these fractions. The galactinol-containing fractions were combined and neutralized using $5 \mathrm{M} \mathrm{HCl}$. This step was necessary because the presense of $0.2 \mathrm{M} \mathrm{NaOH}$ in the eluate might lead to the condensation (caramelization) of sugars under alkaline conditions during the following concentration of the combined fractions. Then, the fractions were combined and the volume was reduced to $10 \mathrm{ml}$ in the rotary evaporator at $34^{\circ} \mathrm{C}$. In this step, $\mathrm{NaCl}$ had been concentrated to up to $2 \mathrm{M}$ which would interfere with the following stachyose synthase activity assay. Therefore, $\mathrm{NaCl}$ was removed from galactinol by descendent paper chromatography. Two pieces of $18 \mathrm{~cm}$ x $45 \mathrm{~cm}$ from chromatography paper Whatman Chr 17 were used. The running solution was n-propanol:ethyl acetate: $\mathrm{H}_{2} \mathrm{O}=7: 1: 2$. For the detection of galactinol, a thin strip was cut off and developed in detection solution $(2.5 \mathrm{ml}$ of a saturated 
$\mathrm{AgNO}_{3}$ solution in $500 \mathrm{ml}$ acetone) for $2.5 \mathrm{~min}$. The strips were then transferred to the stop solution ( $10 \mathrm{~g} \mathrm{NaOH}$ in $15 \mathrm{ml} \mathrm{H} \mathrm{H}_{2} \mathrm{O}$ added to $500 \mathrm{ml}$ of $\left.96 \% \mathrm{EtOH}\right) . \mathrm{NaCl}$ moved along the chromatogram faster than galactinol, but even after nine hours, the separation was not complete. A large part of the galactinol had not yet been separated from the $\mathrm{NaCl}$ and thus was lost. The part of the chromatogram containing galactinol was cut into pieces and galactinol was eluted with $200 \mathrm{ml} \mathrm{dd} \mathrm{H}_{2} \mathrm{O}$ in an ultrasonication bath for $20 \mathrm{~min}$ (Branson Sonifier B 15, Branson Ultrasonics Corp., Geneva, Switzerland). The elution was repeated three times. The eluates $(600 \mathrm{ml}$ in total) were combined and the volume was reduced in the rotary evaporator at $34^{\circ} \mathrm{C}$ to concentrate the galactinol. Then, the concentration of galactinol was determined by HPLC (2.8.1). Altogether, $35 \mathrm{mg}$ of galactinol were isolated from $450 \mathrm{~g}$ of leaves.

\subsubsection{Preparative isolation and confirmation of the chemical structure of antirrhinoside}

The isolation of antirrhinoside from leaves of Asarina was performed in the same way as that of galactinol (2.3.2.1). $100 \mathrm{~g}$ leaves of Asarina with an antirrhinoside content of up to 15 $\mathrm{mg} / \mathrm{g}$ fresh weight were harvested. After elution from paper chromatograms with $\mathrm{dd}^{\mathrm{H}} \mathrm{H}_{2} \mathrm{O}$ and concentration in a rotary evaporator, $35 \mathrm{ml}$ of ca. $30 \mathrm{mM}$ antirrhinoside solution were obtained (i.e. ca. $350 \mathrm{mg}$ antirrhinoside). From this solution, $5 \mathrm{ml}$ (ca. $50 \mathrm{mg}$ antirrhinoside dissolved in water) were used for the analysis of the chemical structure of antirrhinoside by NMR at the Institute for anorganic chemistry, University of Göttingen (Figure 2.1).

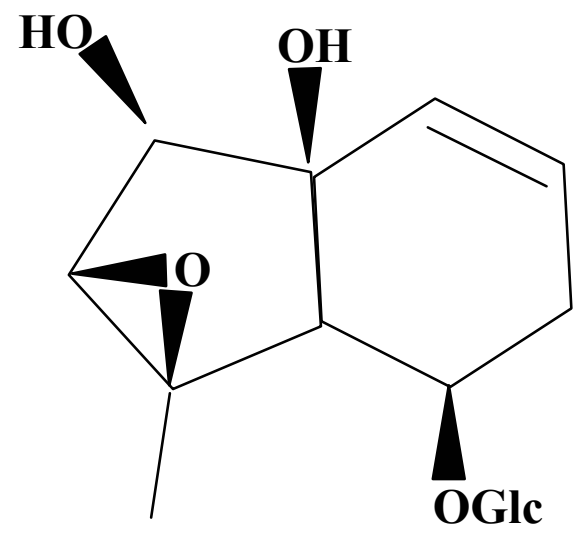

Antirrhinoside
Figure 2.1. An unknown compound isolated from the leaves of Asarina barclaiana was identified by NMR as an iridoid glucoside antirrhinoside. Antirrhinoside was also a major component of the phloem exudate of Asarina barclaiana. 


\subsection{Extraction of apoplastic sap (intercellular washing fluid)}

The intercellular washing fluid (IWF) was obtained from leaves according to the method of Speer and Kaiser (1991) and Lohaus et al. (2001). Leaves were detached from the plants and infiltrated with $50 \mathrm{mM} \mathrm{CaCl}_{2}$ solution using a $60 \mathrm{ml}$ syringe. Prior to the infiltration, the infiltrating solution was cooled on ice. Fully infiltrated leaves were transparent. The leaves were then carefully blotted dry, positioned into a $10 \mathrm{ml}$ vessel located on top of a centrifuge tube and centrifuged for $5 \mathrm{~min}$ at $80-160 \mathrm{~g}$ and $4^{\circ} \mathrm{C}$ (Megafuge 1.0, Heraeus Sepatech, Osterode), the time interval between infiltration and centrifugation being no longer than $5 \mathrm{~min}$. By this procedure, between 50 and $200 \mu 1$ of apoplastic sap diluted with the infiltration solution were obtained per gram fresh weight.

Apoplastic sugar concentrations in the leaves were determined on the basis of the dilution factor $\mathrm{F}$

$$
\mathrm{F}=\left(\mathrm{V}_{\text {apoplast }}-\mathrm{V}_{\text {gas space }}\right) / \mathrm{V}_{\text {gas space }}
$$

The volume of the apoplastic gaseous phase was calculated from the difference of the fresh weight of leaves before and after the infiltration. Apoplastic sugar concentrations were calculated under the assumption that the apoplastic water phase of leaves is about $10 \%$ of the leaf volume (Lüttge and Higinbotham, 1979; Speer and Kaiser, 1991). For the leaves of Alonsoa meridionalis, a more precise estimation of the volume of the liquid apoplast was made as follows. Leaf discs were floated on water until completely hydratized. Leaf discs were then infiltrated with water containing $0.005 \mu \mathrm{Ci} / \mathrm{ml}{ }^{14} \mathrm{C}$-sorbitol. After a centrifugation for $5 \mathrm{~min}$ at $80-160 \mathrm{~g}$ and $4^{\circ} \mathrm{C}$, the radioactivity of the obtained intercellular washing fluid was determined in a liquid scintillation analyser (Packard 1900 TR, Canberra-Packard, Dreieich, Germany). The dilution of the radioactivity of the infiltration solution due to the apoplastic water phase was calculated and its volume was determined:

$\mathrm{V}_{\text {apoplast }}=\mathrm{V}_{\text {gas space }}\left(\mathrm{dpm}_{\text {infiltrated solution }}-\mathrm{dpm}_{\mathrm{IWF}}\right) / \mathrm{dpm}_{\mathrm{IWF}}$

The absence of cellular contamination of the apoplastic extracts was proven by measurements of the activity of glucose-6-phosphate dehydrogenase (G6PDH) in the samples (2.5.1). The activities of G6PDH in leaves and apoplastic extracts were compared. For further measurements, only apoplastic extracts were used with less than $0.01 \%$ of total leaf G6PDH activity detected in the apoplastic extract.

\subsection{Determination of enzyme activities}

The activities of the enzymes listed below were measured in leaf extracts (2.5.1, 2.5.6.1), density gradient fractions $(2.5 .2,2.5 .3,2.5 .4)$, apoplastic extracts $(2.5 .1,2.5 .5)$ and 
bacterial cells (2.5.6.2). The OD measurements were performed using a double-beam photometer Uvikon 932, Kontron $(2.5 .1,2.5 .2,2.5 .4)$ or a two wavelength spectrophotometer Sigma SFP $22(2.5 .3,2.5 .5)$.

\subsubsection{Glucose-6-phosphate dehydrogenase (G6PDH)}

Leaves (ca. $0.3 \mathrm{~g}$ ) were homogenized with $0.1 \mathrm{~g}$ Polyclar AT, $20 \mathrm{mg}$ Na-ascorbate and $2 \mathrm{ml}$ buffer $\left(0.1 \mathrm{M} \mathrm{NaH}_{2} \mathrm{PO}_{4}: 0.1 \mathrm{M} \mathrm{Na}_{2} \mathrm{HPO}_{4}=1: 2 \mathrm{v} / \mathrm{v}, \mathrm{pH}\right.$ 7.4). The homogenate was centrifuged and the activity of G6PDH was determined by adding $10 \mu 1$ supernatant or $10-$ $50 \mu 1$ apoplastic extract (IWF) to a $1 \mathrm{ml}$ reaction volume containing

$\begin{array}{ll}\text { Tricine pH } 8.0 & 0.1 \mathrm{M} \\ \text { NADP } & 1 \mathrm{mM} \\ \mathrm{MgCl}_{2} & 5 \mathrm{mM} \\ \text { glucose-6-phospate } & 10 \mathrm{mM}\end{array}$

The activity was calculated based on an increase in absorbance at $340 \mathrm{~nm}$ due to the formation of NADPH in the reaction

$$
\text { glucose-6-phosphate }+\mathrm{NADP}^{+} \stackrel{\mathrm{G} 6 \mathrm{PDH}}{\longrightarrow} \text { 6-phosphogluconate + NADPH }
$$

using a molar extinction coefficient for NADPH of $6.22 \mathrm{mM}^{-1} \mathrm{~cm}^{-1}$ at $340 \mathrm{~nm}$.

\subsubsection{NADP-dependent Glyceraldehyde 3-phosphate dehydrogenase (GAPDH)}

The activity was measured using $20 \mu \mathrm{l}$ of density gradient fraction extracts (2.6.3) in a total volume $600 \mu \mathrm{l}$. The method is based on a decrease in the absorbance at $340 \mathrm{~nm}$ due to the oxidation of NADPH in two coupled reactions (Wirtz et al., 1980):

$$
\begin{aligned}
& \text { 3-phosphoglycerate }+ \text { ATP } \stackrel{\text { phosphoglycerate kinase }}{\longrightarrow} \text { 1,3-bis-phosphoglycerate } \\
& \text { 1,3-bis-phosphoglycerate }+ \text { NADPH } \stackrel{\text { GAPDH }}{\longrightarrow} \mathrm{NADP}^{+}+3 \text {-phosphoglycerol aldehyde }
\end{aligned}
$$

The activity was calculated using a molar extinction coefficient for NADPH of $6.22 \mathrm{mM}^{-1} \mathrm{~cm}$ -1 at $340 \mathrm{~nm}$.

The reaction mixture contained

$\begin{array}{ll}\text { HEPES-KOH pH } 8.0 & 0.1 \mathrm{M} \\ \mathrm{KCl} & 20 \mathrm{mM} \\ \mathrm{Na}_{2} \text {-EDTA } & 2 \mathrm{mM} \\ \mathrm{MgCl}_{2} & 30 \mathrm{mM} \\ \text { DTT } & 200 \mathrm{mM} \\ \text { ATP } & 200 \mathrm{mM} \\ \text { NADPH } & 10 \mathrm{mM} \\ \text { phosphoglycerate kinase } & 6 \mathrm{U} \\ \text { 3-phosphoglycerate } & 200 \mathrm{mM} \quad \text { (start) }\end{array}$




\subsubsection{Phosphoenolpyruvate carboxylase (PEPCX)}

$70 \mu \mathrm{l}$ of extracts of each density gradient fraction (2.6.3) were used for this assay. The assay volume was $600 \mu 1$. The enzyme activity was determined based on a decrease in the absorbance at $334 \mathrm{~nm}$ due to the oxidation of NADH in two coupled reactions (Stitt et al., 1978):

$$
\begin{aligned}
& \text { phosphoenolpyruvate }+\mathrm{HCO}_{3}{ }^{-\mathrm{PEPCx}} \longrightarrow \text { oxaloacetate }+\mathrm{P}_{\mathrm{i}} \\
& \text { oxaloacetate }+\mathrm{NADH} \stackrel{\text { L-malate dehydrogenase }}{\longrightarrow} \mathrm{NAD}^{+}+\text {L-malate }
\end{aligned}
$$

The activity was calculated using a molar extinction coefficient for NADPH of $6.18 \mathrm{mM}^{-1}$ $\mathrm{cm}^{-1}$ at $334 \mathrm{~nm}$.

The reaction mixture contained

$\begin{array}{lll}\text { glycylglycine } \mathrm{pH} 7.9 & 50 \mathrm{mM} & \\ \mathrm{MgCl}_{2} & 10 \mathrm{mM} & \\ \mathrm{KHCO}_{3} & 4 \mathrm{mM} & \\ \mathrm{NADH} & 20 \mathrm{mM} & \\ \text { L-malate dehydrogenase } & 4.8 \mathrm{U} & \\ \text { PEP } & 8 \mathrm{mM} & \text { (start) }\end{array}$

\subsection{4. $\alpha$-Mannosidase}

The activity of $\alpha$-mannosidase was determined according to Ye-The (1967) based on an increase in the absorbance at $405 \mathrm{~nm}$ due to the formation of $\mathrm{p}$-nitrophenol in the reaction

$$
\text { p-nitrophenyl- } \alpha \text {-D-mannopyranoside }+\mathrm{H} 2 \mathrm{O} \stackrel{\alpha \text {-mannosidase }}{\longrightarrow} \text { D-mannose }+ \text { p-nitrophenol }
$$
$50 \mu 1$ of extracts of each density gradient fraction (2.6.3) were used for this enzyme assay which took place in a total volume of $1050 \mu 1$. The reaction mixture contained:

$$
\begin{array}{ll}
\text { sodium citrate } \mathrm{pH} 4.5 & 50 \mathrm{mM} \\
\text { p-nitrophenyl- } \alpha \text {-D-mannopyranoside } & 4.8 \mathrm{mM}
\end{array}
$$

The assay mixture was incubated at $37^{\circ} \mathrm{C}$ for $50 \mathrm{~min}$. Then the reaction was stopped by the addition of $500 \mu 10.8 \mathrm{M}$ boric acid ( $\mathrm{pH}$ 9.8). The enzyme activity was calculated using a molar extinction coefficient for p-nitrophenol of $18.5 \mathrm{mM}^{-1} \mathrm{~cm}^{-1}$ at $405 \mathrm{~nm}$.

\subsubsection{Malate dehydrogenase}

The activity was measured based on a decrease in the absorbance at $334 \mathrm{~nm}$ due to the oxidation of NADH in the reaction

$$
\text { oxaloacetate }+\mathrm{NADH}+\mathrm{H}^{+} \stackrel{\text { malate dehydrogenase }}{\longrightarrow} \mathrm{L}-\text { malate }+\mathrm{NAD}^{+}
$$

The reaction mixture contained in a total volume of $1 \mathrm{ml}$ : 

$850 \mu 1$ MOPS pH 7.5
$0.1 \mathrm{M}$
$25 \mu 1 \mathrm{NADH}$
$100 \mu 1$ oxaloacetate in MOPS
$20 \mathrm{mM}$
$20 \mathrm{mM}$

(start)

\subsubsection{Stachyose synthase activity assays}

\subsubsection{Establishment of the AmSTS activity assay using leaves of Alonsoa}

$250-350 \mathrm{mg}$ of Alonsoa leaves were ground on ice in $2 \mathrm{ml}$ of extraction buffer using mortar and pestle. Extraction buffers with four different $\mathrm{pH}$ values, 5.5, 6.0, 6.5 and 7.0 were used to determine the $\mathrm{pH}$ optimum of AmSTS. The extracts were transferred into $2 \mathrm{ml}$ plastic Eppendorf tubes and centrifuged for $5 \mathrm{~min}$ at $4^{\circ} \mathrm{C}$. The supernatants were desalted on Sephadex G25 columns (Amersham Pharmacia Biotech, Freiburg, Germany). Before desalting, the columns were equilibrated with $25-40 \mathrm{ml}$ Na phosphate buffer by applying buffer on the column and centrifuging at $1800 \mathrm{rpm}$ for $2 \mathrm{~min}$ (Megafuge 1.0, Heraeus Sepatech, Osterode, Germany). Before the application of the protein extracts, the columns were emptied by centrifugation for $5 \mathrm{~min}$ at $2000 \mathrm{rpm}$. For desalting, $4 \mathrm{ml}$ of each supernatant were pipetted onto a column and centrifuged for $5 \mathrm{~min}$ at $2000 \mathrm{rpm}$. The recovered desalted extracts were kept on ice until use.

The activity of Alonsoa stachyose synthase was determined by masurements of a timedependent formation of stachyose in the assays according to the reaction:

$$
\text { galactinol + raffinose } \stackrel{\text { stachyose synthase }}{\longrightarrow} \text { myo-inositol + stachyose }
$$

The assays were performed at $30^{\circ} \mathrm{C}$ in $1.5 \mathrm{ml}$ Eppendorf tubes in a total volume of $100 \mu \mathrm{l}$ containing (final concentrations):

$\begin{array}{ll}\text { sodium phosphate buffer } \mathrm{pH} 6.5 & 50 \mathrm{mM} \\ \text { galactinol } & 1 \mathrm{mM} \\ \text { raffinose } & 4 \mathrm{mM} \\ \text { DTT } & 0.6 \mathrm{mM}\end{array}$

The reaction was started by the addition of $25 \mu \mathrm{l}$ of protein extract. To stop the reaction, the tubes were placed at $100^{\circ} \mathrm{C}$ for $5 \mathrm{~min}$. Aliquots were stopped at $0,20,40,60,80$, 100 and $120 \mathrm{~min}$, to reveal a time course of the reaction. For the first timepoint, the tubes were placed at $100^{\circ} \mathrm{C}$ immediately after the addition of the extract. After 5 min incubation at $100^{\circ} \mathrm{C}$, the tubes were centrifuged for $5 \mathrm{~min}$ at $13000 \mathrm{rpm}$ and the sugar contents of the supernatants were analysed by HPLC (2.8.1). Negative control reactions were performed for 80 min under the same conditions but galactinol was omitted from the assay mixture. 


\subsubsection{AmSTS activity assay in protein extracts of $E$. coli BL21 (DE3) (pET*/STS)}

The extraction buffer was prepared from $\mathrm{Na}$ phosphate stock solution. Other components were added freshly before the extraction. The pelleted cells were resuspended in $10 \mathrm{ml}$ extraction buffer and broken up via four cycles of ultrasonication on ice (15 sec pulse and 45 min pause)in Branson Sonifier B 15 (Branson Ultrasonics Corporation, Geneva, Switzerland). The broken cells were spun down in a Sorvall ultracentrifuge at $4^{\circ} \mathrm{C}$ and 12000 $\mathrm{g}$ for $20 \mathrm{~min}$. The supernatants were saved and desalted on Sephadex G25 columns as described in 2.5.6.1. The protein extracts recovered from the columns were kept on ice until use for stachyose synthase activity assays.

Extraction buffer:

$$
\begin{array}{ll}
\text { Na phosphate, pH } 6.5 & 50 \mathrm{mM} \\
\text { DTT } & 5 \mathrm{mM} \text { (freshly added) } \\
\text { Protease inhibitor cocktail } & 1: 200 \text { (freshly added) } \\
\text { (Roche Molecular Biochemicals, Mannheim, Germany) }
\end{array}
$$

The assays were performed at $\mathrm{pH} 6.5$ which has been established as the $\mathrm{pH}$ optimum of AmSTS from Alonsoa leaves. Other conditions were as indicated in 2.5.6.1. The reaction was started by the addition of $49 \mu 1$ protein extract from BL21 (DE3) (pET*/STS) or BL21 (DE3) (pET3b), respectively. The negative control reactions were performed with extracts from both strains with reaction mixtures lacking galactinol.

\subsection{Non-aqueous fractionation of leaves}

\subsubsection{Preparation of leaf material}

Leaves were cut from the plants after 5 hours of the light period. The middle rib was removed, and the samples were ground to a fine powder in liquid nitrogen in a precooled mortar. The leaf tissue powder was then placed in a plastic box and, after the nitrogen had evaporated but before the samples had begun to thaw, transferred into a lyophilizer Lyovac GT3 (Leybold-Heraeus, Köln, Germany). The powder was lyophilized at $-25{ }^{\circ} \mathrm{C}$ for 5 days. The lyophilizer was opened under nitrogen atmosphere. The plastic box with the leaf tissue powder was placed in a desiccator and stored at $-20^{\circ} \mathrm{C}$ until fractionation on a density gradient.

\subsubsection{Non-aqueous fractionation of leaf tissue in a density gradient}

The separation of the leaf tissue into fractions enriched with either chloroplastic, cytosolic or vacuolar content was achieved by a centrifugation in an exponential density gradient (Gerhard and Heldt, 1984). The liquid constituents of the gradient were virtually non- 
aqueous (heptane and tetrachloroethylene). This prevented the redistribution of the watersoluble metabolites and enzymes during the separation of the plant material within the gradient and therefore made it possible to attribute the amounts of metabolites to the subcellular compartments determined via the activities of specific marker enzymes. Spatial separation of subsellular components within the density gradient occurs due to different density of membranes from cell compartments (Gerhardt and Heldt, 1984).

For the preparation of the density gradient, two solutions of different density (solution A and solution B) were used which were prepared from heptane $\left(\rho=0.68 \mathrm{~g} / \mathrm{cm}^{3}\right)$ and tetrachloroethylene $\left(\rho=1.62 \mathrm{~g} / \mathrm{cm}^{3}\right)$ at least two days before the fractionation procedure. The densities were for Alonsoa:

Solution A: $1.29 \mathrm{~g} / \mathrm{cm}^{3}$

Solution B: $\quad 1.58 \mathrm{~g} / \mathrm{cm}^{3}$

and for Asarina:

Solution A: $1.34 \mathrm{~g} / \mathrm{cm}^{3}$

Solution B: $1.62 \mathrm{~g} / \mathrm{cm}^{3}$.

The solutions were stored over a layer of a water adsorbent (Molecular sieve $0.4 \mu \mathrm{m}$, Merck, Darmstadt, Germany) at $4^{\circ} \mathrm{C}$. It was important to prepare the solutions A and B from fresh tetrachloroethylene as well as to protect tetrachloroethylene and the solutions from light because the formation of $\mathrm{Cl}$ radicals during the storage would have resulted in the complete inhibition of the activities of the marker enzymes in the fractions.

The following steps were performed at $4^{\circ} \mathrm{C}$. The exponential density gradient was prepared in a cellulose nitrate centrifuge tube. $1 \mathrm{ml}$ of solution $\mathrm{B}$ was pipetted into the tube and carefully underlayed with $0.5 \mathrm{ml}$ of tetrachloroethylene using a Pasteur pipette. This was overlayed with $9.2 \mathrm{ml}$ of a mixture of solutions A and B with exponentially changing density prepared in a gradient mixer. The lyophilized leaf tissue powder (about $200 \mathrm{mg}$ ) was suspended in $2 \mathrm{ml}$ of solution A and vortexed. Then the powder was ultrasonicated in a Branson Sonifier B 15 (Branson Ultrasonics Corp., Geneva, Switzerland) while being kept in a heptane bathe containing dry ice according to the following scheme:

2 minutes: $5 \mathrm{~s}$ pulse / $5 \mathrm{~s}$ pause

1 minute: $5 \mathrm{~s}$ pulse / $25 \mathrm{~s}$ pause

1 minute: $5 \mathrm{~s}$ pulse / $5 \mathrm{~s}$ pause.

Afterward, the powder was filtered through a metallic sieve and poured into 4 plastic $10 \mathrm{ml}$-centrifuge tubes which then were filled up with heptane. After centrifugation for 2 min at $3000 \mathrm{rpm}$ (Megafuge 1.0, Heraeus Sepatech, Osterode) the supernatant was discarded, and 
the sediments were resuspended in $2 \mathrm{ml}$ of solution A and filtered through a nylon net with 40 $\mu \mathrm{m}$ pore size. From this filtrate, $200 \mu \mathrm{l}$ were saved for the determination of the activities of the marker enzymes and of metabolites in the leaf tissue before fractionation. 1.5 to $2 \mathrm{ml}$ of the filtrate were carefully pipetted on the top of the gradient. The separation in the gradient was performed by centrifugation at $4^{\circ} \mathrm{C}$ at $25000 \mathrm{x}$ g for $130 \mathrm{~min}$ (Sorvall Du Pont, Dreieich, Germany) using an HB4 rotor. The separated material was collected in six or seven fractions, of which two aliquots were taken for the determination of activities of the marker enzymes (ca. $600 \mu \mathrm{l}$ ) and metabolites (ca. $800-1000 \mu \mathrm{l}$ ). The exact volumes were noted. The aliquots were pipetted into $1.5 \mathrm{ml}$ plastic Eppendorf tubes containing ca. $100 \mu 1$ quartz sand, filled up with heptane and centrifuged at $13000 \mathrm{rpm}$ for $15 \mathrm{~min}$. The supernatant was discarded, the sediments were dried in the desiccator and stored at $-80{ }^{\circ} \mathrm{C}$ until used for the determination of the marker enzyme activities and metabolite contents.

\subsubsection{Determination of the activities of marker enzymes in the gradient fractions}

The enzymes NADP-dependent glyceraldehyde 3-phosphate dehydrogenase, PEPcarboxylase and $\alpha$-mannosidase were used as markers for chloroplast, cytosol and vacuole, respectively. Usually, the chloroplastic material was found to be concentrated in the middle region of the gradient, the cytosolic material appeared in the lower region whereas the vacuolar material was mainly found in the fraction of highest density. Dried sediments were resuspended in $500 \mu 1$ of potassium-phosphate buffer (50 mM pH 7.5) containing $1 \mathrm{mM}$ DTT, vortexed for $1 \mathrm{~min}$ and kept on ice for $5 \mathrm{~min}$ for extraction of the proteins. Then, another 500 $\mu 1$ buffer were added, and the samples were centrifuged at $13000 \mathrm{rpm}$ for $2 \mathrm{~min}$ at $4^{\circ} \mathrm{C}$. The supernatants were used for the measurements of the enzyme activities $(2.5 .2-2.5 .4)$ and for determination of the protein concentration (2.6.6).

\subsubsection{Determination of metabolite concentrations in the gradient fractions}

For determination of metabolite concentrations in the gradient fractions, a chloroform: methanol extraction of the resuspended fraction was performed (2.3.1). The dried sediments were extracted in $5 \mathrm{ml}$ of the chloroform:methanol mixture. The vacuum-dried extracts were redissolved in $700 \mu 1 \mathrm{H}_{2} \mathrm{O}$ (Millipore) and used for HPLC analyses of sugars and amino acids (2.8.1.).

\subsubsection{Calculation of the subcellular distribution of metabolites}

For the evaluation of the subcellular distribution of sugars and amino acids between the stromal, cytosolic, and vacuolar compartments, a calculation procedure according to Riens et al. (1991) was used. This calculation method is based on the assumption that the 
metabolites are confined to the three biggest cellular compartments (chloroplasts, cytosol and vacuole), designated by the corresponding marker enzymes. The evaluation is done by a computer program testing all possible cases for the percentage distribution of a certain metabolite between the three compartments at intervals of $1 \%$. With this interval, 5151 distribution patterns can be analysed. The program calculates which of these 5151 patterns yields the best fit (agreement) with the experimental results. A coefficient $\mathrm{Q}$ is taken as the measure for the best agreement:

$$
\mathrm{Q}=\sqrt{\Sigma \mathrm{r}_{\mathrm{i}}^{2} /(\mathrm{n}-1)}
$$

where $r_{i}$ is the difference between the measured and the calculated distribution for each fraction and $\mathrm{n}$ is the number of the fractions.

To avoid the results being falsified by analytical errors, the calculations are usually based on mean values obtained from measurements from at least three density gradient fractionations. Only the results with the lowest $\mathrm{Q}$ value were used.

\subsubsection{Determination of the chlorophyll:protein ratio}

The chlorophyll:protein ratio was determined for each preparation of leaf tissue powder. A sample of the powder (about $50 \mathrm{mg}$ ) was dissolved in $5 \mathrm{ml}$ potassium phosphate buffer (2.6.3), ultrasonicated for $1 \mathrm{~min}$ ( $5 \mathrm{sec}$ pulse and $5 \mathrm{sec}$ pause) and filtered through a nylon net with $40 \mu \mathrm{m}$ pore size. In the filtrate, the protein concentration was determined according to Lowry et al. (1951) (2.7). Chlorophyll was extracted from the filtrate by the addition of $99 \%$ ethanol so that the final ethanol concentration of the extract was adjusted to $80 \%$. The optical density of the extract was measured at $652 \mathrm{~nm}$ in a spectrophotometer (Uvikon 932, Kontron) against $80 \%$ ethanol. The amount of chlorophyll was calculated using an extinction coefficient of $36 \mathrm{ml} \mathrm{mg}^{-1} \mathrm{Chl} \mathrm{cm}^{-1}$ at $652 \mathrm{~nm}$ (Arnon, 1949).

For each density gradient fractionation, the total protein amounts in the fractions were compared with the protein amount in the leaf tissue powder before fractionation. The percentage of recovery characterized the loss of leaf material during the fractionation procedure. For most gradients, the recovery of protein from the fractions was between $85 \%$ and $100 \%$, and only the gradients with recovery rates better than $90 \%$ were taken for the calculation of the subcellular distribution of metabolites. Based on the known chlorophyll:protein ratio, the amounts of metabolites were recalculated as $\mu \mathrm{mol} / \mathrm{mg} \mathrm{Chl}$ which allowed the comparison between several gradients from independent preparations of leaf tissue powder. 


\subsection{Protein determination}

The protein concentrations were measured in gradient fractions from Alonsoa and Asarina leaves according to Lowry et al. (1951). Before an analysis, a solution containing $\mathrm{A}: \mathrm{B}: \mathrm{C}=$ 99:0.5:0.5 was freshly prepared from the stock solutions:

Solution $\mathrm{A}=2 \%(\mathrm{w} / \mathrm{v}) \mathrm{Na} 2 \mathrm{CO} 3$ in $0.1 \mathrm{M} \mathrm{NaOH}$

Solution $\mathrm{B}=1 \%(\mathrm{w} / \mathrm{v}) \mathrm{CuSO}_{4} \times 5 \mathrm{H}_{2} \mathrm{O}$

Solution $\mathrm{C}=2 \%(\mathrm{w} / \mathrm{v}) \mathrm{Na}-\mathrm{K}$-tartrate

$130 \mu 1$ water, $20 \mu 1$ of the sample and $700 \mu \mathrm{ABC}$ mixture were pipetted together, vortexed and incubated for $15 \mathrm{~min}$. Afterwards, $100 \mu \mathrm{l}$ of Folin-Ciocalteu's phenol reagent (diluted 1:2) were added, and the samples were incubated for $10 \mathrm{~min}$. From each sample, two aliquots were analysed. A third aliquot was used to determine the background absorbance at $578 \mathrm{~nm}$. For this purpose, the $20 \mu \mathrm{l}$ aliquot was added to the reaction mixture only after both incubations were completed. The samples were centrifuged for $2 \mathrm{~min}$ at $13000 \mathrm{rpm}$ in an Eppendorf centrifuge and the extinction was measured at $578 \mathrm{~nm}$. For each analysis, a calibration curve was made using BSA solutions in the same buffer as used for the sample extraction. The calibration curve points corresponded usually to $9,18,27,36$ and $45 \mu \mathrm{g}$ protein in the sample.

\subsection{Sugar analysis}

\subsubsection{HPLC}

Sugars in leaf extracts, density gradient fractions and apoplastic washing fluid samples were assayed by HPLC. An anion exchange column (CarboPAC10; Dionex Corp, Sunnyvale, CA., USA) was used for the determination of mono-, di- and oligosaccharides. Another column, MA1, from the same firm allowed a better resolution in the region of polyols and cyclitols. Both columns were eluted with $\mathrm{NaOH}$ using the LC-9A pump from Shimatzu (Kyoto, Japan).

The CarboPAC10 column was eluted isocratically with $80 \mathrm{mM} \mathrm{NaOH}$ with a flow rate of $1 \mathrm{ml} \mathrm{min}{ }^{-1}$ and the MA1 column with $600 \mathrm{mM} \mathrm{NaOH}$ with a flow rate of $0.4 \mathrm{ml} \mathrm{min}^{-1}$. Both solutions were prepared using Millipore water washed with helium for $15 \mathrm{~min}$ to prevent the formation of $\mathrm{NaHCO}_{3} . \mathrm{NaOH}(50 \%)$ of the purest quality commercially available was used (Baker, England), which resulted in a good stability of the base line.

An autosampler \# 2157, Pharmacia, LKB was thermostated at $12{ }^{\circ} \mathrm{C}$. Sugars were detected by a thin layer amperometric cell (ESA, Model 5200, Bedford, USA) with a gold 
electrode. A Pulse amperometric detector (Coulochem II, Bedford, USA) set a pulse according to the following scheme:

$\begin{array}{llll}\text { pulse mode } & \text { voltage } & \text { duration } & \text { measure } \\ \text { measurement } & 50 \mathrm{mV} & 500 \mathrm{~ms} & 400 \mathrm{~ms} \\ \text { clearance } & 700 \mathrm{mV} & 540 \mathrm{~ms} & \\ \text { regeneration } & -800 \mathrm{mV} & 540 \mathrm{~ms}\end{array}$

The calibration was done with $50 \mu \mathrm{M}, 100 \mu \mathrm{M}, 250 \mu \mathrm{M}$ and $500 \mu \mathrm{M}$ sugar concentrations. Myo-inositol, galactinol, mannitol, sorbitol, glucose, fructose, sucrose, raffinose, stachyose and verbascose were used as standards and showed a linear range of the detector response between 50 and $500 \mu \mathrm{M}\left(\mathrm{r}^{2}=0.99\right)$. Plant samples were diluted before measurements to provide concentrations within this range. The evaluation of chromatograms was performed with the integration program Peaknet 5.1 (Dionex, Idstein, Germany).

\subsubsection{Enzymatic measurements of glucose, fructose and sucrose}

In some samples of apoplastic washing fluid glucose, fructose and sucrose contents were measured by enzymatic reactions (Bergmeyer, 1983). Glucose was measured by the hexokinase/glucose-6-phosphate dehydrogenase-linked assay. The total volume of the reaction mixture $(1 \mathrm{ml})$ contained:

$\begin{array}{ll}\text { Sample } & 10-50 \mu l \\ \text { Tricine pH } 8.0 & 0.1 \mathrm{M} \\ \text { NADP } & 1 \mathrm{mM} \\ \mathrm{MgCl}_{2} & 5 \mathrm{mM} \\ \text { ATP } & 1 \mathrm{mM} \\ \text { Glucose-6-phosphate dehydrogenase } & 0.5 \mathrm{U} \\ \text { Hexokinase } & 0.75 \mathrm{U}\end{array}$

Glucose-6-phosphate dehydrogenase was added first, and after the stabilization of the absorbance the reaction was started by the addition of hexokinase to the assay mixture.

After the reaction was completed, fructose was measured by the addition of phosphoglucose isomerase $(0.5 \mathrm{U}$ per reaction) to the hexokinase/glucose-6-phosphate dehydrogenase-linked assay.

In parallel, sucrose was measured as glucose released after hydrolysis with invertase. For this purpose, another aliquot of the same sample was pipetted into a cuvette containing in a total volume of $300 \mu 1$ :
Na-acetate $\mathrm{pH} 4.5$
$0.1 \mathrm{M}$ 


$\begin{array}{ll}\text { invertase } & 2 \mathrm{U} \\ \text { sample } & 10-50 \mu \mathrm{l}\end{array}$

The reaction proceeded for $10 \mathrm{~min}$. Then, $700 \mu \mathrm{l}$ of $0.1 \mathrm{M}$ tricine $\mathrm{pH} 8.0$ were added to the reaction mixture which resulted in a $\mathrm{pH}$ shift to 7.5. NADP, ATP and $\mathrm{MgCl}_{2}$ were added up to the concentrations listed for glucose determination. Glucose-6-phosphate dehydrogenase was added as well, and the reaction was started by the addition of hexokinase.

From the increase in the absorbance at $340 \mathrm{~nm}$ (see 2.5.1), the amount of NADPH formed in the reactions could be calculated which was stoichiometrically related to the amounts of the oxidized sugars (Bergmeyer, 1983). The amount of sucrose was calculated as the difference between glucose amounts measured after and before the hydrolysis of the sample by invertase.

\subsection{Determination of the osmolality of the leaf sap}

Discs were cut from the leaves, placed in $1.5 \mathrm{ml}$ Eppendorf tubes and frozen at $-20^{\circ} \mathrm{C}$. The thawing resulted in the exudation of cellular sap from the tissue. This sap was used for the determination of the osmolality. The osmometer Wescor 5100B was calibrated using 290 mOsmol kg-1 and $1000 \mathrm{mOsmol} \mathrm{kg}{ }^{-1}$ standards. An $8 \mu \mathrm{l}$ sample of tissue sap was added onto a 5-mm diameter paper disc. The disc was then transferred to the sample holder of the osmometer, and the osmotic pressure was determined according to the instruction provided by the manufacturer.

\subsection{Analyses in single cell sap}

Single cell sap was extracted from individual epidermal and mesophyll cells by the glass microcapillary technique and analysed for sugar contents as described in Koroleva et al., 1997.

\subsubsection{Single cell sampling}

For sampling, drawn-out „sampling“ capillaries were used where the exact volume was not important. The capillaries were produced from $1 \mathrm{~mm}$ (external diameter) glass capillary tubing (Clark) using a commercial micropipette puller (Harvard Apparatus Ltd., Kent, UK). The very end of each capillary was broken off on a de Fonbrune microforge (Technical Products International Inc., O`Fallon, MI., USA) to produce an aperture of the required diameter. Prior to use, a microcapillary was back-filled with low-viscosity watersaturated paraffin oil (Sigma). It was then connected to a $50 \mathrm{ml}$ plastic syringe and a footoperated solenoid valve by a series of plastic tubing. The capillary was mounted on a 
micromanipulator (Leica, Nussloch, Germany). Use of a stereo microscope (Wild M8, Leica, maximum magnification $160 \mathrm{x}$ ) allowed the tip of the microcapillary to be precisely aligned with the desired cell. The cell was punctured by moving the tip of the capillary with the micromanipulator. The cell turgor forced the cellular content into the microcapillary. The microcapillary was rapidly removed from the sampled cell and immersed under watersaturated liquid paraffin (previously centrifuged at $1300 \mathrm{~g}$ for $10 \mathrm{~min}$ ). Ejection of the single cell sample under oil allowed the determination of osmotic pressure and sugars (glucose, fructose and sucrose) by enzymatic assay.

\subsubsection{Osmolality of single cell sap}

The osmotic pressure of single cell sap was measured by freezing point osmometry (Malone et al., 1989; Tomos et al., 1994). A custom-made picoliter osmometer was used to determine the freezing point of single cell saps. The temperature of the Peltier stage of the osmometer was rapidly cooled to $-40^{\circ} \mathrm{C}$ to overcome the effects of supercooling and to induce freezing before returning to about $-2^{\circ} \mathrm{C}$. Using a stereo microscope, minute ice crystals in each microdroplet were seen to decrease in size as the stage temperature was slowly increased from $-2^{\circ} \mathrm{C}$ to $+1{ }^{\circ} \mathrm{C}$. The melting point of each droplet was then recorded as the approximate temperature displayed at the osmometer hand-set at which the last ice crystal melted and just disappeared. This temperature was then referenced against the melting point of standard solution series of $\mathrm{KCl}$ with known osmotic pressure measured in the same way.

\subsubsection{Sugar concentrations in single cell sap}

Constriction capillaries (constriction pipettes) were used for measuring identical volumes of samples, standards or reagents. Exact volumes are usually unknown and samples were measured by comparison with concentration standards using the same pipette. Constriction pipettes were produced at the microforge. A heated fine-gauge filament was aligned closely with one side of pipette. Upon applying a current to the filament, the glass melted leading to constriction of the lumen as the pipette bent towards the heat. Constriction pipettes of various volumes (from ca. $10 \mathrm{pl}$ to ca $5 \mathrm{nl}$ ) could be produced in this way.

Glucose, fructose and sucrose were measured in single cell samples using imidazole buffer containing additives in the following concentrations:

imidazole- $\mathrm{HCl}$ buffer $\mathrm{pH} 7.5 \quad 68 \mathrm{mM}$

$\begin{array}{ll}\mathrm{MgCl}_{2} & 5.6 \mathrm{mM}\end{array}$ 

$\mathrm{KH}_{2} \mathrm{PO}_{4}$
$1.2 \mathrm{mM}$

BSA

$0.1 \%(\mathrm{w} / \mathrm{v})$

The enzymes were dissolved in the imidazole buffer containing additives. The following concentrations of the enzymes were used:
G6PDH
$43 \mathrm{U} / \mathrm{ml}$
Hexokinase
$85 \mathrm{U} / \mathrm{ml}$
Phosphoglucose isomerase
$175 \mathrm{U} / \mathrm{ml}$
Invertase
$1330 \mathrm{U} / \mathrm{ml}$

(an excess of invertase was necessary because the $\mathrm{pH}$ conditions were suboptimal).

Constriction pipettes of ca. $4 \mathrm{nl}$ volume were used for pipetting droplets of buffer under paraffin oil. $100 \mathrm{pl}$ pipettes were used for enzymes and $20 \mathrm{pl}$ pipettes for samples and standards. Using the same pipette for both samples and standards enabled a calibration of the assay.

Four sets of droplets of buffer with cofactors were pipetted to the glass slide inside a 4-mm deep aluminum ring under paraffin oil. The first set was used for the determination of glucose and fructose in the single cell samples, the second for the determination of sucrose in the same samples, and the two other sets were used in the same way to provide a calibration with standards (50, 100 and $200 \mathrm{mM}$ solutions of glucose, fructose and sucrose). Hexokinase and either samples or standards were pipetted into all droplets. Then, invertase was added to those droplets where the sucrose concentration was measured, and the droplets were incubated for 5-10 min to allow the completion of the reaction.

The commonly used principle of enzymatic determination of sugar concentrations based on the different optical densities of the reduced and oxidized forms of NADP(H) at 340 $\mathrm{nm}$ was not suitable for single cell samples. The reason is the very small volume of the samples which does not allow single wavelength absorption measurements. Enzymatic assays of the single cell sap, therefore, have to make use of the ability of the reduced cofactors to fluoresce at $460 \mathrm{~nm}$ when excited with light at their absorbing wavelength $\left(\lambda_{\max }=340 \mathrm{~nm}\right)$.

A fluorescent microscope equipped with a photometer (MPV Conpact 2 Fluorovert, Leitz, Wetzlar, Germany) measured the increase in fluorescence in the droplets. The signal was measured against a dark background. The initial fluorescence of the droplets was recorded, and G6PDH was added to all droplets. The measurements of the fluorescence were repeated in intervals of $1 \mathrm{~min}$ until the fluorescence stabilized. After that, phosphoglucose 
isomerase was pipetted into the droplets. This initiated the fluorescence increase due to fructose oxidation. The increase in fluorescence was plotted against the concentrations of the standards, and the concentrations of glucose and fructose in the single cell samples were calculated from these calibration curves. For the determination of sucrose, the glucose concentration in the invertase-treated samples was calculated from the sucrose standard calibration curve and corrected based on the glucose concentration measured in the samples.

\subsection{Inhibition of phloem translocation}

In a series of experiments, the accumulation of sugars in the leaf apoplast caused by export inhibition was studied. To prevent assimilate export from the leaves, three experimental procedures were used.

(1) Cold block. Ice wrapped in tissue was applied to the petiole of leaves (Webb and Gorham, 1965). Ice lost by melting was replaced. Both control and cold-blocked leaves were harvested after periods of 1, 2, 4 and 6 hours, respectively, after cold jacket application.

(2) Girdling. Two shrubs, Ligustrum and Atropa, were taken for girdling experiments. Leaves were harvested from the plants at 10 a.m. and after that, a ring of bark was removed from several branches. After 3, 9 and 24 hours leaves were harvested from both intact and girdled branches.

(3) Placement of detached leaves in $\mathrm{CaCl}_{2}$ or EDTA. In the experiments with Alonsoa and Asarina, leaves were cut from these plants, and the petioles were placed in $2 \mathrm{mM} \mathrm{CaCl} 2$ solution for 24 hours. During this time, the leaves were kept under continuous light of 500 $\mu \mathrm{mol}$ photons $\mathrm{m}^{-2} \mathrm{~s}^{-1}$. After that, the apoplastic exudate (IWF) was obtained from the leaves as described in 2.4, and the leaves were extracted with chloroform:methanol (2.3.1). The sugar contents were determined in IWF samples and in leaf extracts. In the experiment in which the incubation in $\mathrm{CaCl}_{2}$ solution was compared with that in $2 \mathrm{mM} \mathrm{Na}-\mathrm{EDTA}$, leaves from Mentha sp. and Chrysanthemum sp. grown outdoors were sampled at 10 a.m., placed in either $2 \mathrm{mM} \mathrm{CaCl}_{2}$ or $2 \mathrm{mM} \mathrm{Na-EDTA} \mathrm{(pH} \mathrm{6.5)} \mathrm{and} \mathrm{exposed} \mathrm{to} \mathrm{a} \mathrm{photon} \mathrm{flux} \mathrm{density} \mathrm{of} 1800$ $\mu \mathrm{mol} \mathrm{m} \mathrm{m}^{-2} \mathrm{~s}^{-1}$. After $30 \mathrm{~min}$, solutions were replaced with water to prevent wilting, and the incubation was continued for 2 hours. The leaves from both species were taken for the determination of apoplastic sugars (2.4).

\subsection{Study of sugar uptake from the apoplast in vivo}

\subsubsection{Feeding experiments}

Petioles of leaves were cut under water or, depending on the experiment, under $20 \mathrm{mM}$ EDTA to prevent sealing of the cut phloem, and left in the solution for $30 \mathrm{~min}$ (King and 
Zeevart, 1974). Subsequently, the leaves were infiltrated with either $\mathrm{pH}$ - or membrane potential-sensitive fluorescent dye solution (2.12.3) and left for 5 min to allow the distribution of the fluorescent dye within the apoplast. Excess infiltrate was removed by centrifugation for $5 \mathrm{~min}$ at $450 \mathrm{~g}$ at room temperature. Part of a leaf was then enclosed in a sandwich-type cuvette with two windows on the upper and lower side (diameter $2.4 \mathrm{~cm}$ ). The petiole of the leaf protruded from the cuvette and was kept in water. The leaves were left in darkness, to make sure that the leaf production of $\mathrm{CO}_{2}$ was of dark respiration origin. Solutes (concentrations $10 \mathrm{mM}, 25 \mathrm{mM}, 50 \mathrm{mM}$ and $100 \mathrm{mM}$ ) were fed to the leaves for $5 \mathrm{~min}$ through the petiole.

\subsubsection{Gas and $\mathrm{H}_{2} \mathrm{O}$ exchange mesurements}

Leaves were placed in a sandwich-type cuvette and exposed to $\mathrm{CO}_{2}$-free air which led to stomata opening. This was achieved by passing pressurized air through a soda lime column before it entered the cuvette. The leaves were left in darkness, to make sure that the leaf production of $\mathrm{CO}_{2}$ was of dark respiration origin. The only light beam reaching the leaf surface was that exiting the fluorescence of fluorescent dyes (2.12.3) which photon flux density $\left(2 \mu \mathrm{mol} \mathrm{m} \mathrm{m}^{-2} \mathrm{~s}^{-1}\right)$ and wavelength $(489 \mathrm{~nm})$ excluded photosynthesis and photorespiration. The rate of air flow $\left(0.251 \mathrm{~min}^{-1}\right)$ was regulated by Tylan flow controllers (Tylan Corp., Carson, CA., USA). Relative humidity was kept at $40 \%$ and temperature at $25^{\circ} \mathrm{C} . \mathrm{CO}_{2}$ and water exchange were measured by an Infra Red Gas Analysis (IRGA) technique using the Binos instrument of Heraeus (Hanau, Germany).

\subsubsection{Recordings of $\mathrm{pH}$ - and membrane potential changes}

The detection of changes in $\mathrm{pH}$ or membrane potential was based on the fluorescence emission of $\mathrm{pH}$ - or membrane potential-sensitive probes infiltrated into the apoplast of leaves. The measurement of the fluorescence of the dyes was performed according to Yin et al. (1990) with some modifications. FITC, a dextran conjugate of fluorescein isothiocyanate (MW 4000 dalton; Sigma, St. Louis, MD., USA; $0.25 \mathrm{mM}$ in aqueous solution), or bis-(1,3dibutylbarbituric acid) trimethine oxonol (BDTO; B-438 of Molecular Probes, Eugene, OR., USA; $0.1 \mathrm{mM}$ in aqueous solution) were infiltrated into the apoplast of leaves. Dextran conjugates of FITC have been used for the investigation of the $\mathrm{pH}$ in the apoplast of plant cells because they are not able to penetrate the plasma membrane and stay in the apoplast as long as 17 hours (Hoffmann and Kosegarten, 1995). Furthermore, FITC-dextran exhibits a pKa value of about 5.92 (Hoffmann and Kosegarten, 1995) that is well suited to the $\mathrm{pH}$ ranges in the apoplast (between 5 and 6.5 in most plants studied; Grignon and Sentenac, 1991). B438 is a lipophilic anionic dye that enters depolarized cells where it binds to intracellular 
proteins or membranes and exhibits enhanced fluorescence and red spectral shifts. Increased depolarization results in more influx of the anionic dye and thus in an increase in fluorescence. Fluorescence of the probes was excited by a halogen lamp (24 V; $250 \mathrm{~W}$; Osram, München, Germany) through a $489 \mathrm{~nm}$ interference filter from Schott (Mainz, Germany). The half bandwidth of transmission was $11 \mathrm{~nm}$. Additional filters were 9782 and 5030 of Corning Glass Works (Corning, NY., USA). The photon flux density of the exciting beam was $2 \mu \mathrm{mol} \mathrm{m} \mathrm{m}^{-2} \mathrm{~s}^{-1}$. Fluorescence emission was collected by fiber optics at an angle of $45^{\circ}$ relative to the incident exciting light and measured by a photomultiplier fitted with two filters 9782 from Corning Glass Works, an OG 515 cutoff filter from Schott and a K55 broad band interference filter from Balzers (Liechtenstein). The half bandwidth of transmission was between 518 and $533 \mathrm{~nm}$.

\subsection{Electron microscopy and determination of partial volumina of subcellular compartments}

Leaf pieces (ca. 4 x $4 \mathrm{~mm}$ ) were excised, transferred immediately into $3 \%$ glutaraldehyde in $50 \mathrm{mM}$ potassium phosphate buffer ( $\mathrm{pH}$ 7.2) supplemented with sucrose and infiltrated with this solution using a syringe. All following steps were done using glass tubes. The leaf pieces were incubated in a fresh solution of glutaraldehyde fixative for 3 hours. The fixative was then removed and the plant material was washed four to six times with $50 \mathrm{mM}$ potassium phosphate buffer for $10-15 \mathrm{~min}$ each and post-fixed in $2 \%$ osmium tetroxide in a refrigerator overnight.

The plant material was dehydrated in a graded ethanol series and then gradually saturated with acetone:

$\begin{array}{ll}\text { ethanol } 30 \% \text { I } & \text { wash shortly } \\ \text { ethanol } 30 \% \text { II } & 20 \mathrm{~min} \\ \text { ethanol } 50 \% & 20 \mathrm{~min} \\ \text { ethanol } 70 \% & \text { wash shortly }\end{array}$

The plant material was then contrasted with $1 \%$ uranyl acetate in $70 \%$ ethanol. The next steps were as follows.

$\begin{array}{ll}\text { ethanol } 80 \% & 15 \mathrm{~min} \\ \text { ethanol } 85 \% & 15 \mathrm{~min} \\ \text { ethanol } 96 \% & 15 \mathrm{~min} \\ \text { ethanol } 100 \% \text { I } & 30 \mathrm{~min} \\ \text { ethanol } 100 \% \text { II } & 30 \mathrm{~min} \\ \text { ethanol } 100 \% \text { :acetone } 100 \%=1: 1 & 1 \mathrm{~h}\end{array}$


acetone $100 \%$ I

acetone $100 \%$ II
$30 \mathrm{~min}$

$30 \mathrm{~min}$

The plant material was embedded in Epon epoxy resin (Fluka-Sigma-Aldrich, Taufkirchen, Germany) dissolved in acetone. The epon mixture C (prepared as described below) was used. The embedding of the plant material proceeded stepwise as follows:

$\begin{array}{ll}\text { Mixture C }: \text { acetone }=0.5: 9.5 & 15 \mathrm{~min} \\ \text { Mixture C }: \text { acetone }=1: 9 & 30 \mathrm{~min} \\ \text { Mixture C }: \text { acetone }=2: 8 & 50 \mathrm{~min} \\ \text { Mixture C }: \text { acetone }=3: 7 & 50 \mathrm{~min} \\ \text { Mixture C }: \text { acetone }=4: 6 & 50 \mathrm{~min} \\ \text { Mixture C }: \text { acetone }=5: 5 & \text { overnight. }\end{array}$

Plastic capsules for the embedding of the plant tissue were also filled with Mixture C : acetone $=5: 5$ and placed in a desiccator containing phosphorus anhydride overnight. The major part of the acetone evaporated from the capsules and from the tubes containing leaf pieces during the night. The leaf pieces were then transferred in the plastic capsules and left for two days in the desiccator at room temperature. The capsules were then transferred into a thermostat and kept at $60^{\circ} \mathrm{C}$ for 2 days.

Ultrathin sections $(40-60 \mathrm{~nm})$ were cut with glass knives on a LKB-III microtome (LKB, Stockholm, Sweden), contrasted on grids by $2 \%$ lead citrate, and viewed and photographed at $75 \mathrm{kV}$ (x $2500-\mathrm{x}$ 4000) with a Hitachi HU-700 electron microscope (Tokyo, Japan).

The partial volumes of the chloroplast, vacuoles and cytosol per mesophyll cell were determined using the micrographs. The determination is based on the principle of Delesse (1874) who found that the volume density of various components making up a rock can be estimated on random sections by measuring the relative areas (A) of their profiles. For the cellular compartments, it is expressed as follows:

$\mathrm{A}_{\text {compartment }} / \mathrm{A}_{\text {cell }}=\mathrm{V}_{\text {compartment }} / \mathrm{V}_{\text {cell }}$

The relative squares of the subcellular compartments on the sections were determined by an image-analysis technique (Bioscan Optimas, Tokyo, Japan). The calculations were carried out using 15-20 sections of the mesophyll tissue (palisade parenchyme) for both species.

\section{Glutaraldehyde fixative:}

$3 \%(\mathrm{v} / \mathrm{v}) \quad$ glutaraldehyde (Sigma-Aldrich, Taufkirchen, Germany)

$50 \mathrm{mM} \quad$ K-phosphate buffer $\mathrm{pH}$ 7.2-7.4

$2 \%(\mathrm{w} / \mathrm{v}) \quad$ sucrose 


\section{Contrasting solution:}

$1.330 \mathrm{~g}$

$1.760 \mathrm{~g}$

$30 \mathrm{ml}$ lead citrate

tri-sodium citrate

dd $\mathrm{H}_{2} \mathrm{O}$

$\mathrm{NaOH} 1 \mathrm{M}$

mix vigorously, then add

$8 \mathrm{ml}$ ad $50 \mathrm{ml}$ with dd $\mathrm{H}_{2} \mathrm{O}$

\section{Postfixative (OsO $\mathrm{Os}_{4}$ 2\%):}

dd $\mathrm{H}_{2} \mathrm{O}+$ potassium phosphate buffer $50 \mathrm{mM}+\mathrm{OsO}_{4}(4 \%$ stock sol. $)=1: 2: 4(\mathrm{v} / \mathrm{v} / \mathrm{v})$ add sucrose to $2.5 \%(\mathrm{w} / \mathrm{v})$

\section{Uranyl acetate:}

$1.5 \%(\mathrm{w} / \mathrm{v})$ uranyl acetate in $70 \%$ ethanol (place in thermostat at $40^{\circ} \mathrm{C}$ for dissolving, store in a refrigerator in darkness)

\section{Epon resins:}

Mixture A: $\quad 38.3 \%$ Epon $812+61.7 \%$ DDSA, mix for $30 \mathrm{~min}$

Mixture B: $\quad 52.9 \%$ Epon $812+47.1 \% \mathrm{MNH}$, mix for $30 \mathrm{~min}$

Mixture C: pour A and B together (3:7), then add a hardener DMP-30 up to 2\% (v/v)

\subsection{Light microscopy}

The sections prepared as described below were used for in situ hybridization of RNA probes. Therefore, the material should be preserved from RNases. RNases in the tissue were destroyed by the fixation procedure. To minimize external RNase activity, autoclaved solutions and sterilized glassware were used throughout the procedure.

Plant tissue (leaves and stems of Alonsoa) was cut into pieces in a fixative, placed in glass vials with fixative and transferred into a desiccator for infiltration. Vacuum was applied for 20-40 minutes, and the infiltration was repeated several times until the tissue was completely infiltrated. The solution was replaced with new fixative, vacuum was applied for $15 \mathrm{~min}$, and the fixation proceeded at room temperature for 2-6 hours or at $4^{\circ} \mathrm{C}$ overnight. The fixative was removed, and the following dehydration steps were performed at room temperature, each step for at least $20 \mathrm{~min}$ :

1x phosphate buffer

dd $\mathrm{H}_{2} \mathrm{O}$

EtOH series prepared from $96 \%$ ethanol and autoclaved dd $\mathrm{H}_{2} \mathrm{O}$, concentrations $10 \%$, $30 \%, 50 \%, 70 \%, 80 \%, 90 \%$ and $96 \%$

$100 \%$ EtOH 4 times for at least 1 hour 
Ethanol was replaced subsequently with chloroform:100\% ethanol mixtures $(1: 3,1: 1$, $3: 1 ; 1$ hour for each step). Then plant material was incubated two times for at least one hour each in $100 \%$ chloroform. To infiltrate the material with embedding paraffin, 4-7 flakes of Paraffin wax (Aldrich, Taufkirchen, Germany) or Paraplast Plus (Sigma-Aldrich, Taufkirchen, Germany) were added to the chloroform. Further addition of paraffin flakes was performed at $37^{\circ} \mathrm{C}$ during 2 days to facilitate the gradual saturation of material with paraffin. The total volume of added paraffin was about equal to the volume of chloroform in the vials. After that, the vials were incubated at $50^{\circ} \mathrm{C}$ to enable the evaporation of chloroform. For embedding, a metallic embedding mold was prewarmed to $60^{\circ} \mathrm{C}$ on a hot plate. Some molten paraffin (filtered through a paper filter) was poured into the mold. The samples were gently stirred and poured into the mold. Plant material was positioned with a pre-warmed needle. For solidification, the mold was quickly dipped into the ice-cold water, incubated for $5 \mathrm{~min}$ and transferred into the $-20^{\circ} \mathrm{C}$ freezer for $5 \mathrm{~min}$. This prevented the formation of paraffin crystals which might disrupt the tissue. The embedded material was stored at $4^{\circ} \mathrm{C}$ for several weeks and could be stored for several years.

For the preparation of slides, precleaned coated glass slides Superfrost ${ }^{\circledR}$ Plus (Roth, Karlsruhe, Germay) were used which electrostatically attract the sections to the slide. The upper right corner of each slide was removed to mark the position of sections on the slide. 8 $\mu \mathrm{m}$ thick sections were cut with a disposable knife on a Microtom (RM 2125RT; Leica, Nussloch, Germany). Paraffin ribbons could be stored at $4^{\circ} \mathrm{C}$ for one week. $600-800 \mu 1$ of autoclaved $\mathrm{dd} \mathrm{H}_{2} \mathrm{O}$ were pipetted onto the slide, and the sections were positioned on the water. To stretch the sections, the slides were incubated at $40^{\circ} \mathrm{C}$ on a hot plate and then left on the plate at $37^{\circ} \mathrm{C}$ overnight to allow the water to evaporate. The slides with sections could be stored at $-20^{\circ} \mathrm{C}$ in plastic boxes sealed with tape for several months.

\section{Fixative:}

$4 \%(\mathrm{w} / \mathrm{v})$ paraformaldehyde (from $10 \%$ stock solution)

$0.25 \%(\mathrm{w} / \mathrm{v})$ glutaraldehyde

$1 \mathrm{x}$ sodium phosphate buffer

$0.1 \%$ Tween 20

$10 \%(\mathrm{v} / \mathrm{v})$ DMSO

\section{$10 \%$ paraformaldehyde stock solution:}

$10 \mathrm{~g}$ paraformaldehyde were dissolved in $70 \mathrm{ml} \mathrm{dd} \mathrm{H}_{2} \mathrm{O}$ at $70^{\circ} \mathrm{C}$ for $30 \mathrm{~min}$ in the presence of one pellet of $\mathrm{NaOH}$; the $\mathrm{pH}$ was adjusted to 7.0 using $0.1 \mathrm{M} \mathrm{HCl}$

10 x phosphate buffer stock solution:

$68.4 \mathrm{ml} 0.1 \mathrm{M} \mathrm{Na}_{2} \mathrm{HPO}_{4}+31.6 \mathrm{ml} 0.1 \mathrm{M} \mathrm{NaH}_{2} \mathrm{PO}_{4}+5.84 \mathrm{~g} \mathrm{NaCl}, \mathrm{pH} 6.8$ 


\subsection{Isolation of total RNA and genomic DNA from plant tissues}

For the isolation of RNA and DNA as well as for all molecular biological methods used in this work, only sterile (autoclaved) glassware and plastic ware (Gilson pipette tips, Eppendorf tubes etc.) were used. The solutions were prepared using sterile (autoclaved) water of MilliQ grade $\left(\mathrm{dd}_{2} \mathrm{O}\right)$. The preparations were performed on ice if not indicated otherwise. The centrifugations were mostly done using an Eppendorf table top centrifuge (Schütt, Göttingen, Germany) at $13000 \mathrm{rpm}(16060 \mathrm{~g})$. RNA samples were stored at $-80^{\circ} \mathrm{C}$ and DNA samples at $-20^{\circ} \mathrm{C}$.

\subsubsection{Isolation of RNA from Asarina and Alonsoa}

To isolate RNA from Asarina and Alonsoa organs, several different methods were tested: a method from Logemann et al. (1987) using guanidinium chloride; the PeqGOLD RNA Pure ${ }^{\mathrm{TM}}$ Kit (Peq Lab, Erlangen, Germany) and the Invisorb Spin Plant-RNA Mini Kit (Invitek, Berlin, Germany). The RNA of the best quality, i.e. with the lowest polysaccharide and DNA content, was obtained using the Invisorb Spin Plant-RNA Mini Kit. The preparation method given in the instruction manual for the kit is described below.

Plant material was harvested and stored at $-80^{\circ} \mathrm{C}$ until use. Ca. $100 \mathrm{mg}$ were ground in liquid nitrogen using mortar and pestle. The fine powder was transferred into a $2 \mathrm{ml}$ plastic Eppendorf tube that contained $450 \mu \mathrm{l}$ of the lysis solution provided in the kit. After vigorous vortexing, the suspension was incubated for $2 \mathrm{~min}$ at room temperature. All following procedures were also performed at room temperature. The lysate was applied to a spin column with a DNA binding filter and incubated for $1 \mathrm{~min}$. Passing of the lysate through the filter during the following centrifugation ( $2 \mathrm{~min}, 10000 \mathrm{rpm}$ ) resulted in the removal of DNA. The addition of 0.5 vol. $99.8 \%$ ethanol to the RNA-containing lysate provided the conditions for precipitation of RNA from the solution during the following centrifugation. The solution was applied to a spin column with an RNA binding filter, incubated for a minute and centrifuged (30 sec, $10000 \mathrm{rpm}$ ). The filter-bound RNA was washed three times with two different buffers (30 sec, $10000 \mathrm{rpm}$ ), the residual ethanol were removed by an additional centrifugation ( $2 \mathrm{~min}, 13000 \mathrm{rpm}$ ), and the RNA was eluted from the filter with dd $\mathrm{H}_{2} \mathrm{O}$ (2 min incubation, dd $\mathrm{H}_{2} \mathrm{O}$ had to be pipetted directly on the filter membrane; then the columns were centrifuged for $1 \mathrm{~min}$ at $13000 \mathrm{rpm}$ ). $20-50 \mu \mathrm{l}$ of $\mathrm{dd}_{2} \mathrm{O}$ were used for elution depending on the desired RNA concentration. The eluted RNA was immediately placed on ice and transferred to $-80^{\circ} \mathrm{C}$. 


\subsubsection{Isolation of genomic DNA from Alonsoa}

Genomic DNA was isolated from young leaves of Alonsoa with DNeasy ${ }^{\mathrm{TM}}$ Plant Maxi Kit (Qiagen, Hilden, Germany) according to the instructions of the manufacturer. All centrifugations were performed at $4000 \mathrm{~g}$ for $5 \mathrm{~min}$ at room temperature (Megafuge 1.0, Heraeus Sepatech, Osterode, Germany). Up to $1 \mathrm{~g}$ of plant tissue was ground in liquid nitrogen using mortar and pestle. $5 \mathrm{ml}$ lysis buffer (preheated to $65^{\circ} \mathrm{C}$ ) with $10 \mu \mathrm{l}$ of RNase (100 $\mathrm{mg} / \mathrm{ml}$ stock solution) were added. The samples were vortexed vigorously and incubated for ten minute at $65^{\circ} \mathrm{C}$. The tubes were inverted several times during the incubation. The addition of the $1.8 \mathrm{ml}$ aliquot of a neutralization buffer, followed by $10 \mathrm{~min}$ incubation on ice, resulted in the precipitation of detergent, proteins and polysaccharides. The lysates were centrifuged, the supernatant containing floating particles was applied to a spin column with a filter and centrifuged again. After this step, most of the particles either remained on the filter or formed a pellet in the receiver tube. To the supernatant, 1.5 vol. of DNA precipitation buffer were added and immediately mixed by pipetting. The samples were applied to a spin column with a DNA-binding membrane filter and centrifuged. The filter was washed with washing buffer and centrifuged for $10 \mathrm{~min}$ to dry the membrane. The DNA was eluted with $0.75 \mathrm{ml}$ elution buffer (preheated to $65^{\circ} \mathrm{C}$ ) in a $5 \mathrm{~min}$ incubation at room temperature and a centrifugation for $5 \mathrm{~min}$. The elution was repeated two times, and the eluates were combined. This resulted in isolation of ca. $120 \mu \mathrm{g}$ DNA from $1 \mathrm{~g}$ of Alonsoa young leaves.

\subsubsection{Isolation of DNA from Arabidopsis thaliana F1 transformants}

For each $A$. thaliana $\mathrm{F} 1$ plant, two leaves were harvested and stored at $-80^{\circ} \mathrm{C}$ until use. $250 \mu 1$ extraction buffer were pipetted into the Eppendorf tube containing frozen leaves (up to $100 \mathrm{mg}$ fresh weight) and crushed with a small pestle. $400 \mu \mathrm{l}$ extraction buffer were added, and the tubes were incubated at $60^{\circ} \mathrm{C}$ for $30 \mathrm{~min}$. Then, $700 \mu 1$ chloroform:isoamyl alcohol (24:1) were added and mixed gently. The tubes were centrifuged at $8000 \mathrm{rpm}(6080 \mathrm{~g})$ for 10 min and the upper phase was saved. DNA was pelleted by the addition of $700 \mu 1$ isopropanol and centrifugation for $10 \mathrm{~min}$ at $10000 \mathrm{rpm}$ (9 $500 \mathrm{~g}$ ). The pellets were washed with $500 \mu \mathrm{l}$ $70 \%$ ethanol, followed by $5 \mathrm{~min}$ centrifugation at $13000 \mathrm{rpm}$, and dried under vacuum. The DNA was resuspended in $50 \mu \mathrm{l}$ sterile $\mathrm{dd}_{2} \mathrm{O}$ containing $40 \mu \mathrm{g} / \mathrm{ml}$ Rnase, and the amount was checked by running $1 \mu \mathrm{l}$ sample on an 1\% agarose gel. 1-2 $\mu 1$ DNA were used per PCR with either insert-specific primers or, in a control reaction, with ubiquitin primers (ubifor/ubirev; Table 2.1.). 


\title{
Extraction buffer:
}

$2 \%(\mathrm{v} / \mathrm{v}) \mathrm{CTAB}$ (hexadecyltrimethylammonium bromide)

\author{
$1.4 \mathrm{M} \mathrm{NaCl}$ \\ $0.2 \mathrm{mM}$ EDTA \\ $10 \mathrm{mM}$ Tris- $\mathrm{HCl} \mathrm{pH} 8.0$ \\ $0.2 \%(\mathrm{v} / \mathrm{v}) \beta$-mercaptoethanol
}

\subsection{Plasmid DNA isolation from bacteria}

\subsubsection{Isolation of plasmid DNA from E. coli (miniprep and maxiprep)}

Plasmid DNA mini preparations were usually performed using a Triton boiling protocol which resulted in a sufficient yield of a plasmid DNA of sufficient quality for most restriction digests and also for transformation. However, for sensitive applications (e.g. sequencing reactions which required a higher purity), the preparations were performed using a Qiagen Miniprep Kit. This kit also was used for plasmid DNA isolation if the Triton boiling procedure had failed to yield enough DNA.

In order to obtain larger amounts of pure plasmid DNA, plasmid DNA preparation was performed using the E.Z.N.A. Plasmid Mini Prep Kit (Peq Lab, Erlangen, Germany).

For mini plasmid preparations, $5 \mathrm{ml} \mathrm{LB}$ medium supplemented with the appropriate antibiotics were inoculated with a bacterial colony grown on an agar plate, or from a glycerol culture (2.20.6). The inoculation was performed under a laminar flow hood (LaminAir HLB 2472, Heraeus, Germany). Colonies were picked with sterile (autoclaved) toothpicks. Glycerol cultures were put on ice and scrubbed with a microbiological loop which was then rapidly dipped into the liquid medium. Bacteria were grown overnight at $37^{\circ} \mathrm{C}$ in a roller. 1.5 $\mathrm{ml}$ of the culture were pipetted into a $1.5 \mathrm{ml}$ Eppendorf tube and the cells were spun down for $2 \mathrm{~min}$ at $13000 \mathrm{rpm}$ at room temperature. The supernatant was removed, the centrifugation was repeated and the residual supernatant was removed using a $200 \mu 1$ Gilson pipette. The cells were stored at $-20^{\circ} \mathrm{C}$ or used directly for plasmid DNA isolation.

For plasmid DNA preparation with the E.Z.N.A. kit, $50 \mathrm{ml}$ of TB medium (with the appropriate antibiotics) were inoculated from plates or glycerol cultures and the bacteria were grown overnight in a $37^{\circ} \mathrm{C}$ shaker. The cells were poured into four $15 \mathrm{ml}$ centrifuge tubes (laminar flow hood) and spun down for $10 \mathrm{~min}$ at $4300 \mathrm{rpm}$ at $4^{\circ} \mathrm{C}$ in a Megafuge (Heraeus Sepatech, Osterode, Germany). The supernatant was discarded and the cells were stored at $-20^{\circ} \mathrm{C}$ or directly used for plasmid DNA isolation. 


\subsubsection{Plasmid DNA miniprep isolation using a triton boiling protocol}

All centrifugations were performed at room temperature and $13000 \mathrm{rpm}$. The pelleted cells were resuspended in $150 \mu \mathrm{l}$ STEL buffer. The tubes were heated for $30 \mathrm{sec}$ to $100^{\circ} \mathrm{C}$ and rapidly transferred to ice. This step led to lysis of the cells and denaturation of proteins and DNA. The small plasmid DNA was then able to renature and remained in the supernatant whereas the larger genomic DNA and proteins were pelleted during the following centrifugation for $20 \mathrm{~min}$. The pellet was removed from the tubes using a toothpick, and the plasmid DNA was precipitated by the addition of $180 \mu 1$ isopropanol to the supernatant. Plasmid DNA was sedimented by a 5 min centrifugation, washed with $500 \mu 1$ of $70 \%$ ethanol ( 5 min centrifugation), dried for $3-15 \mathrm{~min}$ at $37^{\circ} \mathrm{C}$ in open tubes and resuspended in $50 \mu \mathrm{dd}$ $\mathrm{H}_{2} \mathrm{O}$ containing $200 \mu \mathrm{g} / \mathrm{ml}$ RNase A.

\section{STEL buffer:}

$\begin{array}{ll}\text { Sucrose } & 8 \%(\mathrm{w} / \mathrm{v}) \\ \text { Triton-X-100 } & 5 \%(\mathrm{v} / \mathrm{v}) \\ \text { Tris-HCl pH } 8.0 & 50 \mathrm{mM} \\ \text { EDTA } & 50 \mathrm{mM} \\ \text { Lysozyme } & 0.5 \mathrm{mg} / \mathrm{ml}\end{array}$

\subsubsection{Plasmid DNA miniprep isolation with the Qiagen Miniprep Kit}

All centrifugations were performed at room temperature and $13000 \mathrm{rpm}$. The pelleted cells were resuspended in alkaline lysis buffer containing RNase A and incubated for $5 \mathrm{~min}$ at room temperature. Then, the SDS-NaOH solution was added, and the tubes were incubated for another $5 \mathrm{~min}$ at room temperature. During this step, the tubes were inverted occasionally. Afterwards, neutralization buffer was added to the lysates and mixed by inverting the tubes. This step led to the precipitation of genomic DNA, polysaccharides and proteins. The precipitates were sedimented by a centrifugation for $10 \mathrm{~min}$. The clear supernatant containing the plasmid DNA was applied onto a spin column with DNA binding filter and centrifuged for $30 \mathrm{sec}$. The filters were washed with an ethanol-containing washing buffer (30 sec centrifugation) and dried ( 2 min centrifugation). DNA was eluted by pipetting $50 \mu 1 \mathrm{dd} \mathrm{H}_{2} \mathrm{O}$ directly onto the filter, incubating for $5 \mathrm{~min}$ and centrifuging for $1 \mathrm{~min}$.

\subsubsection{Plasmid DNA maxiprep isolation with E.Z.N.A. Plasmid Miniprep Kit}

The isolation procedure was very similar to that described in 2.16.1.2, the differences being: (1) different kit; (2) larger amount of bacterial cells ( $1 / 4$ of $50 \mathrm{ml} \mathrm{TB}$ culture) used for the preparation; (3) filter washing with a special HB buffer before the ethanol washing step; (4) elution with $100 \mu$ water. 


\subsubsection{Isolation of plasmid DNA from Agrobacterium tumefaciens}

Cells of A. tumefaciens have very stable cell walls which makes a preparative plasmid isolation very difficult. Therefore, only small amounts of plasmid were isolated from $A$. tumefaciens transformed with pBIstsA or pBIstsB (2.2.3) which were then used for E. coli transformation for a preparative isolation and characterization of plasmids.

$5 \mathrm{ml}$ cultures of $A$. tumefaciens were grown in YEB medium supplemented with kanamycin and rifampicin (2.2.2) for two days at $29^{\circ} \mathrm{C}$ in a roller. $1.5 \mathrm{ml}$ of the culture was spun down for $5 \mathrm{~min}$, and the cells were resuspended in $100 \mu \mathrm{l}$ solution I. Then, $200 \mu \mathrm{l}$ solution II were added. The lysates were supplemented with $200 \mu 1$ chloroform and incubated for $5 \mathrm{~min}$ at room temperature. After that, $150 \mu \mathrm{l}$ solution III were added, and the lysates were vortexed and centrifuged for $10 \mathrm{~min}$. This resulted in a phase separation, and the upper phase containing the DNA was transferred to a new Eppendorf tube. 1 volume of a phenol:chloroform mixture $(1: 1)$ was added to the upper phase and vortexed vigorously. After the next centrifugation, the upper phase was transferred to a new Eppendorf tube, and 2 volumes of cold ethanol (99\%) were added. Plasmid DNA was pelleted in a 5 min centrifugation step. The pellet was washed with $150 \mu 170 \%$ ethanol, dried for $15 \mathrm{~min}$ at room temperature and redissolved in $50 \mu 1 \mathrm{dd} \mathrm{H}_{2} \mathrm{O}$ containing $200 \mu \mathrm{g} / \mathrm{ml}$ RNase A.

Solution I: $\quad$ glucose $\quad 50 \mathrm{mM}$

EDTA $10 \mathrm{mM}$

Solution II $\quad \mathrm{NaOH}: \quad 0.2 \mathrm{M}$

$\begin{array}{lll} & \text { SDS } & 1 \%(\mathrm{w} / \mathrm{v}) \\ \text { Solution III: } & \text { K acetate } \mathrm{pH} 4.8 & 3 \mathrm{M}\end{array}$

Solutions I, II and III were either prepared or taken from the Qiagen Miniprep kit.

\subsection{Determination of RNA and DNA concentration by spectrophotometry}

The concentrations of DNA or RNA in aqueous solution could be determined using a spectrophotometer (Uvikon 932, Kontron). A $1 \mu 1$ aliquot of the nucleic acid solution was diluted in $600 \mu \mathrm{ldd} \mathrm{H}_{2} \mathrm{O}$ and the extinction was measured at $260 \mathrm{~nm}$ and $280 \mathrm{~nm}$, respectively. Double measurements were performed. The $\mathrm{E}_{260} / \mathrm{E}_{280}$ ratio represents a measure for the protein contamination of the nucleic acid sample and should be between 1.8 and 2.0. The concentration of DNA or RNA was then calculated as follows:

RNA $[\mu \mathrm{g} / \mu \mathrm{l}]=\mathrm{E}_{260} \times 42 \times \mathrm{V}_{\text {cuvette }} \times \mathrm{V}_{\text {aliquot }^{-1}}$
DNA $[\mu \mathrm{g} / \mu \mathrm{l}]=\mathrm{E}_{260} \times 50 \times \mathrm{V}_{\text {cuvette }} \times \mathrm{V}_{\text {aliquot }^{-1}}$ 
The extinction coefficients are valid for double-stranded DNA and single-stranded RNA (Sambrook et al., 1989).

\subsection{Purification and precipitation of DNA and RNA}

All centrifugations were performed at room temperature at $13000 \mathrm{rpm}(16060 \mathrm{~g})$. Phenol:chloroform extraction of the nucleic acids was used to remove proteins from the samples (polysaccharides cannot be completely removed by this procedure). The nucleic acids were then precipitated with ethanol and redissolved in $\mathrm{dd} \mathrm{H}_{2} \mathrm{O}$. One volume of a phenol:chloroform mixture $(1: 1, \mathrm{v} / \mathrm{v})$ was added. The samples were vortexed and centrifuged for $5 \mathrm{~min}$ to separate the upper aqueous phase (containing the nucleic acids) from the phenol:chloroform phase. Proteins were denatured by phenol and formed a layer between both phases. The water phase was transferred to a new Eppendorf tube, vortexed with 1 volume of chloroform and centrifuged again. The upper phase was transferred to a new Eppendorf tube. $1 / 10$ volume of $3 \mathrm{M} \mathrm{Na}$ acetate $\mathrm{pH} 6.2$ and 2.5 volumes of $96 \%$ ethanol were added, and nucleic acids were precipitated at $-20^{\circ} \mathrm{C}$ for one hour. The following centrifugation for $10 \mathrm{~min}$ resulted in the sedimentation of the nucleic acids. The pellet (usually not visible) was washed with $75 \%$ ice-cold ethanol, followed by a centrifugation for $10 \mathrm{~min}$, dried at $37^{\circ} \mathrm{C}$ for ca. $10 \mathrm{~min}$ and dissolved in $\mathrm{dd} \mathrm{H}_{2} \mathrm{O}$.

\subsection{Agarose gel electrophoresis of DNA and RNA}

\subsubsection{Separation of $\mathrm{DNA}$}

Usually, $1 \%$ agarose gels in $1 \mathrm{x}$ TEA buffer were used. An ethidium bromide stock solution $(10 \mathrm{mg} / \mathrm{ml})$ was added to a final concentration of $0.25 \mu \mathrm{g} / \mathrm{ml} .0 .75 \%$ agarose gels were used for better resolution of larger DNA fragments, e.g. for the separation of restriction enzyme-digested genomic DNA, and 1.5\% agarose gels were used for the better resolution of smaller fragments. 1/10 volume of loading dye was added to DNA samples before loading them on a gel. Electrophoresis proceeded at $20-70 \mathrm{~V}$ with 1 x TEA as running buffer. Bacteriophage $\lambda$ DNA restricted with PstI, to which blue marker had been added, was used as size marker ( $1 \mu \mathrm{g}$ per slot). DNA was photographed under UV light using a transilluminator (FLX-20M, Fa. Vilber Lourmat, Marne La-Vallet, France) and a computer program PhotoFinish ${ }^{\circledR} 3.0$ (WordStar Atlante Technology Center Inc.).

50 x TEA buffer:

Tris-acetate $\mathrm{pH} 8.3$ $2 \mathrm{M}$

EDTA $100 \mathrm{mM}$ 


\section{Loading dye:}

$\begin{array}{ll}\text { glycerol } & 50 \%(\mathrm{v} / \mathrm{v}) \\ \text { Tris-acetate } \mathrm{pH} 8.3 & 40 \mathrm{mM} \\ \text { EDTA } & 2 \mathrm{mM} \\ \text { Orange G } & 0.2 \%(\mathrm{v} / \mathrm{v})\end{array}$

\section{Blue marker:}

$\begin{array}{ll}\text { xylene cyanol } & 0.1 \%(\mathrm{w} / \mathrm{v}) \\ \text { sucrose } & 0.2 \mathrm{~g} / \mathrm{ml} \\ \text { EDTA } & 250 \mathrm{mM} \\ \text { bromphenol blue } & 0.5 \mathrm{~g} / \mathrm{ml}\end{array}$

\subsubsection{DNA gel blots (Southern blots)}

The principle of this method (Southern, 1975) is the electrophoretical separation of DNA fragments of various sizes on an agarose gel, followed by transfer and immobilization of the DNA on a nylone membrane. The membrane-bound DNA afterwards can be hybridized with labelled DNA probes to identify complementary sequences among the immobilized DNA.

Five samples of genomic DNA from Alonsoa (2.15.2) were digested overnight with different restriction enzymes: EcoRI, HindIII, PstI, SalI and BamHI. For each enzyme, the reaction was performed under the following conditions:

$\begin{array}{ll}\text { genomic DNA } & 10 \mu \mathrm{g} \\ 10 x \text { buffer (specific for the restriction enzyme) } & 40 \mu \mathrm{l} \\ \text { restriction enzyme } & 50 \mathrm{U} \\ \text { dd } \mathrm{H}_{2} \mathrm{O} & \text { ad } 400 \mu \mathrm{l}\end{array}$

incubation at $37^{\circ} \mathrm{C}$ overnight.

The completeness of the restriction was checked by electrophoresis of $1 / 20$ volume of each reaction (i.e. $10 \mu \mathrm{l}$ ) at $60 \mathrm{~V}$. The restricted DNA samples were purified by a phenol:chloroform extraction (2.18), precipitated with ethanol at $-20^{\circ} \mathrm{C}$ and redissolved in 15 $\mu \mathrm{ldd} \mathrm{H}_{2} \mathrm{O}$. In some cases, to make sure that the restriction digests were complete, the phenol:chloroform-extracted DNA was subjected to the second restriction overnight and then extracted again with phenol:chloroform. After supplementation with blue loading dye, the DNA samples were loaded on a $0.75 \%$ agarose gel $(13.5 \mathrm{~cm} \mathrm{x} 14 \mathrm{~cm})$ next to $1 \mu \mathrm{g} \lambda / P s t \mathrm{I}$ DNA as size marker. The electrophoresis was started at $80 \mathrm{~V}$ and run at $20 \mathrm{~V}$ overnight after the DNA had moved out of the slots. 
Blotting was performed by alkaline transfer to a Hybond $\mathrm{N}^{+}$nylon membrane (Amersham-Pharmacia, Braunschweig, Germany). First, the gel was photographed and shortly washed in water. The upper part of the gel that contained DNA fragments $>10 \mathrm{~kb}$ was washed with depurination solution for $1.5 \mathrm{~min}$. The gel was placed in denaturation (alkaline) buffer and incubated for 20 min under gentle shaking. The incubation was repeated with a fresh portion of the buffer. In the meantime, a piece of Hybond $\mathrm{N}^{+}$membrane of the size of the gel was wetted with water and incubated for $20 \mathrm{~min}$ in denaturation buffer. Then, a capillary blot was set up as follows. A plastic tray was half filled with denaturation buffer, a wick of the breadth of the gel was cut from Whatman 3MM paper, wetted with denaturation buffer and placed on a platform on top of the plastic tray with its ends hanging into the buffer. The gel was placed on the wick with the DNA-side upwards, and the membrane was placed on top of the gel. The lower right corners of gel and membrane were cut off to mark the orientation. The membrane was overlayed with three sheets of 3MM paper of membrane size prewetted in denaturation buffer, and a stack of absorbent towels was placed on top of the 3 MM paper. The parts of the wick that were not in contact with the gel were covered with pieces of parafilm to ensure that the suction of the buffer proceeded only through the gel. Finally, a plastic plate and a weight of ca.1 kg were placed on the stack, and the transfer proceeded overnight. Afterwards, the quality of the transfer was briefly checked using a UV transilluminator, the membrane was washed in 2 x SSC for $20 \mathrm{~min}$ for neutralization and dried at room temperature on $3 \mathrm{MM}$ paper. The membrane was stored in a plastic bag at $4^{\circ} \mathrm{C}$ until used for DNA hybridization (2.19.5.2).

Depurination solution (can be stored at room temperature for up to $1 \mathrm{month}$ ):

$\mathrm{HCl} \quad 0.125 \mathrm{M}$

Denaturation (transfer) buffer (made fresh before each blotting):

$\begin{array}{lll}\mathrm{NaCl} & 87.66 & \mathrm{~g} \\ \mathrm{NaOH} & 20 & \mathrm{~g} \\ \mathrm{dd} \mathrm{H}_{2} \mathrm{O} & \text { ad } 1 & 1\end{array}$

$20 \times$ SSC (can be stored at room temperature up to 3 month):

$\begin{array}{lcc}\mathrm{NaCl} & 3 & \mathrm{M} \\ \mathrm{Na}_{3} \text { citrate } & 0.3 & \mathrm{M} \\ \mathrm{pH} \text { adjusted to } & 7.0 \text { using } \mathrm{NaOH} \text { or } \mathrm{HCl}\end{array}$

\subsubsection{Separation of $R N A$}

To test the quality and (roughly) the amount of the isolated RNA, a 1\% agarose gel was prepared, and electrophoresis and UV detection were performed as described for DNA 
(2.19.1) with the exception that the combs and the gel chamber were incubated in $1 \%$ SDS for at least $30 \mathrm{~min}$ before use to get rid of RNase activity. In case that RNA was of good quality, the $28 \mathrm{~S}$ ribosomal RNA band was thicker than the $18 \mathrm{~S}$ rRNA band.

For a more precise estimation of the RNA concentration in the samples for the following Northern blots, small agarose-formaldehyde denaturating gels were prepared as for the RNA separation for Northern blots (2.19.4)

\subsubsection{RNA gel blot (Northern blot)}

For size-dependent separation of RNA, denaturing conditions are required because single-stranded RNA molecules form secondary structures. Here, agarose-formaldehyde gels were used. $3 \mathrm{~g}$ agarose were boiled in $150 \mathrm{ml} \mathrm{dd} \mathrm{H}_{2} \mathrm{O}$ and cooled down to $70{ }^{\circ} \mathrm{C}$. Then, $20 \mathrm{ml}$ $10 \mathrm{x}$ MEN and $33 \mathrm{ml}$ formaldehyde (37\% stock solution) were added and the gel $(13.5 \mathrm{~cm} \mathrm{x}$ $14 \mathrm{~cm}$ size) was poured.

$10 \mu \mathrm{g}$ RNA in $9 \mu \mathrm{l}$ water per slot were used for the separation. A size marker ( $3 \mu 1$ of $0.5 \mathrm{mg}$ RNA/ml; MBI Fermentas, Vilnius, Lithuania) was prepared along with the samples. Two master mixes were prepared as follows:

master mix I (amounts for one sample): $\quad 3 \mu 110 \times$ MEN

$12 \mu 1$ deionized formamide

$3 \mu \mathrm{l}$ formaldehyde $(37 \%)$

master mix II (total amount): $\quad 85 \mu 1$ blue marker

$15 \mu 1$ ethidium bromide ( $10 \mathrm{mg} / \mathrm{ml}$ stock solution)

$18 \mu 1$ of the master mix I were added to each Eppendorf tube with RNA sample, and 3 $\mu 1$ of the master mix II were pipetted to the wall of each tube. The tubes were vortexed and briefly centrifuged. The RNA samples were denatured at $65^{\circ} \mathrm{C}$ for $10 \mathrm{~min}$, cooled down on ice and loaded on the gel. The running buffer ( 1 x MEN) was added up to the gel surface which was left non-submerged. The slots were filled with the same buffer. Electrophoresis was performed at $120 \mathrm{~V}$ for three to four hours.

The gel was photographed and briefly washed with water. The RNA was transferred onto a Hybond $\mathrm{N}$ nylon membrane which had been wetted with $\mathrm{dd} \mathrm{H}_{2} \mathrm{O}$ and incubated for 20 min in $10 \mathrm{x}$ SSC. The blot was built up as described in 2.19.2. using $10 \mathrm{x}$ SSC as transfer buffer. On the next day, the membrane was washed shortly in $2 \times \mathrm{SSC}$, and the quality of the transfer was checked using a UV transilluminator. The membrane was put on 3MM paper and baked for $2-3 \mathrm{~h}$ at $80^{\circ} \mathrm{C}$ which resulted in the non-covalent binding of the RNA to the membrane. The membrane was stored at $4^{\circ} \mathrm{C}$ in a plastic bag until use. 
10 x MEN buffer: $\quad$ MOPS pH 7.0 EDTA

$\mathrm{Na}$ acetate
$200 \mathrm{mM}$

$5 \mathrm{mM}$

$50 \mathrm{mM}$

\subsubsection{Hybridization of $D N A$ and $R N A$ gel blots}

\subsubsection{Labelling of probes}

For hybridization of DNA (Southern blot) or RNA (Northern blot) immobilized on a nylon membrane, DNA probes were labelled radioactively using $\alpha-{ }^{32} \mathrm{P}-\mathrm{dATP}$. The probes were prepared using the HexaLabel Kit from MBI Fermentas (Vilnius, Lithuania). $100 \mathrm{ng}$ of DNA template (DNA fragment isolated from an agarose gel) and $10 \mu 1$ of a hexanucleotide mixture provided in the kit were denatured in buffer at $100^{\circ} \mathrm{C}$ for $10 \mathrm{~min}$ in a total volume of $40 \mu 1$. Then, $3 \mu \mathrm{l}$ of Klenow nucleotide mixture (minus dATP), $3 \mu 1 \alpha-{ }^{32} \mathrm{P}-\mathrm{dATP}(10 \mu \mathrm{Ci} / \mu \mathrm{l}$; Hartmann Analytik, Braunschweig, Germany) and $1 \mu 1$ Klenow exo polymerase were added. The reaction took place at $37^{\circ} \mathrm{C}$ for $10 \mathrm{~min}$. After this time, $4 \mu \mathrm{l}$ of a mixture of non-labelled dNTPs $(0.25 \mathrm{mM}$ of each nucleotide) provided in the kit was added, and the reaction was continued for another $5 \mathrm{~min}$. The reaction was stopped by the addition of $1 \mu 10.5 \mathrm{M}$ EDTA $\mathrm{pH}$ 8.0. Free $\alpha-{ }^{32} \mathrm{P}-\mathrm{dATP}$ was removed from the probes using a Concert Kit (Gibco BRL, Eggenstein, Germany). The probes were eluted from the DNA-binding spin columns with 100 $\mu 11 \times$ TE buffer preheated to $65^{\circ} \mathrm{C}$. The incorporation of $\alpha-{ }^{32} \mathrm{P}-\mathrm{dATP}$ into the probes was quantified by measuring the radioactivity of $1 \mu \mathrm{l}$ of the eluted DNA in a liquid scintillation analyser (Packard 1900 TR, Canberra-Packard, Dreieich, Germany). 2-4 x $10^{7} \mathrm{cpm}$ of labelled DNA were used per hybridization.

5 x buffer with random hexanucleotides:

$\begin{array}{lc}\text { Tris- } \mathrm{HCl} & 0.25 \mathrm{M} \\ \mathrm{MgCl}_{2} & 25 \mathrm{mM} \\ \text { DTT } & 5 \mathrm{mM}\end{array}$

random hexanucleotides $\quad 7.5 \mathrm{U} / \mu \mathrm{l} \quad \mathrm{pH} 8.0$

\subsubsection{Hybridization and washing of blots}

The RNA or DNA blots were placed in plastic bags containing ca. $15 \mathrm{ml}$ of hybridization buffer and incubated at $65^{\circ} \mathrm{C}$ for at least 1 hour in a shaking water bath. The labelled probes (2.19.5.1) were denatured for $5 \mathrm{~min}$ at $95{ }^{\circ} \mathrm{C}$ and pipetted into the plastic bags with the prehybridized filters. The hybridization proceeded at $65^{\circ} \mathrm{C}$ in a shaking water bath for $16-20$ hours. Afterwards, the filters were washed to remove non-hybridized label. The washing was performed either under stringent or non-stringent conditions depending on the 
specificity of the probes used. Stringent conditions were provided by washing the filter two times for 20 min each with $2 \times \mathrm{SSC}, 0.1 \% \mathrm{SDS}(\mathrm{w} / \mathrm{v})$ and once with $0.5 \times \mathrm{SSC}, 0.1 \% \mathrm{SDS}$ $(\mathrm{w} / \mathrm{v})$. Under non-stringent conditions, filters were washed with 2 x SSC containing 1\% SDS $(\mathrm{w} / \mathrm{v})$ three times for $20 \mathrm{~min}$ each. The filters were then dried on 3MM paper, sealed into plastic bags, and the hybridization signal was detected by phosphoimaging (Fuji BAS-1000, Raytest, Sprockhövel, Germany) for at least three hours. If necessary, longer exposure times of up to one week were applied. The results were evaluated with the computer programm Tina 2.0 (Raytest, Sprockhövel, Germany).

Hybridization buffer:

100 x Denhardt's:
$5 \times \mathrm{SSC}$ (for the preparation of $20 \mathrm{x}$ SSC see 2.19.2)

$5 \mathrm{x}$ Denhardt's

$0.5 \%(\mathrm{w} / \mathrm{v}) \mathrm{SDS}$

$\begin{array}{ll}\text { Ficoll } 400 & 2 \%(\mathrm{w} / \mathrm{v}) \\ \text { PVP } & 2 \%(\mathrm{w} / \mathrm{v}) \\ \text { BSA (lyophilized) } & 2 \%(\mathrm{w} / \mathrm{v})\end{array}$

\subsection{Gene cloning}

Either PCR products or DNA fragments excised from plasmids using restriction enzymes were cloned in E. coli. PCR products were ligated into the cloning vector pGEM®-T Easy (Promega, Madison, WI., USA). This vector has 3'-overhanging T-residues on both sides of the insertion site which makes it suitable for the cloning of PCR products because Taq polymerase and Tth polymerase leave overhanging A residues on the 3 '-ends of amplified DNA fragments.

For the production of templates for in vitro transcription, cDNA fragments were excised from pGEM®-T Easy and cloned in pBluescript ${ }^{\circledR} \mathrm{IIKS}^{+}$using EcoRI. For the construction of binary vectors for plant transformation, inserts whose ends had been filled up with Klenow polymerase were ligated into the vector pBI101.3 which had been restricted with SmaI to produce blunt ends.

Both fragments and vectors (except for pGEM®-T Easy which was provided in a kit) were purified via agarose gel electrophoresis using the Qiaquick gel extraction kit before ligation (2.20.1). In case of pBI101.3, the purification of the digested vector via an agarose gel was omitted because due to the large size of the vector, the risk of damage to the DNA during the procedure was too high. Therefore, proteins were removed by phenol:chloroform extraction (2.18) after restriction. The DNA was precipitated with ethanol and resuspended in $10 \mu \mathrm{l}$ of dd $\mathrm{H}_{2} \mathrm{O}$. 


\subsubsection{Elution of DNA fragments from agarose gels}

DNA fragments deriving from PCRs or restriction enzyme reactions were separated on $1 \%$ agarose gels (2.19.1). This step allowed the purification of DNA from proteins/enzymes and the isolation of the DNA fragment of the desired size. The DNA bands were cut from the gel under long-waved UV light. Agarose was removed using the Qiaquick gel extraction kit (Qiagen). After dissolving the agarose at $50^{\circ} \mathrm{C}$ in a chaotropic reagent, DNA was bound to a silica gel filter in a spin column in the presence of high salt concentrations, washed and eluted from the filter with $\mathrm{dd}_{2} \mathrm{O}$.

\subsubsection{Filling of 5' overhanging ends with Klenow polymerase}

When a restriction fragment had to be cloned in a vector, but no compatible restriction site was available, blunt-end cloning was performed. In this case, restriction enzymes producing either blunt or $5^{\prime}$ overhanging ends were used. In the latter case, single-stranded DNA ends were filled-in using Klenow DNA polymerase to obtain blunt ends. A fill-in reaction contained:

$\begin{array}{ll}10 \text { x buffer } & 4 \mu \mathrm{l} \\ \text { Klenow fragment 2 U/ } \mu 1 & 1 \mu 1 \text { (ca. 1 U per } \mu \text { g DNA) } \\ 10 \mathrm{mM} \text { dNTPs } & 4 \mu 1 \\ \text { DNA } & 2 \mu \mathrm{g} \\ \text { dd } \mathrm{H}_{2} \mathrm{O} & \text { ad } 40 \mu \mathrm{l}\end{array}$

The reaction took place at $37^{\circ} \mathrm{C}$ for no longer than $20 \mathrm{~min}$ to prevent that Klenow polymerase, after using up the free dNTPs, acted as a $3^{\prime}-5^{\prime}$ exonuclease. The DNA fragment was purified via an agarose gel using the Qiaquick gel extraction kit (2.20.1).

\subsubsection{Ligation}

The reaction volume $(10 \mu \mathrm{l})$ contained $1 \mu \mathrm{l}(1 \mathrm{U} / \mu \mathrm{l})$ T4-DNA-ligase (Gibco BRL), 2 $\mu 15 \mathrm{x}$ ligase buffer, 5 - $10 \mathrm{ng}$ vector and the insert in an amount suited to provide a molar vector:insert ratio in the range of $1: 3$ to $1: 30$. The reaction took place at $15^{\circ} \mathrm{C}$ overnight. $5 \mathrm{x}$ ligase buffer contained $10 \mathrm{mM}$ dATP, $50 \mathrm{mM} \mathrm{MgCl}, 10 \mathrm{mM}$ DTT and $660 \mathrm{mM}$ Tris- $\mathrm{HCl}$ at pH 7.6.

\subsubsection{Preparation of competent cells of E. coli strains DH5 $\alpha$ and BL21 (DE3)}

Competent cells of DH5 $\alpha$ were used for transformation with the ligation products and should possess, therefore, a high competence for transformation. BL21 (DE3) were only transformed with purified plasmid DNA. Such a transformation does not require the cells to be highly transformation-competent. 


\subsubsection{Competent cells of DH5 $\alpha$}

The method of Inoue et al. (1990) was used with some modifications. To obtain optimal competent cells, the glassware used in the protocol had to be free of any detergents. For this purpose, glassware was first autoclaved filled with $\mathrm{dd} \mathrm{H}_{2} \mathrm{O}$ to remove traces of detergents, and then autoclaved again empty. $5 \mathrm{ml}$ SOC medium were inoculated with $10-20$ $\mu \mathrm{l}$ of a DH5 $\alpha$ glycerol culture and grown overnight $\left(37^{\circ} \mathrm{C}\right.$, shaking). This inoculum was then added to $250 \mathrm{ml}$ SOC medium and grown $\left(37^{\circ} \mathrm{C}\right.$, shaking) until the cell density reached an $\mathrm{OD}_{600}$ of 0.2 . After that, the growth was continued at $18^{\circ} \mathrm{C}$ (shaking) for about an hour until the $\mathrm{OD}_{600}$ had reached 0.3 . The grown cells were poured into four $50 \mathrm{ml}$ conical centrifuge tubes and sedimented at $4300 \mathrm{rpm}$ at $4^{\circ} \mathrm{C}$ for $10 \mathrm{~min}$ (Megafuge 1.0, Heraeus Sepatech, Osterode). The following steps were performed on ice under a laminar flow hood (LaminAir HLB 2472, Heraeus, Germany). The pelleted cells were resuspended in $15 \mathrm{ml}$ ice-cold transformation buffer per tube and incubated on ice for $15 \mathrm{~min}$. The suspensions were combined pairwise into two centrifuge tubes and centrifuged again at $4300 \mathrm{rpm}$ for $10 \mathrm{~min}$ at $4^{\circ} \mathrm{C}$. The pellets were resuspended in $10 \mathrm{ml}$ per tube (total $20 \mathrm{ml}$ ) of transformation buffer and $350 \mu \mathrm{l}$ DMSO were carefully added to each tube under gentle vortexing to avoid a high local DMSO concentration. After $5 \mathrm{~min}$ incubation on ice, this step was repeated resulting in a final concentration of DMSO 7\% (v/v). $200 \mu 1$ aliquots of the competent cells were pipetted into pre-cooled $1.5 \mathrm{ml}$ Eppendorf tubes and shock-frozen in liquid nitrogen. The cells were stored at $-80^{\circ} \mathrm{C}$.

\section{SOC medium:}

$\begin{array}{ll}\text { Select Pepton } 140 & 2 \%(\mathrm{w} / \mathrm{v}) \\ \text { yeast extract } & 0.5 \%(\mathrm{w} / \mathrm{v}) \\ \mathrm{NaCl} & 10 \mathrm{mM} \\ \mathrm{KCl} & 2.5 \mathrm{mM}\end{array}$

The mixture was autoclaved for $10 \mathrm{~min}$, and the filter-sterilized solutions of $\mathrm{MgCl}_{2}(1 \mathrm{M})$, $\mathrm{MgSO}_{4}(1 \mathrm{M})$ and glucose $(2 \mathrm{M})$ were added under a clean bench to a final concentrations of $10 \mathrm{mM}, 10 \mathrm{mM}$ and $20 \mathrm{mM}$, respectively.

Transformation buffer: PIPES $\quad 10 \mathrm{mM}$

$\begin{array}{ll}\mathrm{CaCl}_{2} & 15 \mathrm{mM} \\ \mathrm{KCl} & 250 \mathrm{mM} \\ \mathrm{MnCl}_{2} & 55 \mathrm{mM}\end{array}$

The $\mathrm{pH}$ was adjusted to 6.7 with $\mathrm{KOH}$ prior to the addition of $\mathrm{MnCl}_{2}$, and the solution was filter-sterilized. 


\subsubsection{Competent cells of BL21 (DE3)}

$2 \mathrm{ml}$ LB medium (2.2.2) were inoculated with a BL21 (DE3) glycerol culture and grown overnight $\left(37^{\circ} \mathrm{C}\right.$, shaking). The cells were added to $200 \mathrm{ml} \mathrm{LB}$ medium and grown at $37^{\circ} \mathrm{C}$ up to an $\mathrm{OD}_{600}$ of 0.3 . The following steps were performed on ice under a laminar flow hood. The culture was cooled down on ice and poured into four $50 \mathrm{ml}$ conical centrifuge tubes. The cells were spun down at $4300 \mathrm{rpm}$ at $4^{\circ} \mathrm{C}$ for $10 \mathrm{~min}$ and carefully resuspended in a total volume of $40 \mathrm{ml}$ transformation buffer I. After $10 \mathrm{~min}$ incubation on ice, the cells were pelleted at $4300 \mathrm{rpm}$ at $4^{\circ} \mathrm{C}$ for $5 \mathrm{~min}$ and resuspended in a total volume of $4 \mathrm{ml}$ transformation buffer II. $200 \mu 1$ aliquots of the competent cells were pipetted into precooled $1.5 \mathrm{ml}$ Eppendorf tubes and shock-frozen in liquid nitrogen. The cells were stored at $-80^{\circ} \mathrm{C}$.

\section{Transformation buffer I:}

$\begin{array}{ll}\mathrm{K} \text { acetate } & 30 \mathrm{mM} \\ \mathrm{MnCl}_{2} & 50 \mathrm{mM} \\ \mathrm{CaCl}_{2} & 10 \mathrm{mM} \\ \mathrm{RbCl} & 100 \mathrm{mM} \\ \text { glycerol } & 15 \%(\mathrm{v} / \mathrm{v}) \\ \text { ajusted to 5.8 with acetic acid }\end{array}$

\section{Transformation buffer II:}

$\begin{array}{ll}\mathrm{Na} \text { MOPS pH } 7.0 & 10 \mathrm{mM} \\ \mathrm{CaCl}_{2} & 75 \mathrm{mM} \\ \mathrm{RbCl} & 10 \mathrm{mM} \\ \text { glycerol } & 15 \%(\mathrm{v} / \mathrm{v})\end{array}$

\subsubsection{Transformation of E. coli}

The competent cells were thawed on ice. $5 \mu$ ligation reaction or $50-200 \mathrm{ng}$ plasmid DNA were added to the competent cell suspension and mixed by pipetting. After an incubation on ice for $20 \mathrm{~min}$, the cells were incubated at $42^{\circ} \mathrm{C}$ for exactly $30 \mathrm{sec}$ and transferred back to ice for a minute. $800 \mu \mathrm{l}$ SOC medium were added to the cells under a laminar flow hood and the cells were incubated at $37^{\circ} \mathrm{C}$ for an hour to allow the expression of antibiotic resistance genes. The cells were pipetted under a clean bench onto LB agar plates supplemented with the appropriate antibiotic(s). If the cells were transformed with a ligation product in pGEM ${ }^{\circledR}-\mathrm{T}$ Easy or pBluescript ${ }^{\circledR} \mathrm{IIKS}^{+}$, the plates were supplemented with IPTG and X-Gal in addition to the antibiotic(s) (2.2.2). The plates were dried and incubated at $37^{\circ} \mathrm{C}$ overnight. Single colonies were picked for growth in LB with antibiotic(s) and Miniprep preparation of plasmid DNA (2.16.1.1 and 2.16.1.2) and characterization by either restriction 
enzyme digestion with the following separation of DNA fragments by a gel electrophoresis (2.19.1) or PCR (2.21.1). In case of plates containing IPTG and X-Gal, blue colonies contained empty vector and only white colonies were picked for further characterization.

\subsubsection{Bacterial glycerol cultures}

Original strains of E. coli and A. tumefaciens as well as strains containing characterized plasmids were grown overnight in $5 \mathrm{ml}$ medium supplemented with antibiotics at appropriate temperature $\left(37^{\circ} \mathrm{C}\right.$ for E. coli, $28-30^{\circ} \mathrm{C}$ for Agrobacterium). $200 \mu 1$ glycerol were pipetted into plastic tubes with screw tops and autoclaved. $800 \mu 1$ of bacterial culture were added to $200 \mu \mathrm{l}$ of sterile glycerol, vortexed, shock-frozen in liquid nitrogen and stored at $-80^{\circ} \mathrm{C}$.

\subsection{Amplification of DNA by the polymerase chain reaction (PCR)}

The polymerase chain reaction was used for amplification of fragments of DNA (plasmid or genomic) and cDNA using either specific or degenerate primers. PCRs were performed using a DNA thermal Cycler MJ Research PTC 100 (Biozym, Hess. Oldendorf, Germany) or TGradient (Biometra, Göttingen, Germany). Usually, Taq polymerase (Promega, Mannheim, Germany) was used. The reaction mixture contained if not otherwise indicated

\begin{tabular}{|c|c|}
\hline DNA template & $2-5 \mu 1$ \\
\hline $10 \times$ PCR buffer (100 mM KCl, $100 \mathrm{mM}$ Tris- $\mathrm{HCl} \mathrm{pH} 9.0)$ & $5 \mu 1$ \\
\hline $\mathrm{MgCl}_{2}(25 \mathrm{mM})$ & $3 \mu 1$ \\
\hline dNTP mixture (10 mM of each nucleotide) & $1 \mu l$ \\
\hline $5^{\prime}$-primer $(10 \mathrm{pmol} / \mu \mathrm{l})$ & $1 \mu l$ \\
\hline $3^{\prime}-$ primer $(10 \mathrm{pmol} / \mu \mathrm{l})$ & $1 \mu 1$ \\
\hline Taq Polymerase $(2 \mathrm{U} / \mu \mathrm{l})$ & $1 \mu 1$ \\
\hline ad dd $\mathrm{H}_{2} \mathrm{O}$ & $50 \mu 1$. \\
\hline
\end{tabular}

Usually, a three step cycle program was used except for the amplification of full length AmSTS cDNA (2.21.3) and Genome walking PCR (2.21.4). The steps were: (1) $30 \mathrm{sec}$ template denaturation at $94^{\circ} \mathrm{C}$; (2) $25-35$ cycles of (a) $30 \mathrm{sec}$ template denaturation at $94^{\circ} \mathrm{C}$, (b) $30 \mathrm{sec}$ annealing of primers to template at $\mathrm{T}_{\mathrm{ann}}$, (c) elongation at the appropriate temperature $\left(72^{\circ} \mathrm{C}\right.$ for $\mathrm{Taq}$ polymerase), elongation time depending on the length of expected product (1 min/kb); (3) 10 min extension of unfinished products at $72^{\circ} \mathrm{C}$.

\subsubsection{Design of specific and degenerate primers}

Specific primers were designed based on the known sequences of the cDNA and promoter region of the Alonsoa stachyose synthase gene. They were designed to meet the following features: (1) a length of at least 18 nucleotides; (2) no more than three G/C residues 
among the six nucleotides at the $3^{\text {c }}$ end of the primer, two of them being in the last two positions; (3) the primers should not form any strong secondary structure or (when using a primer pair) hybridize with each other; $(4)$ the melting temperature $\left(\mathrm{T}_{\mathrm{m}}\right)$ of the primer should not exceed the amplification temperature. $\mathrm{T}_{\mathrm{m}}$, the melting temperature at which $50 \%$ of the primer are bound to template, was calculated using the formula

$$
\mathrm{T}_{\mathrm{m}}=69.3+41 \times \mathrm{n}_{\mathrm{GC}} / \mathrm{N}-650 / \mathrm{N}
$$

where $\mathrm{N}$ is the total number of nucleotides and $\mathrm{n}_{\mathrm{GC}}$ is the number of $\mathrm{G} / \mathrm{C}$ in the primer.

Another formula can be used also:

$\mathrm{T}_{\mathrm{m}}=4 \times \mathrm{n}_{\mathrm{GC}}+2 \times \mathrm{n}_{\mathrm{AT}}$

where $\mathrm{n}_{\mathrm{AT}}$ is the number of $\mathrm{A} / \mathrm{T}$ in the primer.

$T_{m}$ determines the annealing temperature $\left(T_{a n n}=T_{m}-3\right)$ of the PCR. Primers used in the same reaction should have similar annealing temperatures.

Degenerate primers were used for amplification of raffinose synthase and stachyose synthase cDNA fragments of total cDNA obtained from Alonsoa. They were designed based on a comparison of several known amino acid sequences of raffinose synthases and the only known amino acid sequence of a stachyose synthase (Vigna angularis, Peterbauer et al., 1999). The primers were derived from two highly conserved sequence regions (Table 2.1). The PCR with this primer pair resulted in amplification of two cDNA fragments corresponding to raffinose and stachyose synthase, respectively.

\subsection{2. cDNA synthesis and Rapid Amplification of cDNA Ends (RACE)}

\subsubsection{1. cDNA synthesis}

Two reverse transcriptases (RT) with different temperature optima were used for the synthesis of first strand cDNA from RNA templates. For cDNA synthesis using the standard oligo-dT 20 primer and for 3'RACE, an RT from MBI (RevertAid M-MuLV-RT) with $\mathrm{T}_{\mathrm{opt}}=$ $37^{\circ} \mathrm{C}$ was taken. For $5^{\prime} \mathrm{RACE}$ that require RT reactions with gene-specific primers, Thermoscript RT from Gibco BRL was chosen which is able to function at temperatures between 50 and $60^{\circ} \mathrm{C}$, thus allowing a reaction temperature to match the annealing temperature of the primer.

Reverse transcriptions were performed in a volume of $20 \mu 1$. Prior to the reverse transcription reaction, $3 \mu \mathrm{g}$ of total RNA and $500 \mathrm{ng}$ of primer $\left(100 \mathrm{pmol} / \mu \mathrm{l}\right.$; oligo- $\mathrm{dT}_{20}$ or AP primer in case of 3 'RACE, primers amsts5racel or 5raceneul in case of 5'RACE; Table 2.1) were denatured at $65^{\circ} \mathrm{C}$ for $5 \mathrm{~min}$ in a total volume of $10 \mu \mathrm{l}$ (adjusted with $\mathrm{dd} \mathrm{H}_{2} \mathrm{O}$ ) and placed on ice. This step leads to binding of the primer to the complementary RNA sequence. Then, the other components of the reaction mixture were added (see 2.21.2.2 and 2.21.2.3), and the reaction proceeded for $60 \mathrm{~min}$ at the temperature appropriate for the enzyme. 


\subsubsection{2. $3^{\prime}$ RACE}

For reverse transcription, $4 \mu \mathrm{l} 5 \mathrm{x}$ RT buffer, $2 \mu \mathrm{dNTPs}(10 \mathrm{mM})$ and $0.75 \mu \mathrm{l}(20 \mathrm{U})$ RNase inhibitor were added to the $10 \mu \mathrm{RNA}$ /primer sample (see 2.21.2.1) and the total volume was adjusted to $19 \mu \mathrm{l}$ with $\mathrm{dd} \mathrm{H}_{2} \mathrm{O}$. The mixture was incubated at $37^{\circ} \mathrm{C}$ for $5 \mathrm{~min}$. After that, $1 \mu \mathrm{l}$ RevertAid M-MuLV-RT (200 U/ $\mu$ l) was added, and the reaction proceeded at $37^{\circ} \mathrm{C}$ for $1 \mathrm{~h}$. After the reaction was completed, the cDNA was either incubated at $70^{\circ} \mathrm{C}$ for 5 min to inactivate the RT or directly used for a PCR.

$2 \mu 1$ cDNA were used for a PCR with the $1^{\text {st }}$ primer for $3^{\prime}-$ RACE and either AP (when oligo-dT 20 had been used for reverse transcription) or UAP primer (when AP had been used). The second 3'RACE-PCR was performed with $2 \mu 1$ of the $1^{\text {st }}$ PCR mixture, the $2^{\text {nd }} 3$ 'RACE primer and UAP. The product of the $2^{\text {nd }}$ PCR was cloned in pGEM ${ }^{\circledR}-\mathrm{T}$ Easy (see 2.20) and sequenced from both ends (2.26).

\subsubsection{5' RACE}

For reverse transcription with Thermoscript RT, the following components were added to the $10 \mu 1 \mathrm{RNA} /$ primer mixture (2.21.2.1):

$\begin{array}{lr}5 \times \text { RT buffer } & 4 \mu \mathrm{l} \\ \text { dNTPs (10 mM each) } & 2 \mu \mathrm{l} \\ \text { RNase Out (MBI Fermentas) } & 1 \mu \mathrm{l} \\ 100 \mathrm{mM} \text { DTT } & 1 \mu \mathrm{l} \\ \text { RT } & 1 \mu \mathrm{l} \\ \mathrm{H}_{2} \mathrm{O} & 1 \mu \mathrm{l}\end{array}$

The reaction proceeded at $55^{\circ} \mathrm{C}$ for $1 \mathrm{~h}$. After the reaction was completed, the free nucleotides were removed using the Concert kit (Gibco BRL, Eggenstein, Germany). Then, terminal desoxynucleotidyl transferase (TdT; Promega, Mannheim, Germany) and dCTP were added to the cDNA for the synthesis of a polyC tail to the $3^{\prime}$ end of the cDNA. For this purpose, the cDNA was eluted from the spin column with $50 \mu 11 \mathrm{x}$ TdT buffer prewarmed to $65^{\circ} \mathrm{C}$. For the TdT reaction, $1 \mu \mathrm{TdT}(15 \mathrm{U} / \mu \mathrm{l}), 1 \mu \mathrm{l} 5 \mathrm{x}$ TdT buffer, $1.5 \mu 11 \mathrm{mM} \mathrm{dCTP}$ and $1.5 \mu \mathrm{dd}$ $\mathrm{H}_{2} \mathrm{O}$ were added to the eluted cDNA and incubated at $37^{\circ} \mathrm{C}$ for $30 \mathrm{~min} .5 \mu \mathrm{l}$ of the TdT reaction mixture were then used for a PCR with the sequence-specific primer amsts 5 race 2 and the 5 'race anchor primer (Table 2.1). The 5 'race anchor primer contains an oligoG sequence and therefore can bind to the polyC tail at the 3 'end of the first strand cDNA. This allowed the amplification of the cDNA fragment between the priming site of amsts5race 2 and the 5 'end of the mRNA. The fragment was then cloned into pGEM®-T Easy (see 2.20) and both ends were sequenced (2.26). For safety, the $5^{\prime} \mathrm{RACE}$ was repeated with two different gene-specific primers (5raceneul and 5raceneu2), yielding the same 5'end sequence of the cDNA. This sequence was then used to design the primer FLCsts 5 which binds to the $5^{\prime}$ end of AmSTS gene, to amplify the full length cDNA (2.21.3). 
Table 2.1. Primers used for $R T$ reactions and/or PCR. Ambiguity code: $N=A / C / G / T ; R=G / A$; $\mathrm{Y}=\mathrm{C} / \mathrm{T}$.

\begin{tabular}{|c|c|c|}
\hline Primer & Sequence $\left(5^{\prime} \rightarrow 3^{\prime}\right)$ & Used for \\
\hline \multicolumn{3}{|c|}{ degenerate primers } \\
\hline Sta-5 & GGNTGGTGYACNTGGGAYGC & \multirow{2}{*}{$\begin{array}{l}\text { RT-PCR to search for cDNA } \\
\text { fragments of } A m S T S \text { and } A m R S\end{array}$} \\
\hline Sta-3' & TGRAACATRTCCCARTCNGG & \\
\hline \multicolumn{3}{|c|}{ gene-specific primers } \\
\hline gen5STS & GTAATAACTCAATAGTTCATGCATAAGC & \multirow{6}{*}{$\begin{array}{c}\text { PCR with genomic DNA of Alonsoa } \\
\text { to analyse the restriction sites in } \\
\text { introns of the stachyose synthase } \\
\text { gene }\end{array}$} \\
\hline gen5STS1 & GTGTGCAAGAGTTTGCTGATGG & \\
\hline gen5STS2 & TCCAGCATGCAGCAATGCAACG & \\
\hline gen $3 S T S$ & AAATCCCACCACACTCTTCATACC & \\
\hline gen3STS1 & ССTCCATCAGCAAACTCTTGC & \\
\hline gen $3 S T S 2$ & TCGTTGCATTGCTGCATGCTGG & \\
\hline amsts5race1 & GTCAGCCCTCCATCAGC & $\begin{array}{c}1^{\text {st }} 5^{\prime} \text {-RACE gene-specific primer } \\
\text { for RT }\end{array}$ \\
\hline amsts5race2 & GCACACCATGGTAAATACCAGC & $\begin{array}{c}2^{\text {nd }} 5^{\prime} \text {-RACE gene-specific primer } \\
\text { for RT }\end{array}$ \\
\hline 5racenеul & GAGGAGCTCGAAAGAGTTGTCC & $\begin{array}{c}1^{\text {st }} 5^{\prime} \text {-RACE gene-specific primer } \\
\text { for PCR }\end{array}$ \\
\hline 5raceneu2 & CAGGAAGTTCAAAATTGCGTTCATGG & $\begin{array}{c}2^{\text {nd }} 5^{\prime} \text {-RACE gene-specific primer } \\
\text { for PCR }\end{array}$ \\
\hline sts3racel & CTCTGGCAAATCAGATAACTTTGG & $\begin{array}{l}3^{\prime} \text {-RACE gene-specific primer for } \\
\text { the } 1^{\text {st }} \mathrm{PCR}\end{array}$ \\
\hline sts3race 2 & ATGCATTGGCTGGTGCATGG & $\begin{array}{l}3^{\prime}-\text { RACE gene-specific primer for } \\
\text { the } 2^{\text {nd }} \mathrm{PCR}\end{array}$ \\
\hline FLCsts 5 & CCAAACTAAGTAATAACTCAATAGTTCATGC & \multirow{2}{*}{$\begin{array}{l}\text { PCR of the full length cDNA of } \\
\qquad A m S T S\end{array}$} \\
\hline FLCsts 3 & CAAAACACATTTTCATGGCCAATTCTGG & \\
\hline nhe3site & TGCTAGCTTAGTAAACAAAAGTTACATTAGAAATCC & \multirow{2}{*}{$\begin{array}{c}\text { insertion of } N h e \text { I sites at the ends of } \\
\text { the } A m S T S \text { full length cDNA for } \\
\text { expression cloning }\end{array}$} \\
\hline nhe5site & AGCTAGCGCACCTCCATATGATCCCATC & \\
\hline$g w 3 G S P a$ & GGTTGAAAAAACAGAGCAAAAACAGG & \multirow{3}{*}{$\begin{array}{l}\text { PCR to obtain AmSTS promoter } \\
\text { fragments, (a) promoter plus } 5^{\prime} \\
\text { UTR and (b) promoter only }\end{array}$} \\
\hline$g w 5 G S P$ & ATCCTCTTGGCCTTGACACCTAGG & \\
\hline$g w 3 G S P b$ & AGAAAAATGTGAAGGGGAGGCAGAC & \\
\hline AmSTSgw1 & GACGTTGCTCGGGATATCGGTCAGAATCGG & \multirow{2}{*}{$\begin{array}{c}\text { gene-specific primers used for } \\
\text { Genome Walking for cloning of the } \\
\text { AmSTS promoter }\end{array}$} \\
\hline AmSTSgw2 & GGATGGGATCATATGGAGGTGCCATGGTTG & \\
\hline 5'race & GGCCACGCGTCGACTAGTACGGGI I GGGI I GGGI IG & 5'-RACE anchor primer \\
\hline$A P$ & GGCCACGCGTCGACTAGTAGTTTTTTTTTTTTTTTTT & 3'-RACE adapter primer \\
\hline$U A P$ & GGCCACGCGTCGACTAGTAG & $3^{\prime}-\mathrm{RACE}$ \\
\hline$d T_{20}$ & тттттттттттттттт & RT reactions \\
\hline ubifor & ATGCAGATYTTTGTGAAGAC & \multirow[b]{2}{*}{$\begin{array}{l}\text { control for traces of DNA in RNA } \\
\text { samples or control of quality of } \\
\text { cDNA (Heidstra et al., 1994) }\end{array}$} \\
\hline ubirev & ACCACCACGRAGACGGGAG & \\
\hline M13forward & TGACCGGCAGCAAAATG & $\begin{array}{l}3^{\prime} \text {-primer for the determination of } \\
\text { the insert orientation in plasmids } \\
\text { pBIstsA and pBIstsB used in } \\
\text { combination with the } 5 \text { '-primer } \\
\text { pmr } 5 \text { seq } 3 \text { (Table } 2.2 \text { ) }\end{array}$ \\
\hline
\end{tabular}




\subsubsection{Amplification and cloning of the AmSTS full length $c D N A$}

Two gene-specific primers, FLCsts5 and FLCsts3 (Table 2.1), were designed from the 5' and 3'sequences of AmSTS obtained by 3' and 5'RACE. PCR was performed with these primers and AmSTS cDNA obtained by RT reaction using oligo $\mathrm{dT}_{20}$ (2.21.2.1). For the PCR, an Advantage Tth Polymerase mix (Clontech, Palo Alto, CA., USA) with 3'-5' exonuclease (,proof-reading“) activity was used to achieve high accuracy of the amplification. Furthermore, the $T$ thStart ${ }^{\mathrm{TM}}$ antibody allowed a hot start of the reaction, to prevent premature degradation of primers by the $3^{\prime}-5^{\prime}$ exonuclease activity.

For this reaction, the PCR program and the reaction conditions were based on the requirements of this special polymerase as described below (2.21.4). The PCR product was purified via agarose gel electrophoresis and ligated into pGEM ${ }^{-T}$ T Easy. Cloning and selection of transformants were performed as described in 2.20.5. The first $300 \mathrm{bp}$ of 5 ' and 3 'ends of the insert were sequenced (2.26) and corresponded to the sequences obtained by RACE. After that, both strands of the full length cDNA were sequenced by SEQLAB Sequence Laboratories Göttingen GmbH (Göttingen, Germany). For these reactions, genespecific primers (Table 2.2) were designed.

\subsubsection{Amplification of a promoter fragment by Genome Walker DNA walking}

The „Genome walking libraries“ of Alonsoa meridionalis genomic DNA were kindly provided by Dr. Christian Knop. They were prepared by separate restriction of Alonsoa genomic DNA with 5 different enzymes (EcoRV, ScaI, DraI, PvuII and SspI) which produce blunt ends. These DNA fragments were then ligated to the ,genome walking adapters“ provided in the Genome Walking kit from Clontech (Palo Alto, CA., USA). For each library, two PCR reactions were performed using adapter primers (APs) and two gene-specific primers which were designed on the basis of the $5^{\prime} \mathrm{RACE}$ results. These primers should have a $\mathrm{T}_{\mathrm{ann}}$ of about $67^{\circ} \mathrm{C}$, i.e. a $\mathrm{T}_{\mathrm{m}}$ of about $70^{\circ} \mathrm{C}$.

For the first PCR, the adaptor primer AP1 and the gene-specific primer AmSTSgw1 which binds about 100 nucleotides downstream from the 5'end of the AmSTS cDNA were used. The reaction mixtures contained:

$\begin{array}{ll}\text { Advantage Tth Polymerase mix } & 1 \mu \mathrm{l} \\ \text { 10x Tth PCR reaction buffer } & 5 \mu \mathrm{l} \\ \text { dNTPs (10 mM each) } & 1 \mu \mathrm{l} \\ 25 \mathrm{mM} \mathrm{Mg} \text { acetate } & 2.2 \mu \mathrm{l} \\ 10 \text { pmol primer AP } & 11 \mu \mathrm{l} \\ 10 \text { pmol primer AmSTSgwl } & 1 \mu \mathrm{l} \\ \text { DNA library } & 1 \mu \mathrm{l} \\ \text { dd } \mathrm{H}_{2} \mathrm{O} & \mathrm{ad} 50 \mu \mathrm{l}\end{array}$


A two-step PCR program was used:

$\begin{array}{ll}7 \text { cycles } & 94^{\circ} \mathrm{C} \quad 25 \mathrm{sec} \\ 32 \text { cycles } & 72^{\circ} \mathrm{C} \quad 3 \mathrm{~min} \\ & 94^{\circ} \mathrm{C} \quad 25 \mathrm{sec} \\ \text { followed by } & 67^{\circ} \mathrm{C} \quad 3 \mathrm{~min} \\ & 67^{\circ} \mathrm{C} \quad 7 \mathrm{~min}\end{array}$

The PCR products were analysed on an agarose gel. For the libraries where DNA bands were observed, a $2^{\text {nd }}$ PCR was performed.

For the second PCR, the adapter primer AP2 which binds downstream of the binding site of AP1, and the gene-specific primer AmSTSgw2 which binds upstream of the binding site of AmSTSgwl were used. The reaction mixtures contained:

$\begin{array}{ll}\text { Advantage Tth Polymerase mix } & 1 \mu \mathrm{l} \\ \text { 10x Tth PCR reaction buffer } & 5 \mu \mathrm{l} \\ \text { dNTP (10 mM each) } & 1 \mu \mathrm{l} \\ 25 \mathrm{mM} \mathrm{Mg} \text { acetate } & 2.2 \mu \mathrm{l} \\ 10 \text { pmol primer AP2 } & 1 \mu \mathrm{l} \\ \text { first reaction mixture diluted 1:50 } & 1 \mu \mathrm{l} \\ 10 \text { pmol primer AmSTSgw2 } & 1 \mu \mathrm{l} \\ \text { dd } \mathrm{H}_{2} \mathrm{O} & \text { ad } 50 \mu \mathrm{l}\end{array}$

The same two step program was used as for the first PCR except for the reduced number of cycles ( 5 instead of 7 for the first set, 20 instead of 32 for the second set). PCR products were analysed on $1 \%$ agarose gel. DNA bands of interest were excised from the gel, cloned and sequenced $(2.20 .1,2.20 .3,2.20 .5,2.26)$.

\subsubsection{Colony PCR}

To identify positive clones of bacteria transformed with pBI101.3 derivatives pBIstsA and pBIstsB where no blue/white selection was possible, colony PCR was performed. 30-40 culture tubes with LB medium containing kanamycin were prepared corresponding to the number of the colonies of transformants to be picked. A PCR master mix was prepared (2.21) and $10 \mu \mathrm{dd} \mathrm{H}_{2} \mathrm{O}$ were pipetted into $0.5 \mathrm{ml}$ Eppendorf tubes. Each colony was picked with a sterile toothpick. The toothpick was first dabbed into a PCR tube and then placed in a correspondingly labelled culture tube. $15 \mu \mathrm{l}$ of master mix were added to each tube, and the PCR was performed using an appropriate program as described in 2.21 except that the first step at $94^{\circ} \mathrm{C}$ was extended $(5 \mathrm{~min})$ to break the cells. The cultures were grown overnight at $37^{\circ} \mathrm{C}$ (shaking). $10 \mu \mathrm{l}$ of each PCR were run on $1 \%$ agarose gel to identify posistive clones. The cultures of these clones were used for the isolation of plasmid DNA. 


\subsection{Expression of $A m S T S$ in $E$. coli using pET expression system}

\subsubsection{Transformation of E. coli BL21 (DE3)}

The AmSTS cDNA was cloned in E. coli cells using the pET3b vector and the T7 RNA polymerase expression system (Rosenberg et al., 1986). For this purpose, $2602 \mathrm{bp}$ of the AmSTS cDNA were inserted into the NheI restriction site of the polylinker of plasmid pET3b under the control of the T7 promoter, yielding $\mathrm{pET} * / \mathrm{STS}$.

The construction of $\mathrm{pET} * \mathrm{STS}$ was performed as follows. Two AmSTS cDNA-specific primers nhe3site and nhe5site (Table 2.1) were designed that carry NheI restriction sites at their 5' ends, and PCR was performed with these primers and the AmSTS cDNA cloned in pGEM®-T Easy as the template. The PCR product was cloned in pGEM®-T Easy, yielding pGEM-AmSTSnhe.

Since pET3b also carries an additional NheI site, the part of pET3b containing this site was removed by EcoRV restriction and religation, yielding pET*3b. Then, the AmSTS cDNA was excised from pGEM-AmSTSnhe using NheI and ligated into the NheI site of pET*3b, yielding $\mathrm{pET}^{*} / \mathrm{STS}$. BL21 (DE3) cells transformed with $\mathrm{pET} * / \mathrm{STS}$ were used to induce the expression of AmSTS, and BL21 (DE3) cells transformed with an empty pET3b vector were used to provide a negative control for stachyose synthase activity measurements. The transformants were grown on LB plates containing ampicillin, and the presence and orientation of the insert were confirmed by restriction analysis using EcoRI, HindIII and BamHI.

\subsubsection{Induction of the expression of the transgene using IPTG}

$5 \mathrm{ml} \mathrm{LB}$-ampicillin medium were inoculated with BL21 (DE3) (pET*/STS) and BL21 (DE3) (pET3b), respectively, and grown overnight at $37^{\circ} \mathrm{C}$. On the next day, $250 \mathrm{ml}$ of LB medium with ampicillin were inoculated with the overnight cultures and grown at $37^{\circ} \mathrm{C}$ up to an $\mathrm{OD}_{600}$ of 0.6. At this point, IPTG was added up to a final concentration of $0.3 \mathrm{mM}$ and cells were grown for three more hours. During the growth, $\mathrm{OD}_{600}$ was measured at time intervals of $30 \mathrm{~min}$ and $600 \mu \mathrm{l}$ aliquots of cells were harvested for the separation of proteins by SDS-PAGE (2.23). At the end of this period the $\mathrm{OD}_{600}$ was determined again to make sure that the cultures had continued to grow. The cells were spun down in $50 \mathrm{ml}$ conic sterile centrifuge tubes (4300 rpm, 10 min; Megafuge 1.0, Heraeus Sepatech, Osterode, Germany), and the pellets were resuspended in extraction buffer (2.5.6.2). This was followed by the extraction of proteins which were then used for protein gel analysis and for STS activity measurements. 


\subsection{SDS - PAGE (Laemmli, 1970)}

To check protein formation in E. coli in IPTG-induced B121 (DE3) cells, SDS - PAGE (Laemmli, 1970) was used.

\subsubsection{Protein extraction from E. coli cells}

$600 \mu \mathrm{l}$ Aliquots of cell cultures were centrifuged and the cells were resuspended in protein extraction buffer to a similar density based on $\mathrm{OD}_{600}$ values measured before harvesting (2.22.2). The samples were solubilized at room temperature for $30 \mathrm{~min}$. Afterwards, the samples were denatured at $95^{\circ} \mathrm{C}$ for $3 \mathrm{~min}$, centrifuged at $13000 \mathrm{rpm}$ for 5 min and loaded into the gel slots using a microsyringe. $5 \mu 1$ of a size marker protein mixture ("Low molecular weight calibration Kit") were treated in the same way.

\section{Protein extraction buffer:}

$\begin{array}{ll}\text { Tris/HCl pH } 6.8 & 15 \mathrm{mM} \\ \text { SDS } & 5 \%(\mathrm{w} / \mathrm{v}) \\ \text { ß-mercaptoethanol } & 2 \%(\mathrm{v} / \mathrm{v}) \\ \text { glycerol } & 5 \%(\mathrm{v} / \mathrm{v}) \\ \text { Bromphenol blue } & 0.01 \%(\mathrm{v} / \mathrm{v})\end{array}$

\section{Low molecular weight marker:}

$\begin{array}{ll}\text { Phosphorylase } \mathrm{b} & 97 \mathrm{kDa} \\ \text { BSA } & 66 \mathrm{kDa} \\ \text { Ovalbumine } & 45 \mathrm{kDa} \\ \text { Carboanhydrase } & 30 \mathrm{kDa} \\ \text { Trypsin inhibitor } & 20 \mathrm{kDa} \\ \alpha \text {-Lactalbumine } & 14 \mathrm{kDa}\end{array}$

\subsubsection{SDS-Polyacrylamide gel electrophoresis}

$7.5 \%$ polyacrylamide gels were prepared as follows. Glass gel plates, combs and silicon spacer tubes were cleaned with dd $\mathrm{H}_{2} \mathrm{O}$, dried, and the gel cassette was mounted. Solutions for the separating gel and the stacking gel were prepared. TEMED was added to the separating gel solution and the separating gel was poured into the cassette until $1 \mathrm{~cm}$ from the ends of comb slots (about $7 \mathrm{~cm}$ from the gel bottom). To ensure that the gel was set with a smooth surface, $\mathrm{ddH}_{2} \mathrm{O}$ was carefully poured into the cassette using a Pasteur pipette forming a layer of about $2 \mathrm{~mm}$. When the gel was polimerized, a clear refractive index change could be seen between the gel and overlaying water. After that, the water was poured off, TEMED was added to the stacking gel solution, and a stacking gel of about $1 \mathrm{~cm}$ was poured. The slot-forming comb was placed into this solution, and the stacking gel was left for 
polymerization. 10-20 $\mu 1$ of the samples (2.23.1) were loaded into the slots. Gel electrophoresis was set at constant current of $30 \mathrm{~mA}$ until the blue marker reached the bottom of the gel.

\section{Acrylamide stock solution}

Acrylamide

$\mathrm{N}, \mathrm{N}$-methylenbisacrylamide

dd $\mathrm{H}_{2} \mathrm{O}$ to $100 \mathrm{ml}$
$29.2 \%(\mathrm{w} / \mathrm{v})$

$0.8 \%(\mathrm{w} / \mathrm{v})$

Separating gel solution $(38.25 \mathrm{ml}$ for two gels required):

Tris/ $\mathrm{HCl} \mathrm{pH} 6.8$

$0.125 \mathrm{M}$

SDS

$0.1 \%$

Acrylamide

$7.5 \%(\mathrm{w} / \mathrm{v})$

$\mathrm{N}, \mathrm{N}$-methylenbisacrylamide

$0.2 \%(\mathrm{w} / \mathrm{v})$

Ammonium persulfate

$0.05 \%(\mathrm{w} / \mathrm{v})$

TEMED (add before pouring the gels)

$0.1 \%(\mathrm{v} / \mathrm{v})$

Stacking gel solution ( $15 \mathrm{ml}$ for two gels required):
Tris/ $\mathrm{HCl} \mathrm{pH} 6.8$
$0.125 \mathrm{M}$
SDS
$0.1 \%$
Acrylamide
$4 \%(\mathrm{w} / \mathrm{v})$
$\mathrm{N}, \mathrm{N}$-methylenbisacrylamide
$0.11 \%(\mathrm{w} / \mathrm{v})$
Ammonium persulfate
$0.05 \%(\mathrm{w} / \mathrm{v})$
TEMED (add before pouring the gels)
$0.1 \%(\mathrm{v} / \mathrm{v})$

\section{Electrophoresis buffer:}

$\begin{array}{ll}\text { Tris (no pH adjustment) } & 0.025 \mathrm{M} \\ \text { Glycine } & 0.192 \mathrm{M} \\ \text { SDS } & 0.1 \%(\mathrm{w} / \mathrm{v})\end{array}$

\subsubsection{Coomassie staining of the gels}

After electrophoresis, the gels were stained for 2 hours in Coomassie staining solution and washed overnight in washing solution containing 10\% (v/v) acetic acid and $50 \%(\mathrm{v} / \mathrm{v})$ methanol. The stained gels were vacuum-dried.

\section{Coomassie staining solution:}

Coomassie Brilliant Blue G-250

$0.25 \%(\mathrm{w} / \mathrm{v})$

Methanol

$40 \%(\mathrm{v} / \mathrm{v})$

Acetic acid

$10 \%(\mathrm{v} / \mathrm{v})$ 


\subsection{Promoter-GUS fusions in transgenic plants}

To investigate the expression pattern of AmSTS and the possible effect of the $5^{\prime} \mathrm{UTR}$ of the AmSTS cDNA on this expression pattern, Arabidopsis thaliana ecotype Columbia plants were transformed with Agrobacterium tumefaciens carrying the plasmids pBIstsA or pBIstsB, respectively. These plasmids were obtained by inserting $1.95 \mathrm{~kb}$ of the AmSTS promoter region into the $S m a \mathrm{I}$ site of plasmid pBI101.3 upstream of the open reading frame of $\beta$-glucuronidase (GUS). The 5'UTR of the AmSTS cDNA was added to the promoter in the plasmid pBIstsA but omitted in pBIstsB (2.2.3). Competent cells of Agrobacterium tumefaciens strain GV3101 (pMP90) were transformed with pBIstsA and pBIstsB, respectively. Positive transformants were used for the infiltration of A. thaliana. Seeds obtained from the infiltrated $A$. thaliana plants were grown on MS2-agar containing kanamycin and then transferred to soil as described in 2.2.1. For determination of GUS activity by staining (2.24.4.1), rosette leaves of first generation transformants (F1) were used while the plants were further grown for seed production. In the second generation of transformants (F2), obtained from F1 seeds, GUS activity staining was performed using whole seedlings, rosette leaves and inflorescences.

\subsubsection{Preparation of competent Agrobacterium tumefaciens GV3101 cells}

$5 \mathrm{ml}$ liquid YEB medium supplemented with rifampicin were inoculated with an A. tumefaciens GV3101 (pMP90) colony and grown at $28^{\circ} \mathrm{C}$ overnight. On the next day, 50 $\mathrm{ml}$ YEB with rifampicin were inoculated with this culture and grown at $28^{\circ} \mathrm{C}$ for about $4 \mathrm{~h}$ until the cell density in the culture had reached an $\mathrm{OD}_{600}$ of $0.5 .10 \mathrm{ml}$ of this culture were used for the preparation of the electroporation-competent cells. The cells were spun down at $4300 \mathrm{rpm}$ (10 min, $4^{\circ} \mathrm{C}$; Megafuge 1.0 Heraeus) and resuspended in $10 \mathrm{ml} \mathrm{dd} \mathrm{H}_{2} \mathrm{O}$. The cells were then washed eight times by centrifuging and resuspending in $10 \mathrm{ml} \mathrm{dd} \mathrm{H}_{2} \mathrm{O}$. This led to the removal of ions from the cell wall and thus rendered the cells suitable for transformation by electroporation. 15-20 $\mu \mathrm{l}$ aliquots were pipetted into sterile $1.5 \mathrm{ml}$ plastic Eppendorf tubes and stored at $-80^{\circ} \mathrm{C}$.

\subsubsection{Transformation of Agrobacterium tumefaciens by electroporation}

$3 \mu \mathrm{l}$ (ca $100 \mathrm{ng}$ ) plasmid DNA of pBIstsA or pBIstsB were added to $20 \mu \mathrm{l}$ of Agrobacterium GV3101 (pMP90) competent cells thawn on ice in a $1.5 \mathrm{ml}$ plastic tube and incubated on ice for $30 \mathrm{~min}$. The electroporation was performed in a $0.2 \mathrm{~cm}$ cuvette using the Gene Pulser ${ }^{\circledR}$ Electroporation system (Bio-Rad Laboratories GmbH, Munich, Germany). The pulse parameters were $2.5 \mathrm{kV} / 25 \mu \mathrm{F} / 200 \mathrm{k} \Omega$. The time constant was set automatically and 
was $4.6 \mathrm{~ms}$. Immediately after the pulse, $1 \mathrm{ml}$ of ice-cold SOC medium was pipetted into the cuvette and the cell suspension was transferred into a sterile $1.5 \mathrm{ml}$ Eppendorf tube and incubated at $28^{\circ} \mathrm{C}$ for $1 \mathrm{~h}$. The transformants were selected on YEB plates supplemented with rifampicin and kanamycin at $28^{\circ} \mathrm{C}$ for 2 days. For purification of transformants, single colonies were streaked onto new plates, and the procedure was repeated two times. For the characterization of transformants, plasmids were isolated (2.16.2) and used for transformation of E. coli DH5 $\alpha$ cells. From E. coli, plasmids were isolated in preparative amounts and characterized by PCR with gene-specific primers and by restriction analysis.

\subsubsection{Transformation of Arabidopsis thaliana with Agrobacterium tumefaciens}

A. thaliana ecotype Columbia plants were grown as described in 2.2.1. Flowering plants were used for transformation with Agrobacterium (Clough and Bent, 1998). $100 \mathrm{ml}$ YEB with rifampicin and kanamycin were inoculated with $5 \mathrm{ml}$ overnight cultures of $A$. tumefaciens GV3101 (pMP90) (pBIstsA) or (pBIstsB), respectively, and were grown at $28^{\circ} \mathrm{C}$ for several hours until the $\mathrm{OD}_{600}$ reached 0.5 . The cells were spun down and resuspended in about $200 \mathrm{ml}$ of a $5 \%$ sucrose solution to final $\mathrm{OD}_{600}$ of 0.8 . For aeration of cells, the suspensions were kept on a magnetic stirrer until they were used for transformation.

Silwet L-77 was added to the cell suspensions up to a concentration of $0.05 \%$ and mixed. The inflorescences of $A$. thaliana plants were then dipped into the Agrobacterium suspension for 2-3 sec under gentle agitation. The dipped plants were left under open air for several hours and then placed under a transparent plastic cover to provide a high humidity for two days. Plants were then watered and grown normally until seed production (2.2.1).

\subsubsection{Qualitative GUS assay}

\subsubsection{Staining of rosette leaves from $F 1$ plants}

The selected kanamycin-resistent F1 plants grown from the seeds of the infiltrated plants were numbered, and from each plant, two leaves were harvested for GUS activity staining and two leaves for DNA isolation (2.15.3). For DNA isolation, leaves were placed in $1.5 \mathrm{ml}$ plastic tubes and stored at $-80^{\circ} \mathrm{C}$. For GUS activity staining, the leaves were placed in $1.5 \mathrm{ml}$ plastic tubes and covered with washing buffer containing $1 \mathrm{mM} \mathrm{X}$-Gluc. The concentration of $\mathrm{K}$-ferri/ferrocyanide in washing buffer differed dependent on experiment but were at least $3 \mathrm{mM}$ except for one experiment where it was omitted (3.3.6.3, Figure 3.29). The tubes were closed and the covers were perforated with a needle. The tubes were placed in a desiccator and vacuum was applied for 15 min to infiltrate the leaves with X-Gluc solution. The tubes were incubated at $37^{\circ} \mathrm{C}$ for $16-24 \mathrm{~h}$. After the incubation, the leaves were incubated 
for $30 \mathrm{~min}$ in $30 \%$ ethanol and fixed in FAA fixative for 1 hour at room temperature. Leaves were then incubated in $96 \%$ ethanol overnight to remove chlorophyll. Leaves treated in this way were stored in $70 \%$ ethanol. On the basis of the GUS activity staining results obtained, F1 plants were selected for further analysis, i.e. F2 seed production.

\section{Washing buffer:}

$\begin{array}{ll}50 \mathrm{mM} & \text { Na phosphate } \mathrm{pH} 7.5 \\ 1 \mathrm{mM} & \text { EDTA } \\ 0,1 \%(\mathrm{v} / \mathrm{v}) & \text { Tween } 20 \\ 3-20 \mathrm{mM} & \text { K-ferrocyanide } \mathrm{K}_{4}\left[\mathrm{Fe}(\mathrm{CN})_{6}\right] \times \mathrm{H}_{2} \mathrm{O} \\ 3-20 \mathrm{mM} & \text { K-ferricyanide } \mathrm{K}_{3}\left[\mathrm{Fe}(\mathrm{CN})_{6}\right]\end{array}$

\section{X-Gluc stock solution:}

100 mM X-Gluc (5-bromo-4-chloro-3-indolyl- $\beta$-D-glucuronide) in DMF

\section{FAA fixative:}

$$
\begin{array}{ll}
50 \% & \text { ethanol } \\
10 \% & \text { acetic acid } \\
5 \% & \text { formamide }
\end{array}
$$

\subsubsection{Infiltration of seedlings to induce GUS expression}

GUS activity staining of seedlings and also of inflorescences and siliques of mature plants was performed as described in 2.24.4.1. For induction experiments, the seedlings were taken directly from plates and were floating for 20 hours in the MS solutions containing additives/no additives. Afterwards, the seedlings were stained for GUS activity.

\section{Incubation solutions:}

MS medium (infiltration control)

MS medium with $180 \mathrm{mM}$ sucrose

MS medium with $200 \mathrm{mM}$ glucose

\subsection{5. in situ RNA hybridization of thin paraffin sections of Alonsoa}

\subsubsection{Preparation of the $R N A$ probes}

\subsubsection{Construction and linearization of plasmids}

RNA antisense probes were produced for in situ hybridization with transcripts of Alonsoa stachyose synthase (AmSTS), raffinose synthase (AmRS) and sucrose transporter (AmSUT1). cDNA fragments of ca. $1.0 \mathrm{~kb}$ for AmSTS and of ca. $0.8 \mathrm{~kb}$ for AmRS had been obtained by RT-PCR using the degenerate primers Sta-5' and Sta-3' (2.21.2.1; Table 2.1). The fragment of AmSUT1 was provided by Christian Knop. The fragments had been cloned in 
pGEM ${ }^{\circledR}-\mathrm{T}$ Easy. From there, they were excised with EcoRI and ligated into pBluescript ${ }^{\circledR I I K S}{ }^{+}$linearized with EcoRI, yielding pAmSTSish, pAmRSish and pAmSUTish. The orientation of the inserts was determined by restriction with HindIII and BamHI.

In all three plasmids, T3 was used for transcription of the antisense RNA. The sense RNA probe was transcribed from AmSUT1ish using T7 RNA Polymerase. Before transcription, the plasmids were linearized with restriction enzymes which should not leave 3 '-overhangs which might lead to unspecific initiation of transcription in the wrong direction.

For transcription of antisense RNA probes, the plasmids were linearized with the following enzymes:

PAmSTSish using $X b a \mathrm{I}$

PAmRSish using BamHI

pAmSUTish using XbaI

For transcription of the sense control probes, plasmid AmSUT1ish was linearized with HindIII.

For each linearization, 5-10 $\mu \mathrm{g}$ plasmid DNA were restricted for 2 hours at $37^{\circ} \mathrm{C}$ in a total volume of $200 \mu \mathrm{l}$ with $30 \mathrm{U}$ of restriction enzyme. The completeness of the restriction was confirmed by agarose gel electrophoresis of a $10 \mu 1$ aliquot. The linearized plasmids were purified by phenol:chloroform extraction (2.18), then precipitated with ethanol and redissolved in $10 \mu \mathrm{ddd} \mathrm{H}_{2} \mathrm{O}$. An $1 \mu \mathrm{l}$ aliquot was used for agarose gel electrophoresis to determine the DNA concentration.

\subsubsection{In vitro transcription}

In vitro transcription was performed with T3 (for antisense probes) or T7 (for sense control) RNA polymerase for 2.5 hours at $37^{\circ} \mathrm{C}$. The reaction mixtures contained in a total volume of $20 \mu \mathrm{l}$ :

$1 \mu \mathrm{g}$ linearized plasmid DNA

$4 \mu 15 \times$ T7 or $5 \times$ T3 buffer

$1 \mu 1100 \mathrm{mM}$ DTT

$0.5 \mu 1$ RNase Out (Gibco BRL, Eggenstein, Germany)

$1 \mu 1$ RNA polymerase (T7 or T3, $50 \mathrm{U} / \mu 1$, Gibco BRL)

$1 \mu \mathrm{dNTP}+$ Dig (= $25 \mathrm{mM}$ each of dATP, dCTP, dGTP; $16.25 \mathrm{mM}$ dUTP; $0.175 \mathrm{mM}$

Dig-UTP; Roche Biochemicals, Mannheim, Germany)

After the reaction had proceeded for $2 \mathrm{~h}, 1 \mu \mathrm{l}$ was removed from the reaction mixtures, and the RNA concentration was determined by agarose gel electrophoresis (2.19.3). The reaction continued for the next $30 \mathrm{~min}$. The RNA concentration should be at least $40 \mathrm{ng} / \mu \mathrm{l}$. After the 
gel electrophoresis, $1 \mu \mathrm{l}$ of $10 \mu \mathrm{g} / \mu \mathrm{l}$ tRNA and $1 \mu \mathrm{l}(1 \mathrm{U} / \mu \mathrm{l})$ RNase-free DNase (Promega, Madison, WI., USA) for degradation of the plasmid DNA templates were added to the reaction mixtures, followed by an incubation for $15 \mathrm{~min}$ at $37^{\circ} \mathrm{C}$. Then, free nucleotides were separated from the RNA by passage through Microspin S-300 HR columns (Amersham Pharmacia Biotech, Freiburg, Germany). If necessary, the RNA was concentrated using $\mathrm{LiCl} /$ ethanol-precipitation. For this procedure, 2.5 volumes of $4 \mathrm{M} \mathrm{LiCl}$ and $75 \mu 1$ of ice-cold 96\% ethanol were added to $20 \mu 1$ RNA mixtures and RNA was precipitated for 2 hours at $20^{\circ} \mathrm{C}$. The precipitated RNA was spun down (13 $\left.000 \mathrm{rpm}, 10 \mathrm{~min}\right)$, washed with ice-cold 75\% ethanol (13 $000 \mathrm{rpm}, 5 \mathrm{~min}$ ) and resuspended in $\mathrm{dd}_{2} \mathrm{O}$ by an incubation at $65^{\circ} \mathrm{C}$ for $5 \mathrm{~min}$.

\subsubsection{Hydrolysis}

The probes longer than 700 nucleotides in size (AmRS and AmSTS) were subjected to hydrolysis to obtain fragments of maximally 150 nucleotides length. $50 \mu 1$ RNA (i.e. half of each probe), $30 \mu \mathrm{l}$ of $0.2 \mathrm{M} \mathrm{Na}_{2} \mathrm{CO}_{3}$ and $20 \mu \mathrm{l}$ of $0.2 \mathrm{M} \mathrm{NaHCO}_{3}$ were incubated at $60^{\circ} \mathrm{C}$. The incubation time was calculated as follows:

$$
\left.\mathrm{t}=\left(\mathrm{L}_{0}-\mathrm{L}_{\mathrm{f}}\right) / 0.11 \times \mathrm{L}_{0} \times \mathrm{L}_{\mathrm{f}}\right)
$$

where $\mathrm{t}=$ time ( $\min ), \mathrm{L}_{0}=$ starting length (in $\left.\mathrm{kb}\right), \mathrm{L}_{\mathrm{f}}=$ desired final length (in $\mathrm{kb}$ ).

The reaction was stopped by the addition of $3 \mu \mathrm{l} 3 \mathrm{M}$ sodium acetate $\mathrm{pH} 6.0$ and $5 \mu \mathrm{l}$ $10 \%$ acetic acid. Then, $1 \mu 1$ of $10 \mu \mathrm{g} / \mu 1$ tRNA carrier was added, and the RNA was precipitated with $250 \mu 1$ ethanol at $-20^{\circ} \mathrm{C}$ for 1 hour and spun down for $15 \mathrm{~min}$ at $13000 \mathrm{rpm}$. The precipitated RNA was redissolved in $\mathrm{dd}_{2} \mathrm{O}$ at room temperature. The concentration of RNA fragments was checked on an agarose gel. The appropriate probe concentrations were achieved by combining equal amounts of hydrolyzed and non-hydrolyzed probes.

\subsubsection{Prehybridization}

Paraffin sections were prepared as described in 2.14. The incubations were performed in a glass rack kept in glass boxes filled with $200 \mathrm{ml}$ of the appropriate solution. Paraffin was removed from the sections by incubation of the slides for 30 min each in $100 \%$ xylene, $100 \%$ ethanol:100\% xylene (1:1) and 100\% ethanol. This was immediately followed by the prehybridization. The sections were rehydrated in a graded EtOH series for 1 minute each: twice in $100 \% \mathrm{EtOH}$, then once in $90 \%, 70 \%, 50 \%, 30 \%$ and $10 \% \mathrm{EtOH}$. Then the slides were washed three times in dd $\mathrm{H}_{2} \mathrm{O}$ for 1 min each. After that, the sections were subjected to Proteinase $\mathrm{K}$ treatment which allowed the partial degradation of cellular proteins to make the target RNA more accessible for the probe. The incubation lasted $10 \mathrm{~min}$ at $37^{\circ} \mathrm{C}$ in $2 \times \mathrm{SSC}$, 0.1\% SDS (Proteinase buffer) containing $1 \mu \mathrm{g} / \mathrm{ml}$ Proteinase $\mathrm{K}$ (Roche Molecular Biochemicals, Mannheim, Germany). The reaction was stopped by washing the slides for 2 
min in $2 \mathrm{mg} / \mathrm{ml}$ glycine in $1 \mathrm{x}$ PBS (stirring) and then twice in $1 \mathrm{x}$ PBS for $2 \mathrm{~min}$ each (stirring). After that, the sections were refixed for $10 \mathrm{~min}$ in a freshly prepared solution of $4 \%$ paraformaldehyde in $1 \mathrm{x}$ PBS.

The refixed sections were washed twice with 1 x PBS for 5 min each and then incubated for $10 \mathrm{~min}$ in $0.1 \mathrm{M}$ triethanolamine with acetic anhydride $\mathrm{pH} 8.0$ (stirring). This step allowed the saturation of the positive charges within the tissue which might bind the negatively-charged RNA probe. Triethanolamine was removed by washing the sections for 5 min in $2 \times$ SSC. Then, the slides were placed in a plastic box with paper towels wetted with 2 x SSC. $800 \mu$ of prehybridization solution was applied on slides, the box was sealed with tape, and the slides were incubated at $45^{\circ} \mathrm{C}$ for $30 \mathrm{~min}$.

Prehybridization solution (end concentrations):

$\begin{array}{ll}\text { formamide (double crystallized) } & 50 \% \\ \mathrm{NaCl} & 300 \mathrm{mM} \\ \text { Tris-HCl pH } 7.5 & 10 \mathrm{mM} \\ \text { EDTA } & 1 \mathrm{mM} \\ \text { Ficoll } & 0.02 \% \\ \text { PVP } & 0.02 \% \\ \text { BSA } & 0.02 \% \\ \text { tRNA } & 150 \mu \mathrm{g} / \mathrm{ml} \\ \text { DTT } & 30 \mathrm{mM}\end{array}$

10 x PBS:

$\begin{array}{ll}\mathrm{NaCl} & 1.3 \mathrm{M} \\ \mathrm{Na}_{2} \mathrm{HPO}_{4} & 70 \mathrm{mM} \\ \mathrm{NaH}_{2} \mathrm{PO}_{4} & 30 \mathrm{mM} \\ \mathrm{KCl} & 1.7 \mathrm{mM}\end{array}$

Triethanolamine:

dd $\mathrm{H}_{2} \mathrm{O}$

$200 \mathrm{ml}$

Triethanolamine (stock solution prewarmed at $80^{\circ} \mathrm{C}$ for ca. $1 \mathrm{~h}$ ) $\quad 2.66 \mathrm{ml}$

$\begin{array}{ll}\text { Acetic anhydride } & 0.6 \mathrm{ml}\end{array}$

\subsubsection{Hybridization}

Solutions A and B were prepared in amounts corresponding to the number of slides plus two.

\section{Solution A per slide:}

double crystallized formamide $50 \mu 1$ 
$100 \mathrm{mM}$ Tris-HCl pH 7.5, 10 mM EDTA

$10 \mu 1$

$50 \mathrm{x}$ Denhardt's

$2 \mu 1$

$50 \%$ dextran sulfate (prewarmed at $80^{\circ} \mathrm{C}$ for pipetting) $20 \mu \mathrm{l}$

dd $\mathrm{H}_{2} \mathrm{O}$

$2 \mu 1$

kept at $37^{\circ} \mathrm{C}$ until use.

\section{Solution B per slide:}

$$
\begin{array}{ll}
3 \mathrm{M} \text { DTT } & 1 \mu \mathrm{l} \\
10 \mu \mathrm{g} / \mu \mathrm{l} \text { tRNA } & 2.5 \mu \mathrm{l} \\
20 \mu \mathrm{g} / \mu \mathrm{l} \text { poly(A) (prewarmed at } 80^{\circ} \mathrm{C} \text { for pipetting) } & 2.5 \mu \mathrm{l}
\end{array}
$$

kept on ice until use.

The probes ( $5 \mu 1$ of each probe corresponding to $100 \mathrm{ng}$ RNA per slide) were pipetted into $1.5 \mathrm{ml}$ Eppendorf tubes, $5 \mu \mathrm{l}$ of solution B were added and 5 min incubation at $80^{\circ} \mathrm{C}$ followed to dissolve secondary structures of the RNA. Then, $90 \mu 1$ of solution A were added by pipetting up and down slowly and carefully to prevent the formation of air bubbles. The mixture was then applied to the slide. The slides were covered by glass coverslips which were pre-cleaned with $96 \%$ ethanol and dried with dust-free paper towels. Care was taken to prevent air bubble formation. The slides were placed in a closed moisture chamber with paper towels wetted with $2 \times \mathrm{SSC}$ and the hybridization proceeded overnight at $45^{\circ} \mathrm{C}$ in the dark to keep the ionization of formamide low.

\section{Hybridization solution:}

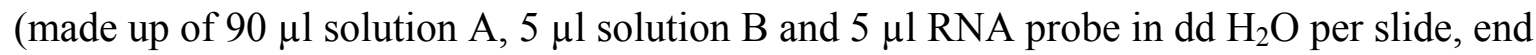
concentrations):

$\begin{array}{ll}\text { formamide (double crystallized) } & 50 \% \\ \mathrm{NaCl} & 300 \mathrm{mM} \\ \text { Tris-HCl pH } 7.5 & 10 \mathrm{mM} \\ \text { EDTA } & 1 \mathrm{mM} \\ \text { Ficoll } & 0.02 \% \\ \text { PVP } & 0.02 \% \\ \text { BSA } & 0.02 \% \\ \text { dextran sulfate } 500.000 & 10 \% \\ \text { poly(A) } & 500 \mu \mathrm{g} / \mathrm{ml} \\ \text { tRNA } & 150 \mu \mathrm{g} / \mathrm{ml} \\ \text { DTT } & 30 \mathrm{mM} \\ \text { RNA probe } & 40-100 \mathrm{ng} / 100 \mu 1\end{array}$




\subsubsection{Washing}

$10 \mathrm{mg} / \mathrm{ml}$ RNase A (Sigma-Aldrich, Taufkirchen, Germany) were dissolved in $\mathrm{dd}_{2} \mathrm{O}$ and boiled for 30 min to remove traces of DNases. RNase A was added to RNase buffer to a final concentration of $20 \mu 1 / \mathrm{ml}$ and prewarmed at $37^{\circ} \mathrm{C}$. The slides were placed in glass racks. Cover slips were removed by placing the racks in $4 \times$ SSC and moving them up and down. The slides were then incubated for $2 \mathrm{~min}$ in RNase buffer and treated with prewarmed RNase A for $30 \mathrm{~min}$ at $37^{\circ} \mathrm{C}$ in a shaking water bath. After the RNase treatment, the slides were washed at room temperature three times for 5 min each in RNase buffer (stirring) and for 30 min with $2 \times \mathrm{SSC}$ (stirring). This was followed by an incubation in $0.2 \times \mathrm{SSC}$ at $56^{\circ} \mathrm{C}$ in a shaking water bath for $30 \mathrm{~min}$ and in $0.2 \mathrm{x}$ SSC at room temperature (stirring) for $10 \mathrm{~min}$.

\section{RNase buffer:}

$\begin{array}{ll}\text { Tris/HCl, pH } 7.5 & 10 \mathrm{mM} \\ \text { EDTA } & 2 \mathrm{mM} \\ \mathrm{NaCl} & 500 \mathrm{mM}\end{array}$

\subsubsection{Detection}

The slides were incubated for $1 \mathrm{~min}$ at room temperature in $1 \mathrm{x}$ PBS (stirring). At this stage, the slides could be kept in $1 \times$ PBS at $4^{\circ} \mathrm{C}$ overnight. The slides were prepared for the detection reaction by incubation for $45 \mathrm{~min}$ in 1\% blocking reagent at room temperature (stirring). This was followed by an incubation in TNT-BSA for $45 \mathrm{~min}$ (stirring). For the detection of digoxigenine-labelled RNA, an anti-Dig-antibody solution was prepared. The slides were put in a plastic box with wet paper towels, and 450-500 $\mu 1$ antibody solution were pipetted onto each slide. The box was closed, and the slides were incubated in darkness for 2 $\mathrm{h}$ at room temperature.

After incubation with the anti-Dig-antibody, the slides were washed in TNT-BSA four times for 15 min each (stirring) and for 10 min in detection buffer (stirring). For the inhibition of endogenous phosphatases, another 5 min incubation was performed in detection buffer containing $1 \mathrm{mM}$ levamisole (stirring). After that, every slide was dipped in a beaker with detection buffer to make sure that all traces of Triton X-100 were removed. For the detection reaction, the slides were put in a plastic box with wet paper towels, and $150 \mu 1$ freshly prepared detection solution was pipetted onto each slide. Cover slips were put on the slides, and the slides were incubated for several hours or overnight in a closed moisture chamber sealed with tape.

The coloration of sense control slides was checked regularly during this incubation. When sense control slides started coloring, or when antisense slides showed enough coloring, 
the reaction was stopped in $1 \mathrm{x}$ PBS containing $20 \mathrm{mM}$ EDTA. The slides were kept in this solution in the dark before mounting.

For the mounting, the tissue was dehydrated in a graded ethanol series $(10 \%, 30 \%$, $50 \%, 70 \%, 90 \%$ and twice $100 \%, 15 \mathrm{sec}$ each). After an incubation for at least $1 \mathrm{~min}$ in ethanol:xylene (1:1) and twice in 100\% xylene for at least $5 \mathrm{~min}$ each, the sections were mounted with Eukit (Kindler, Freiburg, Germany). Several drops of Eukit were pipetted onto the xylene-wet slides, the cover slips were dipped in xylene and then placed on the slides, and the slides were left under the fume hood over night for the evaporation of xylene and the hardening of the resin. Then, photographs could be taken under a microscope.

Blocking reagent $(200 \mathrm{ml})$

Blocking reagent (Roche Molecular Biochemicals, Mannheim, Germany) $\quad$ 1\% (w/v)

Tris/HCl pH 7.5 $100 \mathrm{mM}$

$\mathrm{NaCl}$

$50 \mathrm{mM}$

stir for at least $1 \mathrm{~h}$ before use

\section{TNT-BSA}

Tris/HCl pH 7.5

$\mathrm{NaCl}$

$150 \mathrm{mM}$

autoclave, then add

Triton X-100

BSA

\section{Anti-dig-antibody}

dilute 1:1250 in TNT-BSA

preadsorb for at least $30 \mathrm{~min}$ before use

\section{Detection buffer}

$$
\begin{array}{ll}
\text { Tris/HCl pH } 9.5 & 100 \mathrm{mM} \\
\mathrm{NaCl} & 100 \mathrm{mM} \\
\mathrm{MgCl}_{2} & 50 \mathrm{mM}
\end{array}
$$

\section{Detection solution (for 10 slides)}

$5 \mathrm{ml}$ detection buffer

$5 \mu 1100 \mathrm{mM}$ levamisole

$22.5 \mu 1100 \mathrm{mg} / \mathrm{ml}$ NBT dissolved in DMF: $\mathrm{H}_{2} \mathrm{O}=7: 3$ (= 4-nitro-blue tetrazolium chloride, Roche Molecular Biochemicals, Mannheim, Germany)

$16.5 \mu 150 \mathrm{mg} / \mathrm{ml}$ BCIP dissolved in DMF (= 5-bromo-4 chloro-3-indoyl phosphate, Roche Molecular Biochemicals, Mannheim, Germany) 


\section{Stop solution}

$1 \times$ PBS

add EDTA to a final concentration of $20 \mathrm{mM}$

\subsection{DNA sequencing}

The sequencing of DNA was based on the method of Sanger et al. (1977) with some modifications. For sequencing, the ABI PRISMs Rhodamine Terminator Cycle sequencing Ready Reaction Kit was used (Perkin Elmer Applied Biosystems, Weiterstadt, Germany). The kit contains rhodamine derivatives of di-desoxynucleotides which differ in their emission and absorption spectra depending on the ddNTP. The rhodamine-labelled ddNTPs were incorporated into the synthetized DNA during elongation of DNA chains in a sequence-PCR. The reaction mixture contained:

$\begin{array}{ll}\text { Terminator Ready Reaction Mix } & 2 \mu \mathrm{l} \\ \text { plasmid DNA } & 200-300 \mathrm{ng} \\ \text { primer } & 8 \mathrm{pmol} \\ \mathrm{dd}_{2} \mathrm{O} \text { ad } & 10 \mu \mathrm{l}\end{array}$

For the sequencing, the primers corresponding to sequences present in the vector (T7, T3, for (M13 forward primer), rev (M13 reverse primer)) or gene-specific primers (Table 2.2) were used. The following program was used for sequence-PCR:

$\begin{array}{ll}96^{\circ} \mathrm{C} & 10 \mathrm{sec} \\ 50^{\circ} \mathrm{C} & 5 \mathrm{sec} \\ 60^{\circ} \mathrm{C} & 4 \mathrm{~min}\end{array}$

This cycle was repeated 25 times. After the PCR, the free rhodamine-labelled ddNTPs were removed by an ethanol precipitation of DNA as follows. $1 \mu \mathrm{Na}$ acetate/EDTA buffer $(1.5 \mathrm{M} \mathrm{Na}$ acetate $+250 \mathrm{mM}$ EDTA, $\mathrm{pH}>8)$ and $41 \mu \mathrm{l}$ of $96 \%$ ethanol were added to $10 \mu \mathrm{l}$ reaction mixture. The end concentration of ethanol in the mixture was $75 \%$. The samples were incubated on ice for 15-20 min and centrifuged (13 $000 \mathrm{rpm}$ ) for $15 \mathrm{~min}$ at room temperature. The supernatant was immediately removed quantitatively, and the pellets were washed with $75 \%$ ethanol (10 min centrifugation at $13000 \mathrm{rpm}$ ). The pellets were dried for $1 \mathrm{~min}$ at $90^{\circ} \mathrm{C}$, resuspended in $17 \mu 1$ Template Suppression Reagent (Perkin Elmer Applied Biosystems, Weiterstadt, Germany) and denatured at $95^{\circ} \mathrm{C}$ for $2 \mathrm{~min}$. The samples were kept on ice until sequencing in a ABI PRISM 310 Genetic Analyser (Perkin Elmer Life Sciences Ltd, Cambridge, UK). 
To obtain the sequences of the cDNA and promoter of AmSTS, the corresponding plasmids and the deduced primers (Table 2.2) were sent to SEQLAB Sequence Laboratories Göttingen GmbH (Göttingen, Germany).

\subsection{DNA and amino acid sequence analysis}

Amino acid and nucleotide sequences of known cDNAs, proteins and vectors were obtained from Genbank of National Center for Biotechnology Information (Altschul et al., 1990; http://www.ncbi.nlm.nih.gov). For alignment of sequences, the programs of the Wisconsin Package from Genetics Computer Group (GCG; Madison, WI., USA) were used which were available through the Gesellschaft für wissenschaftliche Datenverarbeitung Göttingen (GWDG). The programs seqed, map, bestfit, lineup, assemble, peptidesort and translate were used.

Table 2.2. Primers used for sequencing.

\begin{tabular}{|c|c|c|}
\hline Primers & Sequence $\left(5^{\prime} \rightarrow 3^{\prime}\right)$ & Used for \\
\hline$T 7$ & TAATACGACTCAATATAGG & \multirow{4}{*}{$\begin{array}{l}\text { sequencing of the ends of } \\
\text { PCR products cloned in } \\
\text { pGEM } \AA-T \text { Easy or } \\
\text { pBluescript }{ }^{\circledR} \mathrm{IIKS}^{+}\end{array}$} \\
\hline$T 3$ & TAACCCTCACTAAAGGGA & \\
\hline for & GTAAAACGACGGCCAGT & \\
\hline rev & AGCGGATAACAATTTCACACAGGA & \\
\hline pmr5seq3 & ATGGCATAAAGGAAGAAGAATGG & \multirow{6}{*}{$\begin{array}{l}\text { SEQLAB sequencing of the } \\
\text { AmSTS promoter (both } \\
\text { directions) }\end{array}$} \\
\hline pmr3seq3 & ACTTGCATGGTGCATGTAAGC & \\
\hline pmr5seq2 & GTTTGGTCGAGCTCAATTGG & \\
\hline pmr3seq2 & CAATTTGTGAAGTTAAGATTAGTAGG & \\
\hline pmr5seql & TGATGCTTACATGCACCATGC & \\
\hline pmr3seq1 & GGGAAAACAAACCACTAGTTGG & \\
\hline FLC5seq1 & CAACTCTTTCGAGCTCCTCGACG & \multirow{12}{*}{$\begin{array}{l}\text { SEQLAB sequencing of the } \\
\text { full length cDNA of } A m S T S \\
\text { (both directions) }\end{array}$} \\
\hline FLC3seq1 & TAGTACAAGACTTATTTCAAGC & \\
\hline FLCs 5 seq 2 & GATAACGACCCGAATGAGGATGC & \\
\hline FLCs 3 seq 2 & GAGAGCAAAATGGATGCACTTGG & \\
\hline FLCs 5 seq 3 & GAGTGGGTGATGACTTTGG & \\
\hline FLCs 3 seq 3 & TCCACCGAACATTTGATCC & \\
\hline$F L C 3$ seq 3 & TTTCCAGCATGCAGCAATGC & \\
\hline FLCs 5 seq 4 & TCAAGGTCTGGTGTACAACG & \\
\hline FLC3seq4 & GACCACCAGGTTTTGAACC & \\
\hline sts 3 seq3 & ATCCTTCGTAAACGCTTTCATCC & \\
\hline sts $3 \operatorname{seq} 5$ & CAGAATCGGGACATTTTTCACG & \\
\hline sts 5 seq 3 & AGGCTGAGAAACTATCCTTGG & \\
\hline
\end{tabular}




\section{RESULTS}

\subsection{Compartmentation of phloem-translocated carbohydrates in leaves and within mesophyll cells in Alonsoa meridionalis and Asarina barclaiana}

\subsubsection{Leaves of Alonsoa and Asarina contain different types of soluble carbohydrates}

HPLC analysis (2.8.1) was used to study the composition of soluble carbohydrates in the leaf extracts of Asarina and Alonsoa. The results showed that the monosaccharides glucose and fructose were present in significant amounts in leaf extracts of Asarina and Alonsoa (Table 3.1). Galactose was also found in both plants. Sucrose was the only disaccharide detected on HPLC chromatograms for Asarina and Alonsoa. Two of the raffinose family oligosaccharides, raffinose and stachyose, as well as the precursor of their synthesis, galactinol, and the cyclitol myo-inositol, were found in both plants. No significant amounts of other soluble carbohydrates were detected by HPLC in Alonsoa. In Asarina, a sugar alcohol, mannitol, was found and also an iridoid glycoside, antirrhinoside, the structure of which was confirmed by NMR (2.3.2.2; Figure 2.1). Antirrhinoside made up nearly half of the total content of soluble carbohydrates of Asarina leaves.

The opportunity to perform GC-MS analysis of the same samples was kindly provided by Dr. T. Peterbauer, University of Vienna, Austria. The mass spectrometric analysis confirmed the results of the HPLC and also detected four more unknown carbohydrates (Figure 3.1). In Asarina leaves, one of them was found in the disaccharide region of the spectrum (Figure 3.1 A). In the leaves of Alonsoa, one unknown carbohydrate was found in the monosaccharide region and three others in disaccharide region (Figure 3.1 B). However, these unknown coumpounds were minor components of the leaf extracts of both plants. No 
galactosylated compounds other than galactinol, raffinose and stachyose were detected by GC-MS.

The subcellular compartmentation of soluble carbohydrates was further studied in mesophyll cells of Alonsoa and Asarina by means of the non-aqueous fractionation technique.

Table 3.1. Sugars, sugar alcohols and oligosaccharides in the leaves of Alonsoa and Asarina ( $\mu \mathrm{mol} / \mathrm{g}$ fresh weight). Listed are mean values from four independent measurements $\pm \mathrm{SD}$.

\begin{tabular}{c|c|c}
\hline & Asarina & Alonsoa \\
\hline myo-Inositol & $2.0 \pm 1.0$ & $3.4 \pm 0.5$ \\
Galactinol & $1.4 \pm 0.5$ & $3.5 \pm 1.1$ \\
Antirrhinoside & $61.4 \pm 10.6$ & not detected \\
Mannitol & $10.7 \pm 0.9$ & not detected \\
Glucose & $16.5 \pm 2.6$ & $7.9 \pm 4.0$ \\
Fructose & $9.2 \pm 2.7$ & $9.7 \pm 4.7$ \\
Galactose & $0.6 \pm 0.3$ & $1.5 \pm 0.5$ \\
Sucrose & $14.5 \pm 2.8$ & $6.8 \pm 1.0$ \\
Raffinose & $0.3 \pm 0.2$ & $1.0 \pm 0.5$ \\
Stachyose & $0.7 \pm 0.2$ & $1.1 \pm 0.3$ \\
\hline
\end{tabular}

\subsubsection{Subcellular compartmentation of carbohydrates}

\subsubsection{Distribution of carbohydrates between the subcellular compartments of mesophyll cells}

The separation of the leaf tissue into fractions enriched with either chloroplastic, cytoplasmic or vacuolar content was achieved by a centrifugation in an exponential density gradient as described in 2.6. The liquid constituents of the gradient were water-insoluble (heptane and tetrachloroethylene). This prevented the redistribution of the water-soluble metabolites and enzymes during the separation of the plant material within the gradient and therefore made it possible to attribute the amounts of metabolites to the subcellular compartments determined via the activities of specific marker enzymes (Gerhardt and Heldt, 1984; 2.6). The non-aqueous fractionation method does not take into account the tissue heterogeneity of the leaf. That means that subcellular concentrations in the mesophyll cells are calculated as if all the sugars were located exclusively within mesophyll cells. Therefore, the values obtained by using non-aqueous fractionation represent the estimations of the highest possible concentrations in each compartment. 


\section{Asarina barclaiana}

A

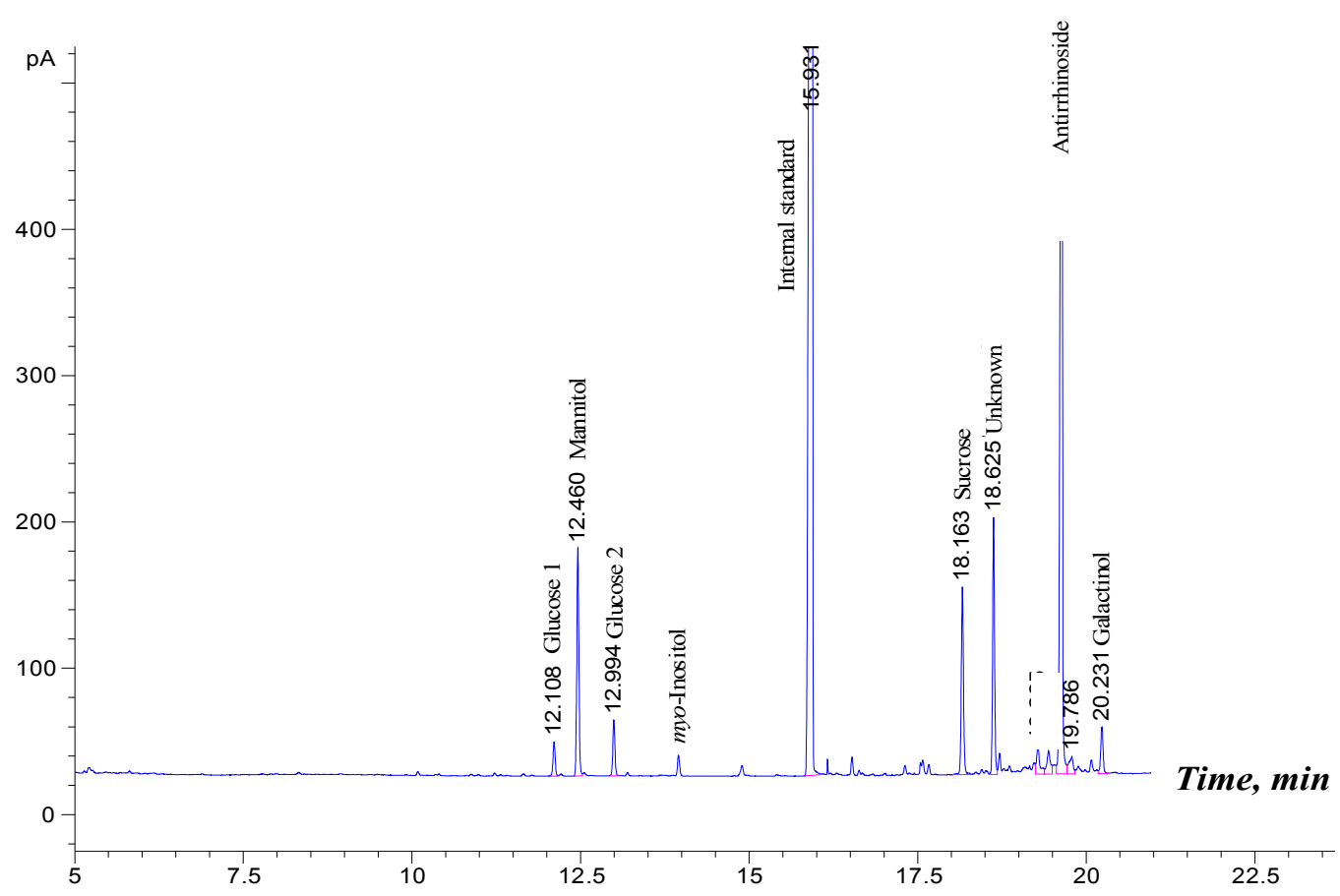

Figure 3.1 A. GC-MS spectrum of leaf extracts from Asarina. The sample also contained traces of raffinose and stachyose (not shown).

B

Alonsoa meridionalis

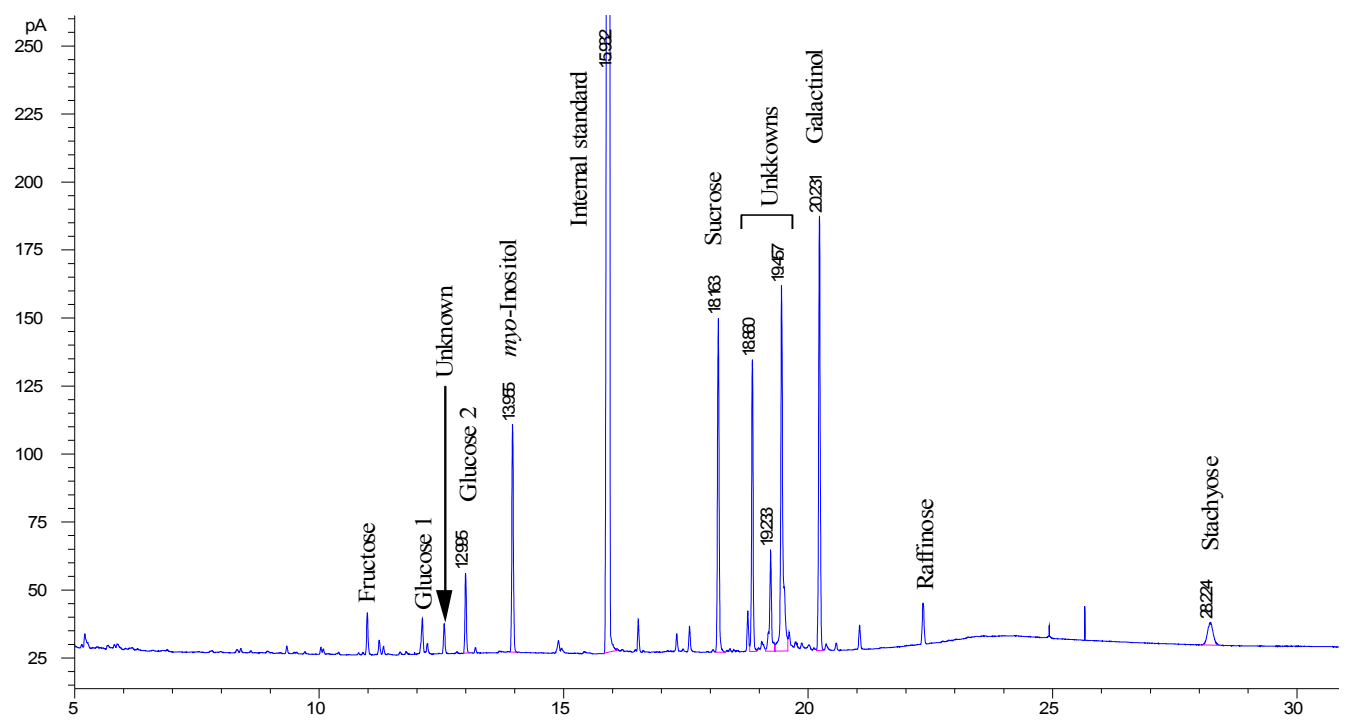

Figure 3.1 B. GC-MS spectrum of leaf extracts from Alonsoa.

Time, $\min$

The gradient fractionations of the powder of Alonsoa and Asarina leaves resulted in the enrichment of each gradient fraction with the contents of a particular subcellular compartment. The enzymes glyceraldehyde-3-phosphate dehydrogenase (GAPDH), 
phosphoenolpyruvate carboxylase (PEPCx) and $\alpha$-mannosidase were chosen as marker enzymes for chloroplastic, cytoplasmic and vacuolar compartments, respectively (2.6.3). In each fractionation, a good resolution between subcellular compartments can only be achieved if the ratios of activities of the marker enzymes are different for each fraction. A typical

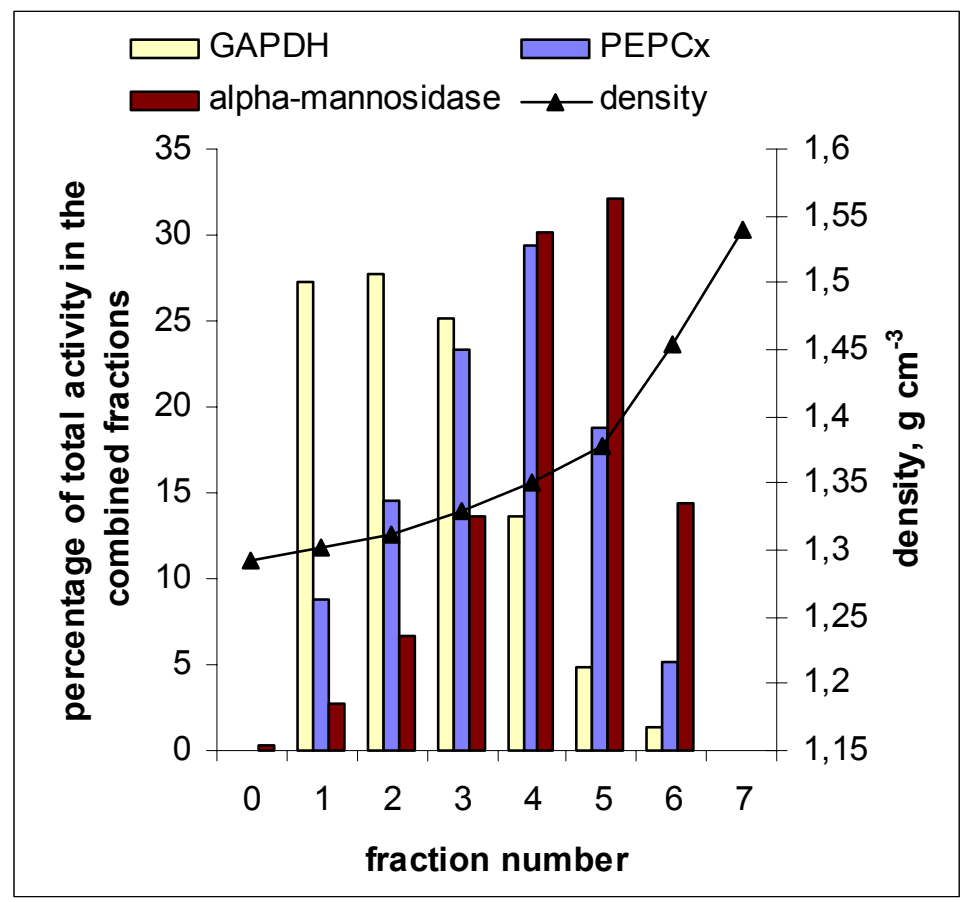

Figure 3.2. Distribution of the activities of marker enzymes between density gradient fractions by one of the fractionations for Asarina barclaiana. Marker enzymes are: GAPDH for chloroplasts, PEPCx for cytosol and $\alpha$ mannosidase for vacuoles.

example is shown in Figure 3.2.

Out of ten gradient fractionations performed for Asarina, four resulted in a good separation of marker enzymes and were used for the determination of metabolites in the fractions. For Alonsoa, five fractionations were selected from a total of eight fractionations performed. The distributions of sugars between chloroplastic, cytoplasmic and vacuolar compartments are shown in Table 3.2.

The percentages summarized in Table 3.2 showed that in Asarina glucose and fructose were entirely confined to the vacuoles. The same was probably true for galactose as well, but since Q values (the measure for deviation of predicted results from the measured ones; 2.6.5) were too high for this sugar, the calculated values are not reliable (data not shown). Antirrhinoside also was mostly present in the vacuoles but a significant part (10\%) was distributed between chloroplasts and cytoplasm.

It was not possible to show that raffinose and stachyose are confined to certain compartments in Asarina because their concentrations in whole leaves were too low (Table 3.1). After the fractionation procedure, the trace amounts of raffinose and stachyose could only be detected in the largest fractions, namely the vacuole-enriched fractions (data not 
shown). Also, the concentration of galactinol was reduced to an undetectable level after fractionation (data not shown).

myo-Inositol and mannitol were present in all three compartments but largest amounts were found in chloroplasts and cytoplasm. Sucrose was also distributed between all three compartments with the highest amounts in vacuoles and cytoplasm.

In Alonsoa, the subcellular distribution of metabolites was very similar to that in Asarina (Table 3.2). Glucose and fructose were located in the vacuoles. Sucrose was distributed between all compartments with a slight predominance in cytoplasm. In Alonsoa, the content of galactinol was higher than in Asarina, which made it possible to determine its subcellular distribution. It was mostly found in the vacuoles. The amounts of raffinose and stachyose in gradient fractions were, however, still too low to obtain a reliable values on the subcellular distributions of these sugars (data not shown).

Table 3.2. Distribution of sugars among subcellular compartments of mesophyll cells from Asarina barclaiana and Alonsoa meridionalis leaves as determined by non-aqueous fractionation (percentages of total sugar content).

Ch: chloroplasts, Cyt: cytoplasm, Vac: vacuoles.

\begin{tabular}{c|c|c|c|c|c|c}
\hline \multirow{2}{*}{} & \multicolumn{3}{|c|}{ Asarina barclaiana } & \multicolumn{3}{|c}{ Alonsoa meridionalis } \\
\cline { 2 - 7 } & $\mathrm{Ch}$ & $\mathrm{Cyt}$ & $\mathrm{Vac}$ & $\mathrm{Ch}$ & $\mathrm{Cyt}$ & $\mathrm{Vac}$ \\
\hline myo-Inositol & 53 & 24 & 23 & 81 & 13 & 6 \\
Galactinol & \multicolumn{3}{|c|}{ not detected } & 2 & 2 & 96 \\
Antirrhinoside & 4 & 6 & 90 & \multicolumn{4}{|c|}{ not detected } \\
Mannitol & 36 & 34 & 30 & \multicolumn{3}{|c|}{ not detected } \\
Glucose & 1 & 1 & 98 & 1 & 1 & 98 \\
Fructose & 1 & 1 & 98 & 1 & 1 & 98 \\
Sucrose & 14 & 35 & 51 & 21 & 44 & 35 \\
\hline
\end{tabular}

\subsubsection{Estimation of the volumes of subcellular compartments of mesophyll cells in Alonsoa and Asarina}

The estimation of subcellular concentrations from the distribution pattern of the sugars is only possible if the volumes of the subcellular compartments are known. Therefore, an estimation of subcellular volumes of mesophyll cells in Asarina and Alonsoa was performed. To this aim, the partial volumes of chloroplasts, vacuoles and cytoplasm (including cytosol, nucleus, peroxisomes and mitochondria) were calculated from electron micrographs of mesophyll cells of Alonsoa and Asarina (2.13). 
In Table 3.3, these partial volumes are listed and compared to values found in other plants. The relative volumes of the vacuolar, chloroplastic and cytoplasmic compartments of mesophyll cells made up $72 \%, 20 \%$ and $8 \%$ in Alonsoa and $70 \%, 23 \%$ and $7 \%$ in Asarina respectively. These values correspond well to the volumes previously determined in barley, spinach and potato (Winter et al., 1993, Leidreiter et al., 1995; Table 3.3)

Table 3.3. Relative volumes (\%) of the subcellular compartments of the total volume of mesophyll cells from Asarina barclaiana and Alonsoa meridionalis as compared with previously determined volumes occupied by subcellular compartments in leaves of potato, spinach, and barley. The total volume of a mesophyll cell is defined as $100 \%$. Cytoplasm is defined as cytosol, peroxisomes, nucleus and mitochondria.

\begin{tabular}{l|c|c|c}
\hline & Chloroplast, \% & Cytoplasm, \% & Vacuole, \% \\
\hline Asarina barclaiana & 23 & 7 & 70 \\
Alonsoa meridionalis & 20 & 8 & 72 \\
Solanum tuberosum* & 18 & 6 & 76 \\
Spinacea oleracea** & 16 & 5 & 73 \\
Hordeum vulgare*** $^{*}$ & 19 & 8 & 79 \\
\hline
\end{tabular}

* Data from Leidreiter et al., 1995; ** Winter et al., 1994; *** Winter et al., 1993

For the estimation of the real volumes of the compartments on the basis of these relative values, the volume of mesophyll cells has to be known. Such morphometric data are available for three plant species: the dicots potato and spinach and the monocot barley (Leidreiter et al., 1995; Winter et al., 1993, 1994). These volumes are presented in Table 3.4.

Table 3.4. Real $\left(\mu \mathrm{mg}^{-1} \mathrm{Chl}\right)$ and partial volumes of mesophyll, epidermis, apoplast and conducting tissue in the leaves of potato, spinach and barley. Data from Winter et al., 1993 (barley), Winter et al., 1994 (spinach) and Leidreiter et al., 1995 (potato).

\begin{tabular}{l|c|c|c}
\hline \multicolumn{1}{c|}{ Aqueous volume } & Potato & Spinach & Barley \\
\hline Leaf & $472 \pm 14100 \%$ & $810 \pm 119100 \%$ & $698 \pm 70100 \%$ \\
Epidermis & $74 \pm 1714 \%$ & $36 \pm 34 \%$ & $244 \pm 3635 \%$ \\
Mesophyll & $394 \pm 2375 \%$ & $688 \pm 1185 \%$ & $379 \pm 2754 \%$ \\
Apoplast & $21 \pm 34 \%$ & $60 \pm 227 \%$ & $41 \pm 46 \%$ \\
Conducting tissue & $30 \pm 36 \%$ & $12 \pm 32 \%$ & $55 \pm 67 \%$ \\
\hline
\end{tabular}

In these three plants, mesophyll cells occupied $54 \%-85 \%$ of the total leaf aqueous volume. Because the leaf anatomy of the monocot barley differs significantly from the typical 
dicot leaf structure, it is reasonable to assume that in the dicots Asarina and Alonsoa the partial volume occupied by the mesophyll at the whole leaf will be close to that of potato and spinach. If the values for potato are taken as the basis, then in Asarina leaves with an average water content of $498 \mu \mathrm{mg}^{-1} \mathrm{Chl}$ the volume of the mesophyll can be estimated as $374 \mu \mathrm{mg}^{-1}$ $\mathrm{Chl}$ and in Alonsoa with an average water content of $394 \mu \mathrm{mg}^{-1} \mathrm{Chl}$ the corresponding volume can be estimated as $296 \mu \mathrm{mg}^{-1} \mathrm{Chl}$. Then, the volumes of the stromal, cytoplasmic and vacuolar compartment of mesophyll cells would correspond to 85,26 and $261 \mu \mathrm{mg}^{-1} \mathrm{Chl}$ for Asarina and 59, 24 and $213 \mu \mathrm{mg}^{-1} \mathrm{Chl}$ for Alonsoa.

However, for the calculation of subcellular concentrations on the basis of these volumes, a correction has to be made which takes the volume of epidermis into account. This is because epidermal cells consist of up to $99 \%$ vacuoles (Winter, 1993) and thus, by fractionation of the whole leaf tissue, their sugar contents will contribute to the vacuolar fraction of the mesophyll cells and lead to somewhat overestimated vacuolar concentrations. This correction can be made by addition of the volumes of epidermis to the volumes calculated for mesophyll vacuoles. These corrected values for the volumes of mesophyll vacuoles were $331 \mu \mathrm{l} \mathrm{mg}^{-1} \mathrm{Chl}$ in Asarina and $268 \mu \mathrm{l} \mathrm{mg}^{-1} \mathrm{Chl}$ in Alonsoa. These values were taken for the calculation of vacuolar concentrations in mesophyll cells of these two species, respectively.

\subsubsection{Sugar contents and concentrations in subcellular compartments of mesophyll cells in Alonsoa and Asarina}

The subcellular concentrations of sugars in Alonsoa and Asarina based on estimated volumes of subcellular compartments (3.1.2.2) are shown in Table 3.5. The sugar contents of each subcellular compartment showed that vacuoles contain the highest amounts of soluble carbohydrates (82\% in Asarina and 69\% in Alonsoa), while cytoplasm and chloroplasts contain much less. However, because of the very different volumes of these compartments, for most sugars the highest concentrations were found in the cytoplasm. In the vacuoles, hexose levels were the highest in Alonsoa. In Asarina, the highest vacuolar concentration was that of antirrhinoside followed by glucose and sucrose.

In the cytoplasm, the sucrose level was the highest in Alonsoa, followed by myoinositol. In Asarina, the highest cytoplasmic level was that of antirrhinoside, followed by mannitol, sucrose and myo-inositol. In Alonsoa chloroplasts, myo-inositol was dominating, and the second concentrated sugar was sucrose. In Asarina chloroplasts, the calculated concentrations of mannitol and antirrhinoside were the highest, followed by myo-inositol. 
A comparison of subcellular concentrations with those in the phloem sap is shown in Figure 3.3. Neither of the subcellular compartments mirrored the phloem with respect to the types of sugars and their concentration ratios. Nevertheless, all metabolites that were transported in the phloem, such as sucrose, antirrhinoside and mannitol were present in the cytoplasm at high concentrations. However, the opposite was not true. For instance, in Alonsoa only trace amounts of myo-inositol were present in the phloem sap although its cytoplasmic concentration was $26 \mathrm{mM}$, surpassed only by sucrose.

Table 3.5. Sugar contents (nmol $\mathrm{mg}^{-1} \mathrm{Chl}$ ) and subcellular concentrations $(\mathrm{mM})$ in the chloroplastic, cytoplasmic and vacuolar compartments of mesophyll cells from Asarina barclaiana and Alonsoa meridionalis.

\begin{tabular}{|c|c|c|c|c|c|c|}
\hline & \multicolumn{2}{|l|}{ Stroma } & \multicolumn{2}{|c|}{ Cytoplasm } & \multicolumn{2}{|l|}{ Vacuole } \\
\hline & nmol mg ${ }^{-1} \mathrm{Chl}$ & $\mathrm{mM}$ & nmol mg ${ }^{-1} \mathrm{Chl}$ & $\mathrm{mM}$ & nmol mg ${ }^{-1} \mathrm{Chl}$ & $\mathrm{mM}$ \\
\hline Asarina barclaiana & & & & & & \\
\hline myo-inositol & 1260 & 15 & 570 & 22 & 546 & 1.5 \\
\hline mannitol & 2080 & 24 & 2400 & 92 & 1250 & 4 \\
\hline antirrhinoside & 2128 & 25 & 3193 & 123 & 47903 & 144 \\
\hline glucose & 40 & 0.5 & 86 & 3 & 5680 & 17 \\
\hline fructose & 48 & 0.5 & 48 & 2 & 1676 & 5 \\
\hline sucrose & 588 & 7 & 1112 & 43 & 3200 & 9 \\
\hline total per compartment & $\begin{array}{l}6144 \\
(8 \%)\end{array}$ & 72 & $\begin{array}{l}7409 \\
(\mathbf{1 0 \%})\end{array}$ & 285 & $\begin{array}{l}60255 \\
(\mathbf{8 2 \%})\end{array}$ & 180 \\
\hline $\begin{array}{c}\text { Alonsoa } \\
\text { meridionalis }\end{array}$ & & & & & & \\
\hline myo-inositol & 3821 & 65 & 613 & 26 & 282 & 0.8 \\
\hline galactinol & 32 & 0.5 & 32 & 1 & 1570 & 5.5 \\
\hline glucose & 52 & 1 & 52 & 2 & 5120 & 19 \\
\hline fructose & 65 & 2 & 65 & 3 & 6320 & 23 \\
\hline sucrose & 818 & 14 & 1715 & 71 & 1365 & 5 \\
\hline $\begin{array}{l}\text { raffinose and } \\
\text { stachyose }\end{array}$ & 4 & 0 & 70 & 3 & 1030 & 3 \\
\hline total per compartment & $\begin{array}{l}4792 \\
(\mathbf{2 0 \%})\end{array}$ & 82 & $\begin{array}{l}2547 \\
(11 \%)\end{array}$ & 106 & $\begin{array}{l}15687 \\
(\mathbf{6 9 \%})\end{array}$ & 56 \\
\hline
\end{tabular}



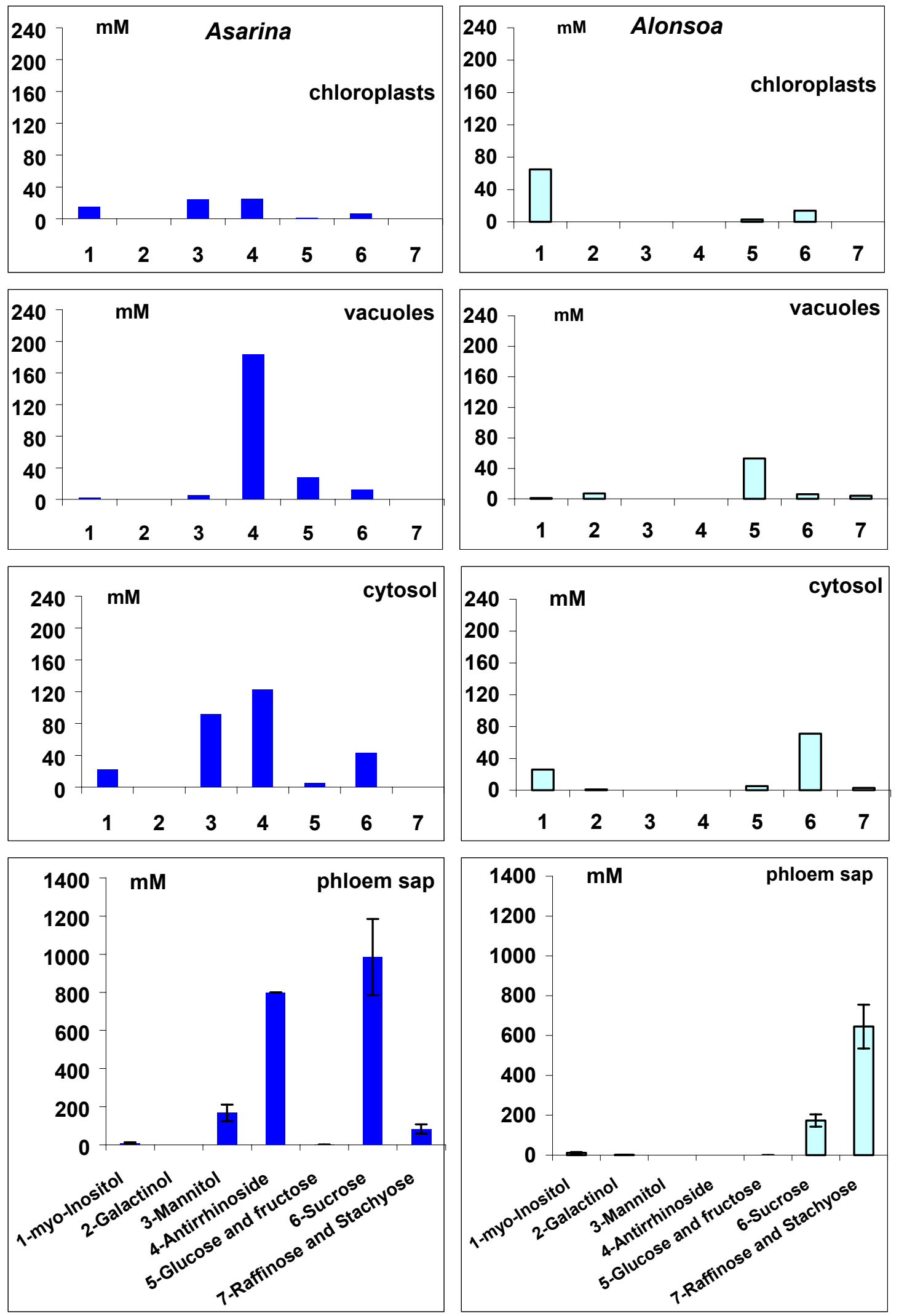

Figure 3.3. Sugar concentrations $(\mathrm{mM})$ in subcellular compartments of mesophyll cells and in phloem sap of Asarina barclaiana (left column) and Alonsoa meridionalis (right column). Data for phloem concentrations are taken from Table 1.1. 1-myo-inositol, 2-galactinol, 3-mannitol, 4-antirrhinoside, 5-glucose + fructose, 6-sucrose, 7-raffinose + stachyose 


\subsubsection{Concentrations of sucrose, glucose and fructose in mesophyll cells measured by single cell sampling technique agree well with the non-aqueous fractionation data}

As already mentioned, the disadvantage of the non-aqueous fractionation method is that it does not take into account the tissue heterogeneity of the leaf. Subcellular concentrations are calculated assuming all the sugars in the leaf to be located exclusively within mesophyll cells, ignoring the fact that some of these sugars are actually located outside of these cells. This assumption can lead to an overestimation of subcellular concentrations because also phloem, epidermis and apoplast contain sugars. Another source of error could be the fact that the partial volumes of leaf tissues in leaves of Asarina and Alonsoa were not determined by morphometry, but estimated from those in potato assuming that the differences between these dicot species may not be significant.

Therefore, direct measurements of sugar concentrations in mesophyll cells of Alonsoa and Asarina leaves are necessary for the proper interpretation of non-aqueous fractionation results. A technique that directly measures the concentrations of metabolites in a single cell is the so-called single cell sampling. It distinguishes between different types of leaf tissues. The single cell sampling technique does not distinguish between subcellular compartments, but results in metabolite concentrations close to those in the vacuole because the vacuole represents the overwhelming portion of a cell (Fricke et al., 1994a).

Before the measurements in the single cell samples from Alonsoa and Asarina were performed, the quantification method had to be calibrated using standards (2.10.3; Figure 3.4). Figure 3.4 shows the high reliability of the measurements in a concentration range between 2

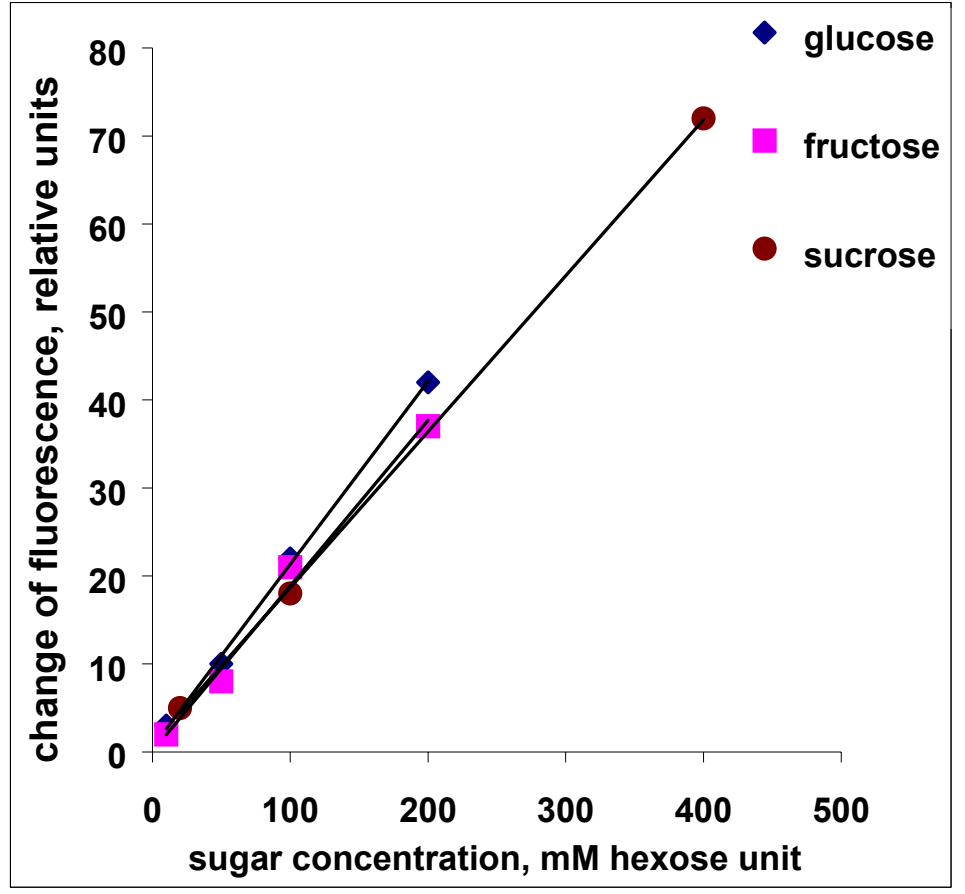

Figure 3.4. Calibration of the single cell sugar assay. The increase of fluorescense was measured against dark background in sets of droplets containing solutions of glucose, fructose or sucrose of known concentration using self-made constriction pipettes of unknown volume. The same pipettes were then used for measurements of sugar concentrations in the single cell samples obtained from epidermis and mesophyll of leaves of Asarina and Alonsoa. The concentrations were calculated using the shown calibration curves. 
and $200 \mathrm{mM}$. Mesophyll cells of Alonsoa and Asarina were sampled in the morning at 10:00 after 3 hours of light and the contents of glucose, fructose and sucrose were determined. The results are compared with the values calculated on the basis of non-aqueous fractionation (Table 3.6). Both methods showed a good agreement not only for hexoses which are entirely vacuolar and do not occur in the phloem sap, but also for sucrose which is present at high concentrations in the phloem (Table 1.1). Hence, the values determined by single cell sampling supported the assumptions made for the calculation of subcellular concentrations in Alonsoa and Asarina by non-aqueous fractionation, and confirmed the results of the subcellular fractionation experiments.

\begin{tabular}{|l|c|c|c|}
\hline & $\begin{array}{c}\text { glucose } \\
(\mathbf{m M})\end{array}$ & $\begin{array}{c}\text { fructose } \\
(\mathbf{m M})\end{array}$ & $\begin{array}{c}\text { sucrose } \\
\text { (mM) }\end{array}$ \\
\hline $\begin{array}{l}\text { Asarina barclaiana } \\
\text { non-aqueous fractionation } \\
\text { single cell sampling }\end{array}$ & 17 & 5 & 9 \\
\hline $\begin{array}{l}\text { Alonsoa meridionalis } \\
\text { non-aqueous fractionation } \\
\text { single cell sampling }\end{array}$ & 9 & 23 & 5 \\
\hline
\end{tabular}

Table 3.6. Vacuolar concentrations (mM) of glucose, fructose and sucrose in mesophyll cells of Alonsoa and Asarina as estimated by non-aqueous fractionation and determined by single cell sampling. For single cell sampling, mean values of 5 independent measurements $\pm \mathrm{SD}$ are shown.

\subsubsection{Epidermal concentrations of sucrose and hexoses in Alonsoa and Asarina were similar to those in mesophyll cells}

The single cell sampling technique provides an opportunity to determine sugar concentrations not only in mesophyll cells but also in epidermal cells and thus to evaluate the role of the epidermis in carbon compartmentation in the leaves of Alonsoa and Asarina. The concentrations of glucose, fructose and sucrose in epidermal cells were compared with those in mesophyll cells in the morning (10:00) and in the evening (18:00) in plants receiving light from 7:00 to 23:00.

At both timepoints, the concentrations of glucose, fructose and sucrose in mesophyll did not differ sighnificantly from those in epidermis (Figure 3.5). To see whether this would be also the case when leaves were forced to accumulate sugars, the translocation from the leaves was blocked. To this aim, the leaves of Alonsoa and Asarina were detached from the plants and placed in continuous light for 24 hours while the petioles were kept in $2 \mathrm{mM} \mathrm{CaCl}_{2}$ solution to favour sealing of the phloem with callose. This caused an increase of the total sugar content of the leaves (3.1.6). Afterwards, the concentrations of sucrose and hexoses were measured in single cell samples from mesophyll and epidermis (Figure 3.6). 

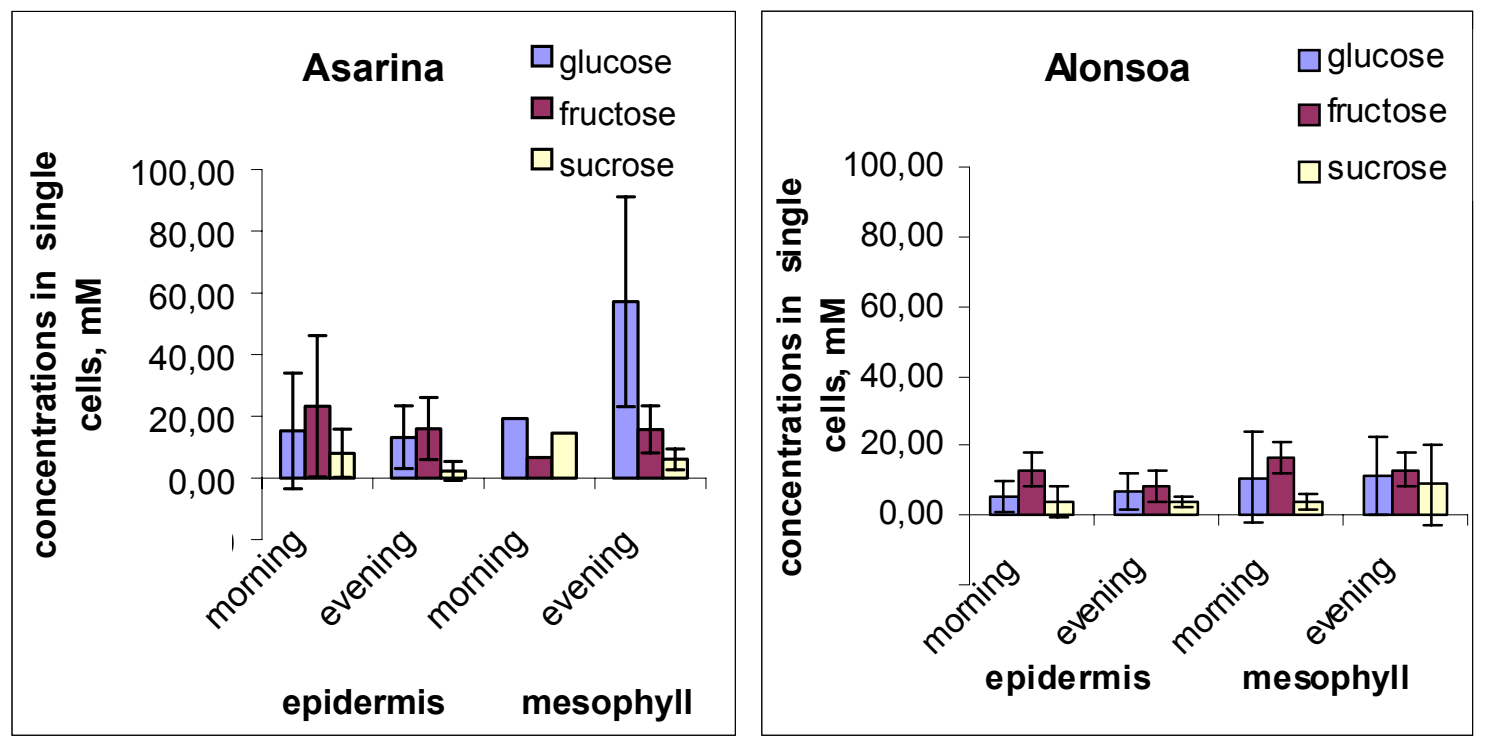

Figure 3.5. Sugar levels in single cell samples of epidermis and mesophyll cells of Asarina barclaiana and Alonsoa meridionalis after 3 hours of light ("morning") and after 11 hours of light ("evening"). Mean values of 5 independent measurements \pm SD are shown.
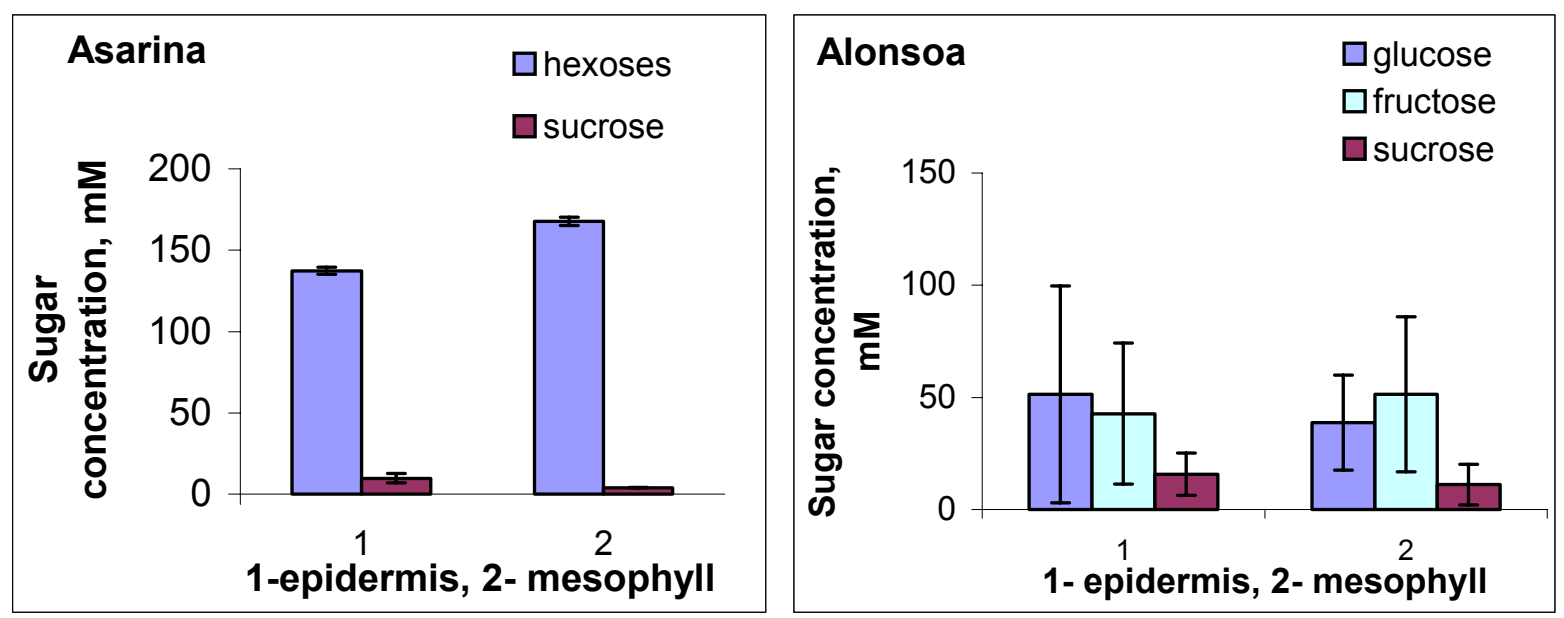

Figure 3.6. Sugar contents in mesophyll and epidermis cells sampled from the detached leaves of Alonsoa meridionalis and Asarina barclaiana after exposure of the leaves to continuous light (photon flux of $500 \mu \mathrm{mol} \mathrm{m} \mathrm{m}^{-2} \mathrm{~s}^{-1}$ ) during 24 hours. Mean values of 5 independent measurements \pm SD are shown.

The results showed that epidermal and mesophyll cells of both plants accumulated similar levels of soluble carbohydrates. In the epidermal cells of Alonsoa, hexose levels were five times higher and sucrose levels were three times higher than in control plants (,morning“ timepoint). In the mesophyll cells of Alonsoa, hexose and sucrose levels increased by a factor of three. In the epidermal cells of Asarina, hexose levels increased by a factor of 3.5 and sucrose levels by a factor of 1.5. In mesophyll cells of Asarina, a sixfold accumulation of hexoses was observed whereas sucrose levels did not increase significantly. The pronounced increase of cellular sugar concentrations not only in the mesophyll but also in the epidermis 
indicated that in Alonsoa and Asarina, the epidermis can serve as a transient reservoir for soluble carbohydrates.

\subsubsection{Soluble carbohydrates in Alonsoa and Asarina essentially contributed to the osmolality of the cytosol in mesophyll cells}

The osmolality of the whole leaf sap and of single cell samples taken from mesophyll and epidermis was determined for Alonsoa and Asarina (2.9, 2.10.2; Figure 3.7). For both plants, the values measured in the single cells were higher than those in the whole leaves. This situation has already been observed in several plant species and is supposed to be due to the dilution of the cellular content in whole leaf sap with water from other tissues like the xylem (Fricke et al., 1994b).

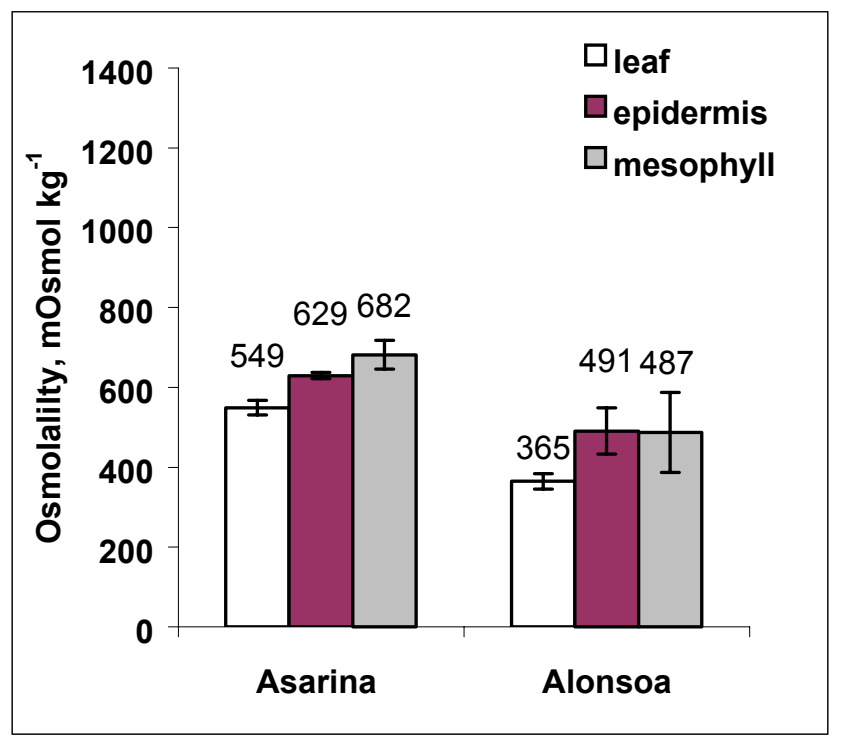

Figure 3.7. Osmolalities of leaf extracts and single cells of epidermis and mesophyll in Asarina barclaiana and Alonsoa meridionalis. Samples were taken from plants after a 3 hour light period. Mean values from 5 independent measurements $\pm \mathrm{SD}$ are shown.

As can be estimated from the data of Figures 3.5 and 3.7, glucose, fructose and sucrose in the single cell samples taken from epidermal cells only contributed $7 \%$ to the osmolality in Asarina and 5\% in Alonsoa. This means that in vacuoles of epidermal cells, other solutes accounted for the bulk osmolalities. These could be inorganic ions and organic acids (Fricke et al., 1994b) as well as those carbohydrates which were not analysed in the epidermal cells by single cell technique in these experiments, for instance, antirrhinoside in Asarina.

Water exchange between subcellular compartments is not limited in the cell. That means that the same osmotic pressure that was measured in single cell samples representing mostly vacuolar sap will be also found in the cytosol of these cells. From the data of Figure 3.7 and Table 3.5, the contribution of soluble carbohydrates to osmolality of subcellular compartments of mesophyll cells in Asarina and Alonsoa can be estimated (to calculate exact 
values, the osmolality coefficients are necessary which are not available for all carbohydrates). For vacuoles of mesophyll cells, total soluble carbohydrates without antirrhinoside accounted for 5\% of osmolality in Asarina, antirrhinoside alone for about $21 \%$. In Alonsoa, soluble carbohydrates accounted for $11 \%$ of vacuolar osmolality. In the cytosol, however, sugars without antirrhinoside accounted for about $26 \%$ osmolality in Asarina and antirrhinoside alone for another 18\%. In Alonsoa, sugars accounted for about 22\% osmolality. With the exception of antirrhinoside, the main osmotica in the cytosol of Asarina mesophyll cells were mannitol, sucrose and myo-inositol. In Alonsoa, these were sucrose and myoinositol.

In the whole leaves of Asarina, the sum of soluble carbohydrates without antirrhinoside contributed to about $10 \%$ of the osmolality of the whole leaf sap and antirrhinoside alone accounted for $11 \%$. In Alonsoa, total soluble carbohydrates made up $9.6 \%$ of the osmolality of whole leaf sap.

\subsubsection{Levels of phloem-translocated carbohydrates other than raffinose and stachyose increased in the leaves with blocked translocation}

The study of the subcellular compartmentation of phloem-translocated sugars within mesophyll cells of Asarina and Alonsoa has revealed that sucrose, antirrhinoside and mannitol in Asarina and sucrose in Alonsoa were present in the cytoplasmic, chloroplastic and vacuolar compartments. However, a re-compartmentation of metabolites within cells can take place under certain conditions. Excess amounts of soluble sugars can enter the vacuoles whose storage function allows the levels of sugars in the leaves to increase severalfold temporarily (Kaiser and Heber, 1984). Asarina and Alonsoa translocate several types of sugars in the phloem. In order to find out whether all these sugars will accumulate in the leaves when assimilate export is prevented, the following experiment was performed.

The leaves of Alonsoa and Asarina were detached from the plants and placed in continuous light (photon flux of $500 \mu \mathrm{mol} \mathrm{m} \mathrm{m}^{-1} \mathrm{~s}^{-1}$ ) while the petioles were kept in $2 \mathrm{mM}$ $\mathrm{CaCl}_{2}$ solution to favour the sealing of the phloem with callose. Sugar concentrations were determined in the leaves after 24 and 96 hours of exposure, respectively (Figure 3.8).

When translocation was blocked in Asarina leaves, the concentrations of the main transport carbohydrates, sucrose and antirrhinoside, increased. These carbohydrates contribute up to 48 and $39 \%$ of total transported carbon, respectively (calculated from Table 1.1). The increase was observed also for one minor transported component, mannitol, which accounted for 3\% of total transported carbon in Asarina. The concentration of other minor transported components, raffinose and stachyose, did not show a significant increase. Glucose and 

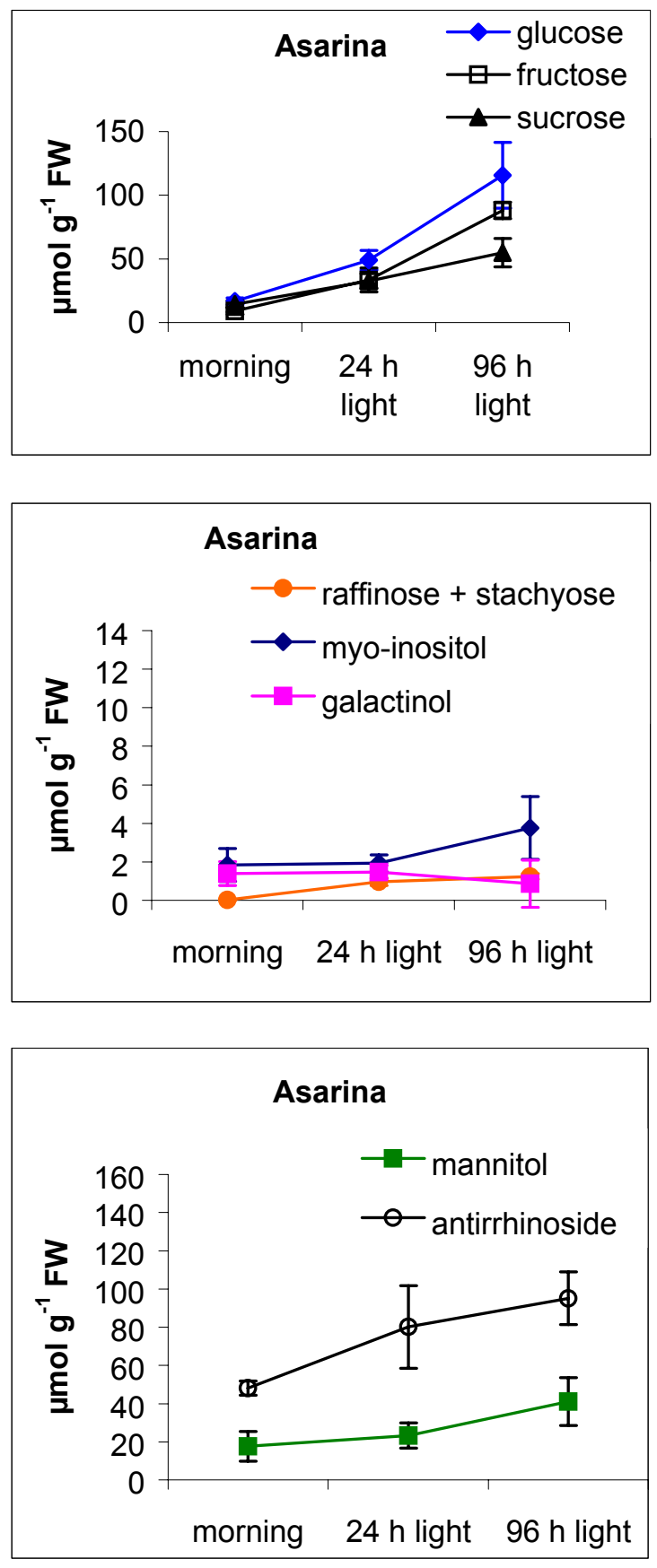
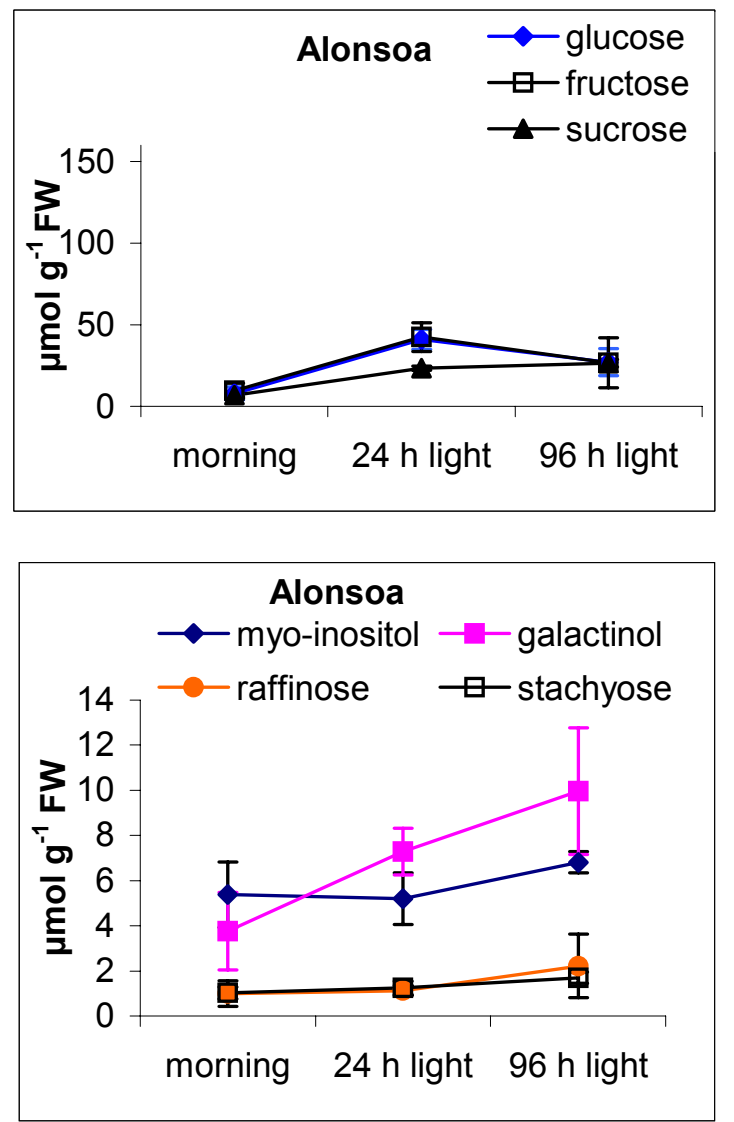

Figure 3.8. Sugar contents in the leaves of Asarina barclaiana (left column) and Alonsoa meridionalis (right column) at the beginning of the light period (after 3 hours of light, "morning") and after 24 and 96 hours exposure of detached leaves to continuous light.

fructose accumulated also, probably due to hydrolysis of sucrose by vacuolar invertase. The slight domination of glucose over fructose may be due to a partial hydrolysis of glucosyl from antirrhinoside during the accumulation of the latter in the vacuoles.

In Alonsoa, glucose, fructose, sucrose and galactinol accumulated in the leaves when phloem translocation was blocked. The contents of glucose and fructose were very similar which suggested their production by hydrolysis of sucrose by invertase. The main transport carbohydrates raffinose and stachyose which contribute $28 \%$ and $59 \%$, respectively, of total transported carbon, did not show significant accumulation. However, their precursor galactinol, and also a minor transported component, sucrose, (13\% of total transported 
carbon) accumulated when translocation was blocked. These results might suggest that the activity of galactinol synthase was not changed but the rate of the galactinol-consuming reactions catalysed by raffinose and stachyose synthases decreased in Alonsoa under blockage of translocation.

It was impossible to determine the subcellular localization of raffinose and stachyose in mesophyll cells, since their overall concentration was too low (3.1.2.1). One possible reason for this may be that raffinose and stachyose synthases are localized outside the mesophyll cells. According to the polymerization trap model (Turgeon, 1991), the most likely location for the synthesis of raffinose and stachyose would be within companion cells. This might also explain the lack of accumulation of raffinose and stachyose in leaves during translocation blockage, assuming that they cannot diffuse into mesophyll cells.

\subsection{Sugar concentrations in the apoplast of leaves in putative symplastic and apoplastic phloem loaders}

The participation of the apoplast in sugar transfer from mesophyll to phloem in plants with different companion cells can be studied by measurements of sugar levels in the apoplast. Apoplastic sugar leves were determined in several plant species with transfer or ordinary companion cells (Vicia faba, Ntsika and Delrot, 1986; Spinacea oleracea and Hordeum vulgare, Lohaus et al., 1995). However, no comparison was made with plants with intermediary cells and presumably symplastic phloem loading. For this study, a number of species with either transfer or ordinary or intermediary companion cells from several plant families had to be selected, to make sure that the observed differences were related to companion cell structure.

The aim of the following experiments was to compare plants with different phloem loading mode with respect to (i) sugar composition and content in the apoplast of source leaves with normal and with inhibited phloem translocation, respectively, and (ii) types of sugars that are taken up from the apoplast into the symplast.

For the comparative study of apoplastic sugar contents in plants with different minor vein anatomy, several species were selected on the basis of the reported companion cell structure in their minor veins (Gamalei, 1990):

\subsubsection{Diurnal levels of the translocated carbohydrates in the apoplast}

Diurnal changes in apoplastic glucose, fructose and sucrose levels in the leaves were compared in two species, a putative symplastic phloem loader Alonsoa meridionalis and an apoplastic phloem loader with transfer cells in minor veins, Vicia faba. Plants were grown in 
a greenhouse (2.2.1). The leaves were sampled, infiltrated with ice-cold $50 \mathrm{mM} \mathrm{CaCl} 2$ solution and centrifuged at low speed (2.4). The presence of $\mathrm{Ca}^{2+}$ ions in the infiltration solution was important for the determination of apoplastic sugar concentrations, as $\mathrm{Ca}^{2+}$ favours the sealing of the damaged phloem cells with callose and thus prevents the contamination of the apoplast with phloem contents during the isolation of intercellular washing fluid (W. Kaiser, personal communication). The fluid obtained by centrifugation represented a diluted apoplastic solution. To check for symplastic contamination, the activity of glucose-6-phosphate dehydrogenase was determined (2.5.1). Glucose, fructose and sucrose concentrations in pure samples were measured by enzymatic analyses (2.8.2) and the concentrations of other carbohydrates were determined by HPLC.

\begin{tabular}{ll|ll}
\multicolumn{2}{c|}{ species with transfer/ordinary cells } & \multicolumn{2}{c}{ species with intermediary cells } \\
\hline Calendula officinalis L. & Asteraceae & Cucurbita pepo L. & Cucurbitaceae \\
Chrysanthemum sp. & Asteraceae & Coleus blumei Benth. & Lamiaceae \\
Symphytum officinale L. & Boraginaceae & Mentha sp. & Lamiaceae \\
Lepidium sativum L. & Brassicaceae & Ligustrum vulgare L. & Oleaceae \\
Spinacea oleracea L. & Chenopodiaceae & Alonsoa & Scrophulariaceae \\
Pisum sativum L. & Fabaceae & & \\
Vicia faba L. & Fabaceae & & \\
Atropa belladonnalion O. Kuntze & Solanaceae & &
\end{tabular}

Apoplastic glucose and fructose levels were somewhat higher than those of sucrose in Alonsoa (Figure 3.9). Importantly, no other carbohydrates were detected by HPLC in the apoplast of this species. In Vicia, similarly, glucose, fructose and sucrose were the only sugars found in the apoplast. However, in this species, sucrose levels were much higher that those of hexoses during the period of observation. The levels of sucrose in Vicia were about three times higher than in Alonsoa.

\subsubsection{Levels of the translocated carbohydrates in the apoplast increased in apoplastic but not in symplastic phloem loaders when phloem translocation was blocked}

The export of assimilates from the leaves of these two species was blocked by application of an ice jacket to the leaf petiole ("cold girdling"; Webb and Gorham, 1965) for several hours (2.11). Ice lost by melting was replaced. Figure 3.10 compares the effects of cold girdling on apoplastic concentrations of glucose, fructose and sucrose in Vicia faba and Alonsoa meridionalis. Neither hexoses nor sucrose levels increased in the apoplast of Alonsoa during the blockage of translocation. Contrarily, in Vicia sucrose levels increased fivefold when compared to non-girdled leaves already after two hours of petiole chilling and remained 
high throughout the experiment. No other sugars were detected in the apoplast of these species by HPLC.
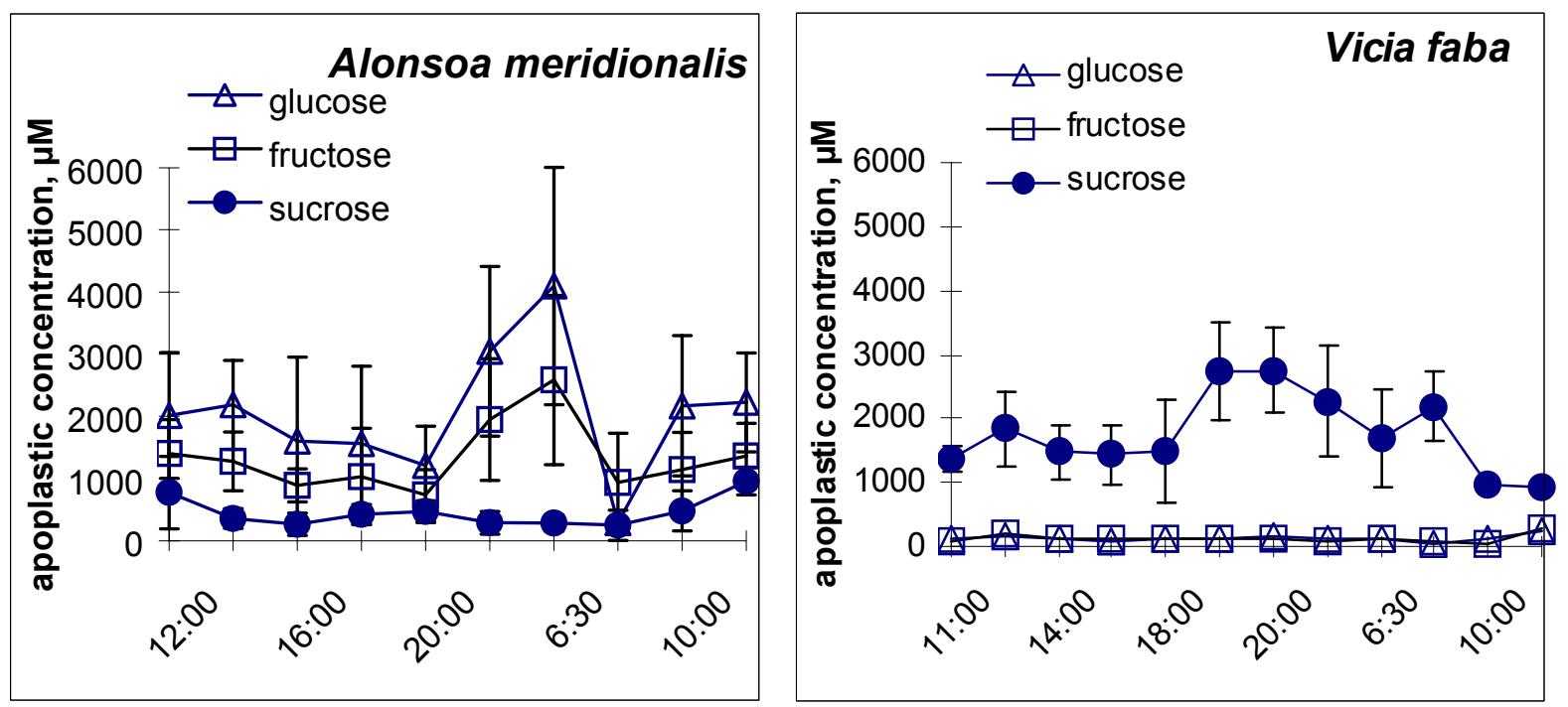

Figure 3.9. Time course of glucose, fructose and sucrose concentrations in the apoplast of leaves of Alonsoa meridionalis and Vicia faba. Mean values of 5 independent measurements $\pm \mathrm{SD}$ are shown.

Figure 3.11 shows a similar experiment performed on Spinacea oleracea, a putative apoplastic phloem loader with ordinary cells in minor veins and the putative symplastic phloem loader Coleus blumei. In the non-girdled controls, levels of all measured apoplastic sugars were in the same range in both plant species. In spinach, the cold jacket increased the apoplastic sucrose concentration above that measured in control leaves within $1 \mathrm{~h}$ of its application. After $4 \mathrm{~h}$ of cold girdling, the apoplastic sucrose levels exceeded those measured in ungirdled controls by a factor of more than four. Apoplastic glucose and fructose levels did not increase significantly. Even their highest levels were far below the apoplastic sucrose concentration in cold-girdled leaves.

In Coleus, no marked changes were observed in apoplastic sucrose and hexose levels under cold girdling. No other sugars were detected in the apoplast of Coleus by HPLC.

In a similar experiment performed with Symphytum officinale (an apoplastic loader with transfer cells in minor veins) and Cucurbita pepo (a putative symplastic loader), the cold jackets around the leaf petioles were maintained for about $3 \mathrm{~h}$. As has already been shown for the apoplastic loaders Spinacea and Vicia (Figures 3.9 and 3.10), the application of the cold jacket increased the apoplastic sucrose levels in leaves of Symphytum. As in case of the symplastic loaders Coleus and Alonsoa (Figures 3.9, 3.10), no increase in either sucrose or hexose levels in the leaf apoplast was observed in cold-blocked leaves of Cucurbita (data not shown). 

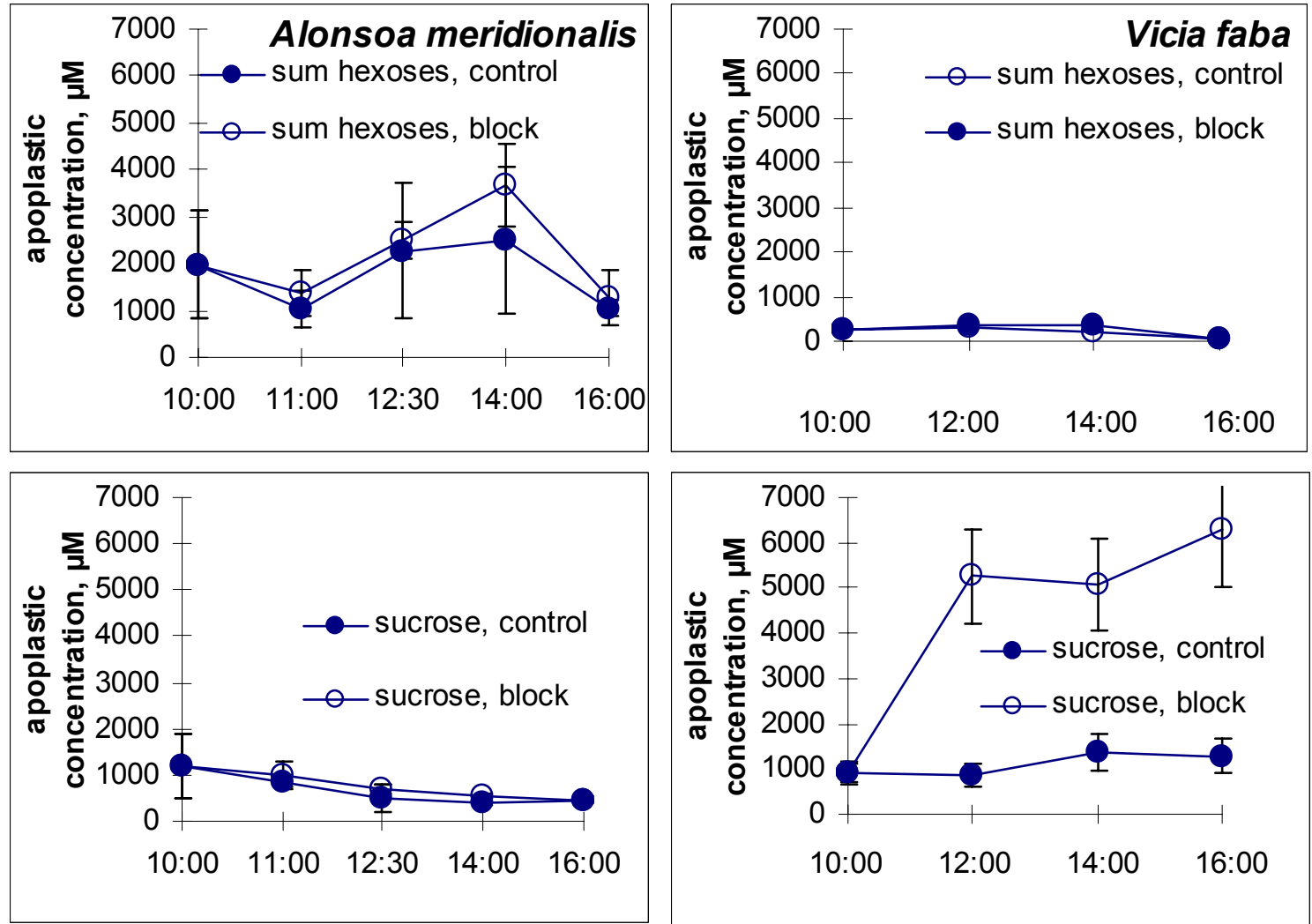

Figure 3.10. Apoplastic concentations of hexoses (glucose + fructose) and sucrose in leaves of Alonsoa meridionalis (left column) and Vicia faba during the day (filled circles) and after the application of a cold jacket on the petiole at 10:00 for 1, 2, 4 and 6 hours (open circles). Mean values of 5 independent measurements \pm SD are shown.

The inhibition of phloem translocation can be achieved not only by application of a cold jacket, but also by other procedures like cutting or removal of the phloem ring from the branches of trees. Figure 3.12 compares the effects of some of these treatments on apoplastic sugar levels in several putative apoplastic and symplastic phloem loaders.

The cut ends of the shoots of Chrysanthemum (apoplastic phloem loader) and Mentha (symplastic phloem loader) were placed in $\mathrm{CaCl}_{2}$ solution to inhibit export of assimilates. Alternatively, EDTA solution was fed to the petioles in order to chelate $\mathrm{Ca}^{2+}$ ions and thus to prevent callose sealing of sieve tubes and to allow the export to continue (King and Zeevaart, 1974). In this experiment, no significant differences between the two treatments could be seen for apoplastic sugar concentrations in either species (Figure 3.12). The apoplastic concentrations of all sugars measured in Mentha were lower than those in Chrysanthemum. 

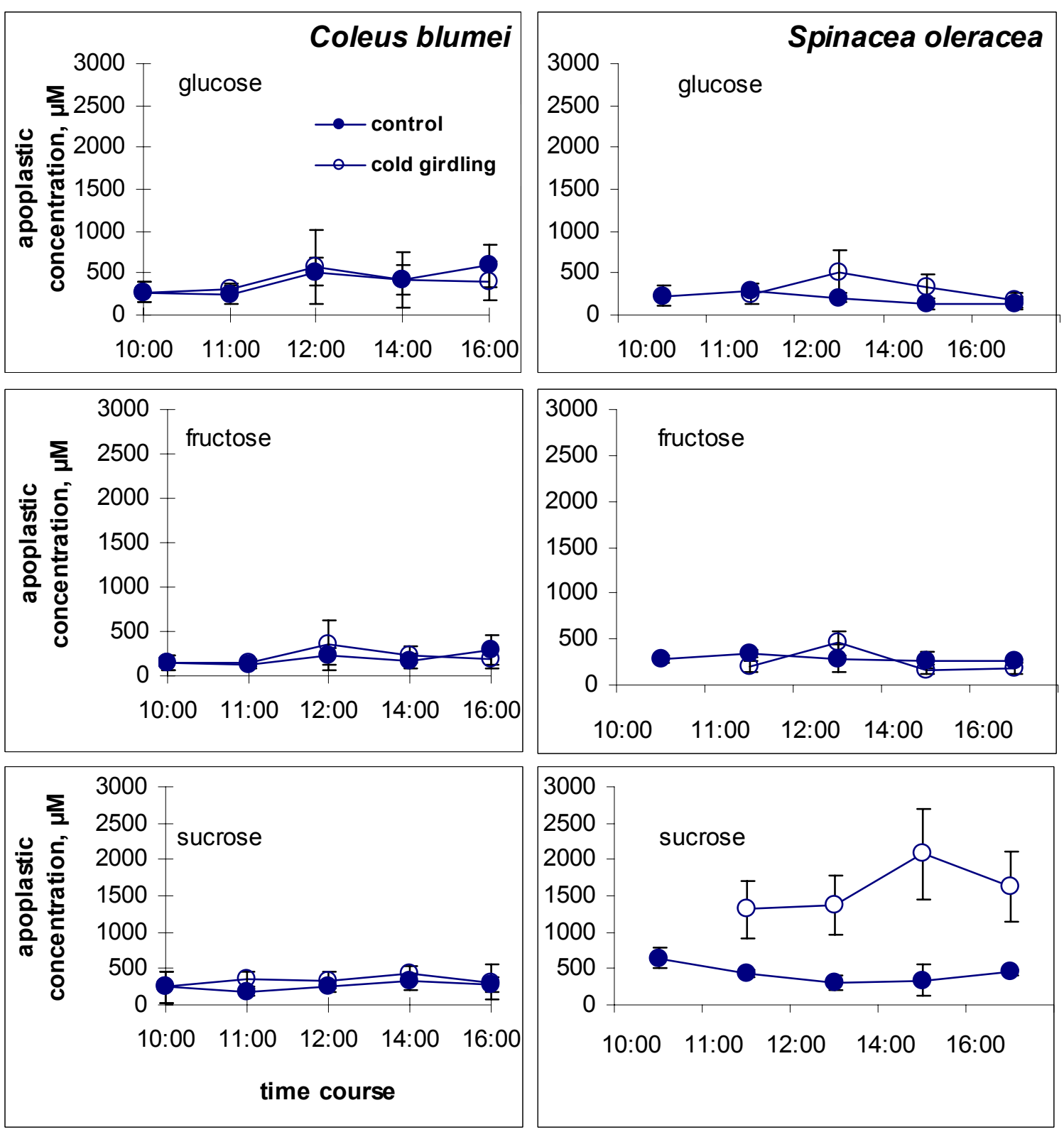

Figure 3.11. Apoplastic glucose, fructose and sucrose concentrations in Coleus blumei (left column) and Spinacea oleracea (right column) in untreated leaves (filled circles) and after application of a cold jacket on the petiole at 10:00 for 1, 2, 4 and 6 hours (open circles). Mean values of 5 independent measurements \pm SD are shown. 

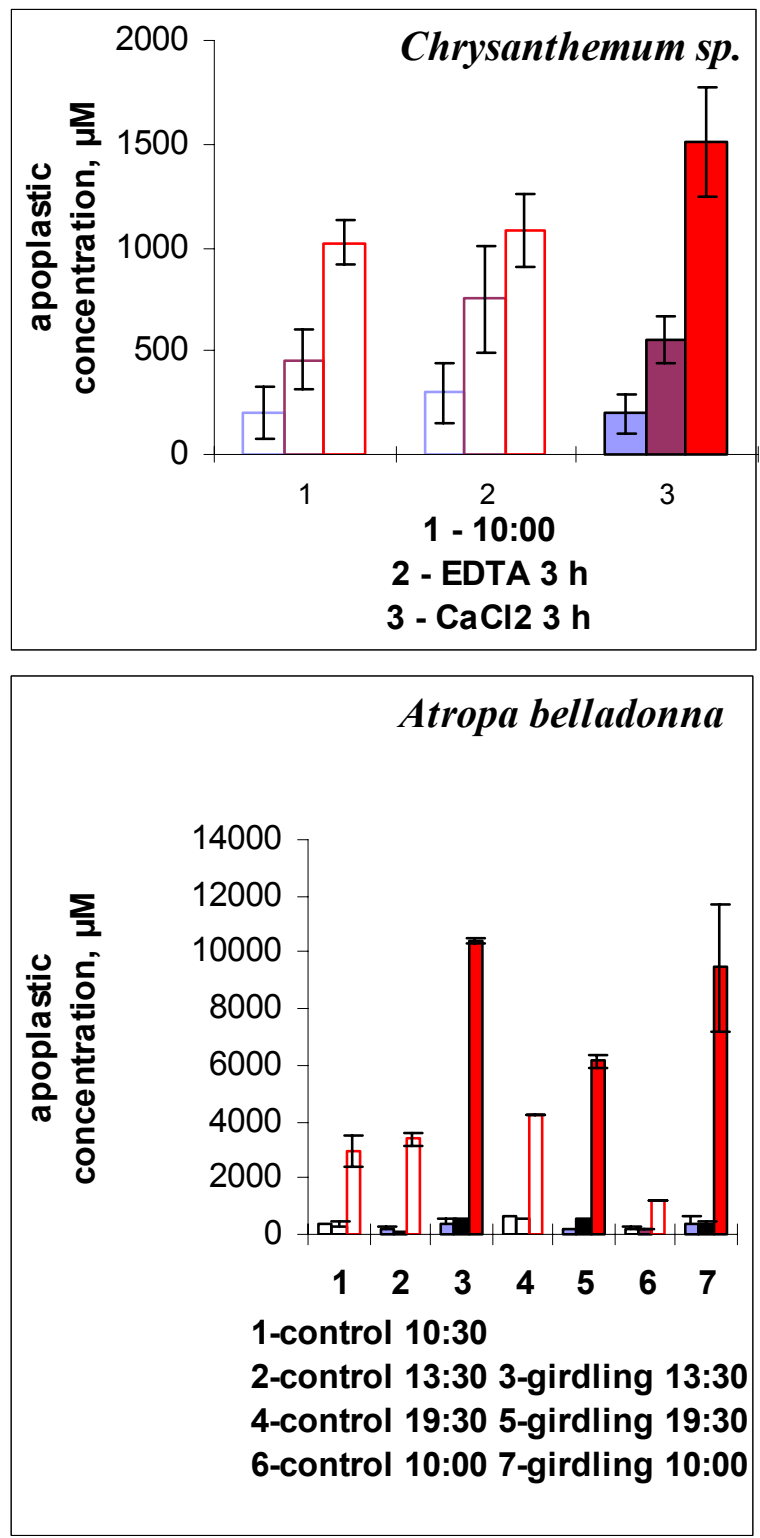

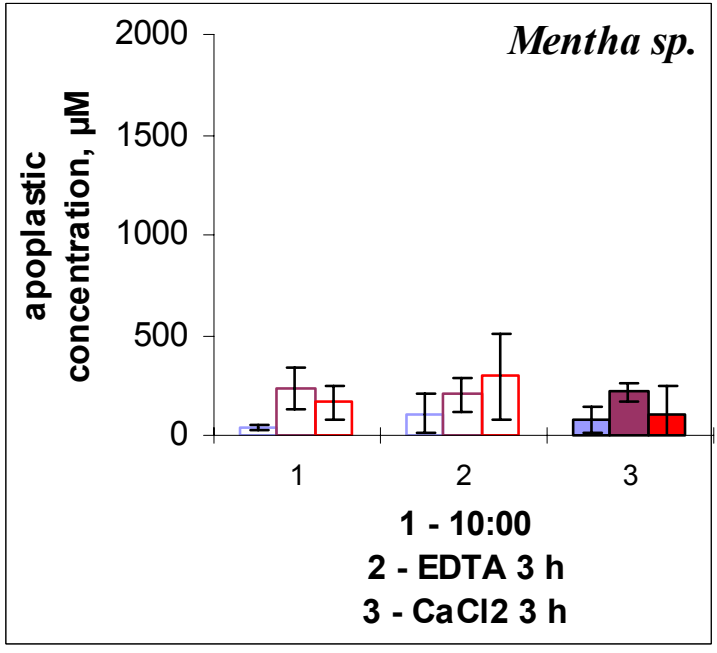

Ligustrum vulgare

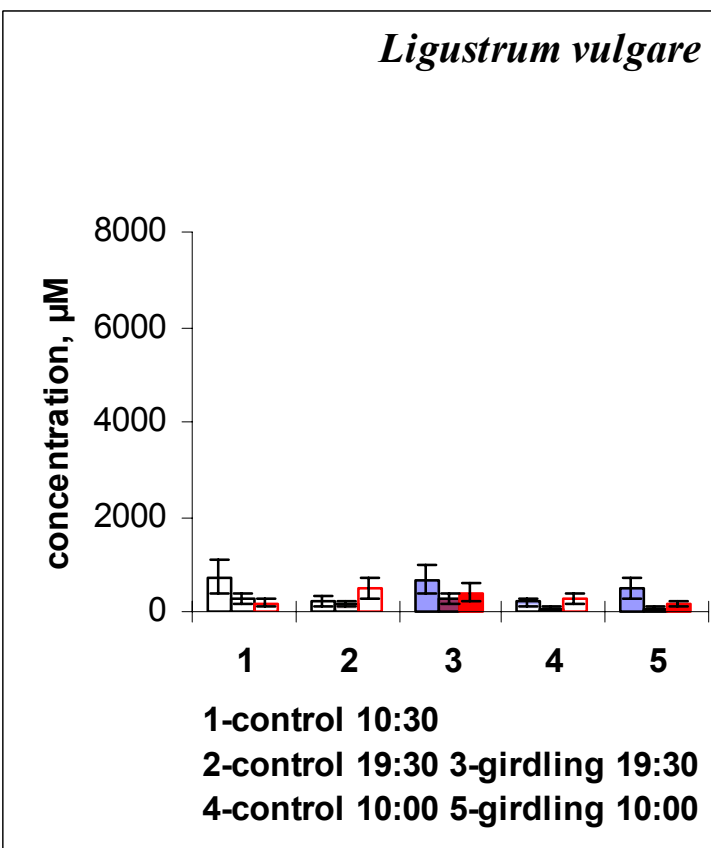

Figure 3.12. Apoplastic sugar concentrations in leaves of putative apoplastic phloem loaders Chrysanthemum sp. and Atropa belladonna and putative symplastic phloem loaders Mentha $s p$. and Ligustrum vulgare as influenced by phloem translocation blockage by cutting (Chrysanthemum, Mentha) and removal of a phloem ring from the branches (Atropa, Ligustrum). Open bars: samples from control plants. Filled bars: samples from experimental plants. Sugars are (right to left): glucose, fructose, sucrose. Mean values of 5 independent measurements \pm SD are shown.

A ring of bark was removed from branches of Atropa belladonna (apoplastic phloem loader) and Ligustrum vulgare (symplastic phloem loader) at 10:00 and the effect on apoplastic leaf sugar concentrations was examined. In Atropa, after $3 \mathrm{~h}$ the apoplastic sucrose levels in leaves from treated branches had increased considerably above the levels measured in the control and remained above that level until the evening (timepoint 19:30) and into the next morning (measured at 10:00). Apoplastic hexose levels were far below sucrose levels. In 
Ligustrum, apoplastic levels of sucrose did not respond to bark removal. No significant changes in hexose levels were observed.

In these experiments, different procedures were used to decrease translocation to exclude method-related artefactual results. A cold jacket may lower transport only temporarily (Geiger and Sovonick, 1970; Krapp and Stitt, 1995), while cutting and removal of the phloem around the branch were intended to block translocation entirely. However, whether transport was inhibited by cold girdling, by mechanical removal of phloem tissue or by callose blockage of sieve tubes, the inhibition always resulted in the increase of sucrose levels in the apoplast of leaves of the apoplastic phloem loaders (Spinacea, Symphytum, Chrysanthemum and Atropa) but not in leaves of the putative symplastic phloem loaders (Cucurbita, Coleus, Ligustrum and Mentha). These data suggest a difference in the extent of apoplast involvement in sugar transfer into the phloem in both groups of plants.

For all studied species, sucrose was the dominant sugar in the apoplast only in apoplastic phloem loaders, while in putative symplastic phloem loaders hexose levels were sometimes higher than sucrose levels (Figures 3.9 - 3.12). Neither raffinose nor stachyose were detected in the apoplast of leaves of Alonsoa and other symplastic phloem loaders that translocate these sugars in the phloem (Coleus, Cucurbita) even when phloem transport was blocked.

\subsubsection{Uptake of sugars including non-metabolizeable isomeres fed exogenously into the apoplast was driven by proton-motive force in both symplastic and apoplastic phloem loaders.}

In order to find out whether there are persistent differences in the mode of sugar uptake from the apoplast into the leaf tissue in apoplastic versus symplastic phloem loaders, a selected number of symplastic and apoplastic phloem loaders was examined. The capacity and energetics of uptake of different carbohydrates fed into the apoplast were compared in the leaves of these plants. One symplastic loader, Alonsoa, and one apoplastic loader, Calendula, were analysed in more detail.

The experiments were performed as described by Hedrich et al. (2001) (2.12.1). Different sugars (concentrations 10, 25, 50 or $100 \mathrm{mM}$, dissolved in $\mathrm{dd}_{2} \mathrm{O}$ ) were fed to the cut petioles of leaves during short time intervals $(5 \mathrm{~min})$. During the experiments, the respiratory $\mathrm{CO}_{2}$ release from the leaves and the leaf transpiration were recorded. To monitor changes in the apoplastic $\mathrm{pH}$, the $\mathrm{pH}$-sensitive fluorescent dye FITC was introduced into the leaf apoplast just before the beginning of the experiments. In the parallel experiments, a membrane-potential sensitive fluorescent dye BDTO was used instead of FITC which allowed the recording of membrane potential changes. 


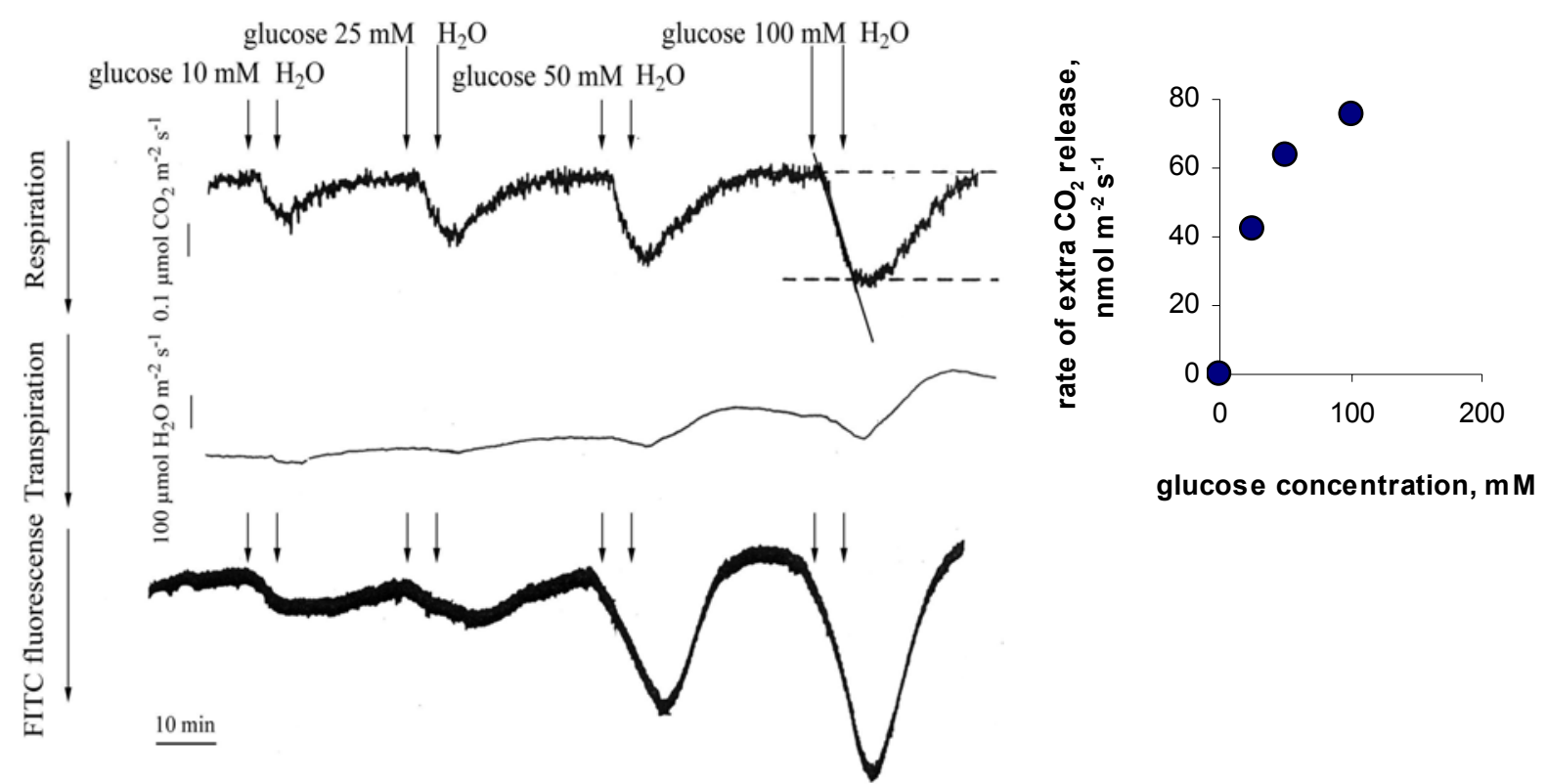

Figure 3.13. Respiration, transpiration and apoplastic $\mathrm{pH}$ of a leaf of Alonsoa meridionalis as influenced by $5 \mathrm{~min}$ feeding of glucose solutions $(10 \mathrm{mM}, 25 \mathrm{mM}, 50$ $\mathrm{mM}$ or $100 \mathrm{mM}$ ). Increase of FITC fluorescence indicates apoplastic alkalinization. Initial rate of the leaf transpiration was $1750 \mu \mathrm{mol} \mathrm{H}_{2} \mathrm{O} \mathrm{m} \mathrm{m}^{-2} \mathrm{~s}^{-1}$. The insert shows calculated glucose-stimulated $\mathrm{CO}_{2}$ release as a function of glucose concentration in the solution fed to the cut petiole (for 25, 50 and $100 \mathrm{mM}$ ).

A close relationship was established between the sugar concentration in the feeding solution and the apoplastic alkalinization and stimulation of respiration recorded during the experiments. This is shown in Figure 3.13. Glucose was fed to the cut petiole for $5 \mathrm{~min}$ at a time as indicated by arrows. It was transported into the leaf with the transpiration stream. As it arrived in the leaf blade, respiration was stimulated. An example of the calculation of the extent of glucose-stimulated respiration from the maxima of stimulated $\mathrm{CO}_{2}$ release is shown in the insert. After glucose had arrived in the apoplast stimulating respiration, the apoplastic $\mathrm{pH}$ increased. After feeding was discontinued, respiration started to decline and, subsequently, alkalinization was slowly reversed.

In similar experiments, the effects of different sugars were compared at a constant feeding concentration of $50 \mathrm{mM}$. Glucose, sucrose, raffinose and stachyose were fed into the apoplast of a leaf of Alonsoa meridionalis. This led to an increase in respiratory $\mathrm{CO}_{2}$ production and to a transient alkalinization of the apoplast as indicated by FITC fluorescence (Figure 3.14, A - D). Both respiration and $\mathrm{pH}$ returned slowly to initial levels after the feeding had been discontinued. In a similar experiment with another Alonsoa leaf, the membrane potential-sensitive dye BDTO was infiltrated into the leaf instead of FITC. When sugars were fed, the membrane potential first depolarized and then repolarized even exhibiting some hyperpolarization (Figure 3.14, A - D). 
In experiments with the apoplastic phloem loader Calendula officinalis, this sequence of events was more clearly resolved (Figure 3.15, A - D). Here, a small acidification preceded apoplastic alkalinization. It was accompanied by the depolarization of the membrane potential which continued as long as this small initial acidification lasted. The beginning of the repolarization of the membrane potential as indicated by the inrease of BDTO fluorescence coincided with the beginning of the apoplastic alkalinization as indicated by the increase of FITC fluorescence (Figure 3.15, A-D). This sequence of events was clearly observed with fed glucose and fructose but was less pronounced with raffinose and stachyose.

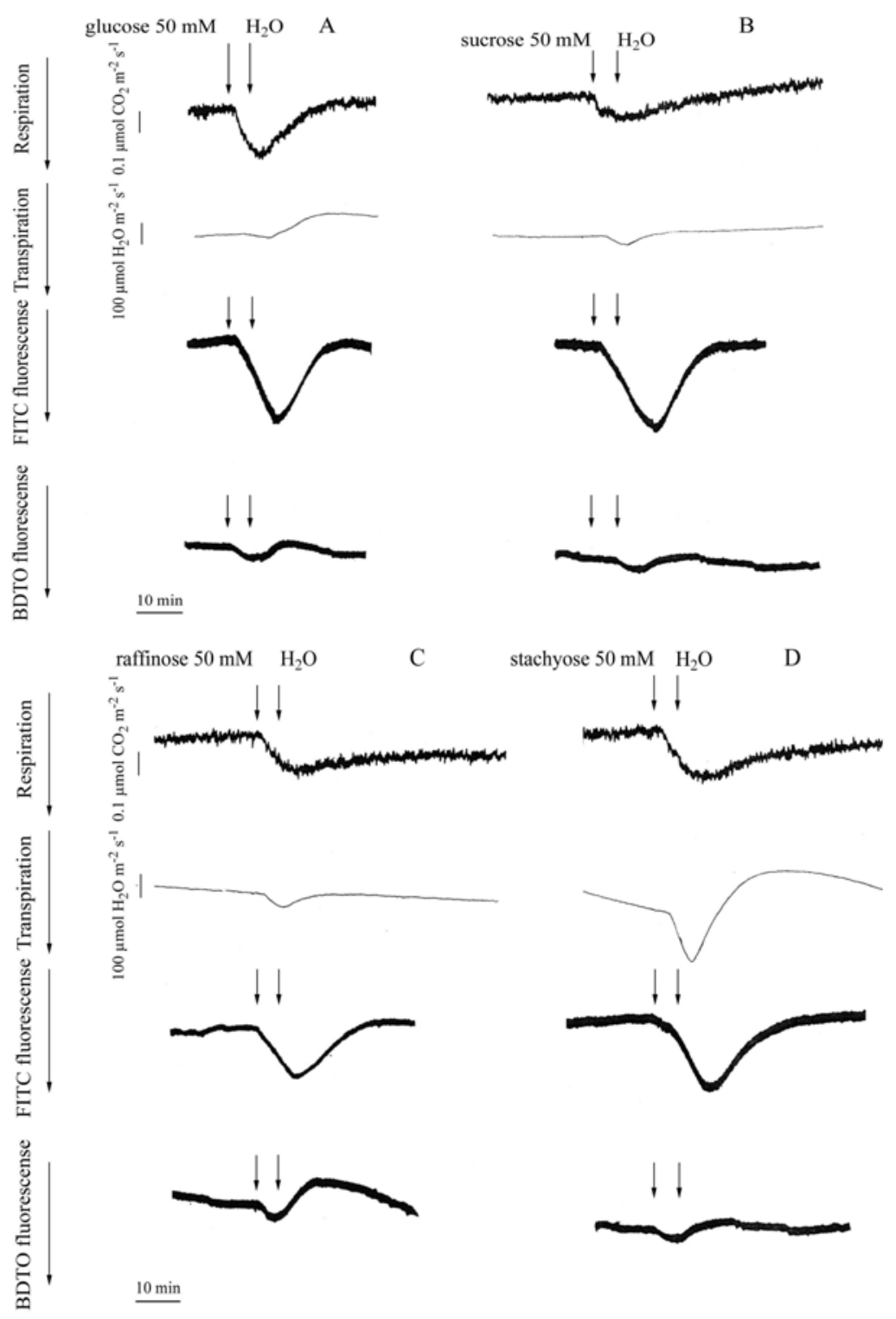

Figure 3.14. Respiration, transpiration, apoplastic $\mathrm{pH}$ and membrane potential of a leaf of Alonsoa meridionalis as influenced by $5 \mathrm{~min}$ feeding of $50 \mathrm{mM}$ solution of A, glucose, $\mathbf{B}$, sucrose, $\mathbf{C}$, raffinose and $\mathbf{D}$, stachyose. Increasing FITC fluorescence indicates alkalinization of apoplast. Increase of BDTO fluorescence indicates a depolarization of membrane potential. Initial rates of leaf transpiration were: $\mathbf{A}, 1750 \mu \mathrm{mol} \mathrm{H} \mathrm{H} \mathrm{m}^{-2} \mathrm{~s}^{-1} ; \mathbf{B}$, $1820 \mu \mathrm{mol} \mathrm{H} \mathrm{O} \mathrm{m}^{-2} \mathrm{~s}^{-1}$; C, $1840 \mu \mathrm{mol} \mathrm{H} \mathrm{O} \mathrm{m}^{-2} \mathrm{~s}^{-1}$; D, $1550 \mu \mathrm{mol} \mathrm{H}_{2} \mathrm{O} \mathrm{m}^{-2} \mathrm{~s}^{-1}$. 


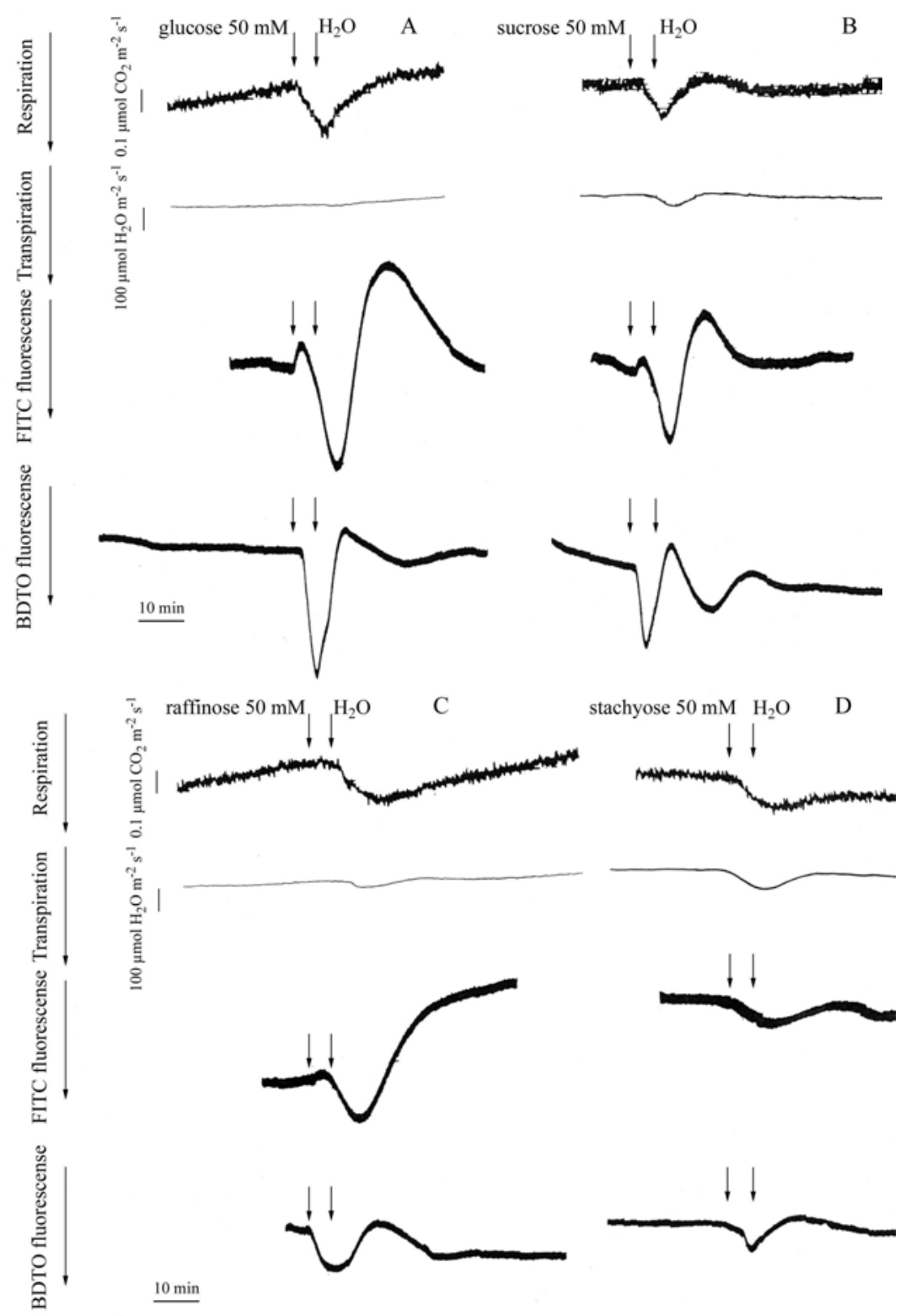

Figure 3.15. Respiration, transpiration, apoplastic $\mathrm{pH}$ and membrane potential of a leaf of Calendula officinalis as influenced by $5 \mathrm{~min}$ feeding of $50 \mathrm{mM}$ solution of $\mathbf{A}$, glucose, $\mathbf{B}$, sucrose, $\mathbf{C}$, raffinose and $\mathbf{D}$, stachyose. Increase of FITC fluorescence indicates an alkalinization of the apoplast. Increase of BDTO fluorescence indicates a depolarization of membrane potential. Initial rates of leaf transpiration rates were:
A, $1860 \mu \mathrm{mol} \mathrm{H} 2 \mathrm{O} \mathrm{m}^{-2} \mathrm{~s}^{-1}$; B, $1575 \mu \mathrm{mol} \mathrm{H}_{2} \mathrm{O} \mathrm{m}^{-2} \mathrm{~s}^{-1}$;
C, $1815 \mu \mathrm{mol} \mathrm{H}_{2} \mathrm{O} \mathrm{m}^{-2} \mathrm{~s}^{-1}$; D, $1680 \mu \mathrm{mol} \mathrm{H}_{2} \mathrm{O} \mathrm{m}^{-2} \mathrm{~s}^{-1}$.

Increases of respiration, apoplastic alkalinization and depolarization of the membrane potential similar to those in the leaves of Alonsoa and Calendula were also observed when 50 $\mathrm{mM}$ sugar solutions were fed to the petioles of detached leaves of the symplastic phloem loaders Mentha sp., Coleus blumei and Cucurbita pepo or to the apoplastic phloem loaders Helianthus tuberosus, Lepidium sativum and Pisum sativum (data not shown).

In general, sugars fed to leaves can be respired. To find out whether this was the reason for the increase of basal respiration in the experiments described thus far, non- 
metabolizeable sugars such as 2-deoxy-D-glucose or turanose (3-O- $\alpha$-D-glucopyranosyl-Dfructofuranose, a non-metabolizeable isomer of sucrose) were fed to leaves. In Figure 3.16, it can be seen that the increases in respiratory $\mathrm{CO}_{2}$ production in response to the feeding of 2deoxy-D-glucose or turanose to the apoplast are comparable to those observed with metabolizeable sugars. Similar results were obtained with palatinose, another nonmetabolizeable sucrose isomer (6-O- $\alpha$-D-glucopyranosyl-D-fructofuranose; data not shown). Apparently, the basal respiration of the leaves used in these experiments was limited not by the lack of respiratory substrates, but by a low demand for energy. However, unlike deoxyglucose and the metabolizeable sugars, turanose and palatinose were efficient not in all species tested. Thus, in Calendula, palatinose was readily taken up as indicated by $\mathrm{pH}$ and membrane potential changes (Figure 3.16) but turanose caused no effects in respiration, apopalstic $\mathrm{pH}$ and membrane potential (not shown). Contrarily, in Lepidium, turanose was readily taken up (Figure 3.16).
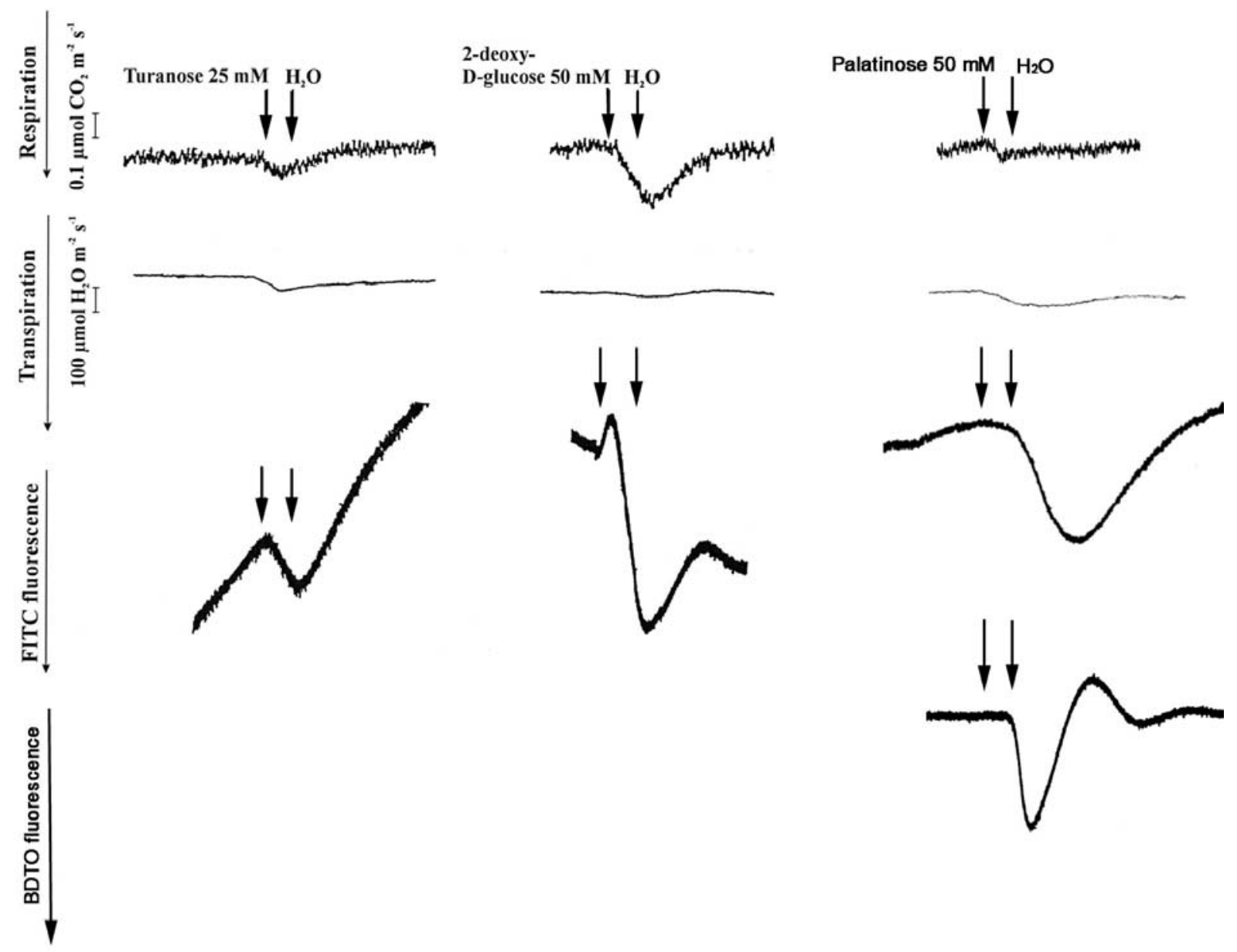

Figure 3.16. Uptake of non-metabolizeable isomeres 2-deoxy-D-glucose, turanose and palatinose fed to leaves of Lepidium sativum (turanose) and Calendula officinalis (2-deoxy-Dglucose and palatinose). The increase of the FITC fluorescence indicates an alkalinization of the apoplast and the increase in BDTO fluorescence (not shown for 2-deoxy-D-glucose and turanose) indicates a depolarization of membrane potential. 
Since non-metabolizeable isomeres could also be taken up by leaf tissues that do not normally contain these sugars, the analysis was extended to include another molecule species, namely an iridoid glycoside, antirrhinoside. Antirrhinoside had been isolated from leaves of Asarina barclaiana (2.3.2.2). It consists of an aglycon and a glucose residue (Figure 2.1). It has been shown that transmembrane transfer of glycosides can occur against their concentration gradient, most probably through hexose transporters which recognize a glycoside residue as substrate (Christmann et al., 1993). Unfortunately, the leaves of Asarina barclaiana, the plant which does transport antirrhinoside in its phloem (1.7.2, Table 1.3) were not suitable for experiments involving the feeding of sugars to the apoplast. Therefore, leaves of Calendula were used. This plant produces a number of glycosides, but not iridoid glycosides and not antirrhinoside (Jensen, 1991).

When antirrhinoside was fed to Calendula leaves, stimulation of respiration, apoplastic alkalinization and the depolarization of membrane potential were observed which indicated that this glucoside is taken up into leaf cells like all other sugar molecules tested (Figure 3.17). However, the hyperpolarization phase was prolonged and the $\mathrm{pH}$ changes were weak when compared to those observed with glucose of the same concentration $(33 \mathrm{mM}$; not shown). This indicates that, in Calendula, antirrhinoside is taken up either via another transporter or the affinity to this glucoside is much weaker than that to glucose.

Figure 3.17.

Respiration, transpiration, apoplastic $\mathrm{pH}$ and membrane potential of a leaf of Calendula officinalis as influenced by 5 min feeding of $33 \mathrm{mM}$ solution of antirrhinoside. Increase of FITC fluorescence indicates an alkalinization of the apoplast. Increase of BDTO fluorescence indicates a depolarization of membrane potential.

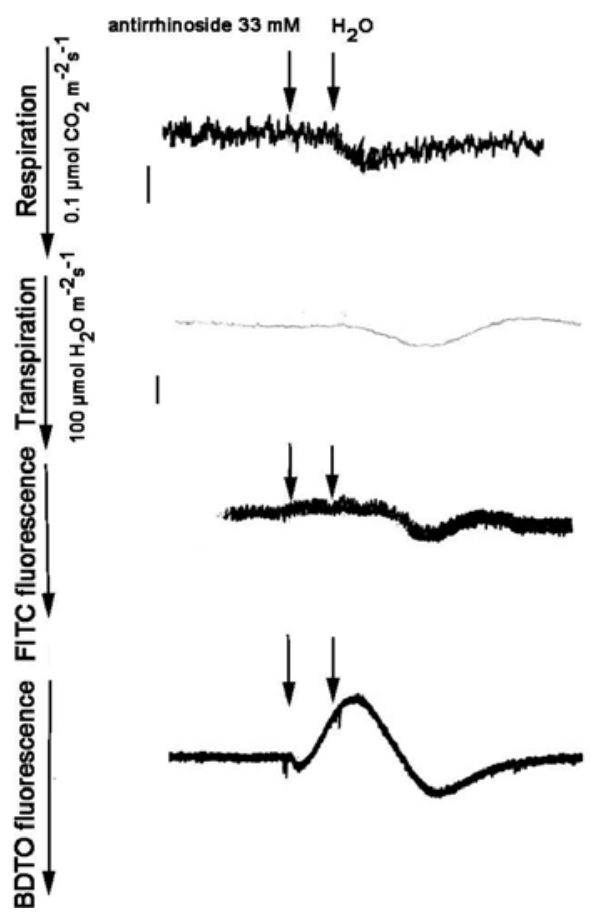


An attempt to compare the uptake rates for different sugars was made using leaves of Alonsoa and Calendula. Both for sucrose, raffinose and stachyose which are phloemtranslocated, and for glucose which is unlikely normally to be taken up by companion cells since no hexoses have been found in the phloem sap of plants to date, the maximum extent of the sugar-dependent increase in respiration were calculated. Representative examples are shown in Table 3.7, both as a rate of $\mathrm{CO}_{2}$ release and as a percentage increase of basal respiration. The values presented in Table 3.7 are typical examples. As a rule, the monosaccharide glucose showed the strongest stimulation of respiration but the trisaccharide raffinose and the tetrasaccharide stachyose were also effective in stimulating respiration in both plants. The amplitudes of respiration responses and changes of apoplastic $\mathrm{pH}$ and of membrane potential were in the same range for all sugars.

For glucose, sucrose and raffinose, sugar-dependent changes in the rate of $\mathrm{CO}_{2}$ release were plotted against sugar concentration (as it is shown in the insert in Figure 3.13) for leaves of Alonsoa (Figure 3.18, A). The leaves showed a high capacity for the uptake of sugars from the apoplast as can be seen from the respiration curves which showed a half-maximum saturation at feeding concentrations of $19-25 \mathrm{mM}$. Figure 3.18, B compares the quantifications of respiration responses caused by feeding raffinose to leaves of three different species, a raffinose-translocating Alonsoa and sucrose-translocating Calendula and Helianthus. The respiration responses were concentration-dependent in all three species and amplitudes were of the same range, although Alonsoa showed somewhat higher capacity for raffinose uptake. Similar comparison was also made for glucose and sucrose fed to leaves of these species. No pronounced differences in uptake capacity has been revealed (data not shown).

Table 3.7. Maximal increase in basal respiration of leaves as observed by sugar feeding into the leaf apoplast. Listed values are typical examples.

\begin{tabular}{|c|c|c|c|c|c|c|}
\hline \multirow[b]{2}{*}{$\begin{array}{l}\text { feeding } \\
\text { solution }\end{array}$} & \multicolumn{3}{|c|}{ Alonsoa } & \multicolumn{3}{|c|}{ Calendula } \\
\hline & $\begin{array}{l}\text { basal } \\
\text { respiration } \\
\text { rate }^{l}\end{array}$ & $\begin{array}{l}\text { maximum } \\
\text { of stimulated } \\
\text { respiration } \\
\text { rate }\end{array}$ & $\begin{array}{l}\text { stimulation } \\
\text { by sugar } \\
\text { feeding }\end{array}$ & $\begin{array}{l}\text { basal } \\
\text { respiration } \\
\text { rate }^{l}\end{array}$ & $\begin{array}{l}\text { maximum } \\
\text { of stimulated } \\
\text { respiration } \\
\text { rate }\end{array}$ & $\begin{array}{l}\text { stimulation } \\
\text { by sugar } \\
\text { feeding }\end{array}$ \\
\hline $\begin{array}{c}\text { glucose } 50 \\
\text { mM }\end{array}$ & 504 & 767 & $52 \%$ & 719 & 1059 & $45 \%$ \\
\hline $\begin{array}{c}\text { sucrose } 50 \\
\text { mM }\end{array}$ & 505 & 631 & $25 \%$ & 796 & 990 & $24 \%$ \\
\hline $\begin{array}{c}\text { raffinose } 50 \\
\text { mM }\end{array}$ & 583 & 768 & $32 \%$ & 680 & 825 & $21 \%$ \\
\hline $\begin{array}{c}\text { stachyose } \\
50 \mathrm{mM}\end{array}$ & 728 & 971 & $33 \%$ & 544 & 690 & $27 \%$ \\
\hline
\end{tabular}

${ }^{1} \mathrm{nmol} \mathrm{CO}_{2} \mathrm{~m}^{-2} \mathrm{~s}^{-1}$ 
The observations made in these experiments can be summarized as follows. First, all carbohydrates introduced into the leaf apoplast were taken up into the symplast, the uptake being powered by proton motive force. Indeed, not only glucose and sucrose, but also raffinose and stachyose were transported together with protons at the expense of the proton motive force across the plasma membrane. Energized uptake from the apoplast into the leaf cells was also observed for the foreign iridoid glycoside antirrhinoside in Calendula. Even the unmetabolizeable sucrose analogs palatinose and turanose were readily taken up when fed into the apoplast although it had been assumed that these sugars cannot be transported into the plant cells because they are not recognized by the known sugar transporters (e.g. M'Batchi and Delrot, 1988).

Second, no persistent differences in the mode of uptake of sugars introduced into a leaf apoplast could be seen between apoplastic and putative symplastic phloem loaders. Uptake of raffinose and stachyose from the apoplast indeed occured both in species that are known to synthetize these sugars in leaves and translocate them (Cucurbita, Coleus, Alonsoa) and in species with transfer/ordinary companion cells in their minor veins which belong to plant families translocating (almost) exclusively sucrose in the phloem (Helianthus, Calendula, Lepidium, Pisum). It can be concluded that, in the described experiments, leaves of symplastic phloem loaders translocating raffinose and stachyose along with sucrose, as well as leaves of apoplastic phloem loaders translocating only sucrose, did not differ in the capacity and specificity of uptake of the three sugars fed exogenously into the apoplast. The mechanism of uptake was similar for the three sugars in that the PMF was the driving
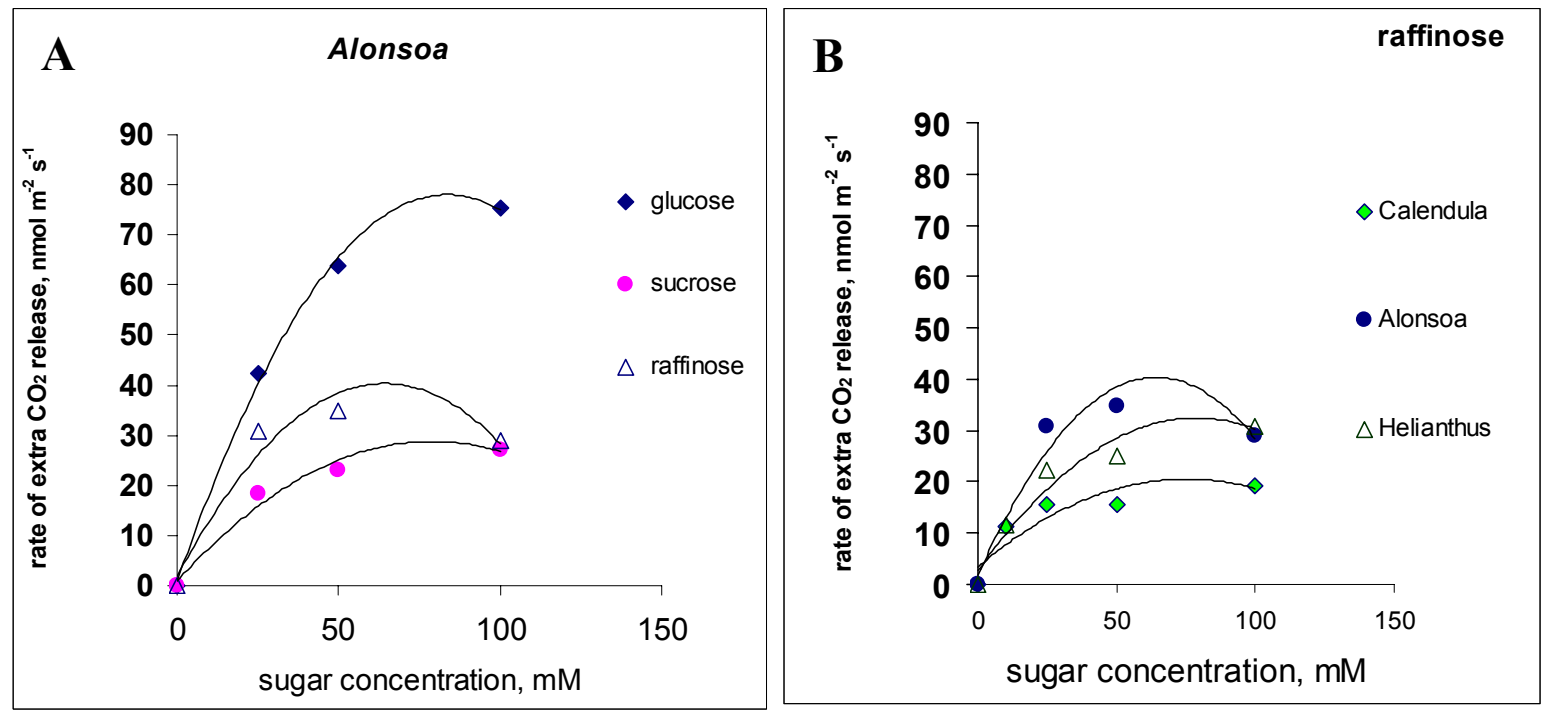

Figure 3.18. Maximum changes in the rate of $\mathrm{CO}_{2}$ release caused in leaves by feeding sugars at concentrations of 25, 50 and $100 \mathrm{mM}$. Comparison is made: $\mathbf{A}$, among different sugars fed to leaves of Alonsoa; B, among different speceis when feeding raffinose. 
force and that the observed apoplastic alkalinization suggested the uptake to proceed via $\mathrm{H}^{+} /$sugar-symporters. The amplitudes of respiration responses and changes of apoplastic $\mathrm{pH}$ and of membrane potential were in the same range for glucose, which is very unlikely to be taken up by companion cells since no hexoses have been found in the phloem sap of plants to date, and for phloem-translocated sugars such as sucrose in apoplastic plants and sucrose, raffinose and stachyose in symplastic plants.

Altogether, the results obtained in the sugar feeding experiments also suggest that in the leaf cells of the plant species examined - apoplastic and symplastic phloem loaders alike the exchange of sugars between symplast and apoplast may not be limited by the presence of specific transporters in the plasma membranes. The concurrent alkalinization of the apoplast suggests that the sugars and an iridoid glycoside were taken up in a proton symport mechanism as is known for sugar transporters. The efficient uptake of non-metabolizeable foreign sucrose analogs argues either for an uptake mechanism with broad specificity that involves the PMF or for participation of transporters $\left(\mathrm{H}^{+}\right.$-symporters $)$which are not characterized as yet.

\subsection{Characterization of AmSTS, a stachyose synthase from Alonsoa meridionalis}

\subsubsection{Cloning of cDNA fragments of Alonsoa meridionalis raffinose synthase and stachyose synthase}

To obtain cDNA fragments of stachyose synthase (AmSTS) and raffinose synthase (AmRS) from Alonsoa meridionalis by RT-PCR, degenerate primers were deduced from conserved motifs of the STS and RS amino acid sequences from Vigna angularis (STS; Peterbauer et al., 1999), Cucumis sativum (RS; Accession No. AAD02832) and Arabidopsis thaliana (RS; Accession No. BAB11595; Figure 3.19). Since STS and RS amino acid sequences are homologous with the exception of a 70 amino acid insertion in the STS sequence, the degenerate primers were deduced from amino acid stretches which were highly conserved in both enzymes (Figure 3.19). The 70 amino acid insertion in the stachyose synthase sequence was located between the two primers, thus allowing to distinguish between RT-PCR products from raffinose and stachyose synthases.

The deduced degenerate primers sta-5' and sta-3' (Table 2.1) were used for RT-PCR on cDNA prepared from leaf RNA (2.21.2.1) with the following PCR program: 


$\left.\begin{array}{ll}94^{\circ} \mathrm{C} & 60 \mathrm{sec} \\ 94^{\circ} \mathrm{C} & 30 \mathrm{sec} \\ 55^{\circ} \mathrm{C} & 30 \mathrm{sec} \\ 72^{\circ} \mathrm{C} & 90 \mathrm{sec}\end{array}\right\} 35$ cycles

This resulted in two PCR products, one of ca $0.8 \mathrm{~kb}$ length and another one of ca $1.1 \mathrm{~kb}$. The fragments were cloned in pGEM®-T Easy and sequenced. The comparison of the encoded amino acid sequences with the two previously known raffinose synthases and the stachyose synthase revealed homologies of $80 \%$, thus confirming that the obtained fragments represented RS (the $0.8 \mathrm{~kb}$ fragment) and STS (the $1.1 \mathrm{~kb}$ fragment) from Alonsoa.

\subsubsection{The full length $c D N A$ of stachyose synthase from Alonsoa (AmSTS) was cloned}

In order to amplify the $3^{\prime}-$ and $5^{\prime}$ end of the AmSTS cDNA by RACE (2.21.2.2, 2.21.2.3), gene-specific primers were deduced from the sequence of the AmSTS cDNA fragment obtained by RT-PCR (3.3.1). 5' RACE was performed two times independently, first with primers amsts5racel and amsts5race2, and the second time with another pair of primers, 5raceneul and 5raceneu2 (Table 2.1). Both amplifications resulted in the same 5' end sequence of the AmSTS cDNA. After the 3'-end and 5'-end sequences of AmSTS cDNA had been obtained, two specific primers FLCsts5 and FLCsts3 (Table 2.1) were deduced and used in an RT-PCR for the amplification of the full length AmSTS cDNA (2.21.3).

The nucleotide sequence and deduced amino acid sequence of the full length AmSTS cDNA clone are shown in Figure 3.20. The nucleotide sequence is 2889 bp in length, including a $5^{\prime}$-untranslated region of $108 \mathrm{bp}$ and a $3^{\prime}$-untranslated region of $172 \mathrm{bp}$. The ORF of stachyose synthase encodes a protein of 868 amino acids with a molecular weight of 95.6 $\mathrm{kDa}$. Interestingly, the 5 '-UTR contains two small uORFs, one encoding four and the other eleven amino acids, both in-frame with the AmSTS ORF (Figure 3.20).

To date, two complete cDNA sequences of stachyose synthases are available, one from Vigna angularis (Peterbauer et al., 1999) and another from Pisum sativum (Peterbauer et al., direct submission; Accession No. CAC38094). The comparison of the AmSTS sequence with these two STS sequences is shown in Figure 3.21. AmSTS shows $71 \%$ similarity (63\% identity) with $\mathrm{VaSTS}$ and 74\% similarity (66\% identity) with PSSTS at the amino acid level. 


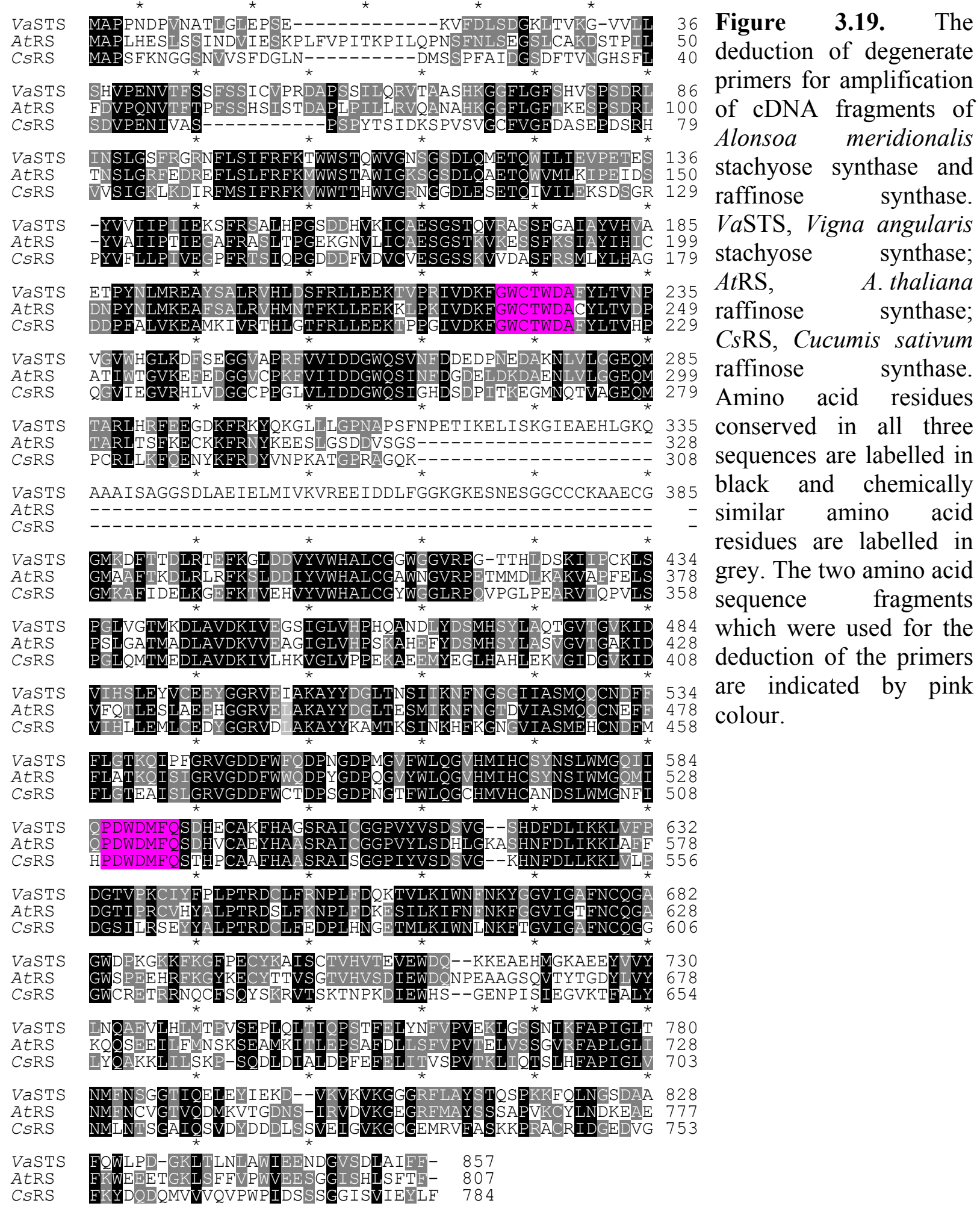




\subsubsection{Stachyose synthase activity assay with protein extracts of Alonsoa meridionalis leaves and of E. coli cells containing an expression vector carrying the AmSTS ORF}

The function of stachyose synthesis was assigned to the cloned AmSTS cDNA on the basis of amino acid sequence homology of the encoded protein with Vigna angularis STS, which has been shown to perform stachyose synthesis when expressed in a Baculovirus system (Peterbauer et al., 1999). To test whether the protein encoded by the AmSTS cDNA is also able to perform stachyose synthesis, the full length AmSTS cDNA was inserted into the E. coli expression vector pET3b (Rosenberg et al., 1986) under the control of an inducible promoter, yielding the plasmid pET*/STS (2.22.1). This plasmid was transformed into the $E$. coli strain BL21 (DE3).

To establish the conditions for the test of enzymatic activity of AmSTS, a stachyose synthase assay was performed using leaves of Alonsoa meridionalis. Galactinol isolated from the leaves of Buddleja davidii (2.3.2.1) was used as a substrate.

\subsubsection{Stachyose synthase activity assay using leaves of Alonsoa}

Determination of the activity of stachyose synthase was performed with crude extracts from Alonsoa leaves (2.5.6.1). Different concentrations of raffinose were tested in the assay. Concentrations higher than $10 \mathrm{mM}$ had an inhibitory effect on STS activity with complete inhibition occuring at a raffinose concentration of $20 \mathrm{mM}$ (data not shown). The assays were performed with $4 \mathrm{mM}$ raffinose at different $\mathrm{pH}$ values ranging from 5.5 to 7.0. The highest activity $\left(1.98 \mu \mathrm{mol}\right.$ stachyose $\left.\mathrm{g}^{-1} \mathrm{FW} \mathrm{h}^{-1}\right)$ was measured at $\mathrm{pH} 6.5$ (Figure $3.22 \mathrm{~B}$ ).

\subsubsection{The induction of $A m S T S$ expression did not function in $E$. coli cells}

The E. coli strain BL21 (DE3) was transformed with the expression vector containing the AmSTS cDNA (pET*/STS), and with the empty expression vector pET3b as a control (2.22.1). After the induction of T7 RNA polymerase expression by the addition of IPTG (2.22.2), the cells were harvested in 30 min intervals to monitor the formation of the protein on a polyacrylamide gel (2.23). Three hours after induction, the cells were harvested for the extraction of total proteins for the STS activity assay (2.5.6.2). Although the $99 \mathrm{kDa}$ protein corresponding to the T7 RNA polymerase appeared in SDS-PAGE of the crude extract on the gel already one hour after the addition of IPTG, no additional protein in the region of $95 \mathrm{kDa}$, the expected size of $A m S T S$, was detected at any timepoint examined (data not shown).

To test if the protein was formed in E. coli cells in amounts too small to detect by SDS-PAGE, the assay of STS activity was performed with the cell extracts harvested three hours after induction (2.5.6.2). No activity could be detected (data not shown). Both 
observations indicated that the E. coli expression system is not suitable for the functional expression of plant stachyose synthase cDNA.

\footnotetext{
1 ATGTGTCCAAACTAAGTAATAACTCAATAGTTCATGCATAAGCTTTTCTACAAAAAAAAT 60

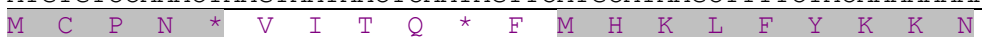

61 AATAACTGATTTTTAGCCTTCCCCTGTTTTTGCTCTGTTTTTTCAACCATGGCACCTCCA 120

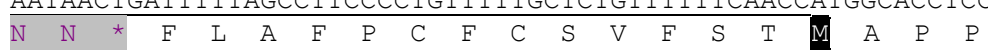

121 TATGATCCCATCCCCATCCCCATCCCCATGAGCGCAATTTTGAACTTCCTGAGCTCCACC 180 $\begin{array}{lllllllllllllllllllllllll}5 & \text { Y } & \text { D } & \text { P } & \text { I } & \text { P } & \text { I } & \text { P } & \text { I } & \text { P } & \text { M } & \text { S } & \text { A } & \text { I } & \text { L } & \text { N } & \text { F } & \text { L } & \text { S } & \text { S } & \text { T }\end{array}$

181 GTAAAGGACAACTCTTTCGAGCTCCTCGACGGAACACTCTCCGTGAAAAATGTCCCGATT 240 $\begin{array}{lllllllllllllllllllll}25 & \text { V } & \text { K } & \text { D } & \text { N } & \text { S } & \text { F } & \text { E } & \text { L } & \text { L } & \text { D } & G & \text { T } & \text { L } & \text { S } & \text { V } & \text { K } & \text { N } & \text { V } & \text { P } & \text { I }\end{array}$

241 CTGACCGATATCCCGAGCAACGTCAGTTTCTCCAGCTTCTCTTCCATAGTCCAATCCTCT 300 $\begin{array}{lllllllllllllllllllll}45 & \mathrm{~L} & \mathrm{~T} & \mathrm{D} & \mathrm{I} & \mathrm{P} & \mathrm{S} & \mathrm{N} & \mathrm{V} & \mathrm{S} & \mathrm{F} & \mathrm{S} & \mathrm{S} & \mathrm{F} & \mathrm{S} & \mathrm{S} & \mathrm{I} & \mathrm{V} & \mathbb{Q} & \mathrm{S} & \mathrm{S}\end{array}$

301 GAAGCTCCAGTTCCCCTGTTCCAGCGCGCTCAATCACTCTCCTCCAGCGGCGGTTTCCTC 360

$\begin{array}{llllllllllllllllllllllllll}65 & \mathrm{E} & \mathrm{A} & \mathrm{P} & \mathrm{V} & \mathrm{P} & \mathrm{L} & \mathrm{F} & \mathrm{Q} & \mathrm{R} & \mathrm{A} & \mathrm{Q} & \mathrm{S} & \mathrm{L} & \mathrm{S} & \mathrm{S} & \mathrm{S} & \mathrm{G} & \mathrm{G} & \mathrm{F} & \mathrm{L}\end{array}$

361 GGGTTCAGCCAGAATGAACCCTCTTCTCGCCTGATGAATTCCCTGGGAAAATTCACCGAT 420

$\begin{array}{lllllllllllllllllllllll}85 & G & F & S & Q & N & E & P & S & S & R & \text { L } & M & N & S & L & G & K & F & T & D\end{array}$

421 AgGGACTTCGTCAGCATTTTCAGGTTCAAAACCTGGTGGTCTACTCAATGGGTCGGGACA 480 $\begin{array}{llllllllllllllllllllll}105 & R & D & F & V & S & I & F & R & F & K & T & W & W & S & T & Q & W & V & G & T\end{array}$

481 ACAGGTTCAGACATACAAATGGAGACACAGTGGATAATGCTAGACGTGCCGGAGATCAAG 540 $\begin{array}{lllllllllllllllllllll}125 & \mathrm{~T} & G & \mathrm{~S} & \mathrm{D} & \mathrm{I} & \mathcal{Q} & \mathrm{M} & \mathrm{E} & \mathrm{T} & \mathcal{Q} & \mathrm{W} & \mathrm{I} & \mathrm{M} & \mathrm{L} & \mathrm{D} & \mathrm{V} & \mathrm{P} & \mathrm{E} & \mathrm{I} & \mathrm{K}\end{array}$

541 TCCTACGCTGTCGTGGTCCCAATAGTTGAAGGGAAATTCAGGTCCGCACTTTTCCCTGGG 600 $\begin{array}{lllllllllllllllllllll}145 & \mathrm{~S} & Y & A & V & V & V & P & I & V & E & G & K & F & R & S & A & L & F & P & G\end{array}$

601 AAAGACGGTCATATCTTGATCGGTGCAGAAAGTGGTTCTACCAAAGTGAAGACATCAAAC 660 $\begin{array}{lllllllllllllllllllll}165 & K & D & G & H & I & L & I & G & A & E & S & G & S & T & K & V & K & T & S & N\end{array}$

661 TTCGACGCGATCGCGTATGTGCACGTGTCTGAAAATCCTTACACCTTGATGAGAGACGCT 720 $\begin{array}{llllllllllllllllllllllll}185 & \mathrm{~F} & \mathrm{D} & \mathrm{A} & \mathrm{I} & \mathrm{A} & \mathrm{Y} & \mathrm{V} & \mathrm{H} & \mathrm{V} & \mathrm{S} & \mathrm{E} & \mathrm{N} & \mathrm{P} & \mathrm{Y} & \mathrm{T} & \mathrm{L} & \mathrm{M} & \mathrm{R} & \mathrm{D} & \mathrm{A}\end{array}$

721 TACACTGCTGTAAGAGTTCATCTCAACACGTTCAAGCTTATCGAAGAGAAATCCGCGCCG 780 $\begin{array}{llllllllllllllllllllll}205 & \text { Y } & \text { T } & \text { A } & \text { V } & R & \text { V } & \text { H } & \text { L } & \text { N } & \text { T } & \text { F } & \text { K } & \text { L } & \text { I } & \text { E } & \text { E } & \text { K } & \text { S } & \text { A } & \text { P }\end{array}$

781 CCCCTGGTGAATAAGTTCGGGTGGTGGACTTGGGATGCTTTTTACTTGACCGTGGAGCCA 840 $\begin{array}{lllllllllllllllllllll}225 & \text { P } & \text { L } & \text { V } & \text { N } & \text { K } & \text { F } & G & \text { W } & \text { W } & \text { T } & \text { W } & \text { D } & \text { A } & \text { F } & \text { Y } & \text { L } & \text { T } & \text { V } & \text { E } & \text { P }\end{array}$

841 GCTGGTATTTACCATGGTGTGCAAGAGTTTGCTGATGGAGGGCTGACCCCGAGGTTTCTG 900 $\begin{array}{llllllllllllllllllllll}245 & A & G & I & Y & H & G & V & Q & E & F & A & D & G & G & L & T & P & R & F & L\end{array}$

901 ATTATAGACGACGGGTGGCAAAGCATTAATAACGATGATAACGACCCGAATGAGGATGCG 960 $\begin{array}{llllllllllllllllllllll}265 & I & I & D & D & G & W & Q & S & I & N & N & D & D & N & D & P & N & E & D & A\end{array}$

961 AAGAATCTCGTACTCGGGGGGACTCAAATGACTGCCAGGCTTCACAGGCTTGATGAATGT 1020 $\begin{array}{ccccccccccccccccccccc}285 & K & N & L & V & L & G & G & T & Q & M & T & A & R & L & H & R & L & D & E & C\end{array}$

1021 GAGAAATTTAGGAAATACAAAGGTGGATCGATGTCGGGACCTAATCGTCCACCGTTTGAT 1080 $\begin{array}{llllllllllllllllllllll}305 & E & K & F & R & K & Y & K & G & G & S & M & S & G & P & N & R & P & P & F & D\end{array}$

1081 CCTAAGAAGCCGAAGTTGTTGATTTCTAAGGCTATTGAGATCGAAGTTGCTGAAAAAGCA 1140 $\begin{array}{llllllllllllllllllllll}325 & \mathrm{P} & \mathrm{K} & \mathrm{K} & \mathrm{P} & \mathrm{K} & \mathrm{L} & \mathrm{L} & \mathrm{I} & \mathrm{S} & \mathrm{K} & \mathrm{A} & \mathrm{I} & \mathrm{E} & \mathrm{I} & \mathrm{E} & \mathrm{V} & \mathrm{A} & \mathrm{E} & \mathrm{K} & \mathrm{A}\end{array}$

1141 CGTGACAAGGCGGCTCAATCGGGTGTCACTGATTTGGCTAGATACGAAGCTGAGATTGAG 1200 $\begin{array}{lllllllllllllllllllll}345 & R & D & K & A & A & Q & S & G & V & T & D & L & A & R & Y & E & A & E & I & E\end{array}$

1201 AAACTGACAAAAGAATTGGATCAAATGTTCGGTGGAGGTGGAGAAGAAACGAGTTCGGGT 1260

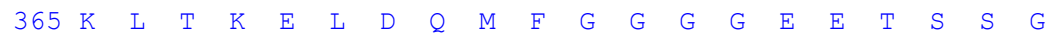

1261 AAAAGCTGTTCGAGTTGCTCTTGCAAATCAGATAACTTTGGGATGAAAGCGTTTACGAAG 1320 $\begin{array}{llllllllllllllllllllll}385 & K & S & C & S & S & C & S & C & K & S & D & N & F & G & M & K & A & F & T & K\end{array}$

1321 GATTTAAGGACGAATTCAAAGGTTTGGATGATATATATGTTTGGCATGCATTGGCTGGT 1380 $\begin{array}{llllllllllllllllllllll}405 & D & L & R & T & N & F & K & G & L & D & D & I & Y & V & W & H & A & L & A & G\end{array}$

1381 GCATGGGGAGGAGTTAGGCCCGGTGCGACTCATTTGAATGCCAAGATTGTCCCGACCAAC 1440 $\begin{array}{llllllllllllllllllllll}425 & \text { A } & W & G & G & V & R & P & G & A & T & H & \text { L } & \text { N } & \text { A } & \text { K } & \text { I } & \text { V } & \text { P } & \text { T } & \text { N }\end{array}$

1441 CTGTCACCCGGACTGGATGGAACAATGACTGATCTGGCAGTTGTGAAGATTATCGAGGGT 1500 $\begin{array}{lllllllllllllllllllll}445 & \text { L } & S & P & G & \text { L } & \text { D } & G & \text { T } & \text { M } & \text { T } & \text { D } & \text { L } & \text { A } & \text { V } & \text { V } & \text { K } & \text { I } & \text { I } & \text { E } & \text { G }\end{array}$

1501 TCAACCGGGCTCGTGGATCCTGATCAGGCGGAGGACTTCTACGACTCCATGCACTCGTAT 1560 $\begin{array}{llllllllllllllllllllllll}465 & S & \text { T } & G & L & V & D & P & D & Q & A & E & D & F & Y & D & S & M & H & S & Y\end{array}$

1561 CTCTCTAGTGTTGGAATACTGGAGTTAAAGTGGATGTTATCCATACGCTTGAATACATA 1620 $\begin{array}{llllllllllllllllllllll}485 & \mathrm{~L} & \mathrm{~S} & \mathrm{~S} & \mathrm{~V} & \mathrm{G} & \mathrm{I} & \mathrm{T} & \mathrm{G} & \mathrm{V} & \mathrm{K} & \mathrm{V} & \mathrm{D} & \mathrm{V} & \mathrm{I} & \mathrm{H} & \mathrm{T} & \mathrm{L} & \mathrm{E} & \mathrm{Y} & \mathrm{I}\end{array}$
} 


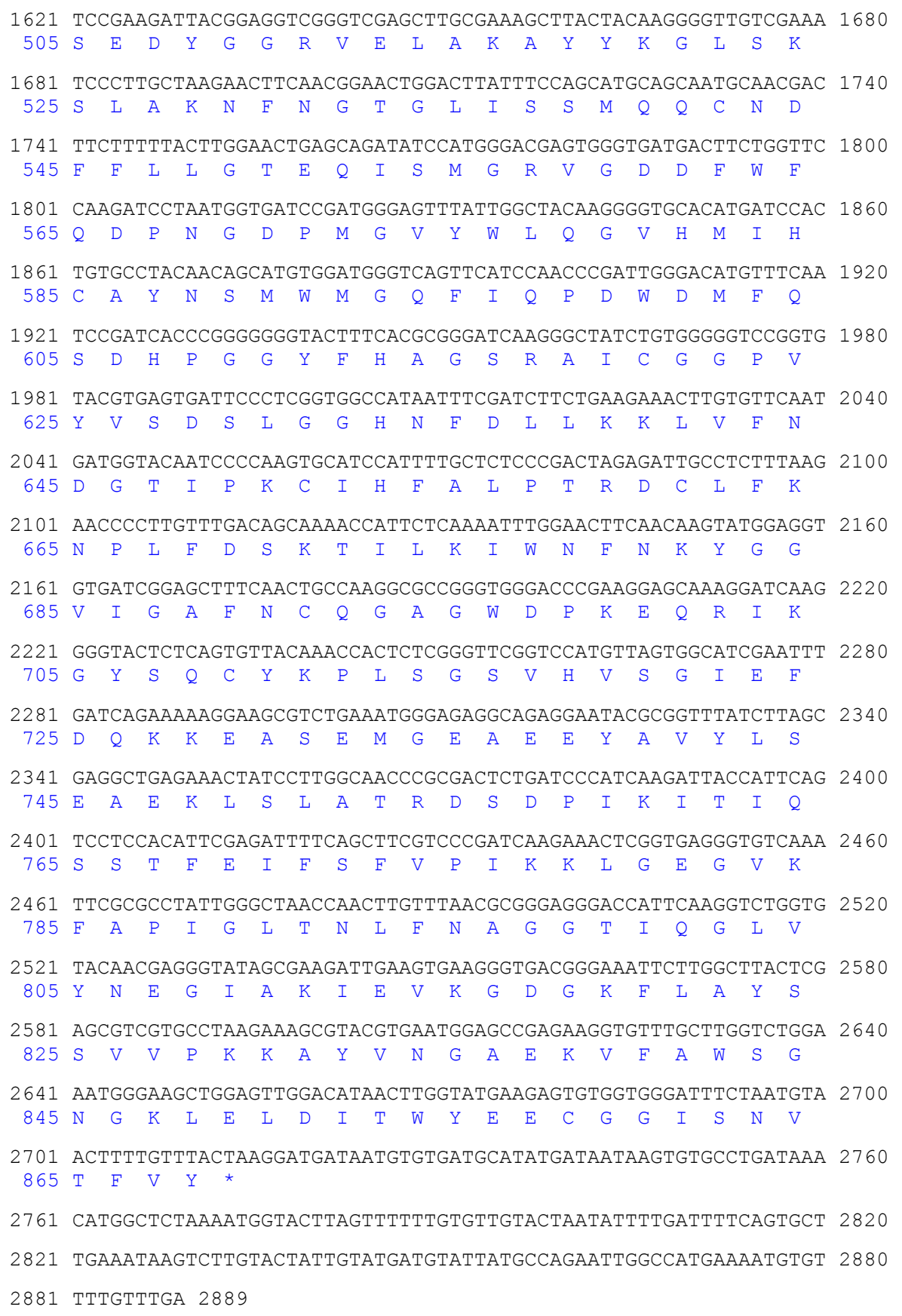

Figure 3.20. The nucleotide and deduced amino acid sequences of the AmSTS cDNA full length clone. The $5^{\prime}$-untranslated region of 108 nucleotides is underlined and the two $5^{\prime}$ uORFs within it are shadowed. The methionine at the start of the STS protein sequence is labelled by inverse printing. 


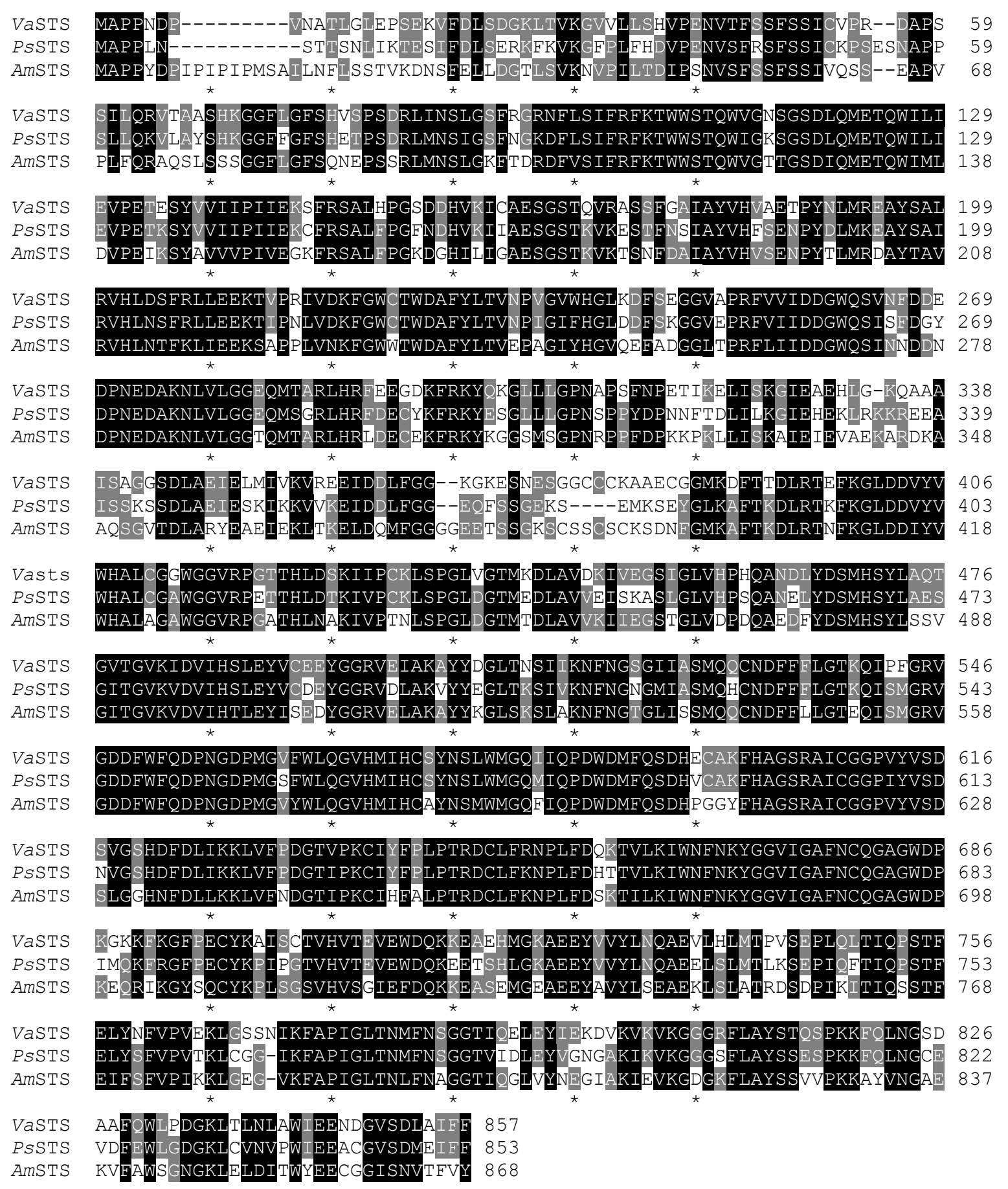

Figure 3.21. A comparison of the deduced amino acid sequence of AmSTS with two known sequences of stachyose synthases: VaSTS from Vigna angularis (Peterbauer et al., 1999) and PsSTS from Pisum sativum (T. Peterbauer, Accession No. CAC38094). AmSTS shows 71\% similarity (63\% identity) with $\mathrm{VaSTS}$ and $74 \%$ similarity (66\% identity) with PsSTS. 

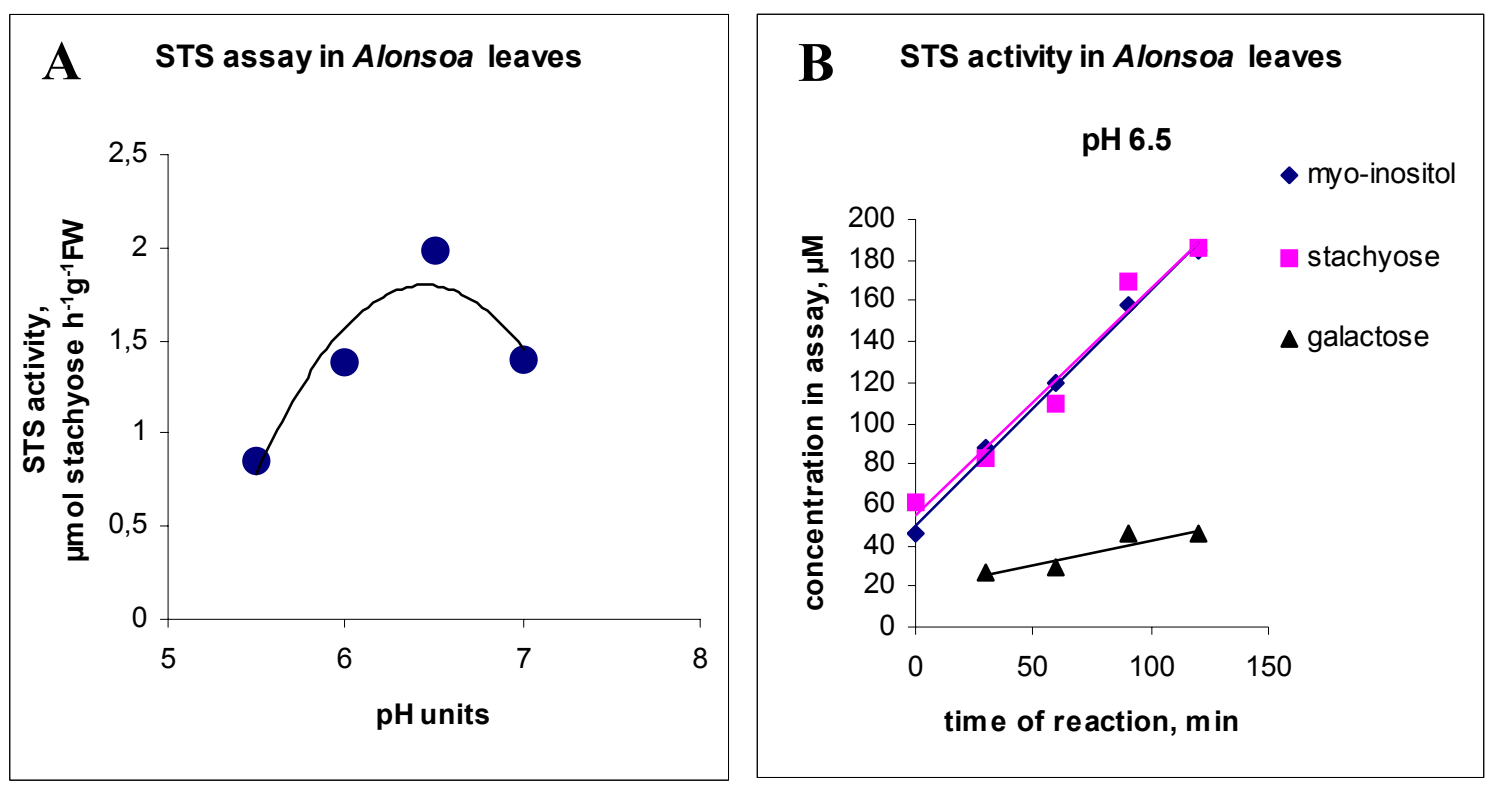

Figure 3.22. Determination of the activity of stachyose synthase in crude extracts of leaves of Alonsoa meridionalis. A, time-dependent increase of stachyose and myoinositol concentrations in the assay; $\mathbf{B}$, activity measured at different $\mathrm{pH}$ values.

\subsubsection{AmSTS is encoded by a small gene family containing most probably two members}

To obtain information about the gene family situation of AmSTS, a Southern blot with total genomic DNA of Alonsoa meridionalis was hybridized with the full size cDNA of AmSTS (2.19.2).

Total DNA from Alonsoa leaves was restricted by five different endonucleases which have different numbers of restriction sites within the AmSTS cDNA sequence: EcoRI (1 site), HindIII (2 sites), BamHI (1 site), PstI (none) and SalI (none) and transferred to a nylon membrane. After hybridization, the membrane was washed under stringent conditions (2.19.5.2).

The hybridization was performed twice with independent preparations of total genomic DNA from Alonsoa. Both blots showed the same hybridization pattern (Figure 3.23). The expected numbers of the hybridizing DNA bands are listed below the image of the blot. In both cases, one additional labelled hybridizing fragment for HindIII-restricted DNA and one additional labelled fragment for BamHI-restricted DNA were present. That means that either, at least one additional restriction site for HindIII and BamHI, respectively, is present within the AmSTS introns, or that the AmSTS gene family includes more than one member. 


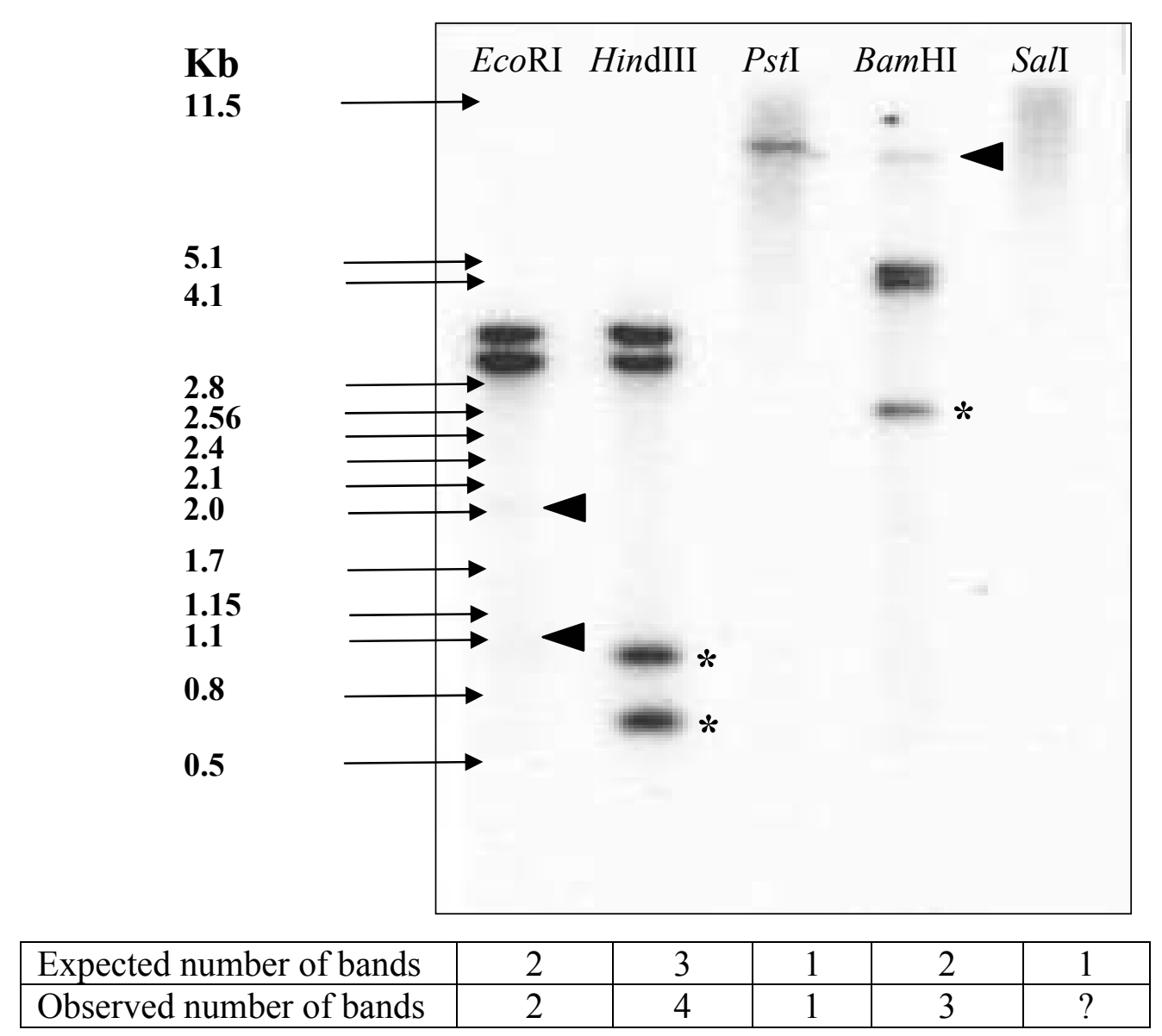

Figure 3.23. Hybridization of a Southern blot containing genomic DNA of Alonsoa meridionalis with the AmSTS full size cDNA. Filled arrow heads point at weak bands. Stars mark internal AmSTS gene fragments. The numbers of hybridizing fragments as expected from the known restriction sites within the AmSTS cDNA and its introns are compared with the numbers of hybridizing fragments observed.

To check whether additional restriction sites are present within AmSTS introns, PCR was performed with genomic DNA isolated from Alonsoa leaves. Primers were designed to obtain three DNA fragments covering the whole length of AmSTS transcribed region. The positions of the specific primers on the AmSTS cDNA sequence are shown in Figure 3.24. The three PCR products obtained were about 50 - 200 bp longer than the corresponding AmSTS cDNA fragments, indicating that the ORF of the AmSTS gene does not contain large introns (data not shown). The PCR products were cloned in pGEM ${ }^{\circledR}-\mathrm{T}$ Easy and subjected to restriction analysis which showed that the amplified DNA fragments contained no restriction sites for EcoRI, HindIII, BamHI and PstI in addition to those already known for the AmSTS cDNA (data not shown). The size of the introns was estimated as 50, 100 and $180 \mathrm{bp}$ (Figure 3.24).

Mapping of the restriction sites for EcoRI, HindIII and BamHI on the AmSTS gene sequence including its $1850 \mathrm{bp} 5^{\prime}$ promoter region (for the isolation of promoter see 3.3.6.1) 


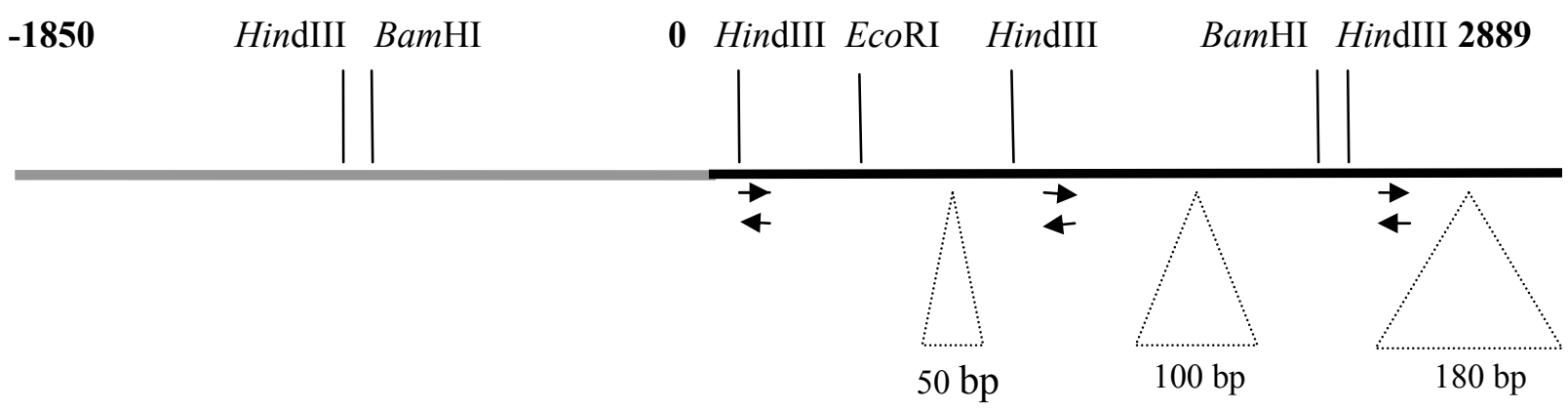

Figure 3.24. The positions of restriction sites for EcoRI, HindIII and BamHI on the AmSTS gene. The promoter region is presented in grey and the transcribed region is given in black. The size and (approximate) positions of the three introns found within the AmSTS ORF are shown as triangles. Arrows indicate the position of primers used to obtain DNA fragments with introns.

allowed to estimate the expected size of several DNA fragments hybridizing on the Southern blot. These were a 890 bp and a 960 bp fragment for DNA restricted with HindIII and a 2565 bp fragment for DNA restricted with BamHI (Figure 3.23). The appearance of two larger DNA fragments (HindIII and BamHI) cannot be explained by additional restriction sites in introns and indicates the presence of (an)other gene family member(s). It is unlikely that these additional fragments are due to cross-hybridization between AmSTS and AmRS sequences, since the hybridization of additional fragments was of similar strength as that of the identified fragments. Rather, this cross-hybridization might explain the appearance of three week bands found. The presence of only one hybridizing fragment in case of PstI restriction might indicate that the number of gene family members is small; there are probably only two gene copies situated not far from each other.

\subsubsection{Localization of AmSTS mRNA in leaves of Alonsoa meridionalis by in situ RNA hybridization: AmSTS expression is confined to intermediary cells}

The in situ antisense RNA hybridization method allows to localize the expression of a gene to specific cells or tissues within plant organs. Since the washing conditions are not stringent, in situ probes do not distinguish between different members of a gene family. Thus, with antisense RNA corresponding to the AmSTS cDNA fragment (3.3.1), the expression of all AmSTS genes can be detected.

The localization of the expression of the genes of stachyose synthase, raffinose synthase and of the sucrose transporter gene (AmSUT) should be compared to each other in Alonsoa meridionalis by the in situ antisense RNA hybridization studies. For this analysis, information about the expression levels of the selected genes in different plant organs was 
necessary. AmSUT expression levels were very low and could only be detected by RT-PCR (Knop et al., 2001). AmSUT expression levels were highest in stems, followed by flowers, mature leaves and roots. To obtain data about the expression levels of AmSTS and AmRS,

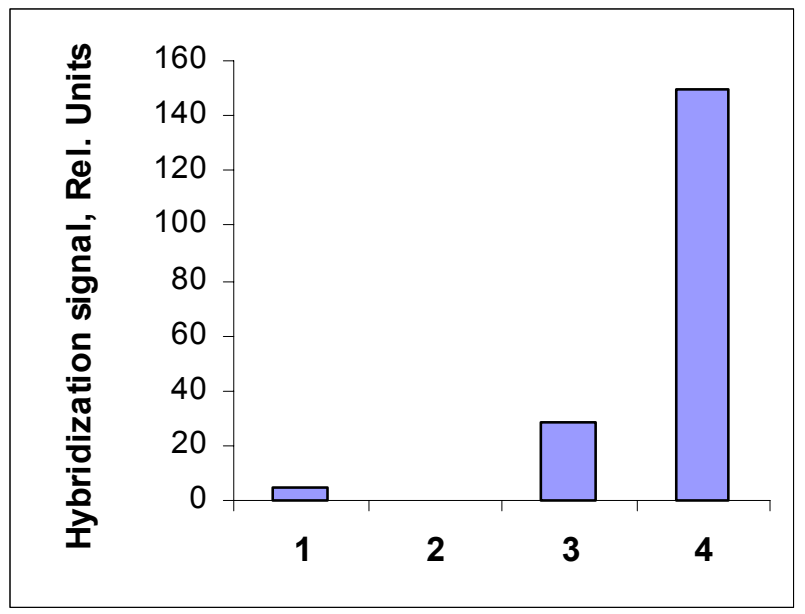

Figure 3.25. Relative expression levels of AmSTS in different organs of Alonsoa meridionalis. 1, flowers; 2, stems; $\mathbf{3}$, young leaves; 4, mature leaves.

RNA gel blot hybridisation analysis was performed with RNA isolated from source leaves, sink leaves, stems and flowers (2.19.4). However, even after long-term exposure of the hybridized blots, no hybridizing bands were observed for $A m R S$ which indicates that this gene has very low expression levels. In case of $A m S T S$, expression levels (quantified on the basis of RNA amounts as indicated by the strength of the 28S rRNA band) was strongest in source leaves, followed by sink leaves and flowers, while no hybridization was found for RNA from stem (Figure 3.25).

For the in situ hybridisation, pieces of stems and leaves of Alonsoa were fixed and embedded in paraffin, and $8 \mu \mathrm{m}$ thick sections were put on slides (2.14). RNA probes were prepared as described in 2.25.1.2 The cloning of the cDNA fragments of both AmRS and AmSTS has been described (3.3.1). In order to obtain templates for in vitro transcription, the EcoRI inserts of the pGEM®-T Easy clones of AmRS and AmSTS, as well as a cDNA fragment of AmSUT provided by Christian Knop, were subcloned in pBluescript ${ }^{\circledR}-\mathrm{IIKS}^{+}$. The in situ hybridisations were performed as described in 2.25.2-5. To preserve the quality of the leaf sections, it was essential not to dry the slides during the whole procedure. Staining of intermediary cells of Alonsoa leaves hybridised with AmSTS antisense RNA was observed after 15 hours incubation in detection reagent (Figure 3.26) in two independent experiments. With the other probes, no staining was detected in sections of both leaves and stems even after 36 hours of incubation in detection reagent (not shown). 
A

B
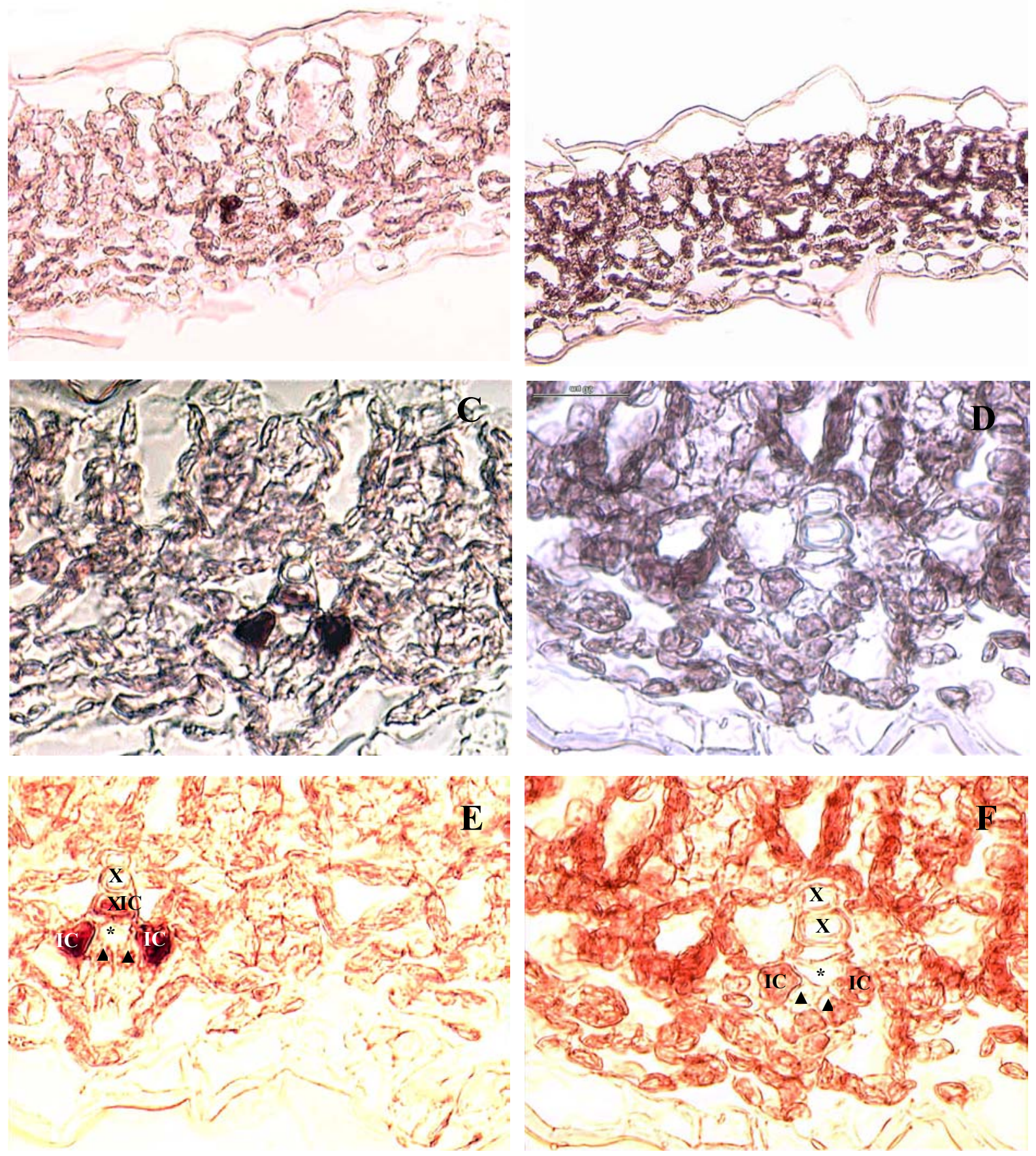

Figure 3.26. In situ hybridization of $8 \mu \mathrm{m}$ thin sections of leaves of Alonsoa meridionalis with a digoxigenine-labelled AmSTS antisense RNA probe. A, C, E hybridization with the antisense probe; $\mathbf{B}, \mathbf{D}, \mathbf{F}$ - hybridization with the sense control. A, $\mathbf{B}$ - an overview of a transverse section through a leaf (magnification x100), arrowheads point at a minor vein; C, D, E, F - a minor vein, magnification x600. C, D - staining of intermediary cells with the AmSTS antisense probe, no staining in control (arrows); E, F - the same minor vein photographed with another filter combination. IC, intermediary cell; $\mathbf{X}$, xylem vessel; *, phloem parenchyma cell; $\boldsymbol{\Delta}$ point at sieve elements. 


\subsubsection{Expression of AmSTS promoter-GUS fusion constructs in Arabidopsis}

Since expression levels of AmSTS were low overall, they might well be below the detection limit of in situ hybridisation in some cells/organs. In such a case, the expression pattern can be studied by using a promoter-reporter gene fusion in transgenic plants. However, no method for transformation of Alonsoa has been established yet. Yet promoter activities are often conserved in other plant species. Therefore a AmSTS promoter- $\beta$ glucuronidase (GUS) fusion construct was prepared in a binary vector in order to study the regulation of the AmSTS promoter in Arabidopsis. To find out whether the 5'untranslated region has a function in the regulation of transcription levels or patterns, two constructs were prepared, one containing only the promoter and one also the 5' UTR.

\subsubsection{Cloning of the AmSTS promoter}

$1.85 \mathrm{~Kb}$ of the AmSTS $5^{\prime}$-upstream sequence were obtained by the Genome Walking method (2.21.4) and cloned in pGEM ${ }^{\circledR}-\mathrm{T}$ Easy. The sequence is shown in Figure 3.27. No known cis-elements for the interaction with plant transcription factors could be found in this sequence in either of two databases as it was checked by two database searches (http://transfac.gbf.de/TRANSFAC; http://pdap1.trc.rwcp.or.jp/research/db/TFSEARCH.html).

\subsubsection{Promoter-GUS fusion constructs and 5 ' $u$ ORF}

The cloning strategy for the promoter-GUS fusion construct in the binary vector pBI101.3 is shown in Figure 3.28. Two constructs were prepared, one that contained only the promoter $(\mathrm{PmrB})$ and another one that contained also the $5^{\prime}$ untranslated region of the AmSTS cDNA with the two small uORFs (PmrA; 3.3.2; Figure 3.28).

\subsubsection{The AmSTS promoter directed GUS activity in minor veins in transgenic F1 lines of Arabidopsis containing either AmSTS promoter-GUS fusion construct}

Arabidopsis thaliana ecotype Columbia was transformed via infiltration (2.24.3) and seeds of the transformed plants were germinated on MS medium containing $2 \%$ sucrose and kanamycin. For each construct, $15 \mathrm{~F} 1$ plantlets were transferred to pot soil and grown for seeds. When the F1 plants were in the rosette stage, two rosette leaves of each plant were used for GUS activity staining (2.24.4.1). All leaves analysed showed GUS activity staining in the vascular tissue (Figure 3.29). Interestingly, the PmrA and PmrB constructs differed in GUS expression levels. Although among lines transformed with the same construct, various levels of GUS expression were observed, most PmrA transformants showed an essentially higher level of GUS activity than the PmrB transformants. For each construct, eleven transgenic F1 plants were selected for further analysis, ten of which showed high and one of which showed low levels of GUS activity. The seeds from these plants were harvested, and 100 F2 seeds per 


\begin{tabular}{|c|c|c|c|c|c|c|}
\hline 50 & ГGG & CCTTGACACC & $\mathrm{AAT}$ & GGT & GGC & \\
\hline-1790 & AGACCTCTA & CCAAGGGACT & TGCTGCGTA & CACAAAATTC & AAACTCGAGA & сTCTTGGTT \\
\hline-1730 & AAGCGACTAA & GCCTCTTCT & TTAAGTCA & стстTTGGT & ATGTAAGGC & TA \\
\hline-1670 & TTATTATT & СтTТСААТт & TAGTCCAAT & GACAAAGAT & TCATAAGAAT & ГТАТСАСАА \\
\hline-161 & CACACGTA & AAGTACAAC & AGGAAATA & TTTGCCCTAT & GATGCTTACA & $\mathrm{BC}$ \\
\hline & AAGTGCATGG & GCTAAAGCCT & CAAAGCCTA & ATTCATAATA & TAATTACAAG & TGT \\
\hline-14 & ATCTGTTT & GGCССТTAA & $\triangle A C C A A A G G$ & АААТTTTTAT & TTAGGCCCAT & TAAG \\
\hline-14 & AGTTATCA & TTTTATCGTC & ATAAAATT & AGTAGGGCCC & TCGGCTCCAT & $\mathrm{CT}$ \\
\hline & AACAACAACC & ACGACGACAA & AATAATAAT & ATATTTGTT & TAAT & GGCA \\
\hline-1 & TATAАТАТАA & CTAGCGAT & GTAGAACAC & CGAGCACGT & TGC & ATAAG \\
\hline-12 & ATAGA & GAATGATT & гтTтTтят & TTTGTTTGA & TTTG & $\mathrm{GTCT}$ \\
\hline & $\mathrm{TCTA}$ & ATTGTATTTT & ттттттсс & ГTTGTGTAG & $\mathrm{BAT}$ & 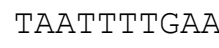 \\
\hline & TAAT & САТСAACAAA & TATGAAATG & CATCСТTTTG & $\mathrm{ACA}$ & $\mathrm{ATA}$ \\
\hline-10 & AAGT & ATCGTATTT & ATTCGCCAA & ATCAGAGCTG & ATT & ССТСC \\
\hline 1 & $\mathrm{CTT}$ & CAA & TTA & $\mathrm{GCC}$ & CA & 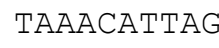 \\
\hline & $\mathrm{TT}$ & GTTTGTCAAG & GTG & GATT & $\mathrm{AT}$ & $H \perp C \rightarrow$ \\
\hline-8 & GGA & GTCGGTCTGA & TCGTT & ATTTCCGCGT & $\mathrm{AAT}$ & I"I'GIC' \\
\hline & AI & $\mathrm{ACGA}$ & GAA & $\Gamma \mathrm{GA}$ & GG & $\mathrm{TC}$ \\
\hline & $\mathrm{TTC}$ & GTTCATATAT & $A G C$ & TCACGAGCTC & $\mathrm{AAT}$ & АтААТАТтTА \\
\hline-7 & TTAC & TATATATTGC & CGA & GCTCGAGCCA & ATT & TAAAGAGTTC \\
\hline & GAG & $A A A G$ & TTG & $\mathrm{GCT}$ & $\mathrm{TT}$ & GTTC \\
\hline & $\mathrm{AAG}$ & TTTTTGTCGA & CCG & TGTGCCTCGA & AGG & ACAGAAATTA \\
\hline-5 & CAAA & ATCAAGCAAT & TAACAA & AGAAGTTTCC & $\mathrm{ACA}$ & TCATTTTCGG \\
\hline & $\mathrm{CCA}$ & GTTCATCAAC & CTC & CTCTGATAAG & GA & TTCATAACAC \\
\hline & $\mathrm{ACA}$ & TGGAGCTAAA & TTC & AAAACTTAAC & CAAA & AGAAAATTCA \\
\hline & $\mathrm{AACAC}$ & TAAAGAATAA & ATTAATATAT & TTGCTAAATA & $\mathrm{CATC}$ & AGAGACCATG \\
\hline & CATG & TAAAATCTGT & TTC & AATACGCGGT & CGTT & TTCCATGGAC \\
\hline & GCCA & GGTTTGTTTT & CCCСCTCGCA & AAAATGGCAT & $A G A A$ & GAATGGAAGC \\
\hline & ATAAACCGCC & CGAACCTTTA & TCTATACACC & тTтсттTтT & TTTATTCTTT & СТАСТTTСтA \\
\hline & AATA & TTTCCCACTT & тстттAтTтT & TTTAтTCCтC & $\begin{array}{l}\text { TGTTTTTATT } \\
+1\end{array}$ & $\mathrm{TT}$ \\
\hline & & ТСТСТСТАТА & TG & ссеттс & ACAтTTTтст & ATGTGTCCAA \\
\hline & ACTAAGTAAT & AACTCAATAG & TTCATGCATA & AGCTTTTCTZ & $\mathrm{AAA}$ & AATAACTGAT \\
\hline & & 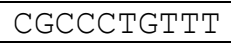 & & & & \\
\hline
\end{tabular}

Figure 3.27. The sequence of the AmSTS promoter region. The sequence corresponding to the 5 '-untranslated region of AmSTS mRNA is underlined and the ATG start codon of the AmSTS ORF is labelled by inverse printing.

plant were germinated on MS medium with 2\% sucrose and kanamycin (50 seeds/plate). The germination rate was protocolled. Germinated seedlings represented either homozygous $(33 \%)$ or heterozygous $(67 \%)$ transformants. For GUS activity staining, six seedlings from each line were used in the primary leaf stage (3.3.6.5). The other seedlings were transferred to soil. For each line, 12 plants were grown for seed production, and 20 plants were grown under 12 hours light/12 hours dark for further GUS activity staining. From eight lines for each construct, two rosette leaves were taken for a quick isolation of total DNA (2.15.3) for PCR analysis with the AmSTS promoter-specific primer pmr5seq 3 and the M13 forward primer (Figure 3.28). PCRs were performed with $5 \mu 1$ of total DNA, an annealing temperature of $54^{\circ} \mathrm{C}$, an amplification time of 150 seconds and 35 cycles. In each case, a PCR product of the expected size (2480 bp for PmrA, 2370 bp for PmrB) was obtained (data not shown). 
$\stackrel{\text { gw5GSP }}{\longrightarrow}$

\begin{tabular}{|c|c|c|}
\hline$\Rightarrow$ & 5'UTR & AmSTS ORF \\
\hline Genome Walking product & & \\
\hline gw3GSPb & $\stackrel{\leftarrow}{\mathrm{gw} 3 \mathrm{G}}$ & \\
\hline
\end{tabular}

PCR, cloning in pGEM ${ }^{\circledR}-\mathrm{T}$ Easy

\section{5'UTR AmSTS Pmr A} AmSTS Pmr B

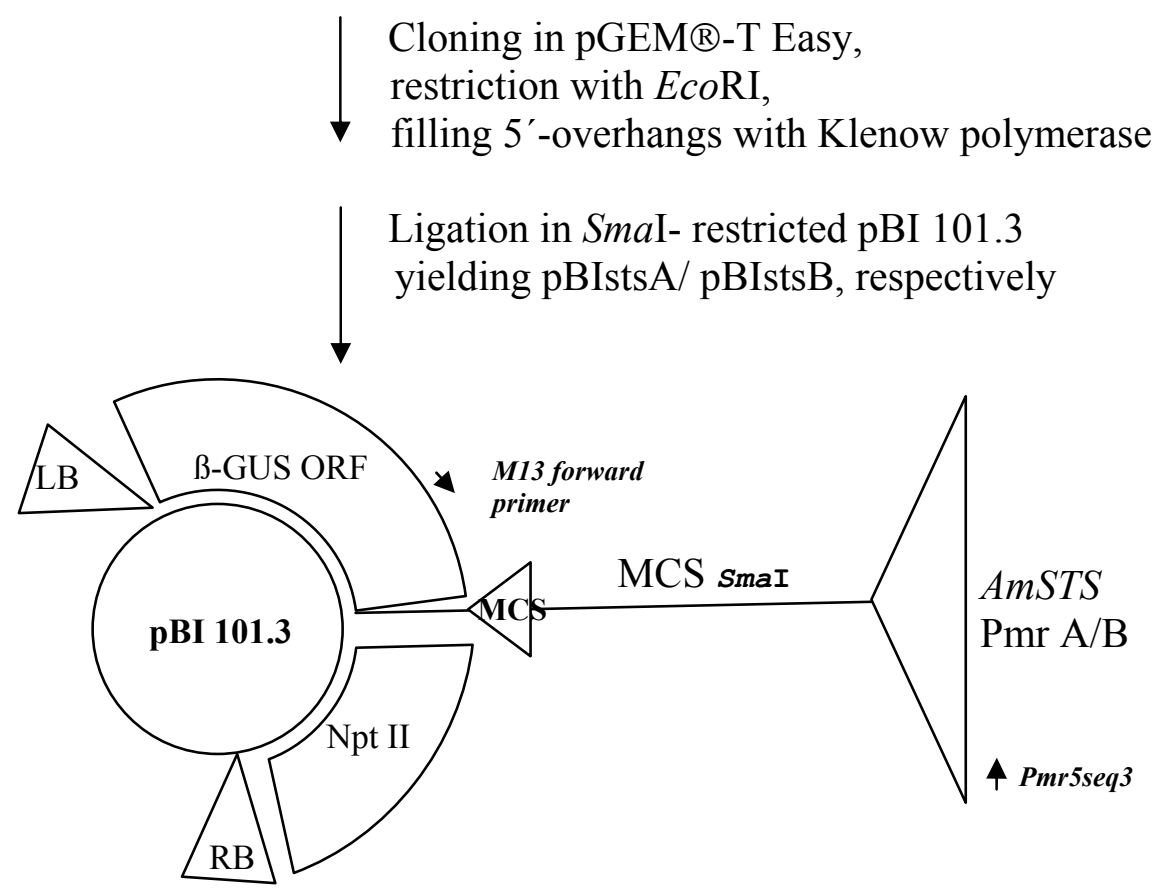

MCS

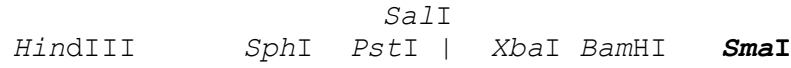
aggaaacagctatgaccatgattacgccaagcttgcatgcctgcaggtcgactctagaggatccccgggtacggtcagtccctte M13 reverse primer

Proof of the insert orientation by PCR using the forward primer and a pmr A/pmrB- specific primer

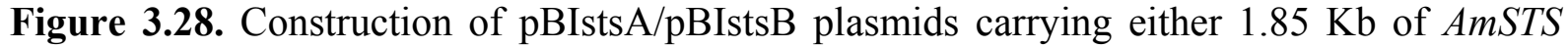
5 'upstream region plus $109 \mathrm{bp} 5$ 'UTR (pBIstsA) or only $1.85 \mathrm{~Kb}$ (pBIstsB) upstream of the $\beta$ glucuronidase (GUS) ORF. The ligation site (SmaI ) and the first codon of GUS ORF are labelled by bold print. NptII, neomycin phosphotransferase; RB, LB - right and left borders of pBI101.3 T-DNA region. PCR with the M13 forward primer and pmr5seq 3 primer was used to identify the positive clones. 

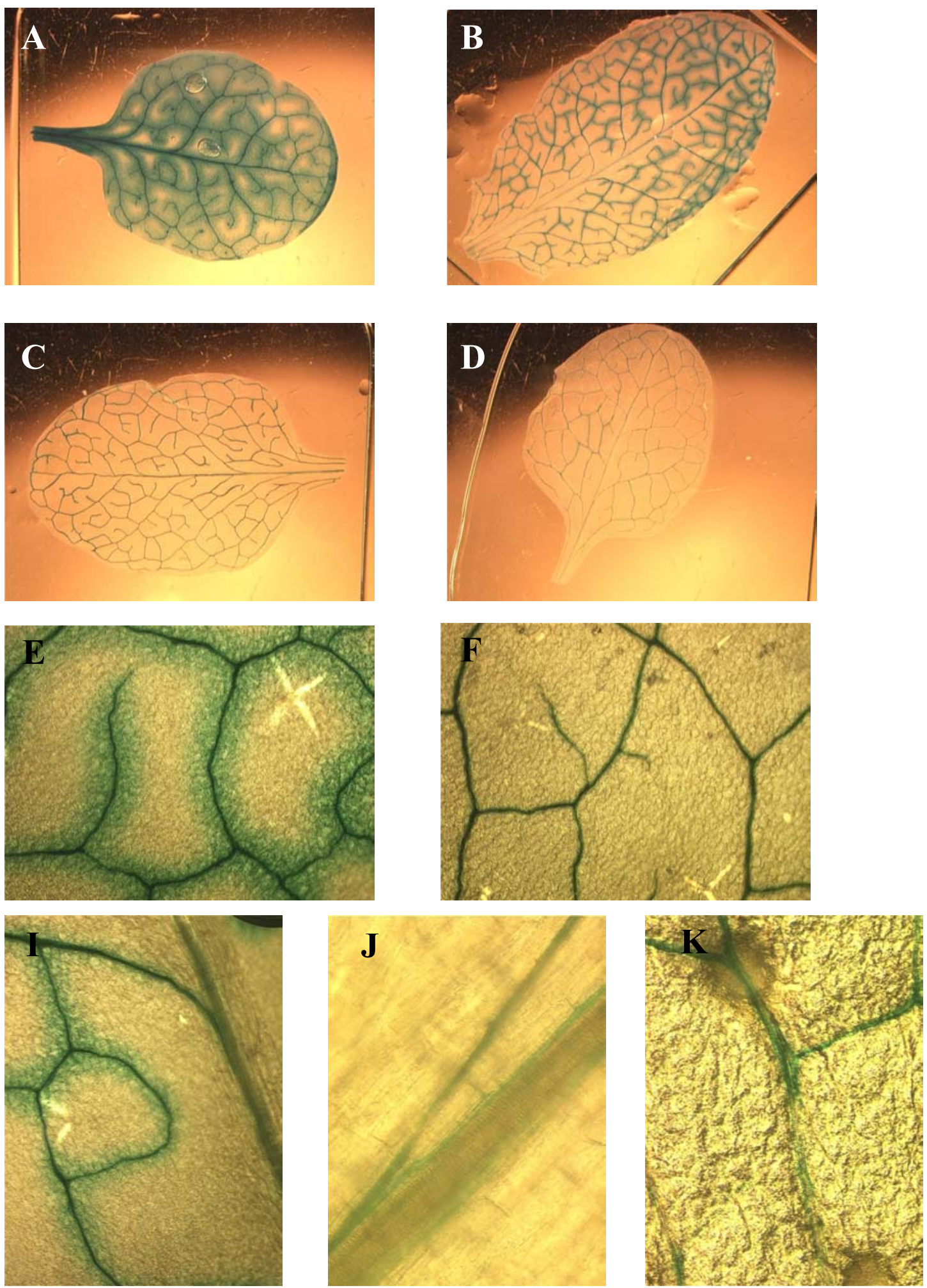

Figure 3.29. Localization of GUS activity in leaves of F1 A. thaliana plants transformed with the AmSTS PmrA-GUS or the AmSTS PmrB-GUS construct, respectively. From 36 lines of F1 transformants analysed, representative lines for both constructs are shown. A, B, E, I - Kferro/ferricyanide not added into the incubation medium; $\mathbf{C}, \mathbf{D}, \mathbf{F}, \mathbf{J}, \mathbf{K}$ - incubation of leaves of the same lines in the presence of $3 \mathrm{mM} \mathrm{K}$-ferro/ferricyanide. A, PmrA, line 5; B, PmrB, line 13; C, PmrA, line 16; D, PmrB, line 22; E, PmrB, line 13, diffusion of the GUS reaction product from the veins into the mesophyll can be observed; F, PmrB line 22, no diffusion of the dye in the presence of Kferro/ferricyanide; $\mathbf{I}, \mathbf{P m r B}$, line 13, diffusion of the dye is stronger in lower order veins; $\mathbf{J}, \mathbf{K}$ - in higher order veins, the dye is localized in the phloem part of the vein $(\mathbf{J}-\mathrm{PmrB}$, line 22; $\mathbf{K}-\mathrm{PmrA}$, line 9). 


\subsubsection{GUS activity was also found in the vascular tissue of sepals and siliques of $F 2$ plants}

When the F2 plants were flowering, flowers, inflorescence shoots and developing siliques were harvested for GUS activity staining. The results are shown in Figure 3.30. GUS activity was found in vascular tissue of sepals and siliques, but not in petals and not in inflorescence shoots. It should be pointed out that this staining was observed in pieces of inflorescences which were cut from the plants before the GUS activity test was performed. Therefore, the staining could not be due to the diffusion of the product of the GUS reaction from the source leaves to the sink tissues. As already mentioned, the source leaves show a very high GUS activity resulting in some diffusion of the dye into the mesophyll even in the presence of $3 \mathrm{mM} \mathrm{K-ferri/ferrocyanide} \mathrm{in} \mathrm{the} \mathrm{reaction} \mathrm{buffer.}$

\subsubsection{The expression of the AmSTS promoter-GUS fusion was strongly enhanced by sucrose and glucose in Arabidopsis}

F2 seedlings in the primary leaf stage from all lines for both constructs were taken from MS agar plates containing 2\% sucrose and kanamycin and used directly for GUS activity staining. In all cases, staining was confined to the vascular system of primary leaves and cotyledons (Figure $3.31 \mathrm{~A}-\mathrm{C}, \mathrm{E}$ ). In some plantlets of lines displaying very high GUS activity, weak staining of roots could also be observed, which was probably due to diffusion of the dye (Figure $3.31 \mathrm{D}$ ). In some plantlets, hydatodes were also stained (Figure $3.31 \mathrm{~F}$ ). From four lines for each construct (PmrA: lines 3, 4, 6, 8; PmrB: lines 13, 17, 20, 25) 18 seedlings were used to examine the inducibility of the promoter by exogenously added sugars. Plantlets were transferred to liquid MS medium containing either (a) no additives, (b) 180 $\mathrm{mM}$ sucrose or (c) $200 \mathrm{mM}$ glucose, and incubated for $20 \mathrm{hrs}$ at a light/dark cycle. They were harvested after 10 hours of light and stained for GUS activity. The results are shown in Figure 3.32 A-F. AmSTS-GUS expression was still confined to the vascular system in all cases. For each construct, in three out of four lines, expression levels after incubation in MS medium without sugar essentially lower than after incubation in MS medium with either sucrose or glucose (Figure 3.31, A-F). The GUS activity in seedlings incubated in MS medium without additives was significantly lower than in seedlings taken from agar plates and stained directly, while seedlings incubated in MS medium with $180 \mathrm{mM}$ sucrose or $200 \mathrm{mM}$ glucose showed significantly higher GUS activity than seedlings directly taken from plates (data not shown).

The question arises whether the induction of the AmSTS promoter observed in seedlings incubated in MS medium containing $180 \mathrm{mM}$ sucrose or $200 \mathrm{mM}$ glucose as compared to MS medium without additives was related to the specific action of sugars, or was caused by the osmotic action of sugars on the turgor of the leaf cells. This question needs 

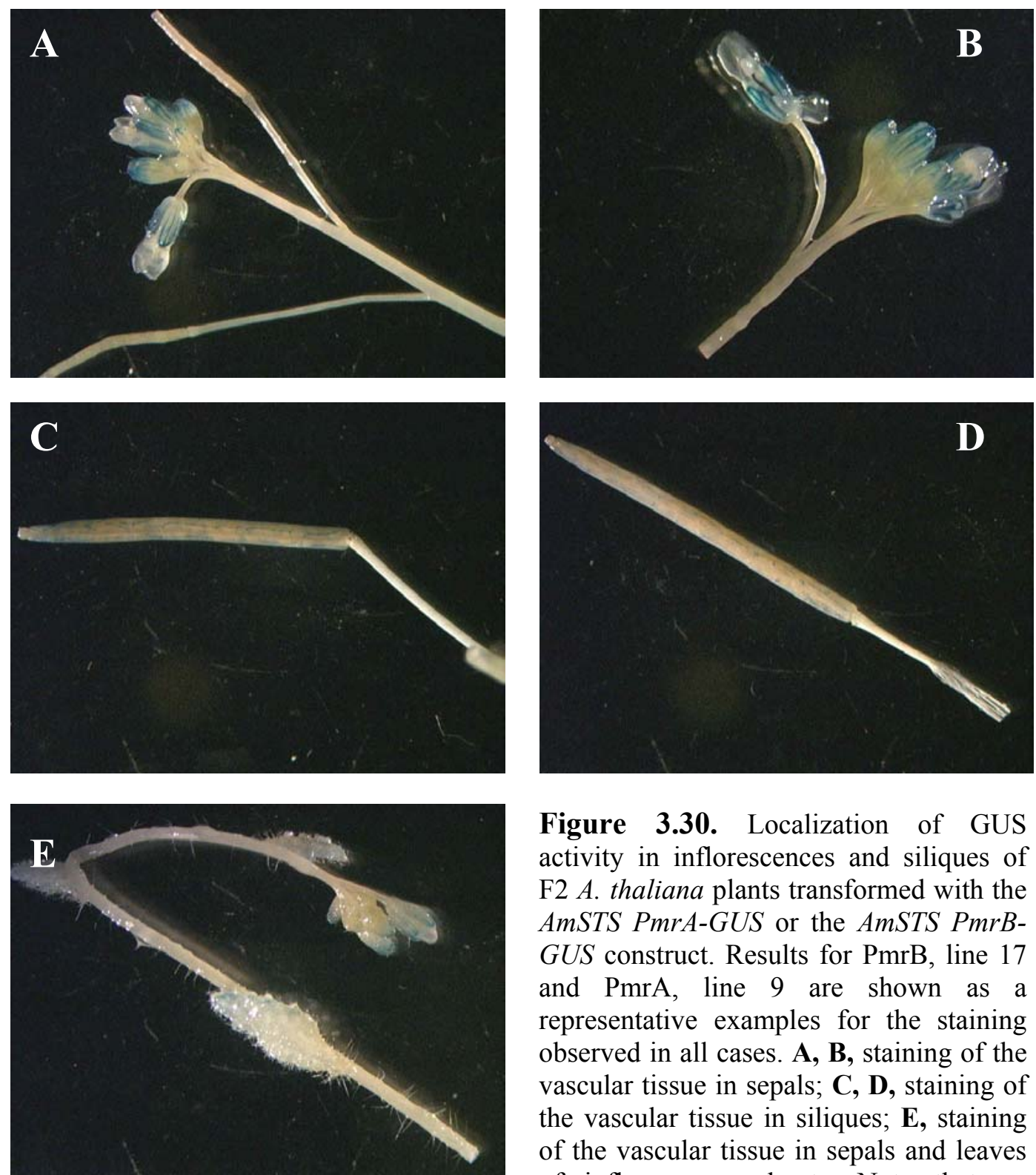

Figure 3.30. Localization of GUS activity in inflorescences and siliques of F2 $A$. thaliana plants transformed with the AmSTS PmrA-GUS or the AmSTS PmrBGUS construct. Results for PmrB, line 17 and PmrA, line 9 are shown as a representative examples for the staining observed in all cases. A, B, staining of the vascular tissue in sepals; $\mathbf{C}, \mathbf{D}$, staining of the vascular tissue in siliques; $\mathbf{E}$, staining of the vascular tissue in sepals and leaves of inflorescence shoots. Note that no staining can be seen in inflorescence shoots (A, B, E).

to be investigated by further experiments as soon as homozygous transformants will be obtained. However, the following experiments suggest that the induction was rather osmotically caused than sugar-specific. In one experiment, six seedlings from two lines were taken from agar plates and incubated in water for one hour, whereas six other seedlings were left in air for the same period to induce drought stress. After incubation, GUS activity staining was performed with all seedlings. The seedlings that were kept in air showed a stronger staining than the seedlings incubated in water (Figure 3.32, G, H). In another experiment, sorbitol showed the same effect on AmSTS-GUS expression as glucose and sucrose. This suggests that AmSTS expression is enhanced rather by an osmotical mechanism than by specific sensing of sugars. 
It should be taken into account that these results were obtained with a mixture of homozygous and heterozygous plants. However, since they were consistent in several independent lines tested, they can be considered to be significant.
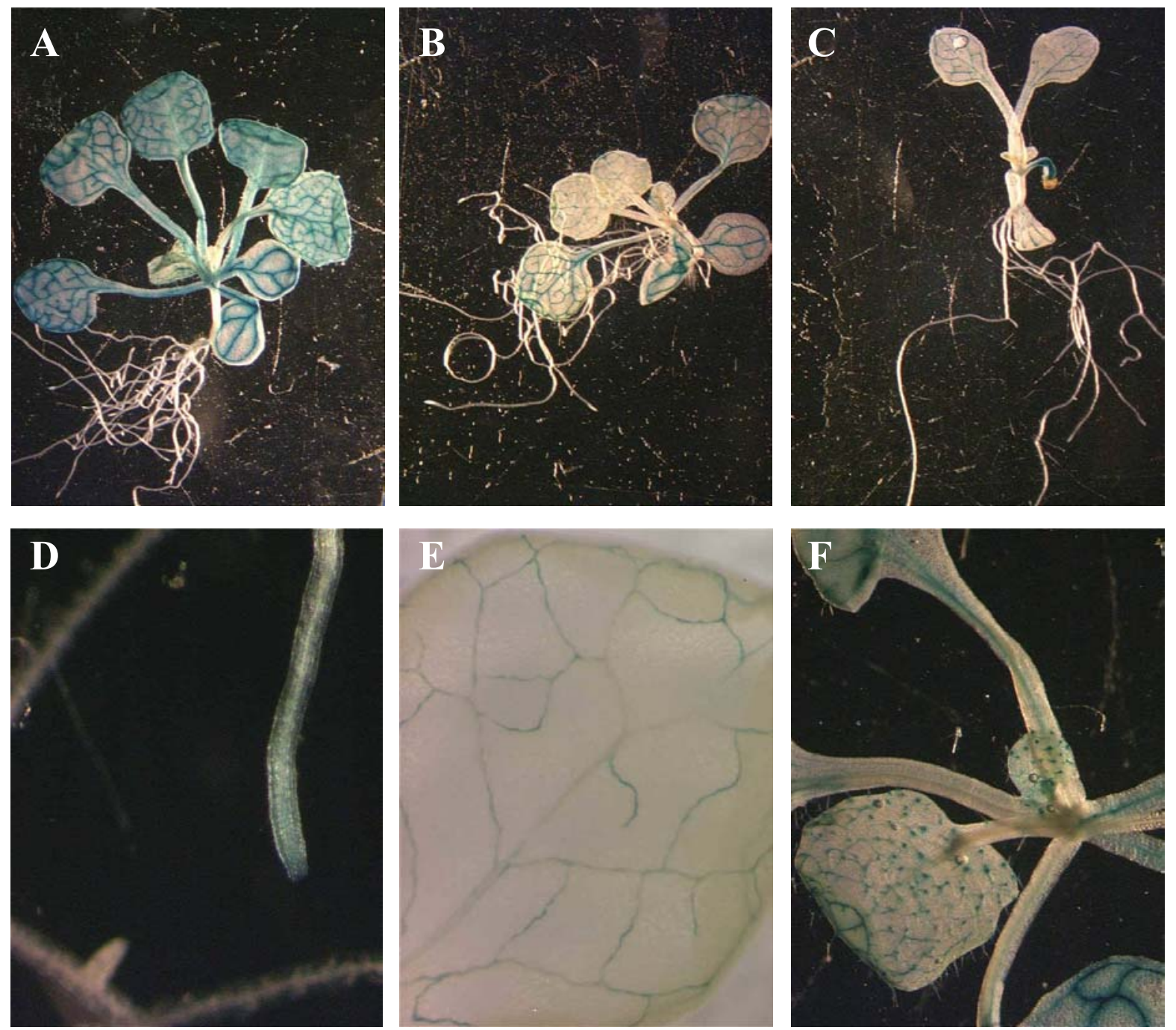

Figure 3.31. Localization of GUS activity in seedlings of $A$. thalinana F2 plants transformed with the AmSTS PmrA-GUS or the AmSTS PmrB-GUS construct. A, B, staining of whole seedlings of PmrA, line 8 (A) and PmrB, line 13 (B); C, staining of the cotyledons in a seedling of PmrB, line13; D, root staining due to the diffusion of the GS reaction product in PmrB, line 17; E, minor veins stained in the leaf of a seedling of PmrB, line 20; F, hydatodes stained in PmrB, line 17. 

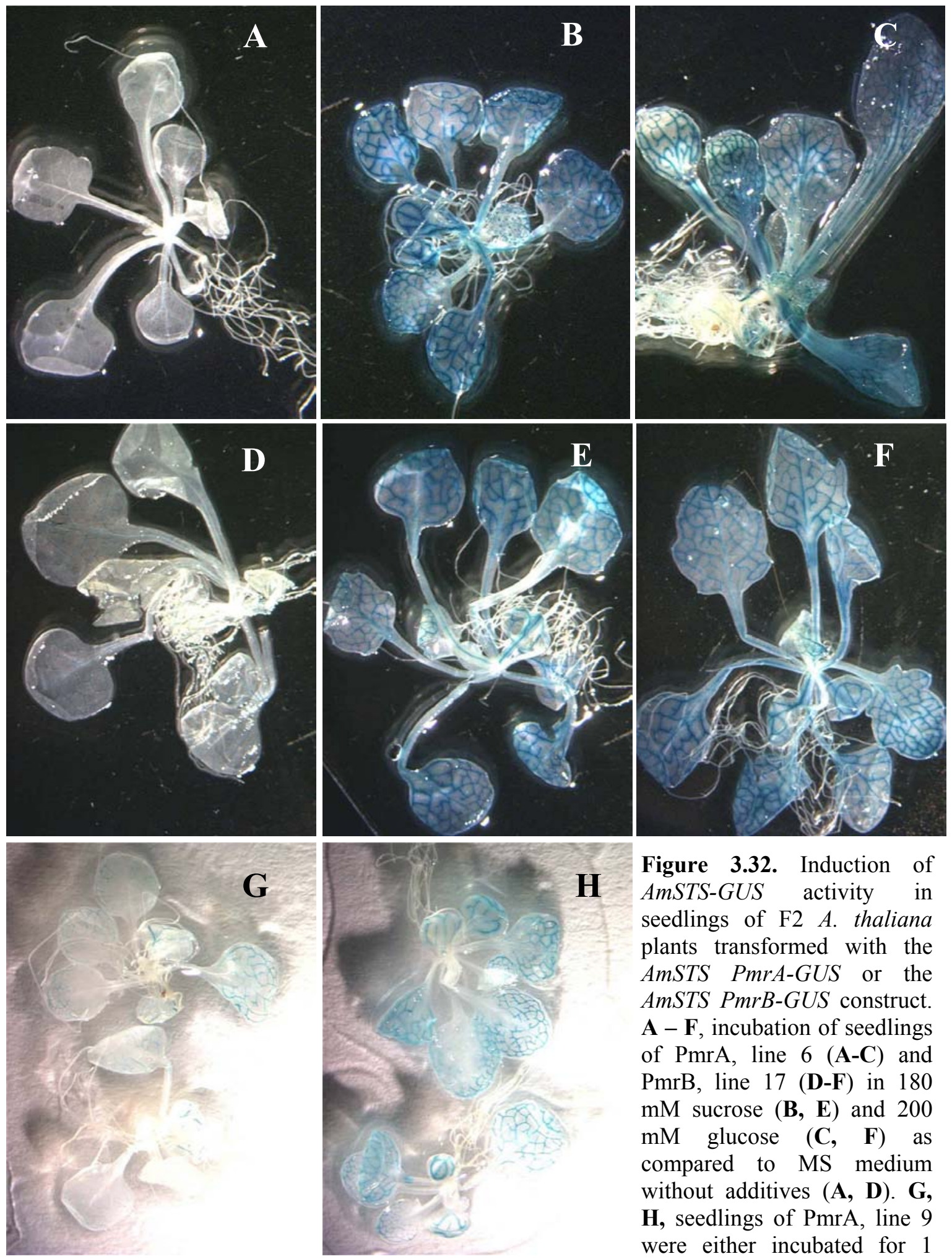

Figure 3.32. Induction of AmSTS-GUS activity in seedlings of F2 $A$. thaliana plants transformed with the AmSTS PmrA-GUS or the AmSTS PmrB-GUS construct. $\mathbf{A}-\mathbf{F}$, incubation of seedlings of PmrA, line 6 (A-C) and PmrB, line 17 (D-F) in 180 $\mathrm{mM}$ sucrose $(\mathbf{B}, \mathbf{E})$ and 200 $\mathrm{mM}$ glucose $(\mathbf{C}, \mathbf{F})$ as compared to MS medium without additives $(\mathbf{A}, \mathbf{D})$. G, $\mathbf{H}$, seedlings of PmrA, line 9 were either incubated for 1 hour in water $(\mathbf{G})$ or left for 1 hour in air $(\mathbf{H})$ before GUS activity staining. 


\section{DISCUSSION}

This study was focused on the following aspects of the phloem loading:

- Are there sugar concentration gradients between the phloem and the cytoplasm of mesophyll cells in a symplastic phloem loader?

- How does the inhibition of phloem translocation affect sugar compartmentation in leaves of Alonsoa meridionalis and Asarina barclaiana?

- Is the leaf apoplast similarly involved in sugar compartmentation in both symplastic and apoplastic loaders?

- In which cells of a leaf is stachyose synthase expressed in the symplastic phloem loader Alonsoa meridionalis? How is this expression regulated?

\subsection{Subcellular compartmentation of carbohydrates and estimation of phloem:mesophyll concentration ratios: implications for the phloem loading mode of different carbohydrates in Asarina and Alonsoa}

\subsubsection{Subcellular distributions of carbohydrates in the symplastic phloem loader Alonsoa meridionalis do not differ from those in apoplastic phloem loaders}

A comparison of the distribution of carbohydrates among subcellular compartments of leaf cells in Alonsoa and Asarina, including data for other plant species, is shown in Table 4.1. For all species listed, the data have been obtained by non-aqueous fractionation of leaves. The data show that the distribution of metabolites between subcellular compartments is similar in different plant species. Hexoses are confined exclusively to vacuoles. Sucrose and mannitol were found in all three subcellular compartments, but in most species the highest amounts of these carbohydrates were found in the cytoplasm. Myo-Inositol was the only substance of which the largest pool was observed in chloroplasts. The subcellular distribution 
of galactinol had previously been determined only in one species, Antirrhinum majus (Moore et al., 1997). Now, the data for Alonsoa meridionalis are available which show that galactinol is confined to the vacuole in both species. The subcellular distribution of the iridoid glucoside antirrhinoside synthesized in Asarina barclaiana was studied for the first time. Antirrhinoside was mostly confined to the vacuoles.

Table 4.1. Percentage distribution of carbohydrates among the stromal (Ch), cytoplasmic (Cyt) and vacuolar (Vac) compartments of leaf cells in different plant species.

\begin{tabular}{|c|c|c|c|c|c|c|c|c|c|c|c|c|c|c|c|c|c|c|}
\hline & \multicolumn{3}{|c|}{ Hexoses } & \multicolumn{3}{|c|}{ Sucrose } & \multicolumn{3}{|c|}{ Mannitol } & \multicolumn{3}{|c|}{$\begin{array}{c}\text { myo- } \\
\text { Inositol }\end{array}$} & \multicolumn{3}{|c|}{ Galactinol } & \multicolumn{3}{|c|}{$\begin{array}{l}\text { Antirrhino- } \\
\text { side }\end{array}$} \\
\hline & $\mathrm{Ch}$ & Cyt & Vac & $\mathrm{Ch}$ & Cyt & $\mathrm{Vac}$ & $\mathrm{Ch}$ & Cyt & Vac & $\mathrm{Ch}$ & Cyt & Vac & $\mathrm{Ch}$ & Cyt & Vac & $\mathrm{Ch}$ & Cyt & Vac \\
\hline $\begin{array}{c}{ }^{1} \text { Asarina } \\
\text { barclaiana }\end{array}$ & 1 & 1 & 98 & 14 & 35 & 51 & 36 & 34 & 30 & 53 & 24 & 23 & & & & 4 & 6 & 90 \\
\hline $\begin{array}{c}{ }^{1} \text { Alonsoa } \\
\text { meridionalis }\end{array}$ & 1 & 1 & 98 & 21 & 44 & 35 & & & & 81 & 13 & 6 & 2 & 2 & 96 & & & \\
\hline $\begin{array}{c}{ }^{2} \text { Antirrhinum } \\
\text { majus }\end{array}$ & 0 & 0 & 100 & 1 & 84 & 15 & 36 & 41 & 24 & 55 & 27 & 18 & 4 & 0 & 96 & & & \\
\hline $\begin{array}{c}{ }^{3} \text { Nicotiana } \\
\text { tabacum }\end{array}$ & 1 & 1 & 98 & 9 & 52 & 38 & & & & & & & & & & & & \\
\hline $\begin{array}{c}{ }^{2} \text { Petroselinum } \\
\text { hortense }\end{array}$ & 3 & 0 & 97 & 5 & 57 & 38 & 19 & 43 & 38 & 43 & 23 & 34 & & & & & & \\
\hline $\begin{array}{l}{ }^{4} \text { Solanum } \\
\text { tuberosum }\end{array}$ & 1 & 1 & 98 & 27 & 40 & 33 & & & & & & & & & & & & \\
\hline
\end{tabular}

${ }^{1}$ This thesis; ${ }^{2}$ data from Moore et al. (1997); ${ }^{3}$ data from Heineke et al. (1994); ${ }^{4}$ data from Leidreiter et al. (1995)

The fact that in all the species studied so far, the patterns of subcellular distribution for each carbohydrate were similar may imply that these substances preferentially accumulate in the compartments where they are synthesized.However, Table 4.2 shows that the subcellular distributions of sugars and of the key enzymes of their biosynthesis do not coincide in most cases. One group of carbohydrates including hexoses, galactinol and antirrhinoside was located mostly in vacuoles. For hexoses, this probably means that they derive mostly from the hydrolysis of sucrose by vacuolar invertase. No exact information is available on the compartmentation of the synthesis of antirrhinoside and other iridoid glucosides within plant cells. For most secondary metabolites, the pathway of their synthesis is distributed among multiple subcellular compartments (e.g. Burbulis and Winkel-Shirley, 1999). Most findings for galactinol synthase indicate that it may be located in the cytosol because of its $\mathrm{pH}$ optimum (about 7.0; Bachmann et al., 1994) although in some cases a galactinol synthase 
with a $\mathrm{pH}$ optimum of about 5 has been found which might imply that one of the isoforms is associated with vacuoles (Keller and Pharr, 1996). However, in mesophyll cells, galactinol was nearly exclusively confined to vacuoles.

Another group of carbohydrates, which includes sucrose, myo-inositol and mannitol, showed more or less equal distribution between all the three subcellular compartments, although they are synthesized in the cytosol (sucrose, mannitol) or in cytosol and plastids (myo-inositol). This might be related to the function of these compounds as compatible solutes (Wyn Jones and Gorham, 1983; Stoop et al., 1996; Nelson et al., 1999) which may require that the distribution of these compounds between cellular compartments is not restricted. These sugars were indeed shown to account for $22-26 \%$ of the cytosolic osmolality in Asarina and Alonsoa (3.1.5). Their relatively large chloroplastic pools might also include a fraction bound to the chloroplastic outer envelope which would be co-isolated with chloroplasts. Relatively large pools of carbohydrates including sucrose were found in the fraction of wheat chloroplasts during their isolation by non-aqueous fractionation (Heber, 1957). This chloroplastic fraction was small in greenhouse-grown plants but increased when chloroplasts were isolated from cold-grown plants. The accumulation of carbohydrates including sucrose in the chloroplastic fraction of such plants was interpreted as a part of the cold acclimation process to protect chloroplastic membranes.

Table 4.2. Comparison of the subcellular localization of carbohydrates as determined by nonaqueous fractionation with the localization of the key enzymes of their biosynthesis in plant cells.

\begin{tabular}{c|c|c}
\hline $\begin{array}{c}\text { Carbohydrates and their } \\
\text { preferential localization }\end{array}$ & $\begin{array}{c}\text { Localization of their key biosynthetic } \\
\text { enzymes }\end{array}$ & Reference \\
\hline $\begin{array}{c}\text { Hexoses } \\
\text { (vacuole) }\end{array}$ & $\begin{array}{c}\text { Cytosol (phosphatases, neutral } \\
\text { invertase); vacuole and apoplast (acidic } \\
\text { invertase); chloroplasts (starch } \\
\text { hydrolysis) }\end{array}$ & Heldt (1996) \\
\hline $\begin{array}{c}\text { Sucrose } \\
\text { (chloroplasts, cytosol, } \\
\text { vacuole) }\end{array}$ & $\begin{array}{c}\text { Cytosol (sucrose phosphate synthase and } \\
\text { sucrose phosphate phosphatase) }\end{array}$ & Bird et al. (1974) \\
\hline $\begin{array}{c}\text { myo-Inositol } \\
\text { (chloroplasts, cytosol, } \\
\text { vacuole) }\end{array}$ & Plastids and cytosol & Adhikari et al. (1987) \\
\hline $\begin{array}{c}\text { Galactinol } \\
\text { (vacuole) }\end{array}$ & Cytosol and vacuoles & Pharr et al. (1981) \\
\hline $\begin{array}{c}\text { Mannitol } \\
\text { (chloroplasts, cytosol, } \\
\text { vacuole) }\end{array}$ & Cytosol and nuclei & $\begin{array}{c}\text { Everard et al. (1993) } \\
\text { Yamamoto et al. (1997) }\end{array}$ \\
\hline $\begin{array}{c}\text { Antirrhinoside } \\
\text { (vacuole) }\end{array}$ & $\begin{array}{c}\text { ? Mevalonate kinase, the key enzyme for } \\
\text { isoprenyl synthesis, is localized in } \\
\text { cytosol and plastids }\end{array}$ & $\begin{array}{c}\text { Newman and Chappell } \\
\text { (1999) for mevalonate } \\
\text { kinase }\end{array}$ \\
\hline
\end{tabular}



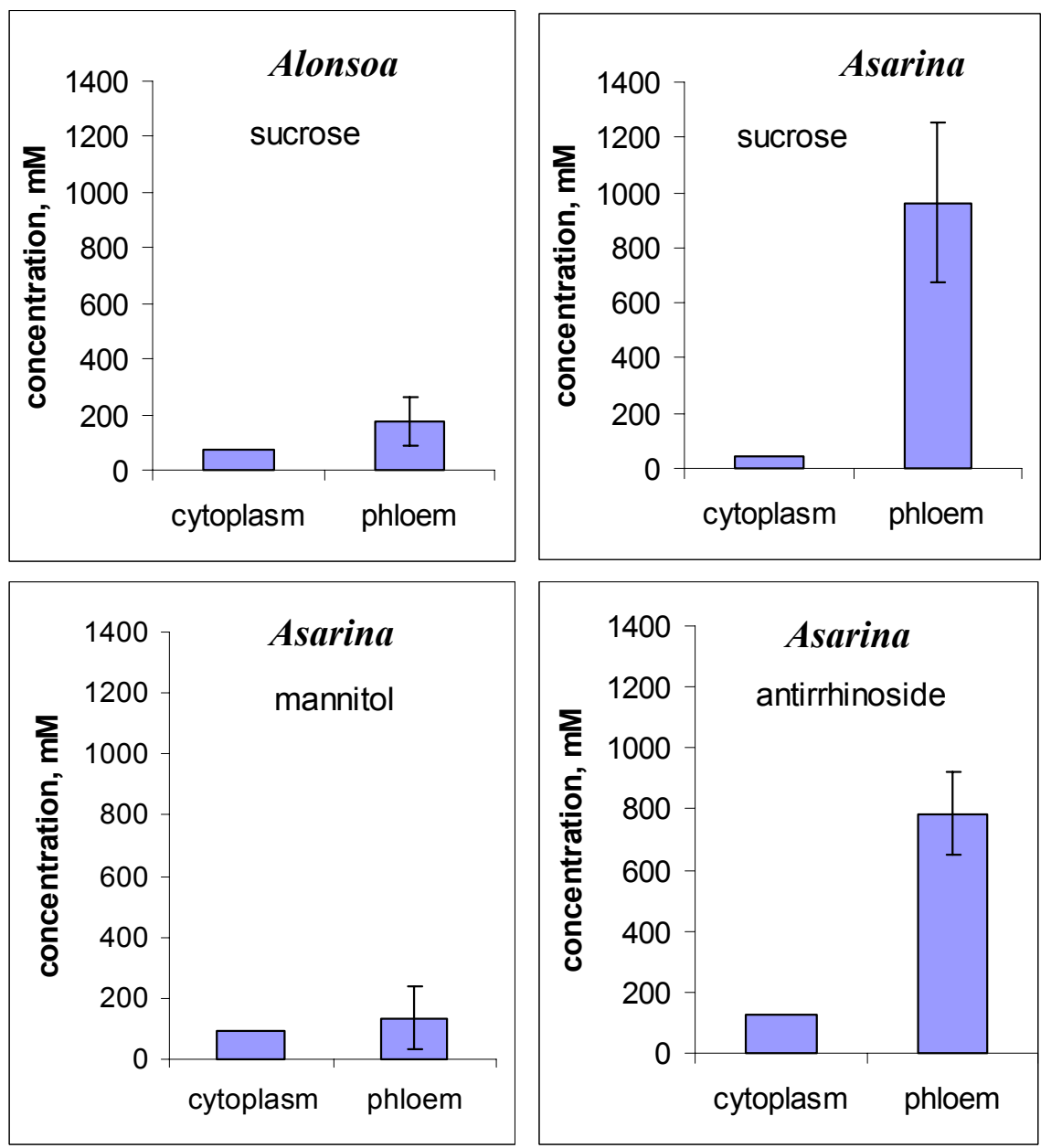

Figure 4.1.

Concentrations of the translocated carbohydrates in the cytoplasm of the mesophyll cells and in the phloem sap of Alonsoa meridionalis and Asarina barclaiana. Data are derived from results of non-aqueous fractionations (cytoplasmic concentrations; 3.1) and of phloem sap analysis by the laser aphid stylet technique $(\mathrm{n}=9$; Table 1.3).

From the species listed in Table 4.1, only Alonsoa meridionalis is a symplastic phloem loader. Other plants have been classified as apoplastic phloem loaders according to their minor vein anatomy (transfer cells in minor veins of Antirrhinum, ordinary cells in minor veins of Nicotiana, Solanum and Petroselinum; data from Gamalei (1990) for Antirrhinum, Nicotiana and Solanum, and from Flora and Madore (1996) for Petroselinum). One might expect that in the symplastic phloem loader Alonsoa, some concentrating mechanisms for sucrose and galactinol exist which would favour the symplastic loading of carbohydrates into the phloem as predicted by the polymerization trap model. However, no differences in the distribution patterns of translocated carbohydrates among subcellular compartments of mesophyll cells were found in Alonsoa as compared with the apoplastic phloem loaders Asarina, Antirrhinum, Nicotiana, Petroselinum and Solanum.

\subsubsection{Concentration ratios between the cytoplasm of mesophyll cells and the phloem sap indicate the presence of an active loading step for sucrose and antirrhinoside, the major transported carbohydrates in Asarina}

In Asarina, the ratio of sucrose concentrations between phloem and cytoplasm was as high as 22. This is in the range of the ratios previously estimated for the apoplastic phloem loaders spinach (16; Lohaus et al., 1995), barley (5; Lohaus et al., 1995) and maize (5; Lohaus 
et al., 1998). These data indicate unequivocally that there must be an active step for the loading of sucrose into the phloem against a concentration gradient in Asarina.

The concentration of antirrhinoside in the phloem sap of Asarina was as high as that of sucrose, and six times higher than its concentration in the cytoplasm of mesophyll cells. This means that the loading of antirrhinoside into the phloem also requires an energization. The increase of dark respiration, the depolarization of the membrane potential and the alkalinization of the apoplast observed when antirrhinoside was introduced into the leaf apoplast, indicate an energizing role of the proton motive force for the uptake of antirrhinoside (3.2.2). Whether this apoplastic transport is the only mechanism for the loading of antirrhinoside into the phloem remains to be established.

In general, the method of non-aqueous fractionation tends to overestimate subcellular concentrations for metabolites which are not exclusively located in the mesophyll (Gerhardt and Heldt, 1984; Riens et al., 1991). However, even the rough estimates made in this thesis show that in Asarina, the transfer of sucrose and antirrhinoside into the phloem requires an active energizing step, for it occurs against at least 22 and 6 times higher concentrations, respectively (Figure 4.1). This is in accordance with the presence of transfer cells and ordinary cells in the minor veins of Asarina (Figure 1.6 B, D). Transfer cells and ordinary cells were shown to be specialized for the apoplastic loading of sucrose against a concentration gradient using the proton motive force as the energizing power. $\mathrm{H}^{+} /$sucrose symporter PmSUT2 was immunolocalized on the plasma membrane of ordinary cells in Plantago major (Stadler et al., 1995) and $\mathrm{H}^{+}$-ATPase was immunolocalized on the cell wall ingrowths of transfer cells in Vicia faba (Bentwood and Cronshaw, 1978). $\mathrm{H}^{+} /$sucrose symporters were also found in Asarina and their function in sucrose uptake was confirmed by functional expression and complementation in yeast (Knop, 2001). Thus, in Asarina, sucrose and antirrhinoside are probably actively loaded into the phloem via the apoplast.

\subsubsection{Concentration ratios between the cytoplasm of mesophyll cells and the phloem sap indicate that the minor transported sugars, mannitol in Asarina and sucrose in Alonsoa, may be symplastically loaded into the phloem}

The concentrations of mannitol in the phloem sap (136 $\pm 101 \mathrm{mM}$; Knop, 1998) and in the cytoplasm of mesophyll cells in Asarina ( $92 \mathrm{mM}$, this thesis) did not differ significantly when the standard deviation value for the phloem sap is taken into account (Figure 4.1). This would imply that there may be no concentration barrier for the diffusion of mannitol from mesophyll cells into the phloem via the symplastic pathway. However, it should be kept in mind that the method of non-aqueous fractionation tends to overestimate subcellular concentrations since it does not account for the non-mesophyll parts of the leaves. That means 
that the actual metabolic situation in the cells might still necessitate an active loading of mannitol into the phloem in Asarina.

The study of the minor vein anatomy of this plant has shown that ordinary companion cells in minor veins possess single plasmodesmal connections with the bundle sheath cells (Figure 1.6 B and D). Thus, a symplastic transfer of carbohydrates, namely of mannitol which accounts for $3 \%$ of total translocated carbon from the mesophyll into the phloem (Table 1.3) could occur in Asarina. This, however, does not preclude the possibility that additionally, apoplastic loading of mannitol may take place in this plant. The kinetics of the uptake of ${ }^{14} \mathrm{C}$ mannitol introduced into the apoplast of the Apiaceae Petroselinum crispum, a plant with ordinary companion cells in minor veins (Flora and Madore, 1996), has revealed two components, a linear one and a saturable one. The latter indicates a participation of transporters in the process. $\mathrm{H}^{+}$/mannitol transporters were found in celery (Noiraud et al., 2001), an Apiaceae that contains ordinary cells with single plasmodesmal connections with the bundle sheath (Gamalei, 1990).

Alonsoa is the only symplastic phloem loader which has been studied by the nonaqueous fractionation technique with respect to the ratio of sucrose concentrations in the phloem sap and in the cytosol of mesophyll cells. In Alonsoa, this ratio was only two. This value is much lower than those determined for apoplastic phloem loaders but is rather similar to values estimated for peach (1.7; Moing et al., 1997) and Cucumis melo (0.7; Haritatos et al., 1996). The lower concentration gradient is due to the lower sucrose concentration in the phloem sap of Alonsoa as compared to apoplastic phloem loaders. For instance, the sucrose concentration in the phloem of Asarina $(963 \pm 280 \mathrm{mM})$ is five times higher than that in Alonsoa $(174 \pm 85 \mathrm{mM})$, whereas the cytoplasmic concentrations of sucrose in both plants differ only by a factor of about two (43 $\mathrm{mM}$ in Asarina and $71 \mathrm{mM}$ in Alonsoa). For Alonsoa, an active uptake of sucrose against a concentration gradient should be also assumed, although the twofold concentration gradient found in this plant is obviously easier to overcome or even reverse, depending on the metabolic situation, than the much steeper gradients found in apoplastic phloem loaders. Most importantly, $\mathrm{a} \mathrm{H}^{+} /$sucrose transporter AmSUT1was shown to be present in plasma membrane of the phloem cells and companion cells of Alonsoa which should participate in the apoplastic loading of sucrose (Knop, 2001).

The real concentration barriers for the movement of sugars from the mesophyll into the phloem via plasmodesmata could essentially differ from the estimated ones for several reasons. First, it is only mesophyll bundle sheath cells which are in close symplastic contact with intermediary cells. It is not impossible that sugar concentrations in these cells differ from 
those in other mesophyll cells, as could be shown for the monocotyledonous plant barley using a single cell sampling technique (Koroleva et al., 1998). In barley, bundle sheath cells differ drastically in sucrose and fructane concentrations from other mesophyll cells. Unfortunately, it was not possible in this thesis to distinguish between mesophyll bundle sheath cells of Asarina and Alonsoa when using the single cell method (data not shown).

Second, the actual concentration barriers would depend on the sugar concentrations in that subcellular compartment which provides the route for the symplastic transfer through the plasmodesmata. There are two possible compartments within a plasmodesma, the cytosolic sleeve and the lumen of the ER desmotubule (1.3). The non-aqueous fractionation technique does not resolve between these compartments. For instance, non-aqueous fractionation of leaves expressing a single chain antibody which was ancored to the ER by the KDEL sequence showed that it was entirely confined to the cytoplasm (Strauß et al., 2001). The additional sub-compartmentation of sugars within the cytoplasm could render their higher concentrations on the "mesophyll side" of plasmodesmata irrelevant for the transport process.

\subsection{Inhibition of the export of sugars from the leaves results in the re- compartmentation of translocated carbohydrates in leaves of Asarina and Alonsoa}

Sugar export from the leaves was blocked but photosynthesis continued when detached leaves of Asarina and Alonsoa were placed under continuous light for 24 to 96 hours. The effects of this treatment on sugar compartmentation in the leaves were studied, in that sugar levels in the two largest tissues of a leaf, epidermis and mesophyll, were determined. Taking into account the very high phloem concentrations of carbohydrates as compared to other plant tissues, it is unlikely that the phloem tissue itself has a sufficient capacity for further accumulation of carbohydrates when their export is inhibited. Therefore, other tissues like mesophyll and epidermis should allow transient accumulation of carbohydrates. The aim of these experiments was to find out whether both tissues are involved in the transient accumulation of carbohydrates in leaves of Alonsoa and Asarina. Also, as these plants translocate five different carbohydrates in the phloem, it was of interest to see whether the inhibition of translocation would affect the accumulation of these carbohydrates differentially.

The results of single cell sampling showed that in both Asarina and Alonsoa, the epidermis significantly contributes to the accumulation of hexoses and sucrose (3.1.4). This corresponds to results obtained with leaves of transgenic potato (Kehr et al., 1999) but 
contradicts results obtained with barley (Koroleva et al., 1998). In transgenic potato, the leaf epidermis took part in the accumulation of excess sugars resulting from the antisense repression of the expression of sucrose transporter in the phloem. In barley, no accumulation of sugars was observed in the leaf epidermis when the export of sugars from the leaves was inhibited by sink cooling. However, in contrast to the situation in both potato and barley, the concentrations of sucrose and hexoses were similar in mesophyll and epidermis of Asarina and Alonsoa also in the absence of phloem translocation blockage (3.1.4). This can indicate that epidermis and mesophyll in both Asarina and Alonsoa are symplastically connected.

Unfortunately, it was not possible to determine whether other carbohydrates also accumulated in the epidermis of these plants. Not distinguishing between epidermis and mesophyll, it could be shown that the inhibition of the phloem translocation resulted in the accumulation of sucrose, antirrhinoside and, to a lesser extent, mannitol in the leaves of Asarina (3.1.5). This indicates that when photosynthesis is not inhibited, the synthesis of these compounds proceeds also in the absence of their export from the leaves. The same situation was observed for sucrose in leaves of Alonsoa. However, the levels of raffinose and stachyose behaved differently. Although the precursor of their synthesis, galactinol, accumulated in the leaves of Alonsoa, no increase in the amounts of raffinose and stachyose was observed. Simultaneously, the myo-inositol level decreased (3.1.6). The concentration of myo-inositol in the leaf represents a balance between its consumption during the synthesis of galactinol and its production during the synthesis of raffinose and stachyose. Thus, the synthesis of RFOs in the leaves of Alonsoa seems to be inhibited by the blockage of phloem translocation. Since the levels of raffinose and stachyose did not increase, it can be concluded that no re-compartmentation of these sugars occurred within Alonsoa leaves during the inhibition of phloem translocation. The sequence of events in this phenomenon may be as follows. Either, the ceased phloem transport may have caused a rapid inhibition of the RFO synthesis by some unknown mechanism, thus preventing the further accumulation of these sugars and, therefore, making their exit from the phloem and redistribution in the leaves unnecessary. Alternatively, the overaccumulation of these sugars in the phloem may itself be a result of the inability of raffinose and stachyose to escape from the phloem and thus lead to the end product inhibition of RFO synthesis when a critical concentration is achieved. Which process is most probably taking place will be discussed below (4.3.4) after the results of the study on membrane transport of raffinose and stachyose will have been considered. 


\subsection{Apoplastic compartmentation of translocated sugars in symplastic and apoplastic phloem loaders}

\subsubsection{Inhibition of phloem translocation leads to the accumulation of sucrose in the apoplast of leaves in apoplastic, but not in symplastic phloem loaders}

The studies on apoplastic sugar concentrations in this thesis were performed on two groups of species taken from different plant families. A common feature for each group was the type of companion cells present in minor veins (intermediary cells versus transfer cells/ordinary cells). This was necessary to minimize the possibility that the observed characteristics were species- or family-specific, and to base the comparison on the type of companion cells (Voitsekhovskaja et al., 2000). The two following questions had to be studied. (1) Which sugars can be found in the leaf apoplast of plants translocating different types of carbohydrates in the phloem? (2) Are the sugar levels in the apoplast of these plants correlated with their presumable phloem loading mode?

The method employed was the inhibition of the phloem translocation with the aim to cause a re-compartmentation of the sugars (originally destined for export) within the leaves and to compare the participation of the apoplast in this re-compartmentation in both plant groups. The export of assimilates from the leaves was blocked in groups of apoplastic and symplastic phloem loaders either by removal of a phloem ring or by application of an ice jacket to the leaf petiole ("cold girdling"; Webb and Gorham, 1965). While the former procedure blocks phloem translocation entirely, the latter treatment has been shown to result only in its retardation (Webb and Gorham, 1965; Geiger and Sovonick, 1970; Faucher et al., 1982; Krapp and Stitt, 1995). The mechanism of this phenomenon is not completely understood but presumably is related to the inhibiting effect of low temperature on cytoskeleton motility (Geiger and Sovonick, 1970; Boevink et al., 1999).

The only sugars which could be detected in the apoplast of all plants studied were sucrose, glucose and fructose (3.2.1). The comparison of apoplastic sugar levels in leaves with normal and inhibited translocation has revealed one difference between apoplastic and symplastic phloem loaders. Sucrose accumulated in the leaf apoplast in apoplastic but not in symplastic loaders when phloem translocation was inhibited (3.2.1). This would be in accordance with the consideration of the apoplast as the main route for sugar loading in apoplastic but not in symplastic loaders. Indeed, neither sucrose nor raffinose and stachyose accumulated in the apoplast of symplastic loaders translocating these sugars in the phloem. However, the question arises which mechanism prevents the exit of sugars into the apoplast of these species. To understand this, the origin of sucrose accumulated in the apoplast of 
apoplastic loaders has to be considered. This sucrose might represent a pool which has been released from the mesophyll cells into the apoplast but has not yet entered the phloem due to a retardation of phloem loading. On the other hand, sucrose may leak back out of the phloem by an inversion of the sucrose transporter reaction due to the overaccumulation of sucrose in these cells as a consequence of retarded phloem translocation.

The assumption that most sugars found in the apoplast come from the mesophyll would explain the failure to find raffinose and stachyose in the apoplast in significant concentrations (this thesis; Madore and Webb, 1981; Schmitz et al., 1987). In a number of symplastic phloem loaders, raffinose and stachyose do not occur in the mesophyll, but are synthesized in the intermediary cells (Holthaus and Schmitz, 1991b; Büchi et al., 1998; Haritatos et al., 1996; this thesis). However, a cytoplasmic sucrose pool comparable to that in apoplastic phloem loaders was found in the symplastic phloem loader Alonsoa (3.1.2), putting forward the question why this sucrose could not be released into the apoplast. Thus, the assumption that the apoplastic sucrose which accumulated during the inhibition of phloem translocation originated from the mesophyll, is unlikely.

The assumption that the sucrose accumulating in the apoplast of apoplastic phloem loaders during transport blockage is mostly of phloem origin, would explain why no increase in apoplastic sucrose was observed in symplastic phloem loaders in similar experiments. In apoplastic phloem loaders, sucrose concentrations in the phloem sap are several times higher than in symplastic phloem loaders (Table 1.3 for Alonsoa; Moing et al., 1997; Ohshima et al., 1999; Knop et al., 2001; Lohaus and Fischer, 2001). Therefore, when phloem translocation is inhibited, sucrose concentration in the phloem of apoplastic loaders can easily exceed a critical level leading to the reversion of the sucrose transporters reaction (see 4.3.2). In this case, the question arises again why no raffinose and stachyose leak out of the phloem into the apoplast in similar experiments performed on symplastic phloem loaders such as Alonsoa, for the phloem concentrations of these sugars are as high as that of sucrose in apoplastic loaders (Table 1.3). One possible explanation for this could be the different equipment of the plasma membrane of leaf cells with specific sugar transporters in symplastic and apoplastic phloem loaders or the different mode of the operation of these transporters. This point will be discussed in 4.3.2.

\subsubsection{The exchange of sucrose, raffinose and stachyose through plasma membrane in both symplastic and apoplastic phloem loaders is not limited by the lack of specific transporters}

A simple approach to estimate the abundance of $\mathrm{H}^{+}$/sugar transporters in the plasma membrane of leaf cells in vivo is based on the energization of the sugar uptake by the $\mathrm{H}^{+}$- 
cotransport (Hedrich et al., 2001; Heber et al., 2002, in press; Voitsekhovskaja et al., 2002, in press). $\mathrm{H}^{+}$/sugar-cotransport is tightly coupled with ATP hydrolysis in the cytosol of the cells via the $\mathrm{H}^{+}$-pumping plasma membrane ATPase the activity of which restores the $\mathrm{pH}$ gradient across the plasma membrane (Sze et al., 1999). That means that the active proton-dependent uptake of sugars from the apoplast into cells can be detected by monitoring apoplastic $\mathrm{pH}$ and dark respiration which is the source of ATP in the absence of photosynthesis.

It should be considered that the transmembrane transfer of sugars catalyzed by $\mathrm{H}^{+} /$sugar symporters represents an enzymatic reaction which is reversible. An example is shown below for the reaction of $\mathrm{H}^{+} /$sucrose symporter, SUT:

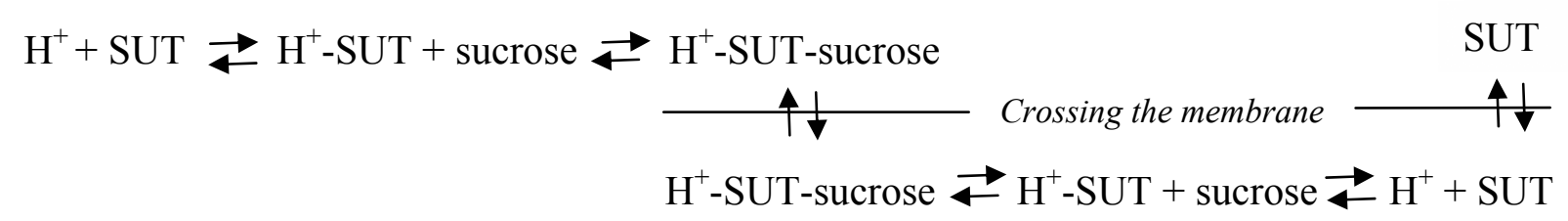

The mechanism of $\mathrm{H}^{+} /$sucrose symport consists of several reversible steps (Boorer et al., 1996). The direction of each reaction depends on the concentration of substrates on both sides of the membrane. The active proton-dependent uptake of sucrose can be detected when monitoring the $\mathrm{pH}$ in the apoplast. Simultaneously, an increase in the dark respiration will indicate the restoration of the proton motive force by $\mathrm{H}^{+}$- ATPase activity.

In this way, not only the transporters performing the uptake of sugars from the apoplast should be detected but also the activities of transporters which normally enable the export of sugars from the cells into the apoplast. This is because of the reversibilty of the reaction of the transporters. The introduction of the exogenous sugars in unusually high concentrations into the leaf apoplast will reverse the reaction and the active proton-dependent uptake can be detected when monitoring apoplastic $\mathrm{pH}$ and respiration.

Sucrose, raffinose, stachyose and glucose were introduced for a short time into the apoplast of leaves from symplastic and apoplastic loaders in concentrations of $50-100 \mathrm{mM}$, i.e. $1-3$ orders higher than the apoplastic concentrations of sucrose and hexoses $(0.1-5$ $\mathrm{mM}$; 3.2.1). In all cases, the proton motive force-dependent uptake was indicated by a transient increase in respiration, a transient alkalinization of the apoplast and oscillations of the membrane potential. This is the first time that proton-dependent transport could be shown unequivocally for raffinose and stachyose. Changes in membrane potential caused by exogenously applied raffinose (van Bel et al., 1995), as well as PCMBS sensitivity of raffinose and stachyose uptake from the apoplast (Madore, 1990; Turgeon and Gowan, 1990; 
Flora and Madore, 1993), had previously suggested the proton motive force-dependent uptake of these sugars. Recently, the plasma membrane depolarization was shown for a variety of sugars (including raffinose and stachyose) exogenously applied to lactifier protoplasts of Hevea brasiliensis (Bouteau et al., 1999). However, no simultaneous measurements of both components of proton motive force, $\mathrm{pH}$ and membrane potential have been performed before.

The introduction of sugars in high concentrations into the leaf apoplast changes the osmotic environment of leaf cells and might induce a "bulk" uptake of any transportable substances present in the apoplast into the cells, to balance the osmotic pressure. However, Figure 4.2 shows that the responses of respiration and proton motive force observed during sugar feeding into the apoplast in the discussed experiments cannot be related to such changes. Mannitol and sucrose introduced into the apoplast of a potato leaf caused strikingly different responses of respiration and apoplastic $\mathrm{pH}$, although both solutes were fed in the same concentration, $200 \mathrm{mM}$.

The experimental approach used in this thesis provides a sensitive and convenient tool to assess the equipment of the plasma membrane of leaf cells with sugar-specific transporters. Although this method actually does not determine whether the uptake is mediated by different systems or by one system with different affinity to single sugars, it does detect the uptake events occuring in vivo. This method has been used for the study of malate and $\mathrm{KCl}$ uptake from the apoplast (Hedrich et al., 2001). Later, it was used for the assessment of the uptake of different classes of compounds from the apoplast including inorganic salts, organic ions, heavy metal cations and even nucleotides (Heber et al., 2002, in press). In most cases, uptake could be shown and was driven by the proton motive force. This has been interpreted to imply

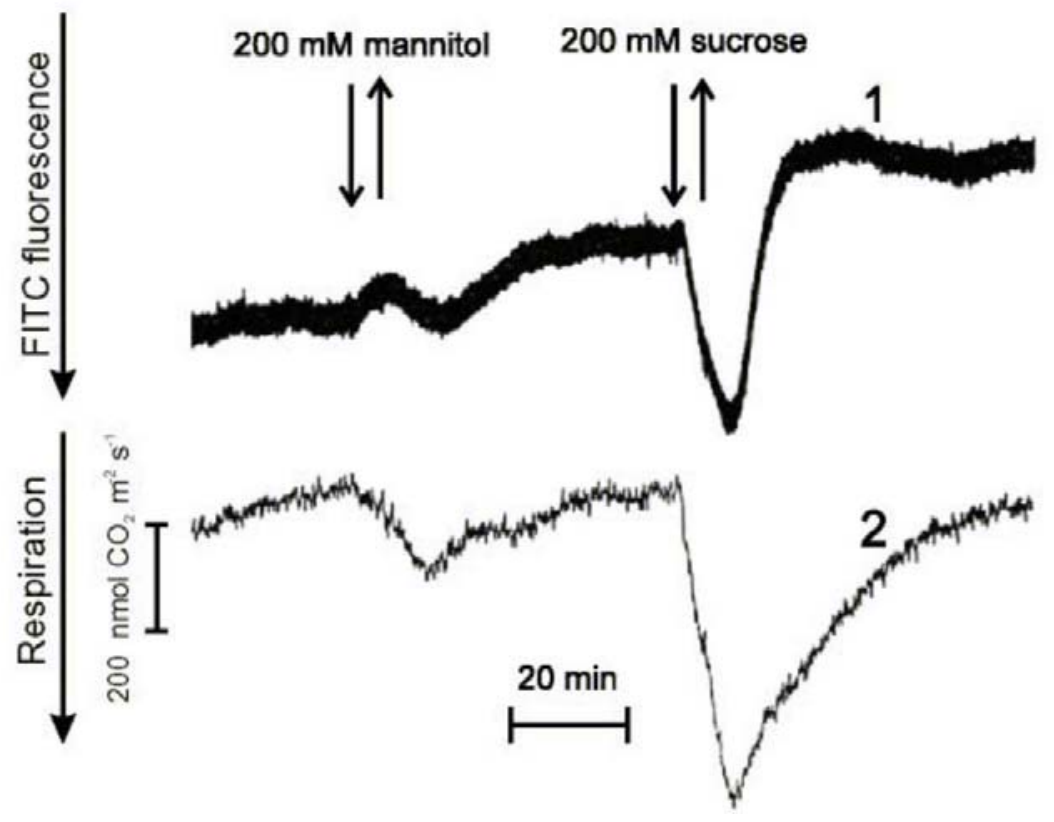

Figure 4.2. Respiratory $\mathrm{CO}_{2}$ release and apoplastic $\mathrm{pH}$ as influenced by $5 \mathrm{~min}$ feeding of mannitol and sucrose in concentrations of $200 \mathrm{mM}$ to the petiole of a potato leaf. Increase in FITC fluorescence indicates an alkalinization of the apoplast. Courtesy of N. Bukhov and U. Heber (unpublished). 
an obvious necessity for the plant to keep the apoplast free of any osmotic solutes which otherwise could lead to the breakdown of turgor control (Heber et al., 2002, in press).

All species studied in these experiments were able to take up not only glucose and sucrose, but also raffinose and stachyose. The symplastic species studied are known to synthesize RFOs in leaves and translocate them (Madore, 1990 for Coleus; Mitchell et al., 1992 for Cucurbita; Knop et al., 2001 for Alonsoa) whereas the apoplastic phloem loaders Helianthus, Calendula and Pisum are sucrose-translocating plants the leaves of which very unlikely contain RFOs (Table 1.3). However, RFOs are commonly synthesized in all plants at least at some developmental stages like seeds (Peterbauer and Richter, 2001).

No drastic differences between symplastic and apoplastic phloem loaders could be observed in the mode of uptake of phloem-translocated carbohydrates. One reason for this could be that it was not possible in these experiments to distinguish between the uptake of sugars into the mesophyll and into the phloem. The extent of the stimulation of respiration (increases by $20-50 \%$ ) suggests the participation of a large portion of the leaf tissue in the uptake. Winter (1993) reported for spinach leaves that mesophyll tissue and companion cell/sieve element complexes occupied about $85 \%$ and $0.5 \%$, respectively, of the leaf volume. However, the partial volume of the mitochondria is reported to be as high as $25 \%$ of the cell volume in companion cells and only $0.5 \%$ in mesophyll cells (Gamalei, 1990). If the availability of mitochondria is taken as a basis, then about $1 / 3$ of the observed sugardependent respiration increase could originate from the CC/SE complexes.

There are also results from previous studies that indicate that the phloem contributes significantly to the uptake of sugars exogenously introduced into the apoplast. When ${ }^{14} \mathrm{C}$ labelled glucose was applied to leaf discs of Coleus blumei in millimolar concentrations, the label directly entered the veins within 30 seconds to two minutes (Turgeon and Gowan, 1992). The labelling of the mesophyll was much weaker. Also in leaf discs of Coleus incubated in ${ }^{14} \mathrm{C}$-labelled stachyose, the veins were labelled preferentially, and the label entered the veins directly (Madore, 1990). Glucose does not occur in the phloem sap. Therefore, the fact that ${ }^{14} \mathrm{C}$-labelled glucose was taken up directly into the veins of Coleus leaf discs indicates that the observed uptake may not represent the part of the phloem loading mechanism of sugars endogenously generated in vivo. This is probably true also for the observed uptake of ${ }^{14} \mathrm{C}$-labelled stachyose into the leaves of Cucurbita (Madore and Webb, 1981) where no further translocation of the labelled stachyose could be observed. In the experiments described in 3.2.3, the high capacity for the uptake of different sugars from the apoplast could be demonstrated by high levels of the uptake-related increases in respiration 
( $20 \%-50 \%$ of basal respiration, 3.2 .3$)$ for several plant species. This indicated that the leaves are able to remove exogenously applied osmotica (sugars) from the apoplast which otherwise could lead to a breakdown of the turgor. However, the mechanism employed for this process is not necessarily related to phloem loading as indicated by the uptake of ${ }^{14} \mathrm{C}$-labelled sugars in the experiments of Turgeon and Gowan (1992) and Madore and Webb (1981), described above. Which transporters are involved in this uptake mechanism characterized by low affinity and high capacity (3.2.3), remains to be clarified.

In summary, the observations made in these experiments indicate that the exchange of sucrose, raffinose and stachyose between symplast and apoplast via the plasma membrane in both symplastic and apoplastic phloem loaders cannot be limited by a lack of specific transporters.

\subsubsection{The non-metabolizeable sucrose isomeres palatinose and turanose can be taken up from the apoplast into the leaf cells in a proton motive force-dependent manner}

The non-metabolizeable sucrose isomeres turanose and palatinose were shown to cause a transient increase in respiration, a transient alkalinization of the apoplast and the depolarization of the plasma membrane, thus indicating the presence of a $\mathrm{H}^{+}$-symport system which can recognize these sugars (3.2.3). Palatinose and turanose are considered to be unable to enter plant cells because they are not recognized as the substrates for known sugar transporters (e.g. M'Batchi and Delrot, 1988; Li et al., 1994; Meyer et al., 2000). In Hevea protoplasts, the depolarization of the plasma membrane was shown in response to turanose, but no $\mathrm{H}^{+}$uptake was monitored in this experiment (Bouteau et al., 1999). Palatinose did not cause the depolarization of the plasma membrane of Hevea protoplasts. In this thesis, speciesspecific differences in the uptake of non-metabolizeable sucrose isomeres were also observed. Calendula leaf cells readily took up palatinose but not turanose, in contrast to Lepidium leaves which were able to perform the uptake of turanose (3.2.3). This fact is especially of interest because palatinose is used in studies of plasma membrane-associated systems of sugar sensing that are based on the assumption that this sugar cannot cross the plasma membrane of plant cells (e.g. Loreti et al., 2000). Recently, the uptake of palatinose from the apoplast into leaf cells was suggested in transgenic tobacco expressing palI, the gene for sucrose isomerase from the bacterium Erwinia rhapontici which performs palatinose synthesis (Börnke et al., 2001). The data obtained in this thesis provide evidence for transmembrane transfer of palatinose in plants, and, at the same time, indicate that plant species may differ in their ability to take up palatinose into leaf cells. 


\subsubsection{Sugar exchange between apoplast and phloem is limited in symplastic but not in apoplastic phloem loaders}

The data on the composition of the apoplastic sugars indicate that sugar exchange between apoplast and phloem is limited in symplastic but not in apoplastic phloem loaders (3.2.2; 4.3.2). This limitation is not due to the lack of specific sugar transporters in the plasma membrane of symplastic loaders $(4.3 .2,4.3 .3)$. One possible explanation for the observed difference could be an additional sub-compartmentation of raffinose and stachyose in the intermediary cells of symplastic loaders. This also might explain the observed inhibition of stachyose and raffinose synthesis in the leaves of Alonsoa meridionalis in response to the inhibition of phloem export (4.2). If stachyose and raffinose could not escape from the phloem into the apoplast, nor into the mesophyll via plasmodesmata, then their levels would increase in the phloem itself when translocation is blocked. Raffinose was shown to inhibit stachyose synthesis in Cucumis leaves in a competitive manner at concentrations higher than $5 \mathrm{mM}$ (Holthaus and Schmitz, 1991a). Also, in this thesis it was observed that the STS activity in partially purified extracts from Alonsoa leaves could not be detected at raffinose concentrations about $20 \mathrm{mM}$ (3.3.3.1). However, the inhibitory effect of raffinose on STS was not observed in Ajuga reptans nor in Ocimum basilicum where STS activity was examined at a raffinose concentration of $40 \mathrm{mM}$ (Bachmann et al., 1994; Büchi et al., 1998). If the increased levels of raffinose in the phloem of Alonsoa would inhibit the synthesis of stachyose, this might result in a negative feedback regulation of stachyose synthesis by the retardation or inhibition of phloem translocation.

\subsection{Molecular characterization of $A m S T S$, a stachyose synthase from the symplastic phloem loader Alonsoa meridionalis.}

\subsubsection{AmSTS is expressed in intermediary cells of Alonsoa meridionalis}

In this study, a full length cDNA clone of stachyose synthase was isolated from the leaves of the symplastic phloem loader Alonsoa meridionalis (3.3.2). The analysis of the AmSTS expression pattern was performed first by hybridization of RNA gel blots containing RNA from flowers, stems, sink leaves and source leaves of Alonsoa (3.3.5). Highest expression levels were observed in source leaves, followed by sink leaves and flowers. No expression could be detected in stems of Alonsoa by this method. This last finding was confusing, for one of the main functions of the stems in plants is phloem translocation. Therefore, a more precise analysis was performed by in situ antisense RNA hybridizazion using thin sections prepared from source leaves and from stems of Alonsoa. 
The results demonstrate that in leaves of Alonsoa, AmSTS expression is confined to the intermediary cells of the minor veins. This is the first time that the expression pattern of stachyose synthase was determined at the cellular level. Interestingly, no hybridization signal could be obtained in companion cells of Alonsoa stems, thus confirming the results of the RNA gel blot analyses.

The in situ RNA hybridization technique does not distinguish between transcripts of the different gene family members because of the low stringency of the washing steps. The results of DNA gel blot hybridization analysis of Alonsoa genomic DNA indicated that AmSTS is encoded by a small gene family with most probably two members (3.3.4). Hence, from the in situ hybridization results (3.3.5) together with the results of the expression of the AmSTS promoter-GUS construct in Arabidopsis (3.3.6), it could only be concluded that either both members of the gene family have a similar expression pattern, or that the second gene is not expressed in leaves, or its expression level in the leaves is too low to be detected by in situ hybridization. The gene family of STS was analysed in Vigna angularis and the results also indicated the presence of at least two isoforms (Peterbauer et al., 1999).

The localization of AmSTS expession in intermediary cells of Alonsoa meridionalis provides a further confirmation of the specialization of intermediary cells for stachyose synthesis in addition to the immunolocalization of stachyose synthase in intermediary cells of Cucumis melo by Holthaus and Schmitz (1991b). Although Alonsoa meridionalis and Cucumis melo belong to different plant families, their intermediary cells have a similar biochemical specialization confirming the similar function of these cells in both symplastic phloem loaders.

\subsubsection{The AmSTS promoter directs GUS expression into the phloem in Arabidopsis}

The cell-specific expression of AmSTS in intermediary cells of Alonsoa meridionalis puts forward the question which transcription factors may be responsible for this specificity and whether companion cells of other structural types also possess these transcription factors. Furthermore, information on the regulation of the expression of STS in intermediary cells is important for the understanding of the functioning of symplastic phloem loading in general. To further investigate these points, a $1.85 \mathrm{~kb}$ fragment of the promoter region of AmSTS was cloned and its sequence was identified (3.6.3.1).

No known regulatory elements could be shown within the AmSTS promoter region (3.6.3.1). For the further study, the AmSTS promoter was fused to the $\beta$-glucuronidase reporter gene in the pBI101.3 plant transformation vector. The transcription start for AmSTS was identified (3.3.2) and the results showed that two small uORFs are present in the $108 \mathrm{bp}$ 
5'UTR of the AmSTS mRNA, both in-frame with the AmSTS ORF (3.3.2). The translation start codons of both uORFs are in a poor nucleotide context whereas the first codon of AmSTS ORF is in a strong context as indicated by the presence of the Kozak consensus sequence around it (RNNatgG; Kozak, 1996). Two uORFs were also found in 5'UTR of mRNA of stachyose synthase from Vigna angularis (Peterbauer et al., 1999). Although mRNAs containing uORFs in 5'UTR are rather rare in eucaryots, representing e.g. less than $10 \%$ of the known mRNAs in vertebrates, they are found with higher frequency in gene families with regulatory importance including transcriptional factors and genes encoding components of signal transduction pathways (Geballe and Morris, 1994). The presence of additional start codons upstream of the translational start was shown to lower the translation efficiency (e.g. for plants: Chang et al., 2000; Kwak and Lee, 2001). In vitro translation studies have shown that this can be due to the stalling of ribosomes at the stop codons of the uORF(s) (Raney et al., 2000). Other regulatory mechanisms depend on the amino acid sequences encoded by $\mathrm{uORF}(\mathrm{s})$.

To examine whether the presense of AmSTS uORFs affected the GUS level in Arabidopsis, two types of AmSTS promoter-GUS fusion constructs were made, one with and one without the 5'UTR. For both constructs it was shown that the AmSTS promoter directs the expression of GUS into the phloem in Arabidopsis (3.3.6.3). The activity of GUS was high as indicated by the very strong production and diffusion of the indigo dye within the entire conducting tissue of Arabidopsis. However, when diffusion was prevented by detachement of the inflorescence shoots from the plants before staining, no dye appeared in the vascular tissue of inflorescence shoots indicating that in whole plants, the staining was derived from dye diffusion via the phloem (3.3.6.4). Not only leaves but also sepals and siliques showed staining in the conducting tissue. In roots, only a slight staining was observed in some cases, associated with conducting tissues and areas around it. Thus, the AmSTS promoter directs the expression of GUS into the phloem of leaves, sepals and green siliques but not into the phloem of inflorescence shoots.

Leaves are the carbon source organs for the whole plant. However, also sepals and siliques can be local source organs for the sinks located nearby like flowers and seeds. For instance, in apple, sepals showed the ability to perform photosynthesis comparable to that in leaves and accounted for 35\% of the carbohydrate balance in flowers (Vemmos and Goldwin, 1994). In siliques of rapeseed, virtually $100 \%$ of the seed dry matter was found to come from photosynthesis activity of the pod (Singh, 1993). As the inflorescence shoots are unlikely to contribute to the carbohydrate balance of reproductive organs by net assimilation, they are 
equivalent to the stems of Alonsoa the main function of which seems to be to ensure the transport of carbohydrates from sources to sinks. In summary, the activity of the AmSTS promoter was presumably associated with organs of Arabidopsis with source function requiring an effective phloem loading.

Both AmSTS promoter constructs, the one including the 5'UTR of AmSTS mRNA (PmrA) and the one without this region $(\mathrm{PmrB})$ were similar in the tissue specificity of GUS activity in Arabidopsis (3.3.6.3, 3.3.6.4). However, the expression levels of GUS differed between lines expressing these two constructs as was shown by the comparison of altogether 14 lines transformed with PmrA and 16 lines transformed with PmrB. This difference was opposite to what would have been predicted on the basis of the known mechanism of translation repression by uORFs. The presense of the two uORFs from the 5'UTR of AmSTS upstream of the GUS ORF did not lower the levels of GUS activity but rather led to an increase in the GUS expression. This preliminary observation has yet to be confirmed by the analysis of the copy number of T-DNAs in all transgenic lines. At present, it is still possible that the difference in GUS activity levels is due to differences in T-DNA copy numbers.

The pattern of GUS expression under the control of the AmSTS promoter in Arabidopsis seems to resemble the expression pattern of a GUS fusion of the promoter region of a galactinol synthase gene from Cucumis melo (CmGAS1; Haritatos et al., 2000b). The $C m G A S 1$ promoter directed the expression of GUS into minor veins of A. thaliana and N. tabacum. The expression patterns for AmSTS-GUS and CmGAS1-GUS constructs in Arabidopsis are compared in Table 4.3. The differences between both patterns were that siliques showed staining in the veins of AmSTS-GUS transgenic plants but not of CmGASIGUS transgenic plants, and that petals (heterotrophic organs) were stained in CmGAS1-GUS but not in AmSTS-GUS transgenic plants. Also, the staining of inflorescence shoots was not analysed in CmGAS1-GUS plants (Haritatos et al., 2000b).

Arabidopsis contains ordinary companion cells in minor veins and is able to synthesize and translocate trace amounts of galactinol and raffinose but not stachyose (Haritatos et al., 2000a). Nevertheless, the expression patterns of AmSTS in Alonsoa and of GUS under control of the AmSTS promoter in Arabidopsis seem to coincide. This indicates that the regulatory factors activating AmSTS expression are present in companion cells of Arabidopsis. The same conclusion was made for the expresion of CmGAS1-GUS in Arabidopsis and tobacco (Haritatos et al., 2000b). Tobacco does not synthesize galactinol and RFOs; nevertheless, $C m G A S 1-G U S$ was expressed also in this plant in the minor veins. However, this comparison is incomplete because it does not include the analysis of expression of CmGAS1 in melon, and 
both tobacco and Arabidopsis differ from melon in their carbohydrate metabolism and minor vein anatomy.

The study of AmSTS expression has shown that expression patterns seem to be conserved between Arabidopsis and Alonsoa, in spite of their different companion cell structure.

Table 4.3. GUS activity in organs of Arabidopsis as shown by staining of plants expressing either a AmSTS-GUS (this thesis) or a CmGAS-GUS (Haritatos et al., 2000b) construct.

\begin{tabular}{|c|c|c|c|}
\hline \multirow{2}{*}{ Plant organs } & \multicolumn{2}{|c|}{ GUS staining observed in } & \multirow{2}{*}{$\begin{array}{l}\text { Material taken } \\
\text { for staining }\end{array}$} \\
\hline & $A m S T S-G U S$ & CmGAS1-GUS & \\
\hline veins of cotyledones & stained & stained & seedlings \\
\hline veins of mature leaves & $\begin{array}{l}\text { strongest staining in minor } \\
\text { veins }\end{array}$ & $\begin{array}{l}\text { strongest staining in } \\
\text { minor veins }\end{array}$ & $\begin{array}{l}\text { seedlings, detached } \\
\text { rosette leaves }\end{array}$ \\
\hline hydatodes & stained & stained & “" \\
\hline $\begin{array}{c}\text { midrib at short staining } \\
\text { times }\end{array}$ & no & no & “ \\
\hline $\begin{array}{l}\text { midrib at longer } \\
\text { staining time }\end{array}$ & stained & stained & “ \\
\hline $\begin{array}{l}\text { minor veins at short } \\
\text { staining time }\end{array}$ & stained & stained & leaves, leaf pieces \\
\hline mesophyll & $\begin{array}{l}\text { no (stained by diffusion in } \\
\text { the absence of FeII/III) }\end{array}$ & $\begin{array}{l}\text { stained in high copy } \\
\text { number lines }\end{array}$ & leaves \\
\hline damaged organs & stained & stained & \\
\hline $\begin{array}{l}\text { veins of sepals and } \\
\text { petals }\end{array}$ & sepals only & both sepals and petals & inflorescences \\
\hline $\begin{array}{c}\text { conducting tissue in } \\
\text { siliques }\end{array}$ & stained & no & detached siliques \\
\hline inflorescence shoots & no & not tested & $\begin{array}{c}\text { cut pieces of } \\
\text { inflorescence shoots }\end{array}$ \\
\hline roots & $\begin{array}{l}\text { no (or faint staining due to } \\
\text { diffusion) }\end{array}$ & patchy staining & seedlings \\
\hline
\end{tabular}

\subsubsection{Preliminary results indicate that the AmSTS promoter is inducible by sugars but also by osmotically active solutes}

The involvement of AmSTS in carbohydrate metabolism and phloem loading made it interesting to investigate the influence of sugars on its expression. In this thesis, only preliminary results could be obtained because no homozygous lines are available yet and transgene copy numbers have not yet been determined. However, the same results were obtained with all F2 plants from 20 independent lines (10 PmrA lines and 10 PmrB lines) indicating that the observations are significant. The data show that the incubation of seedlings 
of transgenic plants on MS medium containing either 5\% sucrose $(180 \mathrm{mM})$ or $4 \%$ glucose (200 mM) for 20 hours led to a strong increase of GUS activity in seedlings as compared with GUS levels after incubation on MS medium without additives or in seedlings taken directly from MS plates with $2 \%$ sucrose (3.3.6.5). However, this induction may be due to a breakdown of the turgor control in the cells. Preliminary results show that a similar increase of GUS activity as caused by sucrose and glucose can also be caused by raffinose and sorbitol. Furthermore, GUS activity increased in seedlings subjected to one hour of drought stress, compared to a watered control (3.3.6.5). Once homozygous lines are available, further studies will reveal which factors affect the expression of AmSTS-GUS in Arabidopsis.

\subsection{Reformulation of the model of symplastic phloem loading}

The current model of symplastic phloem loading, the polymerization trap model, is based on two postulates (1.6). First, the synthesis of stachyose is assumed to take place in intermediary cells. Second, plasmodesmal connections between the intermediary cells and the mesophyll bundle sheath cells represent a mechanical barrier for the diffusion of stachyose into the mesophyll cells because of their size exclusion limit. Thus, stachyose is trapped in intermediary cells and can only diffuse into sieve elements via much larger plasmodesmata.

The first postulate has been directly confirmed by the immunolocalization of stachyose synthase in intermediary cells of Cucumis melo (Holthaus and Schmitz, 1991b) and now by the localization of the expression of AmSTS in intermediary cells of Alonsoa meridionalis in this thesis. The second postulate, however, about the diameter of plasmodesmata limiting the diffusion of stachyose into the mesophyll, is contradicted by the accumulating information on the transport of large proteins and riboprotein complexes via plasmodesmata from mesophyll cells into intermediary cells. This contradiction arises when the cytosol is considered as the transport compartment for the protein transfer through plasmodesmata and also as the site of stachyose synthesis in intermediary cells (1.6).

Some observations made in this thesis are not consistent with the presumed compartmentation of stachyose in the cytosol of intermediary cells. First, it could be shown that the transfer of stachyose across the plasma membranes of leaf cells takes place with a capacity similar to that for the transfer of other sugars like sucrose (3.2.3). The boundary between apoplast and cytosol is represented by the plasma membrane. Thus, if stachyose is synthetized in the cytosol of intermediary cells, it should be able to escape from the cytosol into the apoplast at least when its release into sieve elements is inhibited. Second, stachyose does not accumulate in the apoplast when phloem translocation is blocked (3.2.2). Altogether, 
stachyose has not yet been found in the apoplast in concentrations higher than trace amounts. These data indicate that it is rather unlikely for stachyose to be localized in the cytosol.

An interesting suggestion about an alternative intracellular compartmentation of stachyose and its synthesis within intermediary cells comes from the studies on lactose biosynthesis that occurs in milk-secreting cells of mammary glands. Lactose is a $\beta$-galactosyl1,4-D-glucose, synthesized from UDP-galactose and glucose by lactose synthase. The biosynthesis of lactose occurs exclusively in cells of mammary glands and was shown to be the key process in milk secretion. This is due to the fact that lactose is synthesized within the lumen of Golgi vesicles and it is not able to escape into the cytosol (White et al., 1980). Thus, lactose synthesis draws water into the vesicles by osmosis. Therefore, lactose synthesis activity determines the volume of the secreted milk. Recently, this mechanism was confirmed by the construction of transgenic mice whose enhanced or reduced lactose synthesis activity resulted in either increased or decreased secretion of milk, respectively, and also determined the composition of the secreted milk (Boston et al., 2001).

A comparison of structural and functional characteristics of intermediary cells and milk-secreting cells shows some similarities. In both cell types, endomembrane vesicles, rough endoplasmic reticulum and mitochondria are highly developed (Figure 4.3 A and B). Both cell types are specialized for the synthesis of galactosylated compounds, $\beta$-galactosyls in milk-secreting cells and $\alpha$-galactosyls in intermediary cells, respectively. Interestingly, the $\mathrm{pH}$ optimum for lactose synthase is about 6.8-7.0, a value similar to that of stachyose synthase and which is considered as an argument for the location of stachyose synthase in the cytosol. However, lactose synthase is confined to the Golgi lumen of milk-secreting cells of mammary glands. This compartmentation of lactose synthesis makes it impossible for lactose to escape into the cytosol which would inhibit milk secretion. In contrast, if lactose were synthesized in the cytosol, it would have to enter the Golgi vesicles via a reversible membrane transportercatalyzed reaction and hence could accumulate in the cytosol. Recently, two different vacuolar compartments were shown to be present in mesophyll protoplasts, a large acidic one and a population of smaller pH-neutral vacuoles (Paris et al., 1996). These compartments require different peptide signals for protein targeing (Di Sansebastiano et al., 1998; 2001). Thus, also in plant cells, the neutral $\mathrm{pH}$ optimum cannot be considered as a feature of the cytosolic enzymes alone.

The mechanism of phloem loading in plants with intermediary cells can be reevaluated if it is postulated that stachyose synthesis occurs within the endomembrane system of these cells. In such a model, stachyose is trapped not in the cytosol but in the 
endomembrane system of intermediary cells. This could draw the water flux into the endomembrane compartment, analogous to the process of milk secretion. In plant cells, the rigid cell wall prevents the release of the contents of endomembrane vesicles into the extracellular space but does not affect the release into sieve elements through plasmodesmata. If the data discussed above are taken into account, it seems unlikely that any recompartmentation of stachyose takes place within the sieve elements. A three-dimentional reconstruction of the endomembrane systems in intermediary cells of Fraxinus excelsior and Lycopus europaeus from serial sections performed by Gamalei and Pakhomova (1981) showed that here, the ER represents a single large endomembrane compartment rather than a population of vesicles and is continuous between intermediary cells and sieve elements. Thus, stachyose could be synthesized and translocated within the endomembrane system.

In this model, the mechanism of symplastic phloem loading would not represent the simple diffusion of stachyose into the phloem. Instead, the osmotically drawn water flux which would be created by the localization of stachyose synthesis in the endomembrane system would draw stachyose from the intermediary cells into the sieve elements. Furthermore, the water flux would allow other compounds to enter the endomembrane system via specific transporters. These molecules could come from the apoplast or arrive in intermediary cells from mesophyll cells via plasmodesmata. It is known that due to the presence of aquaporines there are no limitations to the water exchange between subcellular compartments (Johansson et al., 2000). Thus, intermediary cells can be considered as osmotic "pumps".

A similar function could also be assumed for raffinose and stachyose in seeds which is common in plants. The synthesis of stachyose and raffinose could help to establish the transport water flux in a developing seedling in a similar way, i.e. by creation of an osmotic "starting point" for this process. Interestingly, many "seed imbibition proteins" represent raffinose synthases based on their amino acid sequences.

Gamalei et al. (2000) have examined the ultrastructural changes of intermediary cells in leaves during inhibition of phloem export. Inhibition of phloem translocation led to complete disappearence of the endomembrane system of intermediary cells (shown in Figure 4.3 C, D). Gamalei postulated in 1994 that the endoplasmic reticulum is the main channel for sugar transport (1.3; Gamalei, 1994; Gamalei et al., 1994) and interpreted the disappearence of endomembranes as a cessation of sugar loading into the ER (Gamalei et al., 2000). It is possible that the cessation of stachyose synthesis in the ER, e.g. due to feedback inhibition (see above), led to a drop of the osmotic pressure within the ER. 

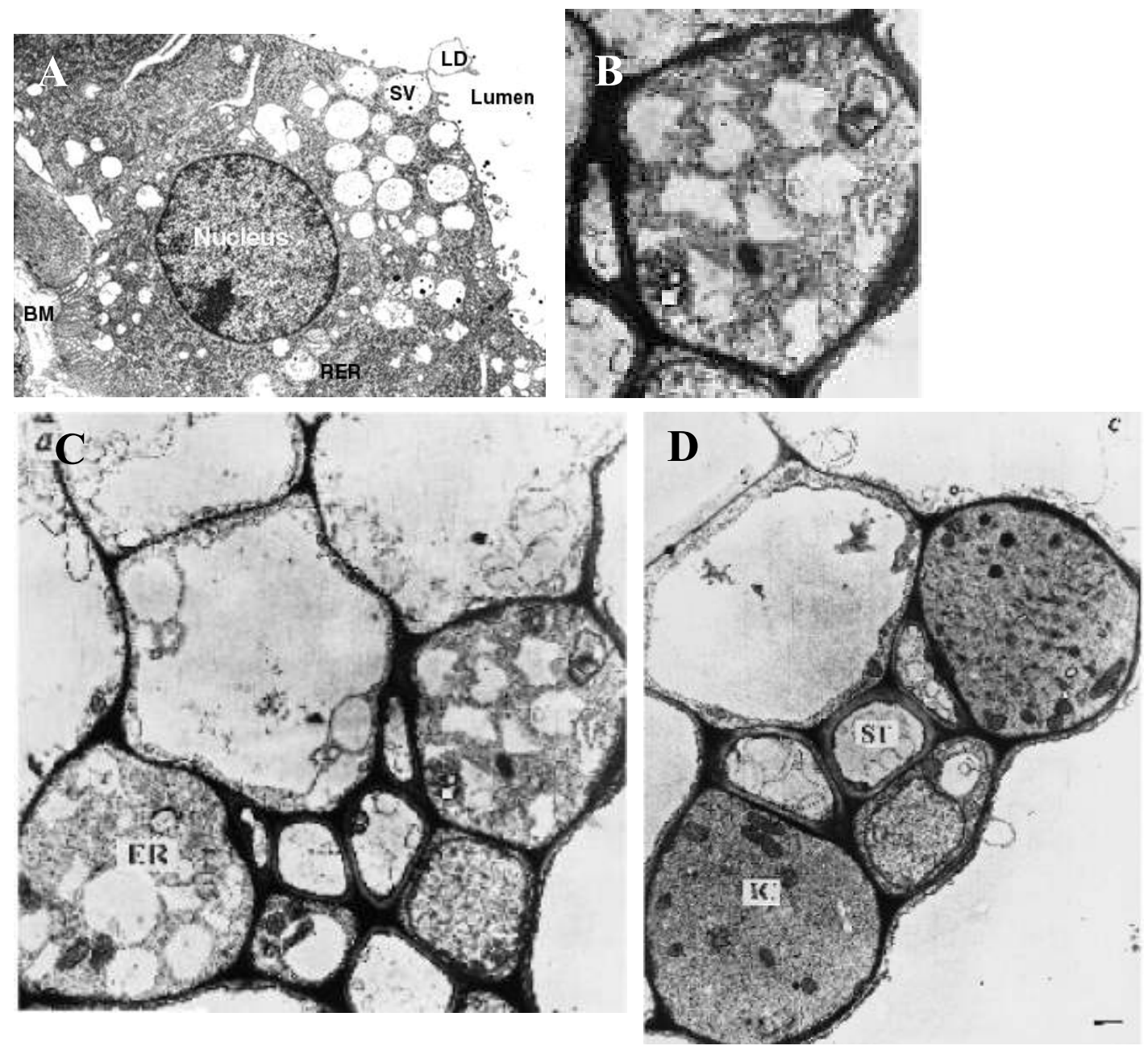

Figure 4.3. Ultrastructure of $\mathbf{A}$, a milk-secreting cell of a cow mammary gland; $\mathbf{B}$, an intermediary cells of Cucumis melo; $\mathbf{C}$ and $\mathbf{D}$, a minor vein of Coleus blumei at normal (C) and inhibited (D) phloem translocation. Data taken from: A, lactation biology homepage (http://classes.aces.uiuc.edu/AnSci308/mamultrastruct.html); B, C and D, Gamalei et al., 2000.

Based on this model, AmSTS should be localized in the ER. However, no putative transmembrane domains could be identified within the amino acid sequence of AmSTS. This finding might contradict the proposed model, but it has to be taken into account that the mechanisms of protein targeting in plants have not yet been studied sufficiently. Interestingly, the only immunolocalization study of stachyose synthase in intermediary cells performed by Holthaus and Schmitz (1991b) has shown that the protein was often associated with the endomembrane vesicles.

The reformulation of the model of symplastic phloem loading made in this thesis would serve to explain some inconsistencies in the polymerization trap model and relate both structural and functional characteristics of intermediary cells. The model postulates that stachyose synthesis occurs within the endomembrane system of intermediary cells and that stachyose cannot escape from the endomembrane system, thus leading to the increase of 
osmotic pressure within this compartment. These postulates could be tested by an examination of the permeability of endomembranes for stachyose. Another approach could be the targeting of a stachyose cleaving enzyme into the endomembrane system in a plant species with intermediary cells in its minor veins. The latter could be achieved by transformation of Cucumis melo (Guis et al., 2000) with a construct containing the ORF of a modified alkaline a-galactosidase (Gao and Schaffer, 1999) with a signal peptide for uptake into the endomembrane system under control of a strong IC-specific promoter, e.g. the AmSTS promoter. 


\section{SUMMARY}

This thesis aimed to investigate the role of compartmentation of phloem-translocated carbohydrates and of the synthesis of one specific transport form, the stachyose, in the process of phloem loading in leaves of symplastic phloem loaders. These plants are characterized by (1) the presence of a special type of companion cells in the minor veins, the intermediary cells, and (2) the translocation of raffinose family oligosaccharides, mainly stachyose, in the phloem. The intermediary cells are characterized by highly developed plasmodesmata connecting mesophyll and phloem. This symplastic continuity between the two tissues provides an additional route for sugars entering the phloem as compared to apoplastic phloem loaders where plasmodesmal connections between companion cells and mesophyll are missing. At the same time, the presence of symplastic connections makes it necessary for a plant, in order to keep the sugar concentrations in the phloem high, to develop an effective mechanism to sustain a concentration gradient between mesophyll and phloem in spite of their symplastic continuity.

To elucidate how the compartmentation of translocated carbohydrates can by used by a plant to establish such a mechanism, this compartmentation between subcellular compartments of mesophyll cells was analysed in one model plant species with intermediary cells in minor veins, Alonsoa meridionalis. A related species, Asarina barclaina, which differs in the minor vein anatomy from Alonsoa was included as a comparison. Furthermore, the capacity to exchange translocated carbohydrates between symplastic and apoplastic compartments was compared in leaves of symplastic and apoplastic phloem loaders. The third part of this study was the characterization of the gene encoding stachyose synthase from leaves of Alonsoa meridionalis (AmSTS). This characterization included the determination of the expression pattern of AmSTS at the cellular level in leaves of Alonsoa and the isolation 
and characterization of the AmSTS promoter by the construction of transgenic Arabidopsis plants expressing a AmSTS-GUS fusion.

\section{The results obtained can be summarized as follows.}

- Distribution patterns of carbohydrates among subcellular compartments of mesophyll cells are similar in different plant species.

- Sugar concentrations in subcellular compartments of mesophyll cells of the symplastic phloem loader Alonsoa meridionalis do not differ from those in apoplastic phloem loaders.

- The concentration gradient between cytosol of mesophyll cells and phloem in Alonsoa meridionalis was 10 times lower than in apoplastic phloem loaders. However, this was due to the lower sucrose concentration in the phloem as compared to apoplastic loaders.

- Evidence was obtained for a proton motive force-dependent transport of raffinose and stachyose, as well as of turanose and palatinose from the apoplast into leaf cells indicating the presence of as yet unidentified plasma membrane tranporters.

- The capacity for the uptake of exogenously added sugars from the apoplast into the leaf cells does not differ between symplastic and apoplastic phloem loaders.

- The sugar composition in the apoplast of symplastic and apoplastic phloem loaders is related to phloem transport in apoplastic but not in symplastic phloem loaders, indicating that exchange of sugars between apoplast and phloem occurs only in apoplastic phloem loaders. As shown above, this cannot be due to the lack of specific plasma membrane transporters in symplastic phloem loaders.

- AmSTS is expressed in leaves and flowers, but not in stems of Alonsoa. The expression of AmSTS in leaves is confined to intermediary cells.

- The isolation of the AmSTS promoter and the construction of transgenic Arabidopsis plants containing a AmSTS-GUS fusion showed that the expression pattern of the AmSTS promoter is conserved in Arabidopsis. AmSTS expression is confined to the phloem of source organs.

- The expression of AmSTS-GUS in Arabidopsis seems to be regulated depending on changes in osmotic pressure.

- The availability of the AmSTS-GUS Arabidopsis plants provides a tool for further studies on the mechanism and the regulation of the phloem loading. 


\section{ABBREVIATIONS}

Amp

$\mathrm{Amp}^{\mathrm{R}}$

AmSTS

AP

ATP

BCIP

BDTO

bp

BS

BSA

$\mathrm{CC}$

cDNA

$\mathrm{Ch}$

Chl

CMV

CTAB

CW

Cyt

dCTP

dd $\mathrm{H}_{2} \mathrm{O}$

DDSA

DIG

DMF

DMP-30

DMSO

DNA

dNTPs

dpm

DTT

EDTA ampicillin

ampicilin resistance

Alonsoa meridionalis stachyose synthase

adapter primer

adenosine $5^{\prime}$ triphosphate

5-bromo-4 chloro-3-indolyl phosphate

bis-(1,3-dibutylbarbituric acid) trimethine oxonol

base pair

bundle sheath cell

bovine serum albumin

companion cell

complementary DNA

chloroplasts

chlorophyll

cucumber mosaic virus

hexadecyltrimethylammonium bromide

cell wall

cytoplasm

deoxycytosine $5^{\prime}$ triphosphate

double distilled water

Dodecenyl Succinic Anhydride hardener for epoxy resin

digoxigenine

dimethylformatide

2,4,6-tris (dimethylaminomethyl) phenol, a tertiary amine epoxy accelerator

dimethylsulfoxide

desoxyribonucleic acid

deoxyribonucleotides

decays per minute

dithiothreitol

ethylenediamine tetraacetic acid 


\begin{tabular}{|c|c|}
\hline ER & endoplasmic reticulum \\
\hline $\mathrm{EtOH}$ & ethanol \\
\hline F1 & transformants of the first generation \\
\hline $\mathrm{F} 2$ & transformants of the second generation \\
\hline FITC & fluorescein isothiocyanate \\
\hline FW & fresh weight \\
\hline G6PDH & glucose-6-phosphate dehydrogenase \\
\hline GAPDH & glyceraldehyde 3-phosphate dehydrogenase \\
\hline GC-MS & Gas Chromatography-Mass Spectrometry \\
\hline GS & $\begin{array}{l}\text { galactinol synthase (UDP-galactose:myo-Inositol } \\
\text { galactosyltransferase) }\end{array}$ \\
\hline GUS & $\beta$-glucuronidase \\
\hline GWDG & Gesellschaft für wissenschaftliche Datenverarbeitung Göttingen \\
\hline HEPES & hydroxyethyl-piperazinethane sulfonic acid \\
\hline HPLC & high pressure liquid chromatography \\
\hline $\mathrm{IC}$ & intermediary cells \\
\hline IPTG & isopropyl- $\beta$-D-thiogalactopyranoside \\
\hline IRGA & Infra Red Gas Analysis \\
\hline IWF & intercellular washing fluid or apoplastic extract \\
\hline $\mathrm{K}_{\mathrm{m}}$ & Michaelis-Menten constant \\
\hline $\mathrm{kb}$ & kilobase pair \\
\hline $\mathrm{kDa}$ & kilodalton \\
\hline $\mathrm{Km}$ & kanamycin \\
\hline $\mathrm{Km}^{\mathrm{R}}$ & kanamycin resistance \\
\hline $\mathrm{MC}$ & mesophyll cell \\
\hline MCS & multiple cloning site \\
\hline MEN & MOPS-sodium acetate-EDTA buffer \\
\hline MES & morpholinoethane sulfonic acid \\
\hline MOPS & morpholinopropane sulfonic acid \\
\hline MS medium & Murashige-Skoog medium \\
\hline MS2 & Murashige-Skoog medium with $2 \%(\mathrm{w} / \mathrm{v})$ sucrose \\
\hline NAD & nicotinamide adenine dinucleotide (oxidized) \\
\hline NADH & nicotinamide adenine dinucleotide (reduced) \\
\hline NADP & nicotinamide adenine dinucleotide phosphate (oxidized) \\
\hline NADPH & nicotinamide adenine dinucleotide phosphate (reduced) \\
\hline NBT & 4-nitro-blue tetrazolium chloride \\
\hline NMR & nuclear magnetic resonance \\
\hline $\mathrm{OC}$ & ordinary cells \\
\hline OD & optical density \\
\hline ORF & open reading frame \\
\hline PAGE & polyacrylamid-gel electrophoresis \\
\hline PBS & phosphate buffer saline \\
\hline PCMBS & para-chloro-mercuribenzene sulphonate \\
\hline PCR & polymerase chain reaction \\
\hline PEP & phosphoenolpyruvate \\
\hline PEPCX & phosphoenolpyruvate carboxylase \\
\hline $\mathrm{pf}$ & plasmodesmal field \\
\hline
\end{tabular}




\begin{tabular}{|c|c|}
\hline PIPES & 1, 4-piperazinediethane sulfonic acid \\
\hline PM & plasma membrane \\
\hline PMF & proton motive force \\
\hline PP & phloem parenchyma \\
\hline rpm & rounds per minute \\
\hline PVP & polyvinylpyrrolidon \\
\hline RACE & rapid amplification of cDNA ends \\
\hline RFOs & raffinose family oligosaccharides \\
\hline RNA & ribonucleic acid \\
\hline $\mathrm{RS}$ & $\begin{array}{l}\text { raffinose synthase (galactinol:sucrose } 6-\alpha-\mathrm{D}- \\
\text { galactosyltransferase) }\end{array}$ \\
\hline RT & reverse transcriptase \\
\hline SD & standard deviation \\
\hline SDS & sodium dodecylsulfate \\
\hline SE & sieve element \\
\hline SE-CC complex & sieve element-companion cell complex \\
\hline SEL & size exclusion limit \\
\hline $\mathrm{sp}$ & single plasmodesma \\
\hline SSC & saline-sodium citrate buffer \\
\hline STEL & sucrose - Triton-X-100 - Tris- EDTA -lysozyme buffer \\
\hline STS & $\begin{array}{l}\text { stachyose synthase (galactinol:raffinose } 6-\alpha-\mathrm{D}- \\
\text { galactosyltransferase) }\end{array}$ \\
\hline SUT & sucrose transporter \\
\hline $\mathrm{T}_{\mathrm{ann}}$ & annealing temperature \\
\hline Taq & Thermus aquaticus \\
\hline $\mathrm{TC}$ & transfer cells \\
\hline TdT & terminal desoxynucleotidyl transferase \\
\hline TEMED & $\mathrm{N}, \mathrm{N}, \mathrm{N}^{\prime}, \mathrm{N}^{\prime}$-tetramethylene diamine \\
\hline $\mathrm{T}_{\mathrm{m}}$ & melting temperature \\
\hline $\mathrm{T}_{\mathrm{op}}$ & temperature optimum \\
\hline Tricine & N-Tris-(hydroxymethyl)-methyl glycine \\
\hline Tris & tris-(hydroxymethyl)-aminomethane \\
\hline Tth & Thermus thermophilus \\
\hline $\mathrm{U}$ & $\begin{array}{l}\text { enzyme activity unit ( } 1 \text { unit corresponds to the conversion of } 1 \\
\mu \text { mol substrate } \min ^{-1} \text { ) }\end{array}$ \\
\hline uORF & upstream open reading frame \\
\hline UTP & uridine $5^{\prime}$ triphosphate \\
\hline UV & ultraviolet light \\
\hline Vac & vacuoles \\
\hline $\mathrm{v} / \mathrm{v}$ & volume/volume \\
\hline $\mathrm{w} / \mathrm{v}$ & weight/volume \\
\hline X-Gal & 5-bromo-4-chloro-3-indolyl- $\beta$-D-galactopyranoside \\
\hline X-Gluc & 5-bromo-4-chloro-3-indolyl- $\beta$-D-glucuronide \\
\hline XV & xylem vessel \\
\hline
\end{tabular}




\section{REFERENCES}

Adhikari, J., Bhaduri, T. J., DasGupta, S. and Majumder, A. L. (1987) Chloroplast as a locale of L-myo-inositol-1-phosphate synthase. Plant Physiol 85, 611-164.

Altschul, S. F., Gish, W., Miller, W., Myers, E. W. and Lipman, D. J. (1990) Basic local alignment search tool. J Mol Biol 215, 403-410.

Arnon, D. I. (1949) Copper enzymes in isolated chloroplasts. Polyphenoloxidase in Beta vulgaris. Plant Physiol 24, 1-15.

Bachmann, M. and Keller, F. (1995) Metabolism of the raffinose family oligosaccharides in leaves of Ajuga reptans L. Inter- and intracellular compartmentation. Plant Physiol 109, 991-998.

Bachmann, M., Matile, P. and Keller, F. (1994) Metabolism of the raffinose family oligosaccharides in leaves of Ajuga reptans L. Cold acclimation, translocation, and sink to source trasition: discovery of chain elongation enzyme. Plant Physiol 105, 13351345.

Batashev, D. (1997) Comparative Anatomy of Leaf Terminal Phloem in Subclasses Lamiidae and Asteridae. In Dissertation, St.-Petersburg.

Batashev, D. and Gamalei, Y. V. (1996) Diurnal changes in cell structures related to assimilate accumulation and export from leaves of Acanthus and Phlomis with and without blocking phloem transport. Russ J Plant Physiol 43, 344-351.

Bentwood, B. J. and Cronshaw, J. (1978) Cytochemical localization of adenosine triphosphatase in the phloem of Pisum sativum and its relation to the function of transfer cells. Planta 140, 111-120.

Bergmeyer, H. U. (1974) Methods of enzymatic analysis, (ed. H. U. Bergmeyer), Verlag Chemie, Weinhein, Academic Press Inc., New York, London.

Bird, I. F., Cornelius, M. J., Keys, A. J. and Whittingham, C. P. (1974) Intracellular site of sucrose synthesis in leaves. Phytochemistry 13, 59-64.

Blackman, L. M. and Overall, R. L. (2001) Structure and function of plasmodesmata. Aust J Plant Physiol 28, 709-721. 
Boevink, P., Martin, B., Oparka, K., Santa Cruz, S. and Hawes, C. (1999) Transport of virally expressed green fluorescent protein through the secretory pathway in tobacco leaves is inhibited by cold shock and brefeldin A. Planta 208, 392-400.

Boorer, K. J., Loo, D. D. F., Frommer, W. B. and Wright, E. M. (1996) Transport mechanism of the cloned potato $\mathrm{H}^{+}$/sucrose cotransporter StSUT1. J Biol Chem 271, 25139-25144.

Boston, W. S., Bleck, G. T., Conroy, J. C., Wheeler, M. B. and Miller, D. J. (2001) Short communications: Effect of increased expression of alpha-lactalbumin in transgenic mice on milk yield and pup growth. J Dairy Sci 84, 620-622.

Bouteau, F., Dellis, O., Bousquet, U. and Rona, J. P. (1999) Evidence of multiple sugar uptake across the plasma membrane of laticifer protoplasts from Hevea. Bioelectrochem Bioenerg 48, 135-139.

Burbulis, I. E. and Winkel-Shirley, B. (1999) Interactions among enzymes of the Arabidopsis flavonoid biosynthetic pathway. Proc Natl Acad Sci USA 96, 12929-12934.

Börnke, F., Hajirezaei, M., Heineke, D., Melzer, M., Herbers, K. and Sonnewald, U. (submitted) High level production of the non-cariogenic sucrose isomer palatinose in transgenic tobacco plants strongly impairs development. Planta.

Büchi, R., Bachmann, M. and Keller, F. (1998) Carbohydrate metabolism in source leaves of sweet basil (Ocimum basilicum L.), a starch-sorting and stachyose-translocating labiate. J Plant Physiol 153, 308-315.

Cantril, L. C., Overall, R. L. and Goodwin, P. B. (2002, in press) Changes in symplastic permeability during adventitious shoot regeneration in tobacco thin cell layers in planta.

Cantrill, L. C., Overall, R. L. and Goodwin, P. B. (1999) Cell-to-cell communication via plasma membrane. Cell Biology International 23, 653-661.

Chang, K. S., Lee, S. H., Hwang, S. B. and Park, K. Y. (2000) Characterization and translational regulation of the arginine decarboxylase gene in carnation (Dianthus caryophyllus L.). Plant J 24, 45-56.

Christmann, J., Kreis, W. and E., R. (1993) Uptake, transport and storage of cardenolides in foxglove: Cardenolide sinks and occurrence of cardenolides in the sieve tubes of Digitalis lanata. Botanica Acta 106, 419-427.

Clough, S. J. and Bent, A. F. (1998) Floral dip: a simplified method for Agrobacteriummediated transformation of Arabidopsis thaliana. Plant J 16, 735-743.

Delesse, M. A. (1847) Procéde mechanique pour determiner la composition des roches. $C R$ Acad Sci Paris 25, 544-559.

Di Sansebastiano, G.-P., Paris, N., Marc-Martin, S. and Neuhaus, J.-M. (1998) Specific accumulation of GFP in a non-acidic vacuolar compartment via a C-terminal propeptide-mediated sorting pathway. Plant $J$ 15, 449-457.

Di Sansebastiano, G.-P., Paris, N., Marc-Martin, S. and Neuhaus, J.-M. (2001) Regeneration of a lytic central vacuole and of neutral peripheral vacuoles can be visualized by green fluorescent proteins targeted to either type of vacuoles. Plant Physiol 126, 78-86.

Esau, K. (1967) Minor veins in Beta leaves: structure related to function. Proc Amer Phil Soc 11, 219-233.

Everard, J. D., Franceschi, V. R. and Loescher, W. H. (1993) Mannose-6-phosphate reductase, a key enzyme in photoassimilate partitioning, is abundant and located in the 
cytosol of photosynthetically active cells of celery (Apium graveolens L.) source leaves. Plant Physiol 102, 345-356.

Faucher, M., Bonnemain, J.-L. and Doffin, M. (1982) Effets de refroidissements localises sur la circulation liberienne chez quelques especes avec on sans proteines-P et influence du mode de refroidissement. Physiol Veg 20, 395-405.

Fischer, D. G. (1986) Ultrastructure, plasmodesmatal frequency and solute concentration in green areas of variegated Coleus blumei Benth. leaves. Planta 169, 141-152.

Flora, L. L. and Madore, M. A. (1993) Stachyose and mannitol transport in olive (Olea europaea L.). Planta 189, 484-490.

Flora, L. L. and Madore, M. A. (1996) Significance of minor-vein anatomy to carbohydrate transport. Planta 198, $171-178$.

Fricke, W., Leigh, R. A. and Tomos, A. D. (1994a) Concentrations of inorganic and organic solutes in extracts from individual epidermal, mesophyll and bundle-sheath cells of barley leaves. Planta 192, 310-316.

Fricke, W., Leigh, R. A. and Tomos, A. D. (1994b) Epidermal solute concentrations and osmolality in barley leaves studied at the single-cell level. Planta 192, 317-323.

Gamalei, Y. V. (1984) The structure of leaf minor veins and the types of translocated carbohydrates. Dokl Akad Nauk (in russ.) 277, 1513-1516.

Gamalei, Y. V. (1990) Leaf Phloem, Nauka, Leningrad.

Gamalei, Y. V. (1994) The endoplasmic reticulum of plants: its origin, structure and functions, BIN RAN, St.-Petersburg.

Gamalei, Y. V. (1995) Comparative biology of trees and herbs intercellular communication. In L'Arbre. Biologie et Development - 3ème colloque, (ed. C. Edelin), pp. 1-11, Montpellier.

Gamalei, Y. V. (2000) Comparative anatomy and physiology of leaf minor veins and bundle sheath parenchyma in leaves of dicotyledonous plants. Botan Zhurnal (in russ.) 85, 3449.

Gamalei, Y. V. and Pakhomova, M. V. (1981) Structure of the companion cells of leaf phloem: the results of a three-dimensional reconstruction from serial sections. Cytologija (in Russian) 23, 117-129.

Gamalei, Y. V. and Pakhomova, M. V. (2000) The time course of carbohydrate transport and storage in the leaves of the plant species with symplastic and apoplastic phloem loaded under the normal and experimentally modified conditions. Russ J Plant Physiol 47, 109-128.

Gamalei, Y. V., Pakhomova, M. V., Syutkina, A. V. and Voitsekhovskaja, O. (2000) Compartmentation of assimilate fluxes in leaves. I. Ultrastructural responses of mesophyll and companion cells to the alteration of assimilate export. Plant biol 2, 98106.

Gamalei, Y. V. and Sjutkina, A. V. (1999) Structural types and ecophysiology of terminal phloem in plant species of steppes and deserts. In International Conference on Assimilate Transport and Partitioning, Book of Abstracts, Newcastle, Australia.

Gamalei, Y. V., van Bel, A. J. E., Pakhomova, M. V. and Sjutkina, A. V. (1994) Effects of temperature on the conformation of the endoplasmic reticulum and on starch 
accumulation in leaves with the symplasmic minor-vein configuration. Planta 494, 443453.

Gao, Z. and Schaffer, A. A. (1999) A novel alkaline -galactosidase from melon fruit with a substrate preference for raffinose. Plant Physiol 119, 979-987.

Geballe, A. P. and Morris, D. R. (1994) Initiation codons within 5'-leaders of mRNAs as regulators of translation. Trend Biochem Sci 19, 159-164.

Geiger, D. (1975) Phloem loading. In Transport in Plants, Springer Verlag, Berlin.

Geiger, D. R. and Sovonick, S. A. (1970) Temporary inhibition of translocation velocity and mass transfer rate by petiole cooling. Plant Physiol 46, 847-849.

Gerhardt, R. and Heldt, H. W. (1984) Measurement of subcellular metabolite levels by fractionation of freeze-stopped material in nonaqeous media. Plant Physiol 75, 542547.

Ghoshroy, S., Lartey, R., Sheng, J. and Citovsky, V. (1997) Transport of proteins and nucleic acids through plasmodesmata. Annu Rev Plant Physiol Plant Mol Biol 48, 27-50.

Giaquinta, R. (1980) Mechanism and control of phloem loading of sucrose. Ber Dtsch bot Ges 93, 187-201.

Grignon, C. and Sentenac, H. (1991) pH and ionic conditions in the apoplast. Annu Rev Plant Physiol Plant Mol Biol 42, 103-128.

Guis, M., Ben Amor, M., Latché, A., Pech, J.-C. and Roustan, J.-P. (2000) A reliable system for the transformation of cantaloupe charentais melon (Cucumis melo L. var. cantalupensis) leading to a majority of diploid regenerants. Scientia Horticulturae 84, 91-99.

Gunning, B. E. S. and Pate, J. S. (1969) "Transfer cells". Plant cells with wall ingrowths, specialized in relation to short distance transport of solutes - their occurrence, structure, and development. Protoplasma 68, 107-133.

Haritatos, E., Ayre, B. G. and Turgeon, R. (2000b) Identification of phloem involved in assimilate loading in leaves by the activity of galactinol synthase promoter. Plant Physiol 123, 929-937.

Haritatos, E., Keller, F. and Turgeon, R. (1996) Raffinose oligosaccharide concentrations measured in individual cell and tissue types in Cucumis melo L. leaves: implications for phloem loading. Planta 198, 614-622.

Haritatos, E., Medville, R. and Turgeon, R. (2000a) Minor vein structure and sugar transport in Arabidopsis thaliana. Planta 211, 105-111.

Heber, U. (1957) Zur Frage der Lokalisation von löslichen Zuckern in der Pflanzenzelle. Ber. Dtsch. Bot. Ges. 70, 371-382.

Heber, U., Wiese, C., Neimanis, S., Savchenko, G., Bukhov, N. and Hedrich, R. (2002, in press) Energy-dependent solute transport from the apoplast into the symplast of leaves during transpiration. Russ J Plant Physiol 49.

Hedrich, R., Neimanis, S., Savchenko, G., Felle, H. H., Kaiser, W. M. and Heber, U. (2001) Changes in apoplastic $\mathrm{pH}$ and membrane potential in leaves in relation to stomal responses to $\mathrm{CO}_{2}$, malate, abscisic acid or interruption of water supply. Planta 213, 594-601. 
Heidstra, R., Geurts, R., Franssen, H., Spaink, H. P., van Kammen, A. and Bisseling, T. (1994) Root hair deformation activity of nodulation factors and their fate on Vicia sativa. Plant Physiol 105, 787-797.

Heineke, D., Wildenberger, K., Sonnewald, U., Willmitzer, L. and Heldt, H. W. (1994) Accumulation of hexoses in leaf vacuoles: Studies with transgenic tobacco plants expressing yeast-derived invertase in the cytosol, vacuole or apoplasm. Planta 194, 2933.

Heldt, H. W. (1996) Pflanzenbiochemie, Spektrum Verlag, Heidelberg.

Hendrix, J. E. (1982) Sugar translocation in two members of the Cucurbitaceae. Plant Sci Lett 25, 1-7.

Hoffmann, B. and Kosegarten, H. (1995) FITC-dextran for measuring apoplast pH and apoplastic $\mathrm{pH}$ gradients between varios cell types in sunflower leaves. Physiol Plant 95, 327-335.

Hoffmann-Thoma, G., van Bel, A. J. E. and Ehlers, K. (2001) Ultrastructure of minor-vein phloem ans assimilate export in summer and winter leaves of the symplasmically loading evergreens Ajuga reptans L., Aucuba japonica Thunb., and Hedera helix L. Planta 212, 231-242.

Holthaus, U. and Schmitz, K. (1991a) Stachyose synthesis in mature leaves of Cucumis melo. Purification and characterization of stachyose synthase (EC 2.4.1.67). Planta 184, 525231.

Holthaus, U. and Schmitz, K. (1991b) Distribution and immunolocalization of stachyose synthase in Cucumis melo L. Planta 185, 479-486.

Häfliger, B., Kindhauser, E. and Keller, F. (1999) Metabolism of D-glycero-D-mannoheptidol, volemitol, in Polyanthus. Discovery of a novel ketose reductase. Plant Physiol 119, 191-197.

Inoue, H., Nojima, H. and Okayama, H. (1990) High efficiency transformation of Escherichia coli with plasmids. Gene 96, 23-28.

Jefferson, R. A. B., S.M. Hirsh, D. (1986) B-glucuronidase from Escherichia coli as a genefusion marker. Proc Natl Acad Sci USA 83, 8447-8451.

Jensen, S. R. (1991) Plant iridoids, their biosynthesis and distribution in angioserms. In Ecological Chemistry and Biochemistry of Plant Terpenoids, (eds. J. B. Harborne and F. A. Tomas-Barbaran), pp. 133-158, Clarendon Press, Oxford.

Johansson, I., Karlsson, M., Johanson, U., Larsson, C. and Kjellbom, P. (2000) The role of aquaporis in cellular and whole plant water balance. Biochim Biophys Acta 1465, 324342.

Kaiser, G. and Heber, U. (1984) Sucrose transport into vacuoles isolated from barley mesophyll protoplasts. Planta 161, 562-568.

Kehr, J., Wagner, U., Willmitzer, L. and Fisahn, J. (1999) Effect of modified carbon allocation on turgor, osmolality, sugar and potassium content, and membrane potential in the epidermis of transgenic potato (Solanum tuberosum L.) plants. J Exp Bot 50, 565571.

Keller, F. and Pharr, D. M. (1996) Metabolism of Carbohydrates in Sinks and Sources: Galactosyl-Sucrose Oligosaccharides. In Photoassimilate Distribution in Plants and Crops: Source-Sink Relationships, (eds. E. Zamski and A. A. Schaffer), pp. 157-183, Marcel Dekker, Inc., New York-Basel-Hong Kong. 
King, R. W. and Zeevaart, J. A. D. (1974) Enhancement of phloem exudation from cut petioles by chelating agents. Plant Physiol 53, 96-103.

Knop, C. (1998) Untersuchungen zum Zucker- und Aminosäuretransport bei der symplastischen Phloembeladung, Diplomarbeit, Math. Nat. Fakultät, Universität Göttingen, Göttingen.

Knop, C. (2001) Zur Bedeutung von Saccharose-Transportern in Pflanzen mit offener Phloemanatomie, Universität Göttingen, Dissertation.

Knop, C., Voitsekhovskaja, O. and Lohaus, G. (2001) Sucrose transporters in two members of the Scrophulariaceae with different types of transport sugar. Planta 213, 80-91.

Koncz, C. and Schell, J. (1985) The promoter of the TL-DNA gene 5 controls the tissue specific expression of chimeric genes carried by a novel type of Agrobacterium binary vector. Mol Gen Genet 204, 383-396.

Koroleva, O. A., Farrar, J. F., Tomos, A. D. and Pollock, C. J. (1997) Patterns of solute in individual mesophyll, bundle sheath and epidermal cells of barley leaves induced to accumulate carbohydrate. New Phytol 136, 97-104.

Koroleva, O. A., Farrar, J. F., Tomos, A. D. and Pollock, C. J. (1998) Carbohydrates in individual cells of epidermis, mesophyll, and bundle sheath in barley leaves with changed export or photosynthetic rate. Plant Physiol 118, 1525-1532.

Kozak, M. (1996) Interpreting cDNA sequences: some insights from studies on translation. Mammalian Genome 7, 536-574.

Kragler, F., Monzer, J., Xoconostle-Cázares, B. and Lucas, W. J. (2000) Peptide antagonists of the plasmodesmal macromolecular trafficking pathway. EMBO J 19, 2856-2868.

Krapp, A. and Stitt, M. (1995) An evaluation of direct and indirect mechanisms for the "sinkregulation" of photosynthesis in spinach: changes in gas exchange, carbohydrates, metabolites enzyme activities and steady-state transcript levels after cold-girdling source leaves. Planta 195, 313-323.

Kursanov, A. L. (1984) Assimilate transport in plants, Elsevier, Amsterdam.

Kwak, S. H. and Lee, S. H. (2001) The regulation of ornithine decarboxylase gene expression by sucrose and small upstream open reading frame in tomato (Lycopersicon esculentum Mill). Plant Cell Physiol 42, 314-323.

Laemmli, U. K. (1970) Cleavage of structural proteins during the assembly of the head of bacteriophage T4. Nature 227, 680-685.

Leidreiter, K., Kruse, A., Heineke, D., Robinson, D. G. and Heldt, H. W. (1995) Subcellular volumes and metabolite concentrations in potato (Solanum tuberosum cv. Désirée) leaves. Bot Acta 108, 439-444.

Lemoine, R. (2000) Sucrose transporters in plants: update on function and structure. Biochim Biophys Acta 1465, 246-262.

Lemoine, R., Kühn, C., Thiele, N., Delrot, S. and Frommer, W. B. (1996) Antisense inhibition of the sucrose transporter in potato: effects on amount and activity. Plant Cell Environ 19, 1124-1131.

Li, Z. S., Noubhani, A. M., Bourbouloux, A. and Delrot, S. (1994) Affinity preparation of sucrose binding proteins from the plasma membrane. Biochem Biophys Acta 1219, 389397. 
Logemann, J., Schell, J. and Willmitzer, L. (1987) Improved method for the isolation of RNA from plant tissues. Anal Biochem 163, 16-20.

Lohaus, G., Burba, M. and Heldt, H. W. (1994) Comparison of the contents of sucrose and amino acids in leaves, phloem sap and taproots of high and low sugar-producing hybrids of sugar beet (Beta vulgaris L.). J Exp Bot 45, 1097-1101.

Lohaus, G., Büker, M., Hußmann, M., Soave, C. and Heldt, H. W. (1998) Transport of amino acids with special emphasis on the synthesis and transport of asparagine in the Illinois Low Protein and Illinois High Protein strains of maize. Planta 205, 181-188.

Lohaus, G. and Fischer, K. (2001, in press) Intracellular and intercellular transport of nitrogen and carbon In: Advances in Photosynthesis: Photosynthetic nitrogen assimilation and associated carbon metabolism, (eds. C. H. Foyer and G. Noctor), Chapter11 Kluwer Acad Publishers, Dordrecht.

Lohaus, G., Pennewiss, K., Sattelmacher, B., Hussmann, M. and Muehling, K. H. (2001) Is the infiltration technique appropriate for the isolation of apoplastic fluid? A critical evaluation with different plant species. Physiol Plant 111, 457-465.

Lohaus, G., Winter, H., Riens, B. and Heldt, H. W. (1995) Further studies of the phloem loading process in leaves of barley and spinach. The comparison of metabolite concentrations in the apoplastic compartment with those in the cytosolic compartment and in the sieve tubes. Bot Acta 108, 270-275.

Loreti, E., Alpi, A. and Perata, P. (2000) Glucose and disaccharide-sensing mechanisms modulate the expression of $\alpha$-amylase in barley embryos. Plant Physiol 123, 939-948.

Lowry, O. H., Rosebrough, N. J., Farr, A. L. and Randall, R. J. (1951) 1951 Protein measurement with the Folin phenol reagent. J Biol Chem 193, 265-275.

Luttge, U. and Higinbotham, N. (1979) Transport in plants, Springer Verlag, New York.

Madore, M. A. (1990) Carbohydrate metabolism in photosynthetic and nonphotosnthetic tissues of variegated leaves of Coleus blumei Benth. Plant Physiol 93, 617-622.

Madore, M. A. and Webb, J. A. (1981) 1981 Leaf free space analysis and vein loading in Cucurbita pepo. Can J Bot 59, 2550-2557.

Malone, M., Leigh, R. A. and Tomos, A. D. (1989) Extraction and analysis of sap from individual wheat leaf cells: the effect of sampling speed on the osmotic pressure of the extracted sap. Plant Cell Environ 12, 919-926.

Meyer, S., Meltzer, M., Truernit, E., Hümmer, C., Besenbeck, R., Stadler, R. and Sauer, N. (2000) AtSUC3, a gene encoding a new Arabidopsis sucrose transporter, is expressed in cells adjacent to the vascular tissues and in a carpel cell layer. Plant $J \mathbf{2 4}, 869-882$.

Mitchell, D. E., Gadus, M. V. and Madore, M. A. (1992) Patterns of assimilate production and translocation in muskmelon (Cucumis melo L.). Plant Physiol 99, 959-965.

Moing, A., Carbonne, F., Zipperlin, B., Svanella, L. and Gaudillère, J.-P. (1997) Phloem loading in peach: symplastic or apoplastic? Physiol Plant 101, 489-496.

Moore, B. D., Palmquist, D. E. and Seemann, J. R. (1997) Influence of plant growth at high $\mathrm{CO}_{2}$ concentrations on leaf content of ribulose-1,5-biphosphate carboxylase/oxygenase and intracellular distribution of solublecarbohydrates in tobacco, snapdragon, and parsley. Plant Physiol 115, 241-248.

Murashige, T. and Skoog, F. (1962) A revised medium for rapid growth and bioassays with tobacco tissue culture. Physiol Plant 15, 473-497. 
M'Batchi, B. and Delrot, S. (1988) Stimulation of sugar exit from leaf tissues of Vicia faba. Planta 174, 340-348.

Münch, E. (1930) Die Stoffwechselbewegungen in der Pflanze, Fischer Verlag, Jena.

Nelson, D. E., Koukoumanos, M. and Bohnert, H. J. (1999) Myo-inositol-dependent sodium uptake in ice plant. Plant Physiol 119, 165-172.

Newman, J. D. and Chappell, J. (1999) Isoprenoid biosynthesis in plants: carbon partitioning within cytoplasmic pathway. Crit Rev Biochem Mol Biol 34, 95-106.

Noiraud, N., Maurousset, L. and Lemoine, R. (2001) Identification of a mannitol transporter, AgMaT1, in celery phloem. Plant Cell 13, 695-705.

Ntsika, G. and Delrot, S. (1986) Changes in apoplastic and intracellular leaf sugars induced by the blocking of export in Vicia faba. Physiol Plant 68, 145-153.

Ohshima, T., Hayashi, H. and Chino, M. (1990) Collection and chemical composition of pure phloem sap from Zea mays L. Plant Cell Physiol 31, 695-705.

Paris, N., Stanley, C. M., Jones, R. L. and Rogers, J. C. (1996) Plant cells contain two functionally distinct vacuolar compartments. Cell 85, 563-572.

Pate, J. S. and Gunning, B. E. S. (1969) Vascular transfer cells in angiosperm leaves. A taxonomic and morphological survey. Protoplasma 68, 135-156.

Peterbauer, T., Mucha, J., Mayer, U., Popp, M., Glössl, J. and Richter, A. (1999) Stachyose synthesis in seeds of adzuki bean (Vigna angularis): molecular cloning and functional expression of stachyose synthase. Plant $J$ 20, 509-518.

Peterbauer, T. and Richter, A. (2001) Biochemistry and physiology of raffinose family oligosaccharides and galactosyl cyclitols in seeds. Seed Science Research 11, 185-197.

Pharr, D. M., Hendrix, J. E., Robbins, N. S., Gross, K. C. and Sox, H. N. (1987) Isolation of galactinol from leaves of Cucumis sativus. Plant Science 50, 21-26.

Pharr, D. M., Sox, H. N., Locy, R. D. and Huber, S. C. (1981) Partial characterization of the galactinol forming enzyme from leaves of Cucumis sativus L. Plant Sci Lett 23, 25-33.

Raney, A., Baron, A. C., Mize, G. J., Law, G. L. and Morris, D. R. (2000) In vitro translation of the upstream open reading frame in the mammalian mRNA encoding SAdenosylmethionine decarboxylase. J Biol Chem 275, 24444-24450.

Riens, B., Lohaus, G., Heineke, D. and Heldt, H. W. (1991) Amino acid and sucrose content determined in the cytosolic, chloroplastic, and vacuolar compartments and in the phloem sap of spinach leaves. Plant Physiol 97, 227-233.

Riesmeier, J. W., Willmitzer, L. and Frommer, W. B. (1994) Evidence for an essential role of the sucrose transporter in phloem loading and assimilate partitioning. EMBO J 13, 1-7.

Robards, A. W. and Lucas, W. J. (1990) Plasmodesmata. Annu Rev Plant Physiol Plant Mol Biol 41, 369-419.

Rosenberg, A. H., Lade, B. N., Chui, D. S., Lin, S.-W., Dunn, J. J. and Studier, F. W. (1986) Vectors for selective expression of cloned DNAs by T7 RNA polymerase. Gene 56, 125-135.

Sambrook, J., Fritsch, E. F. and Maniatis, T. (1989) Molecular cloning: A laboratory manual, Cold Spring Harbor, New York.

Sanger, F., Nickler, S. and Coulson, A. R. (1977) DNA sequencing with chain-terminating inhibitors. Proc Natl Acad Sci USA 74, 5463-5467. 
Schmitz, K., Cuypers, B. and Moll, M. (1987) Pathway of assimilate transfer between mesophyll cells and minor veins in leaves of Cucumis melo L. Planta 171, 19-29.

Schulz, A. (1997) Phloem. Structure related to function. In Progress in Botany, Vol. 59, pp. 429-475, Springer-Verlag, Berlin, Heidelberg, New York.

Schulz, A., Kühn, C., Riesmeier, J. W. and Frommer, W. B. (1998) Ultrastructural effects in potato leaves due to antisense-inhibition of the sucrose transporter indicate an apoplasmic mode of phloem loading. Planta 206, 533-543.

Senser, M. and Kandler, O. (1967) Vorkommen und Verbreitung von Galactinol in Blättern Höherer Pflanzen. Phytochemistry 7, 1533-1540.

Shalitin, D. and Wolf, S. (2000) Cucumber mosaic virus infection affects sugar transport in melon plants. Plant Physiol 123.

Singh, R. (1993) Photosynthesis characteristics of fruiting structures of cultivated crops. In Photosynthesis: Photoreactions to Plant Productivity, (eds. Y. P. Abrol, P. Mohanty and E. E. Govindi), pp. 390-415, Kluwer Academic Publishers, Dordrecht.

Southern, E. M. (1975) Detection of specific sequences among DNA fragments separated by gel electropheresis. J Mol Biol 98, 479-483.

Speer, M. and Kaiser, W. M. (1991) Ion relations of symplastic and apoplastic space in leaves from Spinacea oleracea L. and Pisum sativum L. under salinity. Plant Physiol 97, 990997.

Sprenger, N. and Keller, F. (2000) Allocation of raffinose family oligosaccharides to transport and storage pools in Ajuga reptans: the roles of two distinct galactinol synthases. Plant $J$ 21, 249-258.

Stadler, R., Brandner, J., Schulz, A., Gahrtz, C. and Sauer, N. (1995) Phloem loading by the PmSUC2 sucrose carrier from Plantago major occurs into companion cells. The Plant Cell 7, 1545-1554.

Stitt, M., Bulpin, T. and Rees, T. (1978) Pathways of starch breakdown in photosynthetic tissues of Pisum sativum. Biochem Biophys Acta 544, 200-214.

Stoop, J. M. N., Williamson, J. D. and Pharr, D. M. (1996) Mannitol metabolism in plants: a method for coping with stress. Trend Plant Sci 1, 139-144.

Strauß, M., Kauder, F., Peisker, M., Sonnewald, U., Conrad, U. and Heineke, D. (2001) Expression of an abscisic acid-binding single chan antibody influences the subcellular distribution of abscisic acid and leads to developmental changes in transgenic popato plants. Planta 213, 361-369.

Studier, F. W. and Moffatt, B. A. (1985) Use of bacteriophage T7 RNA polymerase to direct selective high-level expression of cloned genes. J Mol Biol 189, 113-130.

Sze, H., Li, X. and Palmgren, M. G. (1999) Energization of plant cell membranes by H+pumping ATPases: regulation and biosynthesis. Plant cell 11, 677-689.

Tomos, A. D., Hinde, P., Richardson, P., Pritchard, J. and Fricke, W. (1994) Microsampling and measurement of solutes in single cells. In Plant Cell Biology - a Practical Approach, (eds. N. Harris and K. J. Oparka), pp. 297-314, IRL Press, Oxford UK.

Turgeon, R. (1991) Symplastic phloem loading and the sink-source transition in leaves: a model. In Recent Advances in Phloem Transport and Assimilate Partitioning, (eds. J. L. Bonnemain, S. Delrot and W. J. Lucas), Ouest Edition, Nantes. 
Turgeon, R., Beebe, D. U. and Gowan, E. (1993) The intermediary cell: minor-vein anatomy and raffinose oligosaccharide synthesis in the Scrophulariaceae. Planta 191, 446-456.

Turgeon, R. and Gowan, E. (1990) Phloem loading in Coleus blumei in the absense of carriermediated uptake. Plant Physiol 94, 1244-1249.

Turgeon, R. and Gowan, E. (1992) Sugar synthesis and phloem loading in Coleus blumei leaves. Planta 187, 388-394.

Turgeon, R. and Webb, J. A. (1973) Leaf development and phloem transport in Cucurbita реро: transition from import to export. Planta 113, 179-191.

Turgeon, R. and Webb, J. A. (1975) Leaf development and phloem transport in Cucurbita pepo: carbon economy. Planta 123, 53-62.

Turgeon, R. and Wimmers, L. E. (1988) Different patterns of vein loading of exogenous $\left[{ }^{14} \mathrm{C}\right]$ sucrose in leaces of Pisum sativum and Coleus blumei. Plant Physiol 87, 179-182.

van Bel, A. J. E., Hendriks, J. H. M., Boon, E. J. M. C., Gamalei, Y. V. and van de Merwe, A. P. (1996) Different ratios of sucrose/raffinose-induced membrane depolarizations in the mesophyll of species with symplastic (Catharanthus roseus, Ocimum basilicum) or apoplastic (Impatiens walleriana, Vicia faba) minor-vein configurations. Planta 199, 185-192.

Vaquero, C., Turner, A. P., Demangeat, G., Sanz, A., Serra, M. T., Roberts, K. and GarciaLuque, I. (1994) The 3a protein from cucumber mosaic virus increases the gating capacity of plasmodesmata in transgenic tobacco plants. J Gen Virol 75, 3193-3197.

Vemmos, S. N. and Glodwin, G. K. (1994) The photosynthetic activity of Cox's orange pippin apple flowers in relation to fruit setting. Ann Bot 73, 385-391.

Voitsekhovskaja, O., Heber, U., Wiese, C., Lohaus, G., Heldt, H. W. and Gamalei, Y. V. (2002, in press) Energized uptake of sugars from the apoplast of leaves: a study of some plants possessing different minor vein anatomy. Russ J Plant Physiol 49.

Voitsekhovskaja, O. V., Pakhomova, M. V., Syutkina, A. V., Gamalei, Y. V. and Heber, U. (2000) Compartmentation of assimilate fluxes in leaves. II. Apoplastic sugar levels in leaves of plants with different companion cell types. Plant Biol 2, 107-112.

Waigmann, E., Lucas, W. J., Citovsky, V. and Zambryski, P. C. (1994) Direct functional assay for tobacco mosaic virus cell-to-cell movement protein and identification of a domain involved in increasing plasmodemal permeability. Proc Natl Acad Sci USA 91, 1433-1437.

Webb, J. A. and Gorham, P. R. (1965) The effect of node temperature on assimilation and translocaton of ${ }^{14} \mathrm{C}$ in squash. Can J Bot 43, 1009-1017.

White, M. D., Kuhn, J. and Ward, S. (1980) Permeability of lactating-rat mammary gland Golgi membranes to monosaccharides. Biochem J 190, 621-624.

Winter, H. (1993) Untersuchung zur Akkumulation und Translokation von Assimilaten: Subzelluläre Volumina und Metabolitkonzentrationen in Blättern von Gerste und Spinat, pp. 144, Georg-August-Universität, Göttingen.

Winter, H., Robinson, D. G. and Heldt, H. W. (1993) Subcellular volumes and metabolite concentrations in barley leaves. Planta 191, 180-190.

Winter, H., Robinson, D. G. and Heldt, H. W. (1994) Subcellular concentrations and metabolite concentrations in spinach leaves. Planta 193, 530-535. 
Winzer, T., Lohaus, G. and Heldt, H. W. (1996) Influence of phloem transport, N-fertilization and ion accumulation on sucrose storage in the taproots of fodder beet and sugar beet. $J$ Exp Bot 47, 863-870.

Wirtz, W., Stitt, M. and Heldt, H. W. (1980) Enzymatic determination of metabolites in the subcellular compartments of spinach chloroplasts. Plant Physiol 106, 661-671.

Wolf, S. and Lucas, W. J. (1994) Virus movement proteins and other molecular probes of plasmodesmal function. Plant Cell Environ 17, 573-585.

Woodcock, D. M., Crowther, P. J., Doherty, J., Jefferson, S., Decruz, E., Noyer Weidner, M., Smith, S. S., Michael, M. Z. and Graham, M. W. (1989) Quantitative evaluation of Escherichia coli host stains for tolerance to cytosine methylation in the plasmid and phage recombinants. Nucl Acids Res 17, 3469-3478.

Wyn Jones, R. G. and Gorham, J. (1983) Osmoregulation. Encyclopedia of Plant Physiology. 12C Physiological Plant Ecology, pp. 35-98, Springer Verlag, Berlin.

Xoconostle-Cázares, B., Ruiz-Medrano, R. and Lucas, W. J. (2000) Proteolytic processing of $\mathrm{CmPP} 36$, a protein from the cytochrome $\mathrm{b}_{5}$ reductase family, is required for entry into the phloem translocation pathway. Plant $J \mathbf{2 4}, 735-747$.

Yamamoto, Y. T., Zamski, E., Williamson, J. D., Conkling, M. A. and Pharr, D. M. (1997) Subcellular localization of celery mannitol dehydrogenase. Plant Physiol 115, 1397 1403.

Ye-The, L. I. (1967) Studies on the glycosidase in Jack bean meal. I. Isolation and properties of $\alpha$-mannosidase. J Biol Chem 242, 5474-5480.

Yin, Z.-H., Neimanis, S., Wagner, U. and Heber, U. (1990) Light-dependent pH changes in leaves of $\mathrm{C}_{3}$ plants. Planta 182, 244-252.

Zhang, W. H. and Tyerman, S. D. (1997) Effect of low oxygen concentration on the electrical properties of cortical cells of wheat roots. Plant Physiol 150, 567-572.

Zimmermann, M. H. and Ziegler, H. (1975) Transport in plants. I. - Phloem transport. Appendix III: list of sugars and sugar alcohols in sieve-tube exudates. In Encyclopedia of Plant Physiology - new series, Vol. 1, (eds. M. H. Zimmermann and J. A. Milburn), pp. 480-503, Springer-Verlag, Berlin, Heidelberg, New York. 


\section{VIELEN DANK AN...}

Herrn Prof. Hans-Walter Heldt für die mir gewährte Möglichkeit, zuerst als DAADStipendiatin und dann als Doktorandin an der von ihm geleiteten Abteilung diese Doktorarbeit durchzuführen, sowie für jede Unterstützung und Interesse seinerseits;

Frau PD Dr. Gertrud Lohaus für die Möglichkeit, in ihrer Arbeitsgruppe am Thema Phloemtransport $\mathrm{zu}$ arbeiten, für ihre Unterstützung bei allen wissenschaftlichen und bürokratischen Problemen und für ihr Verständnis, die das Gelingen dieser Arbeit ermöglichten;

Herrn Prof. Yuri Gamalei für die Anregung, biochemische Untersuchungen im Zusammenhang mit der Struktur der pflanzlichen Zellen zu setzen, für sein Interesse am Verlauf und sein Glauben an den Erfolg dieser Arbeit sowie häufige Diskussionen zu Fragen des Phloemtransports.

Mein besonderer Dank gilt Frau Dr. Katharina Pawlowski für ihre Anregung, meine Arbeit auf der Stachyose-Synthese zu fokussieren, und für die Einführung in die faszinierende Welt der Molekularbiologie; für ihr ständiges Interesse an meinen Fortschritten; unsere Diskussionen und permanenten Austausch der Meinungen, die als „tägliches Brot“ für meine Ausbildung als Doktorandin dienten; und für das rechtzeitig erledigte Lesen und die Korrektur dieser Arbeit.

Herrn Prof. Em. Dr. Ulrich Heber (Universität Würzburg) danke ich besonders herzlich für die Möglichkeit, Versuche zum Thema Apoplast in seinem Labor durchzuführen und mehr über die Pflanzenphysiologie zu lernen, für sein Interesse an meiner Arbeit und die einfach unvergeßliche Atmosphäre brisanter Diskussionen in einer internationalen wissenschaftlichen Umgebung.

I would like to thank Dr. Olga Koroleva (University of Wales, Bangor) for her generous hospitality in Wales, for the introduction to the Single Cell Sampling and Analysis Technique and for the experiments we did together.

Dr. Thomas Peterbauer (Universität Wien) danke ich für die freundlicherweise gewährte Möglichkeit, die GC-MS Analyse meiner Versuchspflanzen durchzuführen.

Dr. Marina Pakhomova (Botanisches Institut, Sankt-Petersburg) bin ich sehr verbunden für die Einführung in die Elektronmikroskopie und die Erklärung von Hunderten von Photos, die mir eine Vorstellung über die Vielfalt der Zellstruktur von Pflanzen vermittelt haben.

Dr. Kirill Demchenko danke ich für die exzellente fachliche Einführung in die Einbettung von Pflanzenmaterial für Lichtmikroskopie und für seine großzügige und unersetzliche Hilfe bei allen Computerproblemen inklusive des Ausdrucks dieser Arbeit. 
Jens Tilsner bin ich dankbar für sein außerordentlich sorgfältiges Lesen und die Korrektur dieser Arbeit und für seinen nie vergessenen "Guten Morgen"-Gruß bei meiner etwas verspäteten Ankunft im Labor nach produktiver Nachtarbeit (trotz unserer deutlichen Meinungsunterschiede zum oft angesprochenen Thema „Kompatibilität von Rockmusik und Arbeitsproduktivität im Labor").

Dr. Sigrun Reumann danke ich für die bereitwillige Korrektur meiner Arbeit und ihre Hilfsbereitschaft bei allen Problemen im Labor.

Dr. Christian Knop danke ich für die Daten zum Phloemsaft von Asarina und Alonsoa und für die Bereitschaft, alle sporadischen Fragen zum Thema meiner Doktorarbeit sachkundig und ausführlich zu beantworten.

Marion Taube danke ich für ihre liebevolle Hilfe bei den Kältegürtel-Versuchen.

Allen Kollegen aus Göttingen, Esteban Antonicelli, Lavanya Babujee, Dr. Mareike Böddeker, Anne Brandeck, Dr. Dieter Heineke, Dr. K.-P. Heise, Melanie Hußmann, Gerd Mader, Andrea Nickel, Dr. Anke Sirrenberg, Maria Schubert, Anita Stottmeister, Michaela Strauß, Dr. Thilo Winzer und Dr. Zewen Zhou danke ich für jegliche Hilfestellung und jedes gutes Wort und vor allem für die einmalige und unvergeßliche warme, herzliche Atmosphäre in der Abteilung, die ich immer vermissen werde...

Herrn Wedemeyer, unseren Gärtner, danke ich für seine besonders freundliche und nette Art und für seine liebevolle Fürsorge um meine Pflanzen.

Dr. Meike Lorenz bin ich dankbar für ihre Hilfe bei der Handhabung der digitalen Kamera ihrer Abteilung.

Der Abteilung von Frau Prof. Dr. Christiane Gatz danke ich für die mir für diese Doktorarbeit freundlicherweise zur Verfügung gestellten Materialien und Geräte. Mein besonderer Dank gilt Wolfram Brenner für seine Hilfe im Umgang mit Arabidopsis und Dr. Corinna Thurow für ihre Unterstützung bei der Handhabung von pET3b.

Jan Nadwodnik danke ich für die gemeinsam überlebte Galaktinol-Isolierung während des Großpraktikums II.

Allen meinen Kollegen aus St.-Peterburg, die mich in Erinnerung behalten haben, danke ich für ihre Briefe, Emails und für ihre Unterstützung aus der Ferne.

Meiner Freundin Anna Boulankina bin ich dankbar für die nächtelangen Diskussionen über mysteriöse Aspekte von Protein Sorting und die Regulation der AmSTS Expression. Meiner Freundin Irina Bulanowa danke ich für ihre ausgezeichneten Übersetzungen mehrerer Dokumente (Russisch-Englisch-Deutsch in allen Richtungen). Meiner Freundin Ekaterina Vorobieva danke ich für ihre liebevolle Unterstützung in allen Dingen. Den anderen Mitglieder der „friedlichen russischen Mafia“ danke für ihre treue Hilfsbereitschaft.

Meinen Eltern danke ich für ihr Warten, ihren Glauben, ihre Verständnis und all ihre Hilfe. 


\section{LEBENSLAUF}

18.05 .1973

1980-1990

Juli 1990

1990-1995

1994-1995

Juli 1995

August 1995 -

August 1998

August 1998 -

September 1998

Oktober 1998 -

März 2000

Seit April 2000 geboren in St. Petersburg (Leningrad), Rußland.

Staatsangehörigkeit: russisch

Besuch der Allgemeinen Mittelschule in St. Petersburg

Schulabschluß: Abitur

Studium an der Staatlichen Universität St. Petersburg,

Fakultät für Biologie und Bodenkunde

Diplomarbeit über „Untersuchungen zur Beziehung zwischen

Photosynthese und Dunkelatmung in $\mathrm{C}_{3}$-Pflanzen mit unterschiedlichen Vegetationsrhythmen" unter Anleitung von Dr. N. S. Mamuschina

Studiumsabschluß: Diplom mit Auszeichnung

Wissenschaftliche Mitarbeiterin am Botanischen Institut der

Russischen Akademie der Wissenschaften, St. Petersburg, unter Leitung von Prof. Dr. Y. V. Gamalei

Deutschkurs am Goethe-Institut Göttingen

DAAD-Stipendiatin an der Abteilung für Biochemie der Pflanze des Albrecht-von-Haller-Instituts für Pflanzenwissenschaften der Universität zu Göttingen, Projekt: „Phloemtransport und Assimilatverteilung in source-Blättern“

Doktorandin an der Abteilung für Biochemie der Pflanze des Albrecht-von-Haller-Instituts für Pflanzenwissenschaften der Universität zu Göttingen, unter der Anleitung von Prof. Dr. H.-W. Heldt 